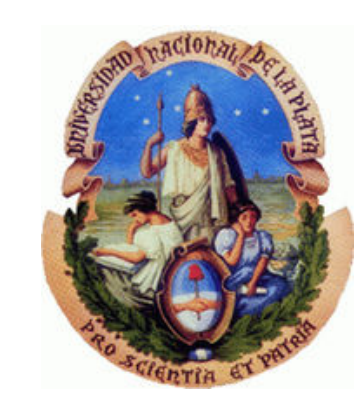

UNIVERSIDAD NACIONAL DE LA PLATA

FACULTAD DE CIENCIAS EXACTAS

DEPARTAMENTO DE FÍSICA

Tesis Doctoral

\title{
SÍNTESIS Y CARACTERIZACIÓN DE NANODISPERSIONES Mg/Ti COMO POTENCIALES RESERVORIOS DE HIDRÓGENO
}

\author{
por \\ Andrés T. Biasetti \\ Director: Marcos Meyer \\ Codirector: Luis Mendoza Zélis
}

TRABAJO DE TESIS PARA LA OBTENCIÓN DEL TÍTULO DE DOCTOR EN CIENCIAS EXACTAS, ÁREA FÍSICA 


\section{RESUMEN}

En el marco del desarrollo tecnológico para una economía energética global sustentable, el estudio de materiales como potenciales reservorios de hidrógeno es un área en pleno desarrollo. La presente Tesis consiste en un estudio básico de materiales nanoestructurados formadores de hidruros basados en Mg. Este material tiene una buena capacidad para almacenar químicamente hidrógeno pero al presentarse en bulk posee limitaciones para hacerlo de manera reversible.

Se ensayaron diferentes composiciones y vías de fabricación mediante molienda mecánica reactiva principalmente en atmósfera de $H_{2}$. Se usaron como aditivos $\mathrm{Ti}$ y $\mathrm{C}$, a fin de estudiar las eventuales mejoras en las propiedades de almacenamiento de los hidruros nanoestructurados. Una vez almacenado químicamente el hidrógeno en los materiales (dispersiones en polvo), se estudiaron las propiedades de absorción y desorción de hidrógeno del hidruro formado $\mathrm{MgH}_{2}$ (almacenamiento reversible) y el rol de los aditivos en estos procesos. Para ello fue necesario someter los especímenes a tratamientos térmicos y de presurización los cuales permitieron la re-obtención del hidrógeno molecular (desorción) y su posterior re-absorción (absorción química). Se utilizó volumetría a fin de estudiar y caracterizar las condiciones termodinámicas correspondientes. La técnica, a través del monitoreo del consumo o liberación del hidrógeno in situ, permitió también estudiar las velocidades de los procesos de sorción (cinética). Se caracterizaron y modelaron las curvas cinéticas obtenidas. Se realizaron también experiencias de calorimetría diferencial (DSC) y termogravimetría que permitieron hacer un estudio y caracterización de la cinética a distintas velocidades de calentamiento y enfriamiento. Se recurrió principalmente a la difracción (DRX) y microscopía (SEM y TEM) para la caracterización estructural tanto de los materiales recién preparados como después de ser sometidos a variados ciclos térmicos a diferentes presiones.

Los resultados de las experiencias mostraron que los materiales así fabricados presentan propiedades cinéticas de interés. De manera complementaria, los resultados experimentales permitieron a través de una análisis cinético formal, aportar a la comprensión de los mecanismos involucrados en los procesos de absorción y desorción, de acuerdo a las condiciones de presión y temperatura, composición y/o la vía de fabricación. 


\section{AGRADECIMIENTOS}

A mi familia: a mi Mamá (Nora), mi Papá (Héctor), mis hermanos Ana, Demián, Sofía y mi Tía Nora, eternamente agradecido, porque todo es posible gracias a ellos.

A Lua Paz, mi sobrina hermosa y amada que ilumina nuestras vidas para siempre.

A Juan Carlos Cozzitorto.

A mis Directores Marcos Meyer y Luis Mendoza Zélis, por haberme dado la oportunidad de trabajar con ellos, por su inmensa generosidad tanto en lo académico como en lo personal, por su paciencia y por generar el mejor clima de trabajo al que uno pueda aspirar.

A Nasly mi amor, mi compañera, que hizo que esta ruta se haga más simple y bella.

A mis amigos Nicolás Keppes y Odin Vázquez Robaina, con quienes he tenido la suerte de compartir de esas amistades hermosas que te da la vida en la adultez.

A mis amigos Gastón Santoiani, Carolina Nilsson y Natalia Vainstein por su amistad y los innumerables momentos compartidos que formaron parte de este recorrido.

A Diana por su amistad, por estar tan atenta, y por ayudarme en la organización de la celebración post-defensa.

A Claudia Rodríguez Torres por su gran ayuda en la realización de varias de las experiencias y análisis más importantes de este trabajo.

A Franacisco Sánchez y Pedro Mendoza Zélis por los lindos almuerzos compartidos y otros momentos más, y por su apoyo en esta etapa al hacer del ambiente de trabajo un lugar tan confortable.

A Fabiana Cabrera, Patricia Rivas y Luciana Juncal por su contribución a la realización de las experiencias de calorimetría.

A Alberto Paschevich por su colaboración con este trabajo y su compromiso con la Facultad. A mis compañeros de oficina Mauricio ("Viri"), Santiago, Mario.

A mis compañeros de CCyP por pugnar para tener una sociedad más justa.

A CONICET por el financiamiento de la Beca con la que pude realizar este Tesis, y sobre todo a aquellos políticos que apostaron al desarrollo de un Sistema Científico Nacional en vistas del desarrollo soberano del país.

A Erika Dematteis y Marcello Baricco de la Uniersidad de Torino (UNITO) y a Stefano Deledda del Instituto IFE de Noruega, por su colaboración para la realización de experiencias que fueron fundamentales para la conclusión de este trabajo.

A Alejandra Floridia y a Alberto Caneiro (de Y-Tec) por darme la posibilidad de utilizar el microscopio electrónico (TEM) y a Victoria Castro y Julián Puszkiel por su colaboración para el análisis de las imágenes de obtenidas.

Finalmente agradezco inmensamente la gran predisposición de los Jurados, Gabriel Meyer, Claudia Rodríguez Torres y Pablo Bruzzoni por haber aceptado formar parte de la Defensa, como así también por su paciencia para corregir varios errores y por brindar observaciones valiosas que permitieron mejorar el trabajo. 
Andrés T. Biasetti 


\section{Índice general}

Índice general $\quad \mathrm{V}$

Índice de tablas $\quad$ IX

Índice de Tablas $\quad$ IX

Índice de figuras $\quad$ XI

Índice de Figuras

$\begin{array}{ll}\text { Bibliografía } & \text { XIV }\end{array}$

1. Introducción 1

1.1. El hidrógeno como portador limpio de energía $\ldots \ldots \ldots \ldots \ldots \ldots$

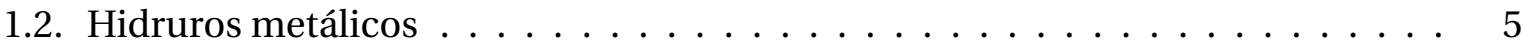

1.3. Materiales nanoestructurados $\ldots \ldots \ldots \ldots \ldots \ldots \ldots$

1.4. Hidruros basados en $\mathrm{Mg} \ldots \ldots \ldots \ldots \ldots \ldots$

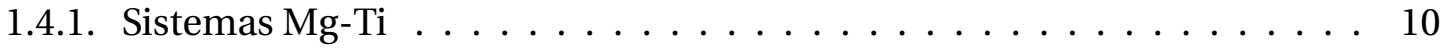

1.4.2. Sistemas con grafito $\ldots \ldots \ldots \ldots \ldots \ldots \ldots \ldots \ldots \ldots$

2. Detrás de los modelos cinéticos 15

2.1. Dos conceptos necesarios: Factor limitante y nucleación-crecimiento _ . . . 15

2.2. Modelos y métodos de análisis . . . . . . . . . . . . . . . . . . 19

2.3. Análisis formal de la cinética . . . . . . . . . . . . . . . . . . 20

3. Experimental. Parte I: formación de los hidruros 25

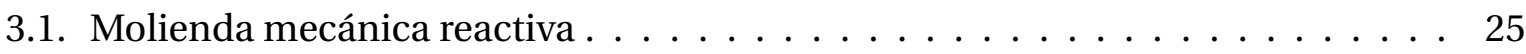

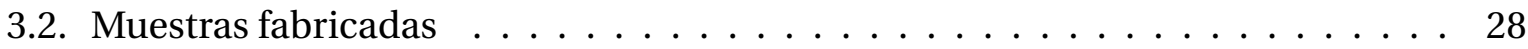

4. Hidruración y deshidruración de los sistemas $\mathrm{Mg}-\mathrm{TiH}_{2} \quad 33$

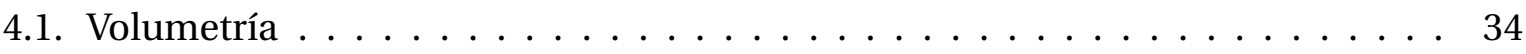

4.2. Cinéticas de absorción y desorción de hidrógeno $\ldots \ldots \ldots \ldots \ldots \ldots$

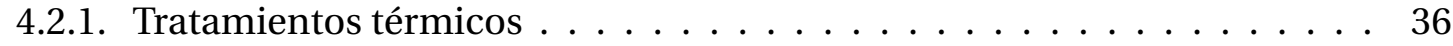

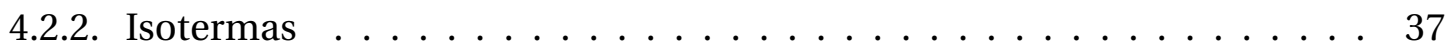

4.3. Calorimetría diferencial (DSC) $\ldots \ldots \ldots \ldots \ldots \ldots \ldots \ldots$

4.3.1. Calorimetría de absorción y desorción $\left(\mathrm{H}_{2}\right) \quad \ldots \ldots \ldots \ldots \ldots$

4.3.2. Calorimetría combinada con termogravimetría (Ar) . . . . . . . . 39

4.3.3. Calorimetría en distintos gases inertes $\left(\mathrm{N}_{2} \mathrm{y} \mathrm{Ar}\right) \ldots \ldots \ldots \ldots \ldots$ 
5. Identificación de fases y caracterización estructural 43

5.1. Patrones de difracción: Rayos X y Neutrones . . . . . . . . . . . . . . . . . . . . . . . . . . . .

5.2. Análisis de los patrones de difracción . . . . . . . . . . . . . . . . 49

5.3. Caracterización microscópica . . . . . . . . . . . . . . . 51

5.3.1. Muestras de composición $\left(\mathrm{MgH}_{2}\right)_{80}-\left(\mathrm{TiH}_{2}\right)_{20}$, preparada por Vía A . . 53

5.3.2. Vías de fabricación . . . . . . . . . . . . . . . 67

5.3.3. Muestras frescas y tratadas . . . . . . . . . . . . 71

6. Resultados Parte I: Cinéticas de formación $\quad \mathbf{7 3}$

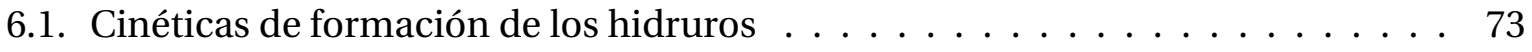

6.1.1. Sistemas $M g_{x} T i_{1-x} \ldots \ldots \ldots \ldots \ldots \ldots \ldots \ldots \ldots$

6.1.2. Sistemas fabricados con grafito . . . . . . . . . . . . . . 79

7. Resultados parte II: Cinéticas en equipo volumétrico. 81

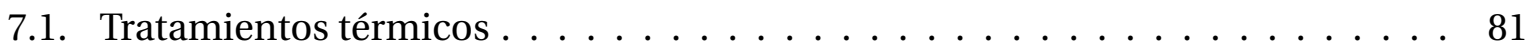

7.2. Isotermas de sorción $\ldots \ldots \ldots \ldots$

7.2.1. Comparación de cinéticas de muestras fabricadas por vías A y B . . . . . 86

7.2.2. Comparación con cinéticas de muestra deuterada . . . . . . . . . . . 89

7.2.3. Comparación de cinéticas de muestras con grafito . . . . . . . . . . . . 89

7.2.4. Absorciones y desorciones en etapas . . . . . . . . . . . . . 91

8. Resultados Parte III: Calorimetría Diferencial $\quad 97$

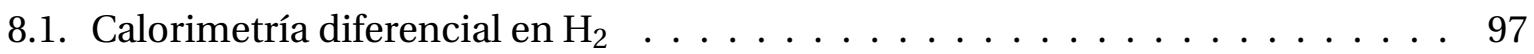

8.1.1. Sobre los barridos DSC . . . . . . . . . . . . . . . . 97

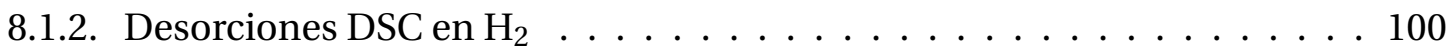

8.1.3. Absorciones DSC en $\mathrm{H}_{2} \ldots \ldots \ldots \ldots 1 . \ldots \ldots 1$

8.1.4. Ciclos de absorción y desorción en $\mathrm{H}_{2}$. Segunda serie . . . . . . . . . . 101

8.2. Calorimetría en $\mathrm{Ar}$ combinada con termogravimetría . . . . . . . . . . . . . . 104

8.2.1. Calorimetría diferencial en $A r$ y $N_{2} \ldots \ldots \ldots$. . . . . . . 106

$\begin{array}{lr}\text { 9. Análisis } & 109\end{array}$

9.1. Cinéticas de absorción y desorción isotérmica . . . . . . . . . . . . . 109

9.2. Cinéticas de absorción y desorción no isotérmica . . . . . . . . . . . . . 115

9.2.1. Análisis de las curvas calorimétricas en $\mathrm{H}_{2} \ldots \ldots \ldots$. . . . . . . . . . . . . . . . 115

9.2.2. Análisis de las curvas calorimétricas en $A r \ldots \ldots$. . . . . . . . . 125

$\begin{array}{lr}\text { 10.Conclusiones } & 129\end{array}$

A. MODELOS CINÉTICOS 133

A.0.1. Modelos cinéticos . . . . . . . . . . . . . . . . . 133

A.0.2. Modelos de Sěstak-Berggren y de Hill . . . . . . . . . . . . . . . . . . 133

A.0.3. Modelo de Kolmogorov-Johonson-Mehl-Avrami y sus alcances . . . . . . 134

B. CINÉTICAS DE FORMACIÓN 139

C. DIFRACCIÓN

$\begin{array}{ll}\text { D. MICROSCOPÍA } & 145\end{array}$ 
E. CINÉTICAS DE ABSORCIÓN/DESORCIÓN 149

$\begin{array}{ll}\text { F. CALORIMETRÍA } & 157\end{array}$

G. ENERGÍAS DE ACTIVACIÓN 167

G.1. Método de Kissinger . . . . . . . . . . . . . . . . . . . . . . 167 


\section{Índice de tablas}

3.1. Muestras fabricadas $\sin$ grafito $\ldots \ldots \ldots \ldots \ldots \ldots \ldots$

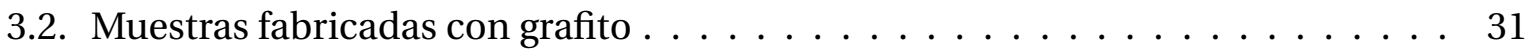

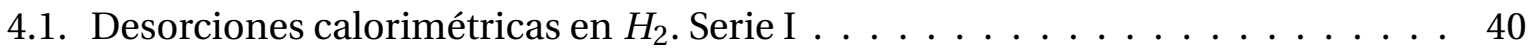

4.2. Desorciones y absorciones calorimétricas en $H_{2}$. Serie II . . . . . . . . . . . 41

4.3. Desorciones calorimétricas combinadas con termogravimetría en Ar. IFE . . . . 41

4.4. Desorciones calorimétricas en $A r$ realizadas sobre muestra fabricadas por las

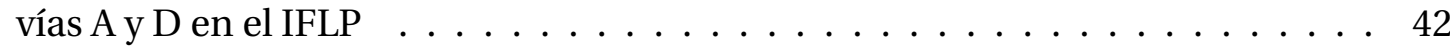

4.5. Desorciones calorimétricas en $\operatorname{Ary~} N_{2}$ realizadas sobre muestras fabricadas por

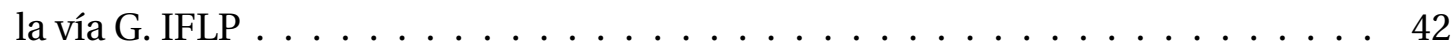

5.1. Parámetros ajuste de patrones de difracción. Distintas vías . . . . . . . . 50

5.2. Prámetros de refinamiento Rietveld . . . . . . . . . . . . . . . 51

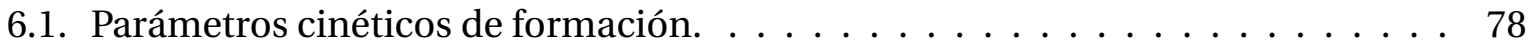

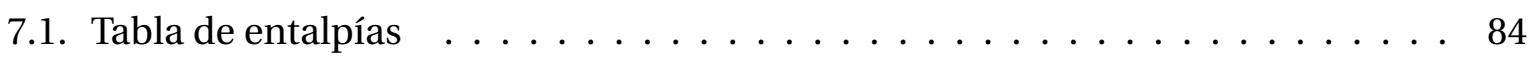

9.1. Parámetros cinéticos de ajuste (I). Componentes Hill . . . . . . . . . . . . . 115

9.2. Parámetros cinéticos de ajuste (II). Componentes Hill . . . . . . . . . . . 115

9.3. Ajuste JMAK. Parámetro n . . . . . . . . . . . . . . . . . . . . . . . . 121

A.1. Tabla de modelos cinéticos … . . . . . . . . . . . . . . . . 133

B.1. Parámetros cinéticos de ajuste para cinéticas de formación . . . . . . . . . . 140

G.1. Temperatura de picos de desorción DSC y energías de activación obtenidas mediante el método de Kissinger. . . . . . . . . . . . . . . . . . . . . . . . . 169

G.2. Temperatura de picos de absorción DSC. . . . . . . . . . . . . . . . . . 169 


\section{Índice de figuras}

2.1. Facción de fase transformada en función de la fracción extendida $\ldots$. . . . . . 16

2.2. Protocolo de Mălek para el análisis isoconversional . . . . . . . . . . . . . . . 22

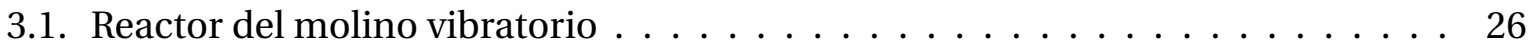

3.2. Monitoreo de la presión durante la molienda . . . . . . . . . . . . . . 28

4.1. Esquema del equipo volumétrico $\ldots \ldots \ldots \ldots \ldots \ldots$

4.2. Tratamiento térmico a volumen constante . . . . . . . . . . . . . 36

5.1. Comapración de patrones de difracción de rayos X, vías A, B y C. . . . . . . . . . 44

5.2. Comapración de patrones de difracción de rayos X, vías A y G . . . . . . . . . . . 45

5.3. Patrón de difracción de neutrones . . . . . . . . . . . . . . . . . . . . . . . . . . 46

5.4. Comparación de patrones de difracción de rayos X, vías B y D . . . . . . . . . . . 47

5.5. Comparación de patrones de difracción de rayos $\mathrm{X}$ de muestras con grafito,

fresca y tratada. . . . . . . . . . . . . . . . . . . . 48

5.6. Refinamiento del patrón de difracción de una muestra preparada por molienda

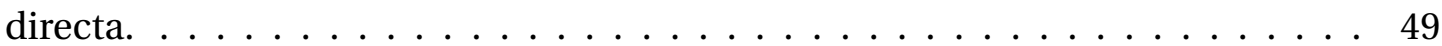

5.7. Serie I de fotografías de sistemas Mg:Ti (vía A) obtenidas por microscopía SEM 53

5.8. Serie II de fotografías de sistemas Mg:Ti (vía A) obtenidas por microscopía SEM 54

5.9. Alta magnificación SEM . . . . . . . . . . . . . . . . . . . 55

5.10.Imágenes TEM. Aglutinamiento de partículas. . . . . . . . . . . . . 56

5.11.Partículas y conglomerados observados por TEM. . . . . . . . . . . . . . 57

5.12. Imágenes de alta resolución TEM tomadas sobre regiones de una partícula. Vía A 58

5.13. Fotografías de alta resolución TEM. Bordes de grano. . . . . . . . . . . . . . . . 59

5.14. Fotografías de alta magnificación TEM. Granos. . . . . . . . . . . . . . . . . 60

5.15. Fotografías de alta resolución TEM. Familias de planos cristalinos. . . . . . . . . 61

5.16. Bordes de grano observados por TEM. . . . . . . . . . . . . . . . . 62

5.17. Patrones de difracción obtenidos por TEM . . . . . . . . . . . . . 63

5.18. Partícula con grafito. Imagen obtenida por TEM . . . . . . . . . . . . . . 63

5.19. Transformada de Fourier de una imágen TEM. . . . . . . . . . . . . . . . . . . . . . 64

5.20. Mapeo elemental de una muestra fabricada por vía A . . . . . . . . . . . . . . . . . . . . . 65

5.21. Análisis EDAX realizado con SEM a media magnificación. . . . . . . . . . . . . 66

5.22. Mapeo elemental a alta resolución obtenido mediante TEM. . . . . . . . . . . 66

5.23. Imagen SEM a media magnificación (vía B) . . . . . . . . . . . . . . . . 67

5.24. Comparación de imágenes SEM a alta magnificación. Muestras preparadas por

las vías A y B. . . . . . . . . . . . . . . . . . . . . 68

5.25. Comparación de imágenes SEM de estructuras agrietadas. Vías A y D. . . . . . . 69 
5.26. Comparación de imágenes SEM de zonas rugosas, vías A y D . . . . . . . . . 70

5.27. Imágenes SEM de muestras preparadas por la vía G . . . . . . . . . . . . . . 71

5.28. Comparación de imágenes SEM para muestras fabricados por distintas vías, en

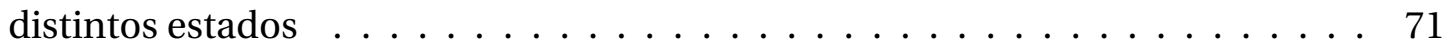

6.1. Curvas cinéticas de formación de hidruros . . . . . . . . . . . . . . . 74

6.2. Velocidades de transformación durante la molienda mecánica. . . . . . . . . . 75

6.3. Componentes de las cinéticas de formación, vía A . . . . . . . . . . . . 77

6.4. Curvas cinéticas de formación para tres composites iguales. . . . . . . . . . 79

6.5. Formación de hidruros con agregado de grafito $\ldots \ldots \ldots$

6.6. Esquema molienda con grafito. . . . . . . . . . . . . . . . . 80

7.1. Tratamientos térmicos de una muestra Mg:Ti:80:20, vía A . . . . . . . . . . . . 81

7.2. Tratamientos térmicos sobre muestras fabricadas por vías A y B . . . . . . . 82

7.3. Gráficos de Vant'Hoff para muestras fabricadas por vías A y B . . . . . . . . . . 83

7.4. Gráficos de Vant'Hoff para distintas rutas de fabricación y distintas composiciones. 83

7.5. Tratamientos sobre muestra deuterada . . . . . . . . . . . . . 85

7.6. Comparación de cinéticas no isotérmicas de muestras con y sin grafito . . . . 86

7.7. Curvas de abosorción de muestras fabricadas por las vías A y B . . . . . . . . . . 87

7.8. Comparación de cinéticas de absorción a 7 bar, vías A y B . . . . . . . . . . . 88

7.9. Comparación de cinéticas de desorción, vías A y B . . . . . . . . . . . . 89

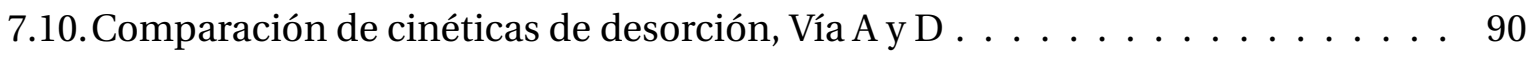

7.11. Comparación de cinéticas de absorción, Vías A y G . . . . . . . . . . . . . 90

7.12. Comparación de cinéticas de desorción, Vías A y G. . . . . . . . . . . . . . . . 91

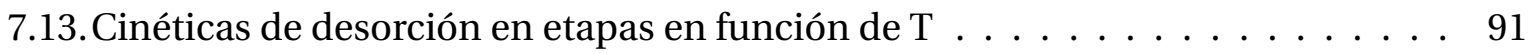

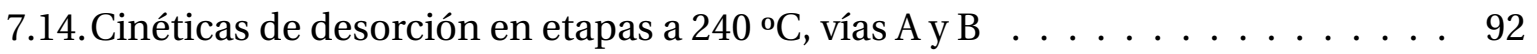

7.15. Cinéticas de desorción en etapas a $250^{\circ} \mathrm{C}$, vía A . . . . . . . . . . . . . . . . . . . . . . . . . . .

7.16. Cinéticas de desorción en etapas a $250{ }^{\circ} \mathrm{C}$, vía $\mathrm{G} \ldots \ldots$. . . . . . . . . . . . . . . . . . . . . . . .

7.17. Cinéticas de absorción en etapas vía G,10\% at. C. . . . . . . . . . . . . . 94

7.18. Cinéticas de absorción en etapas vía G,20\% at. C. . . . . . . . . . . . . . . . 95

7.19. Cinéticas de absorción en etapas vía G,20\% at. C. . . . . . . . . . . . . 95

8.1. Desorciones y absorciones DSC en hidrógeno. Dobles picos. . . . . . . . . . 98

8.2. Señal DSC(mW/mg) vs. t(min). Comparación de Áreas . . . . . . . . . . . . . . . 99

8.3. Desorciones DSC en $\mathrm{H}_{2}$. Serie I. . . . . . . . . . . . . . . . . . . 100

8.4. Ciclos de absorción/desorción calorimétricos. Serie II ～. . . . . . . . . . . 102

8.5. Ciclos de absorción DSC. Serie II . . . . . . . . . . . . . . . . . . . 103

8.6. Comparación de ciclos de desorción DSC de la serie II . . . . . . . . . . . . . . . . . . . . . . 103

8.7. Medidas termogravimétricas combinadas con DSC, Ar . . . . . . . . . . . . 104

8.8. Desorciones DSC en Ar, IFE. Vías B y G. . . . . . . . . . . . . . . . . 105

8.9. Corridas DSC realizadas en Ar y $N_{2}$ sobre muestras frescas y tratadas,IFLP . . . 106

8.10. Corridas calorimétricas para muestras con grafito envejecidas . . . . . . . 107

9.1. Gráficos de Avrami comparando las vías A y B a distintas temperaturas . . . . 110

9.2. Comparación entre cinéticas de absorción y desorción y gráficos de Avrami. Vía A110

9.3. Exponentes de Avrami calculados para curvas de absorción a 7 bar, Vía A. . . 111 
9.4. Exponentes de Avrami calculados para curvas de absorción a 7 bar, Vía B. . . . 112

9.5. Derivadas de cinéticas no isotérmicas. . . . . . . . . . . . . . 113

9.6. Ajustes de cinéticas de absorción isotérmica, vías A y B. . . . . . . . . . . . . . 114

9.7. Fracción transformada $\alpha(T)$ para la as desorciones en $H_{2} \ldots \ldots \ldots \ldots$

9.8. Gráfico Isoconversional. Componente 1 de las corridas de desorción den $H_{2}$, vía A116

9.9. Energías de activación obtenidas mediante el método isconversional. Desorcio-

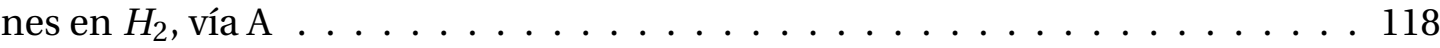

9.10. Funciones $y(\alpha)$ y $z(\alpha)$ correspondientes al primer proceso durante la desorción no isotérmica programada, vía A . . . . . . . . . . . . . . . . . 119

9.11. Ajustes de JMAK de las funciones $f(\alpha)$ correspondientes al primer proceso durante la desorción no isotérmica programada, vía A . . . . . . . . . . . 120

9.12. Funciones $f(\alpha)$ y $z(\alpha)$ correspondientes al segundo proceso durante la desorción no isotérmica programada, vía A . . . . . . . . . . . . . . . . . 121

9.13. Iso-Plots correspondientes a las corridas en $H_{2}$, muestra MT48, vía B . . . . . 122

9.14.Energías de activación obtenidas mediante el método isoconversional. Desorciones en $H_{2}$ y en Ar, vía B . . . . . . . . . . . . . . . . . . . . 123

9.15. Funciones $y(\alpha)$ y $z(\alpha)$ correspondientes a las desorciones en $H_{2}$, vía B $\ldots \ldots 123$

9.16. Funciones $y(\alpha)$ y $z(\alpha)$ correspondientes a las desorciones en Ar, muestra MT45, vía

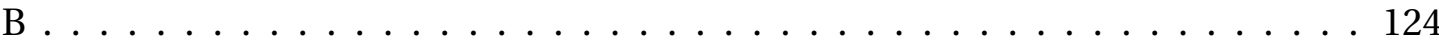

9.17. Energías de activación obtenidas mediante el método isoconversional para muestras con ciclado, vía A (MT42 y MT50) . . . . . . . . . . . . . . . . . . 125

9.18. Energías de activación obtenidas mediante el método isoconversional para las desorciones de una muestra con grafito, $20 \%$ at. C, CMT14 . . . . . . . . . 126

9.19. Funciones $f(\alpha)$ y $z(\alpha)$ correspondientes al segundo proceso durante la desorción no isotérmica programada, vía A . . . . . . . . . . . . . . . 126

9.20. IsoPLot 3D para las corridas en Ar de la muestra con grafito CMT14, realizadas en el IFLP . . . . . . . . . . . . . . . . . . . . 127

B.1. Ajustes de cinéticas de formación para muestras homólogas-Vía A . . . . . . 139

B.2. Ajustes de cinéticas de formación para muestras homólogas-Vía B . . . . . . . . 139

B.3. Formación de $\mathrm{TiH}_{2} \ldots \ldots \ldots \ldots$. . . . . . . . . . . . . . . 140

C.1. Patrones de difracción de los materiales usados para la molienda . . . . . . . . 141

C.2. Patrones de difracción de un sistema Mg-Ti hidrurado y de $\mathrm{TiH}_{2}$. . . . . . . . . 142

C.3. Patrones de difracción de rayos $\mathrm{X}$ para sistemas fabricados por la vía A, variando la composición Mg:Ti. . . . . . . . . . . . . . . . . . . . . . . . . . . 142

C.4. Refinamiento Rietveld. Muestra fresca . . . . . . . . . . . . . . . . . . . 143

C.5. Refinamiento Rietveld. Muestra tratada . . . . . . . . . . . . . . . . . . . 143

D.1. Serie de imágenes TEM (FCV) a bajas magnificaciones mostrando tamaños y morfología de los conglomerados. . . . . . . . . . . . . . . . . . 145

D.2. Imágen de campo oscuro de una muestra con grafito, CMT12 . . . . . . . . . . 146

D.3. Imágen de alta resolucion HR para una muestra con grafito. . . . . . . . . . . 147

D.4. Imágen de campo oscuro y patrón de difracción para una muestra con grafito. 147

E.1. Tratamientos térmicos en coordenadas de Van't Hoff . . . . . . . . . . . . . . . 149 
E.2. Comparación de cinéticas de absorción a 10 bar, vías A y B . . . . . . . . . . 149

E.3. Dependencia de la cinética de desorción con la temperatura, Vía A . . . . . 150

E.4. Volumen efectivo . . . . . . . . . . . . . . . . . . . . . . . . . 152

E.5. Desorciones en etapas, vía G (10\% at. C). Comparación de varios ciclos. . . . 152

E.6. Comparación de cinéticas de desorción en etapas, Vías G. . . . . . . . . . . . . 153

E.7. Gráficos de Avrami comparando las vías A y B a distintas temperaturas y presiones iniciales . . . . . . . . . . . . . . . . . . . . . . 154

E.8. Gráficos de Avrami a 5 bar para una muestra de composición Mg:Ti:90:10 . . 154

E.9. Exponentes de Avrami calculados para curvas de absorción a 5 bar, Vía A, Mg:Ti:90:10 . . . . . . . . . . . . . . . . . . . . 155

E.10.Exponentes de Avrami calculados para curvas de absorción a 5 bar, Vías A y B . 155

F.1. P(T) durante las corridas de desorción DSC en $H_{2}$, muestras MT42 y MT48 . . . 157

F.2. $\mathrm{P}(\mathrm{T})$ durante las corridas de desorción/absorción DSC en $H_{2}$, muestra CMT13 158

F.3. $\mathrm{P}(\mathrm{T})$ durante los ciclos de desorción/absorción DSC en $\mathrm{H}_{2}$, muestra MT42 . . . 158

F.4. Medidas TG realizadas para las muestras fabricadas por las vías A ( MT44) y B

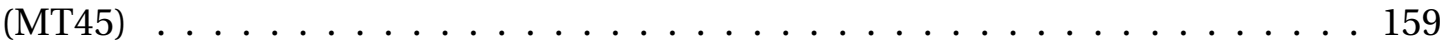

F.5. Medidas TG a $2 \mathrm{~K} / \mathrm{min} \ldots \ldots \ldots \ldots$

F.6. Medidas TG-DSC realizadas para las muestras fabricadas por las vías A ( MT44) y B (MT45) . . . . . . . . . . . . . . . . . . . . . . 160

F.7. Medida TG a $10 \mathrm{~K} / \mathrm{min} . \mathrm{TiH}_{2} \ldots \ldots \ldots \ldots \ldots \ldots$

F.8. Medidas DSC en flujo de Ar o $N_{2}$ a distintas velocidades. Muestra con grafito . 161

F.9. Absorciones DSC en $H_{2}$. Serie I . . . . . . . . . . . . . . . . . . . . . 162

F.10. Ajustes de las desorciones en $H_{2}$, MT42 . . . . . . . . . . . . . . . 163

F.11. IsoPlot 3D para la componente C1 ajustada con el modelo de JMAK, MT42, vía A 164

F.12. Fracciones de fase transformadas en función de T, obtenidas de las corridas DSC en Ar e $H_{2}$. Muestras MT45 y MT48 respectivamente . . . . . . . . . . . . 165

F.13. Ejemplos de ajustes isoconversionales para obtener la energía de activación . . 165

G.1. Gráficos de Kissinger para la obtención de las energías de activación. . . . . . . 168

G.2. Gráficos de Kissinger para la obtención de las energías de activación. . . . . . 169 


\section{Capítulo 1}

\section{Introducción}

\subsection{El hidrógeno como portador limpio de energía}

Desde hace décadas la matriz y demanda energéticas, se han convertido en un asunto crucial para el desarrollo de la humanidad. El transporte, la producción y el desarrollo tecnológico-industrial se inscriben en una realidad socioeconómica que probablemente exija su incremento y con ello también los desafíos por optimizar el esquema energético vigente minimizando el impacto medioambiental. En este contexto se generan cada vez mas ideas para modificar esa matriz energética basada fuertemente en la combustión térmica de recursos fósiles y/o el uso de recursos no renovables. Esta imperiosa necesidad de cambio se debe principalmente al alto grado de contaminación e impacto ambiental negativo (cambio climático global, pérdida de recursos), pero también al alto grado de ineficiencia que presenta el estado actual del uso de la energía (un automóvil por persona, los calefones con el piloto encendido las 24 hs, etc). Se necesita pensar en una nueva matriz energética, tanto desde el punto de vista cultural como técnico. Esto ha impulsado la investigación y desarrollo de las energías no convencionales. En particular este trabajo se enmarca en el desafío de profundizar la construcción de un esquema de desarrollo sustentable basado en un uso responsable, seguro, económico, eficiente y limpio de la energía, a partir de la investigación básica de materiales orientada en ese sentido.

Las fuentes de energía renovable pueden ser consideradas casi inagotables y una gran variedad de tecnologías se han desarrollado y están disponibles a fin de convertir energía primaria ${ }^{1}$ [1] en energía térmica y/o eléctrica para uso doméstico o industrial. Sin embargo la obtención de energía a partir de fuentes primarias es intrínsecamente intermitente y por sí mismas se ven limitadas para satisfacer in-situ el consumo energético de acuerdo a la demanda. Por lo tanto es necesario optimizar la relación entre la producción de potencia ya la demanda. Una de las estrategias es almacenar la energía excedente producida (electricidad) de manera de disponer de ella en momentos posteriores o de mayor demanda. ${ }^{2}$ Una de las cuestiones mandatorias es por tanto, que los sistemas de almacenamiento sean seguros, eficientes y permitan almacenar

\footnotetext{
${ }^{1}$ Refiérase a aquella contenida en los combustibles crudos, la energía solar, la eólica, la geotérmica y otras formas de energía que constituyen una entrada al sistema.

${ }^{2}$ Además se trabaja en estrategias complementarias en relación a mejorar la gestión del balance suministro/demanda (Demand Side Mangement[2]), y a la existencia perjudicial de picos altos de demanda (Energy peak shaving[3],[4],[5]).
} 
grandes cantidades de energía durante intervalos de tiempo relativamente largos. Entre otras cosas, esto ha provocado que en las últimas décadas se haya incrementado particularmente el interés mundial por la utilización del hidrógeno como portador de energía. Puede decirse que una creciente parte de la comunidad científico-tecnológica, compañías, instituciones gubernamentales, no gubernamentales y organismos de financiación han mostrado estar convencidos de la relevancia/protagonismo del $\mathrm{H}_{2}$ en términos de perspectivas globales hacia el nuevo esquema energético sustentable, y esto sin dejar de lado la visión complementaria entre las distintas energías renovables $[6,7,8,9,10]$.

De acuerdo a los objetivos planteados, lo que convierte en atractivo al hidrógeno son su gran abundancia, su densidad energética comparativamente alta $(33,33 \mathrm{kWh} / \mathrm{kg}$ ) y la posibilidad de utilizar energía de manera limpia. El hecho de que el electrón del hidrógeno atómico esté acompañado solo por un protón hace que el hidrógeno tenga la mejor relación electrones de valencia/masa atómica de la tabla periódica, y por tanto, la ganancia de energía por electrón es muy alta comparativamente. A modo ilustrativo, la densidad másica de energía química del hidrógeno es $142 \mathrm{MJ} \mathrm{kg}^{-} 1$ [7], al menos tres veces mayor que otros combustibles químicos ${ }^{3}$. Por otro lado el hidrógeno es el elemento más abundante en el universo y en la Tierra. Finalmente, la energía almacenada en la molécula $H_{2}$ puede liberarse a través de la combustión convencional y/o electroquímica produciendo como residuo solo agua: $2 \mathrm{H}_{2}+\mathrm{O}_{2} \Rightarrow 2 \mathrm{H}_{2} \mathrm{O}+$ energia Desde el punto de vista de la factibilidad, es justamente el notable progreso de la tecnología de las celdas de combustible lo que le ha otorgado impulso a las investigaciones orientadas al uso del hidrógeno [11, 12]. Mientras que en las máquinas térmicas el rendimiento tiene una limitación teórica (ciclo de Carnot), en dichas celdas pueden lograrse eficiencias superiores al $50 \%$ mediante la combustión electroquímica y más del $80 \%$ si se aprovecha el calor involucrado. Así, el uso del hidrógeno como portador de energía, es decir, como intermediario entre la producción de energía y el consumo, junto a su aprovechamiento en celdas de

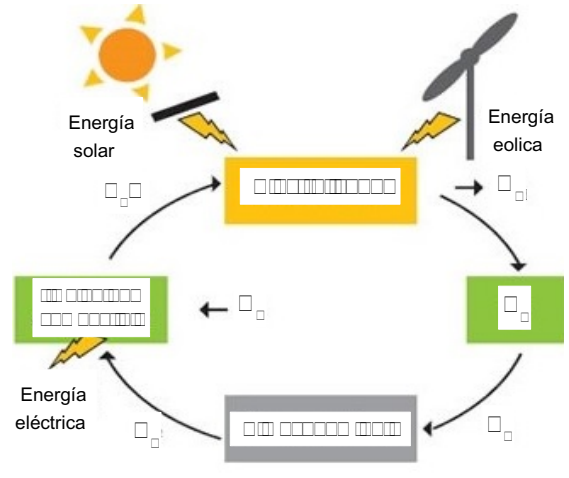

Ciclo del uso del hidrógeno en una economía del hidrógeno combustible, se vislumbran hoy como opciones concretas para brindar, en combinación con fuentes de energía primarias renovables/sustentables, una solución limpia y eficiente al problema energético global.

En este esquema de economía global sustentable, aún se requiere trabajar denodadamente en la integración de las energías primarias renovables dado que todavía subsisten numerosos problemas por resolver antes de poder alcanzar el uso a gran escala de estas tecnologías. Por ejemplo, si bien el $\mathrm{H}$ es el elemento más abundante, menos del $1 \%$ del total se presenta como $\mathrm{H}_{2}$ gaseoso. La inmensa mayoría se halla formando enlaces químicos como $\mathrm{H}_{2} \mathrm{O}$ y otra parte en hidrocarburos líquidos o gaseosos. El hidrógeno consumido como material crudo (521010 kg mundiales por año[13] ) es mayoritariamente producido usando combustibles fósiles y a través de la reacción de cadenas de hidrocarburos (-CH2-), lo que produce $\mathrm{H}_{2}$ pero también $\mathrm{CO}_{2}$ (contribuyendo negativamente al impacto ambiental). Por otro lado, la disociación térmica directa del agua requiere temperaturas superiores a $2.000{ }^{\circ} \mathrm{C}$ (mayor que

\footnotetext{
${ }^{3}$ Por ejemplo el valor equivalente para hidrocarburos es de $47 \mathrm{MJkg}^{-}$.
} 
$900{ }^{\circ} \mathrm{C}$ con catalizadores $\mathrm{Pt} / \mathrm{Ru}$ )[7]. Así, la manera limpia por excelencia hasta el momento ${ }^{4}$ de producir $\mathrm{H}_{2}$ sería la electrólisis del $\mathrm{H}_{2} \mathrm{O}$, por tanto la producción a gran escala mediante esta vía constituye uno de los principales desafíos.

El esquema sustentable de producción y consumo de la energía almacenada en $\mathrm{H}_{2}$ sería por medio de un ciclo cerrado (carbon-free cycle): utilizando energía solar, eólica, geotérmica, mareomotriz, etc( [15],[16]) para efectuar la electrólisis[17] que produciría el $H_{2}$ utilizado luego en las celdas de combustible, y allí re-obtener energía eléctrica y térmica. Pero además del necesario desarrollo de infraestructura para la producción limpia de $H_{2}$, distribución, abastecimiento, y la optimización de las celdas (rendimiento y condiciones de trabajo), es crucial resolver el problema del almacenamiento del hidrógeno, que es hacia donde se orienta la investigación presentada en esta tesis.

Actualmente existen variadas formas de almacenar hidrógeno $[8,18]$. Convencionalmente el hidrógeno es almacenado como gas comprimido en tubos a alta presión El almacenamiento y transporte del gas comprimido ha sido extensamente usado durante más de cien años. De hecho puede decirse que la tecnología de compresión y almacenamiento de hidrógeno comprimido es una tecnología madura[18], aunque en los últimos años se han hecho grandes esfuerzos en desarrollo para pasar de los 200 bar a los equipos más avanzados de 800 bar [8, 19]. Para este último caso de presiones más elevadas, se han desarrollado nuevas generaciones de materiales especiales compuestos -composites- de fibras de carbono. Uno de los inconvenientes de almacenar el hidrógeno como gas comprimido es que requiere el uso de cilindros contenedores mas caros cuanto mayor sea la presión, por lo que sólo suele ser práctico para pequeñas cantidades. Los materiales comunes de las bombonas de almacenamiento suelen ser acero ligero, aluminio y sus compuestos y las presiones de almacenamiento van entre 20 a $69 \mathrm{MPa}$. Un tanque de acero presurizado, por ejemplo, puede llegar a soportar presiones de 350bar (es decir, $35 \mathrm{MPa}$ ) [8].

El hidrógeno en grandes cantidades y moderadamente presurizado se almacena en forma estacionaria en tanques esféricos (por ejemplo un volumen de $10.000 \mathrm{Nm}^{3}\left(^{5}\right.$ ) a presión entre 1 y 1,5 MPa o un volumen de $15.000 \mathrm{Nm}^{3}$ a presión entre 1,2 y 1,6 MPa. Pero para los enormes volúmenes que involucran una amplia utilización del hidrógeno, esta manera ya no resulta factible. Podría pensarse otra alternativa que es el almacenamiento subterráneo, cantidades mucho mayores (varios millones de $\mathrm{Nm}^{3}$ a presiones entre 3-6 $\mathrm{MPa}$ ) pueden almacenarse en pozos de petróleo o de gas agotados, o en cavernas porosas de acuíferos subterráneos con pérdidas entre el 1 y el $3 \%$

Para algunas aplicaciones industriales el hidrógeno se almacena en pequeñas botellas a alta presión $\left(0,05 \mathrm{Nm}^{3} / 20 \mathrm{MPa}\right)$ o en tanques cilíndricos de tamaño medio a mayor presión (10-20 Nm $\mathrm{N}^{3} />20 \mathrm{MPa}$ ) [20]. De todas formas puede decirse que la principal desventaja del almacenamiento comprimido es la baja densidad volumétrica ${ }^{6}$ ( $23 \mathrm{~g} \mathrm{H}_{2} / \mathrm{L}$ tanque.) que no puede superarse comprimiéndolo aún más por el sacrificio que implica en términos de densidad gravimétrica (peso del reservorio) ya que se requieren de materiales especiales, y además por el costo energético (trabajo) necesario para comprimirlo [8, 20, 21]. Esto podría mejorarse mediante la licuefacción del $\mathrm{H}_{2}$ almacenándolo en contenedores criogénicos (40

\footnotetext{
${ }^{4}$ También se estudian formas de producirlo mediante procesos biológicos.Ref[ (14)]

${ }^{5} \mathrm{~N}$ se refiere a metros cúbicos Normales.

${ }^{6}$ Sin comprimir y a temperatura ambiente, $1 \mathrm{~kg}$ de hidrógeno ocupa $11 \mathrm{~m}^{3}$ 
g $\mathrm{H}_{2}$ /L.tanque, con lo que se logra una densidad de $\left.71 \mathrm{gH}_{2} / \mathrm{L}\right)$ ). Sin embargo a a temperaturas de $20 \mathrm{~K}$ varios factores contribuyen a pérdidas que condicionan esta práctica solamente a aplicaciones especiales [16].

Alternativamente el hidrógeno puede ser almacenado en compuestos sólidos de diversa índole conteniendo hidrógeno atómico o molecular[22, 23]. De esta manera el hidrógeno puede almacenarse reversiblemente en materiales sólidos, ya sea a través de la fisisorción en materiales porosos o a través de quimisorción en hidruros metálicos. La fisisorción involucra interacciones débiles entre la molécula de $H_{2}$ y los átomos de la superficie del sólido adsorbente. Este mecanismo resulta eficiente solo a bajas temperaturas, típicamente $77 \mathrm{~K}$ donde puede alcanzar una densidad ${ }^{7}$ de 7,5 wt. \% H para los mejores materiales, es decir los de mayor área superficial (compuestos metalorgánicos) [21, 24]. Aunque la densidad volumétrica alcanzada está limitada a $34 \mathrm{~g} \mathrm{H}_{2}$ /L.material, muchas investigaciones giran en torno a las maneras de mejorar el almacenamiento en materiales de carbono como nanotubos de carbono $[25,26,27]$. En contraste, la bondad de los hidruros metálicos reside en la alta densidad

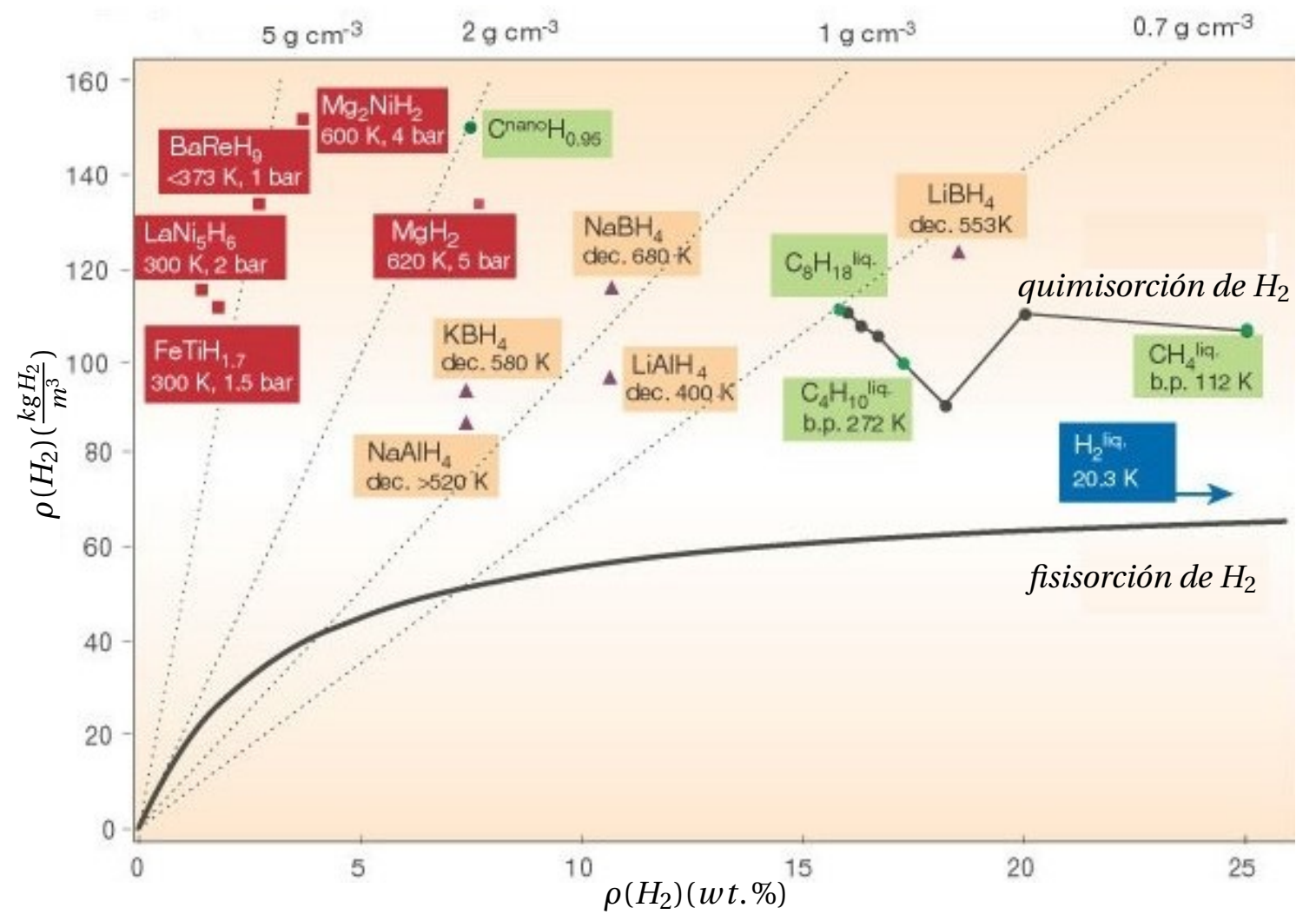

Comparación de la relación entre la capacidad volumétrica y gravimétrica para distintos materiales como reservorios de hidrógeno.

volumétrica (hasta $150 \mathrm{gH}_{2} /$ L.material).

Los hidruros sólidos, metálicos o complejos ${ }^{8}$, son excelentes candidatos para cumplir con las demandas de almacenamiento de hidrógeno. Por un lado porque puede almacenarse el

\footnotetext{
${ }^{7}$ Se usará la notación $w t$. \% para referirse al peso porcentual.

${ }^{8}$ Se mencionarán los distintos tipos de hidruros en la próxima sección.
} 
hidrógeno a temperaturas y presiones moderadas reduciendo considerablemente el peligro de uso. Además, en estos reservorios sólidos, se alcanzan densidades volumétricas comparables o superiores a la del hidrógeno líquido. Como contraparte para mejorar la practicidad del uso de hidruros como reservorios de hidrógeno en aplicaciones móviles, estos reservorios presentan lentas cinéticas de hidruración/deshidruración, y/o requieren de 'altas' temperaturas de descarga (dada su alta entalpía de formación) y de control térmico durante las reacciones en reservorios masivos (powder beds[28]) en los cuales a entalpía de reacción influye en la cinética durante el progreso de la misma[29, 30]). Aún en este contexto, las perspectivas se consideran promisorias y los hidruros sólidos son ampliamente considerados de crucial importancia como materiales reservorios de hidrógeno en las perspectivas energéticas globales basadas en el hidrógeno como portador de energía. Entre los principales desafíos se encuentran, mejorar la cinética de carga/descarga y en adecuar su temperatura de operación a las condiciones particulares de uso. Grandes avances se han obtenido mediante el empleo de materiales nanoestructurados y el agregado de diversos aditivos que catalizan las reacciones de absorción y desorción de hidrógeno[31, 32, 33, 7, 34]. Suelen citarse en la literatura las metas estándar que periódicamente establece el Departamento de Energía de los Estados Unidos (DOE,[35]), en términos de parámetros ambientales,económicos y de comodidad, etc. De acuerdo a las últimas metas establecidas, el peso porcentual del $\mathrm{H}_{2}$ en los reservorios tendría que hallarse en el rango 6-9 wt. \%, mientras que la densidad volumétrica entre $0.028-0.040 \mathrm{~kg} / \mathrm{L}$ [36, p.108] En lo referente al almacenamiento, una de las metas más extendidas es hallar sistemas metal-hidrógeno $(\mathrm{MH})$ con densidades gravimétricas mayores a 6 wt.\%,volumétricas mayores a $65 \mathrm{~g} \mathrm{H}_{2} / \mathrm{L}$ y que absorban y desorban $\mathrm{H}_{2}$ a presiones relativamente bajas, $\leq 10$ bar, y temperaturas entre 60 y $120^{\circ} \mathrm{C}$. En el caso de aplicaciones relacionadas con celdas de combustible, por ejemplo, existe el interés por el desarrollo de celdas de temperatura intermedia[37] (IT-SOFCs) debido a los inconvenientes ${ }^{9}$ que acarrean sus elevadas temperaturas de operación. Esto muestra entre otros aspectos[12] la relatividad de estos estándares dominantes en la discusión hacia una economía global del hidrógeno. De hecho existen proyectos orientados a reducir las dificultades de disipación acoplando el reservorio de hidruro a un intercambiador de calor que recupere el calor remanente durante las reacciones exotérmicas. Por otro lado, ya existen modelos de reservorios comerciales basados en Mg, y aún cuando se espera mejorar la termodinámica de estos sistemas, el actual estado del arte muestra que la factibilidad de desarrollar estas tecnologías puede ser mayor al sofisticar el diseño y/o relativizar algunos estándares de uso de la energía. Esto convierte en más relevante a la proyección de uso del Mg como reservorio.

\subsection{Hidruros metálicos}

\section{Hidruros en general}

Los materiales formadores de hidruro $(\mathrm{MFH})$ poseen múltiples aplicaciones prácticas por su capacidad de almacenar hidrógeno de manera reversible [38, 39, 40, 41, 42]. Entre las nume-

\footnotetext{
${ }^{9}$ Otro de los desafíos es también reducir las temperaturas de operación de las celdas SOFCs a $\sim 500^{\circ} \mathrm{C}$ lo cual tendría varias ventajas, por ejemplo hacer más factible el uso de materiales nanoestructurados los cuales presentan propiedades de operación ventajosas en esas temperaturas.
} 
rosas aplicaciones pueden mencionarse las baterías recargables de níquel, los purificadores de gas $H_{2}$ y separación de isótopos a través de membranas de hidruros metálicos empleando aleaciones de Pd, sensores y compresores de hidrógeno, etc. Además los sistemas Mg-metal de transición (M-MT) y aleaciones de $\mathrm{Mg}$ y Ni, han revelado tener un comportamiento óptico ajustable a la cantidad de hidrógeno [43], similar a lo que ocurre con los sistemas Mg-tierras raras.

En cuanto al almacenamiento en hidruros, su uso resulta ventajoso respecto al almacenamiento en fase gaseosa por su alta capacidad volumétrica ( 1000 veces superior al gas a la misma presión), y porque su carga y descarga se realiza a una presión casi constante. En las últimas décadas se han publicado una gran cantidad de trabajos reportando las propiedades cinéticas y termodinámicas de los hidruros metálicos[39]. Los MFH pueden agruparse de la siguiente forma:

- compuestos intermetálicos

- hidruros complejos

- hidruros basados en Mg

En [28], [39] y[44], se da una descripción más detallada de cada grupo.

Entre los sistemas más estudiados se encuentra el $L a N i_{5}$ que permite absorber y desorber hidrógeno a temperatura ambiente y presiones debajo de 5 bar. Sin embargo su capacidad no excede el $2 \mathrm{wt} \% \mathrm{H}$ lo que es insuficiente para algunas aplicaciones, por ejemplo para aplicaciones móviles.

Es importante mencionar que generalmente los metales de partida presentan una capa de óxido o hidróxido superficial que es necesario remover a fin de hacer posible la incorporación del hidrógeno para la formación del hidruro. Esto puede implicar por ejemplo tratamientos a presión y/o térmicos (annealing o recocido), proceso denominado usualmente activación.

\subsection{Materiales nanoestructurados}

\section{Efectos de tamaño sobre las propiedades de almacenamiento}

Los materiales nanoestructurados se han estado investigando a fin de superar limitaciones de las propiedades de bulk vinculadas a sus propiedades físico-químicas, termodinámicas y cinéticas. La reducción de tamaño de las partículas ${ }^{10}$ de hidruros metálicos conduce a un cambio dramático en las propiedades del sistema y esto constituye comunmente el punto de partida para la investigación de estos sistemas. Aprovechando las propiedades químicas y físicas observadas en materiales nanoestructurados, se han podido superar algunas limitaciones en las cinéticas de formación y sorción de hidrógeno. En estos materiales, la reducción del tamaño de partícula, produce una reducción significativa de la entalpía de formación y de las temperaturas de absorción y desorción. Paralelamente, algunas nanoestructuras no resultan estables durante los ciclos de carga y descarga, degradándose las propiedades

${ }^{10}$ Aquí específicamente el término partícula es usado para referirse al cristal o grano, pero en general, se usará el término grano o cristalita para distinguir de partícula, que puede incluir varios granos formando parte de la misma. 
de sorción con los ciclos de carga y descarga. Además en los materiales nanoestructurados también se reduce, de manera significativa, la conductividad térmica, lo cual dificulta extraer el calor del reservorio durante la carga. Estos son algunos de los desafíos a vencer para lograr la practicidad de los hidruros metálicos como reservorios de hidrógeno.

Los beneficios de las nanoestructuras para el almacenamiento de hidrógeno han sido reportados en numerosos trabajos por muchos grupos [45, 46]. En la literatura también se describen ampliamente los progresos alcanzados con nanoestructuras de carbón [26, 36, 47, 48, 49], y con hidruros metálicos basados en procesos de quimisorción. Pueden señalarse en primer lugar dos aspectos fundamentales respecto a las propiedades que generan la disminución del tamaño de partícula y de grano. Por un lado esto incrementa la superficie específica disponible para la quimisorción de $\mathrm{H}$ mejorando las posibilidades de las primeras etapas de la reacción. Y por otro, permite acortar la longitud del camino de difusión de los átomos de $\mathrm{H}$, relacionada con las etapas siguientes [13]. El Mg puro en bulk particularmente presenta cinéticas de hidruración muy lentas pudiendo inclusive no alcanzarse nunca la hidruración completa. Experimentalmente se ha mostrado que esto cambia favorablemente con la reducción de tamaño de partícula/grano respecto al Mg comercial [50]. Además hay cálculos realizados en los que distintos autores estiman que se puede disminuir notablemente la temperatura de desorción de hidrógeno en $\mathrm{Mg} \mathrm{H}_{2}$, reduciendo el tamaño de cristalita por debajo de un umbral crítico teórico de $\sim 1 \mathrm{~nm}$, debido a una notable disminución de la entalpía de desorción de hidrógeno[51, 52]. Aguey-Zinsou et al.[53] aseguran que la disminución de la presión de equilibrio de desorción para magnesio nanocristalino es fundamental para el uso de materiales basados en Mg como reservorios de hidrógeno. Establecen además, que la clave para mejorar la cinética de hidruración/deshidruración del Mg por debajo de los $523 \mathrm{~K}$ $\left(250^{\circ} \mathrm{C}\right)$ es reduciendo aún más el tamaño de partícula y que "no hay que hacer esfuerzos en otra dirección". No obstante, K.B.Gerasimov et al. [54] advierten por ejemplo que los sistemas nanocristalinos basados en magnesio (partículas por debajo de $1 \mu \mathrm{m}$ ) pueden ver afectada negativamente su cinética a presiones de absorción cercanas a las de equilibrio (la etapa de nucleación de la fase hidruro se convierte en etapa limitante).

En este contexto puede decirse entonces que las propiedades de almacenamiento se ven favorecidas en general, pero no estrictamente, con la reducción de tamaño. Esto se debe a varios factores que deben tenerse en cuenta[44] y cuya comprensión definitiva no está saldada. Por ello es necesario profundizar una comprensión detallada de los principios físicos subyacentes en los efectos emergentes a escala nanométrica.

Para polvos de metales y nanoclusters, es esencial no solo comprender las capacidades potenciales de almacenamiento sino también la influencia del tamaño y cambios de propiedades durante las reacciones de hidruración/deshidruración. Tal conocimiento es clave, por un lado para la correcta determinación de las propiedades cinéticas de acuerdo ala presión de equilibrio, pero también para el diseño exitoso de nuevos reservorios de hidruros.

\section{Métodos de fabricación de hidruros metálicos nanocristalinos.}

Varios métodos se han ido desarrollando en el campo de la nanotecnología para lograr materiales nanoestructurados [55, 56, 57]. Métodos como ablación laser, condensación de vapor, sputtering y molienda mecánica reactiva, son algunos de los métodos convencionales usados para producir materiales nanocristalinos. La molienda mecánica reactiva es uno de 
los métodos más vastamente utilizados entre los investigadores experimentales debido a su relativamente fácil escalabilidad y uso. Comúnmente se usan molinos rotatorios (entre ellos los planetarios) y también los molinos vibratorios. La técnica de molienda se basa en la colocación del material base en un cilindro rotatorio/vibratorio junto con material no reactivo en la molienda (generalmente esferas de acero). Durante el movimiento a altas velocidades o frecuencias se producen impactos mecánicos de la bola con el material original crudo y la cámara de acero o reactor (la cual debe tener mayor dureza que los materiales reactivos). De esta manera se estimula mecánicamente la fractura y 'soldado en frío' de los materiales constituyentes, reduciendo así el tamaño, generando grietas, dislocaciones(defectos en general) y produciendo superficies 'frescas'. Inclusive en el caso de materiales prácticamente inmiscibles (en condiciones de equilibrio) puede producirse cierto grado de aleación (defectos substitucionales). El resultado es la obtención de grandes conglomerados de partículas generalmente poli y nano- cristalinas $(10-100 \mathrm{~nm})[58,59]$. El refinamiento mecánico de los granos está mencionado en los trabajos de Koch [60] y Fecht[61]. Las técnicas de fabricación utilizadas en este trabajo (al igual que otras de las mencionadas arriba) constituyen rutas fuera del equilibrio que conducen inevitablemente a la creación de fases metaestables y gran cantidad de defectos puntuales (antisitios y vacancias) y extendidos (dislocaciones. bordes de grano, fallas de apilamiento, etc.). Además la estructura y morfología finales pueden depender fuertemente de la ruta y/o método de fabricación (frecuencia, relación masa bola/material, tipo de molino, condiciones de molienda, entre otros). La experiencia con hidruros muestra la sensible dependencia de las propiedades cinéticas con estas características. Esto motiva el ensayo de distintas vías de fabricación a través de la molienda mecánica normal o reactiva. En particular se utilizaron distintos molinos, habiéndose usado principalmente un molino vibratorio de bolas que será descrito mas adelante. Los sistemas en su mayoría fueron fabricados a presiones comparativamente bajas de $\mathrm{H}_{2}$ respecto a la literatura en general. Aún así se lograron propiedades cinéticas comparativamente buenas, lo cual constituye uno de los aspectos destacables de la Tesis. Sin embargo también se contó con la posibilidad de realizar una molienda a alta presión en atmósfera de $D_{2}$, de manera que pudieron compararse los resultados y estudiar el efecto de la presión sobre la microestructura y las propiedades de sorción ${ }^{11}$.

\subsection{Hidruros basados en Mg}

Gran cantidad de trabajos proponen que los hidruros basados en Mg resultan prometedores como reservorios de hidrógeno $[62,31,63]$ y en particular para aplicaciones móviles. Entre otras características, su abundancia y bajo costo convierten al Mg una de las alternativas más interesantes para almacenar hidrógeno en estado sólido [63]. El hidruro de magnesio $\left(\mathrm{MgH}_{2}\right)$ presenta una capacidad másica de almacenamiento cercana a 7.6\%p y volumétrica de $109 \mathrm{gH}_{2} / \mathrm{L}$.

Por otro lado, su alta estabilidad termodinámica $\left(\Delta H_{\text {des }}=75 \mathrm{~kJ} / \mathrm{mol} \mathrm{H}_{2}\right.$ y $\left.\Delta S=135 \mathrm{~J} / \mathrm{K} \cdot \mathrm{mol} \mathrm{H}_{2}\right)$ y la baja difusividad del hidrógeno en el hidruro constituyen los principales impedimentos para su uso práctico. La lenta cinética del sistema $\mathrm{Mg} / \mathrm{Mg}-\mathrm{H}_{2}$ en bulk es generalmente atribuida a la baja capacidad del Mg para promover la disociación de $H_{2}$, la baja difusividad

${ }^{11}$ Se hablará de sorción para hacer referencia simultánea a los procesos de absorción y desorción de $H_{2}$. 
del $\mathrm{H}$ en la fase estequiométrica rutilo- $\mathrm{MgH}_{2}$ y se lo ha asociado también a la naturaleza iónica del enlace entre el Mg y el H [64, 65]. Si embargo entre los enlaces iónicos con cationes alcalinos, particularmente el del Mg-H es el menos iónico y puede considerarse, parcialmente covalente y parcialmente iónico. Cálculos realizados por Noritake y col., muestran que las cargas iónicas del $\mathrm{Mg}$ y el $\mathrm{H}$ pueden representarse por $\mathrm{Mg}^{1.91+}$ y $H^{0.26-12}$, siendo este carácter incluso motivo de discusión como aspecto relativamente favorable. También la gran avidez del Mg por el oxígeno conlleva a la formación de una capa superficial de óxido (pasivación [67]) que puede perjudicar la hidruración/deshidruración y por lo que debe manipularse en condiciones de atmósfera controlada para evitarlo. No obstante algunos grupos investigan materiales basados en magnesio incluyendo $\mathrm{MgO}$ o grupos $\mathrm{OH}^{-1}$ en el material $[53,54,68]$. Se han desarrollado numerosas investigaciones tendientes a determinar las condiciones para que materiales basados en $\mathrm{Mg}$ y/o sistemas afines puedan cargarse fácilmente con hidrógeno, liberándolo luego de manera controlada y en condiciones de temperatura y presión razonables. Después de varias décadas de investigación de materiales basados en Mg se han logrado importantes avances en el mejoramiento de las propiedades de hidrogenación. En particular se han logrado mejoras incorporando aditivos ${ }^{13}$. Por ejemplo la incorporación de distintos metales de transición (MT) favorece la disociación de $H_{2}$ (carga) y re-asociación de los átomos de $\mathrm{H}$ (descarga) en sistemas metal hidrógeno: $M-H \Leftrightarrow M+H_{2}[69,70]$. Para la síntesis de los materiales obtenidos, también denominados 'composites ${ }^{14}$, el procedimiento general consiste en el molido mecánico del material de estudio, comunmente polvo de $\mathrm{Mg} \mathrm{o}$ $\mathrm{MgH}_{2}$, junto con una pequeña cantidad del material aditivo ( $1 \mathrm{a} 5$ at. \% TM) .

El mejoramiento significativo de la cinética por agregado de aditivos (catalizadores) se logra al permitir la transferencia de electrones y disociación de hidrógeno molecular a través de un mecanismo denominado spillover (Mitchel et al 2003[71]). Mediante este mecanismo las moléculas de $\mathrm{H}_{2}$ se disocian sobre la superficie del catalizador. Los átomos de $\mathrm{H}$ pueden mantenerse sobre el catalizador o difundir hacia el soporte del catalizador o a la superficie de la capa de óxido nativa. De esta manera la molienda mecánica reactiva ofrece más beneficios aún, dado que permite combinar dos factores cruciales: reducción de tamaño y agregado de catalizador. En los materiales nanoestructurados así producidos, se reducen las distancias de difusión y se favorece la disociación de las moléculas de hidrógenos al ofrecer un gran número de sitios de disociación y permitiendo una rápida difusión del hidrógeno atómico hacia el interior del material. Además puede decirse que uno de los aspectos trascendentes requeridos para lograr buenas propiedades catalíticas estables sin perder capacidad, es la

${ }^{12}$ La electronegatividad para el Mg es 1,2 y para el H 2,1. En esos términos tiene sentido referirse al Mg y al H como el catión y el anión respectivamente dado que el $\mathrm{Mg}$ se encuentra casi completamente ionizado como $\mathrm{Mg}^{2+}$. Las cargas separadas del Mg se distribuyen en las regiones intersticiales contribuyendo a los enlaces covalentes Mg-H y H-H.

${ }^{13} \mathrm{El}$ término aditivo se refiere en forma general a un elemento o sustancia incorporada al material, ya sea reaccionando químicamente o no al ser incorporado. Suele usarse en general para hacer referencia a elementos o sustancias que juegan un rol de desestabilización termodinámica del sistema, participando de una o más reacciones. Debe distinguirse del término catalizador, que es un aditivo pero que no participa de las reacciones, solo las acelera.

${ }^{14}$ Se usará este término dado que no existe una traducción directa al castellano que haga referencia al mismo tipo de material. El término hace referencia entonces a una mezcla fina heterogénea no necesariamente química (es decir no es necesariamente una aleación) de elementos o sustancias. 
distribución uniforme de la menor cantidad posible de partículas del catalizador sobre la superficie de las partículas de $\mathrm{Mg} / \mathrm{MgH}_{2}$. Combinar la molienda con el agregado de un catalizador contribuye a minimizar la cantidad de catalizador requerida, dado que el mismo está disperso a escala nanométrica en la microestructura. Además esto generalmente suele evitar o minimizar la necesidad de una etapa de activación previa. El tipo de molienda, las condiciones de molido, la cantidad de aditivo y el estado inicial del polvo son condiciones que pueden influir en las propiedades del material. Con el objetivo de poder vincular los parámetros de la fabricación con dichas propiedades es necesario realizar estudios comparativos de los diferentes procedimientos de fabricación con distintos aditivos.

Como tendencia general se observa claramente un mejoramiento de la cinética del $\mathrm{Mg} \mathrm{H}_{2}$ [72, 73]. El Nb , V y Ti se destacan como aditivos entre la gran cantidad de resultados reportados [73, 74, 75, 76, 77, 78, 79]. Estos metales son inmiscibles con el $\mathrm{Mg}$ por lo que lo que no se obtienen aleaciones sino dispersiones. Por ejemplo, $\mathrm{MgH}_{2}+5$ at. \% V molido durante 20 horas, desorbe hidrógeno en 33 min a $508 \mathrm{~K}$ y subsiguientemente absorbe 5.6 wt. \% $\mathrm{H}$ en 4 min a $473 \mathrm{~K}$. Además, estas destacadas propiedades de hidrogenación se conservan con el ciclado (2000 ciclos) [79, 80]. El rol que juegan los aditivos catalizadores sigue sujeto a debate pudiendo haber varios efectos involucrados en el mejoramiento de la cinética. En el caso de las fases metaestables de los hidruros $N b H_{x}$ o $V H_{x}$ varios autores lo atribuyen a un rol tipo 'gateway' para la difusión de hidrógeno. Conclusiones similares se han reportado para el $\mathrm{MgH}_{2}$ catalizado con $\mathrm{Ti}[74,76,77,78,81,82]$.

\subsubsection{Sistemas Mg-Ti}

El uso de Sc como aditivo ha mostrado tener buenas propiedades [13].El sistema $M g_{y} S c_{1-y} H_{x}$ de simetría fcc ha mostrado tener una alta velocidad de difusión de hidrógeno. En vistas de limitar la pérdida de capacidad gravimétrica al sustituir su rol por el de otros MT (mas pesados), aparecen como prometedores los que le siguen en la tabla periódica, Ti, $\mathrm{V}$ y Cr, porque además forman una estructura (hidruro) fcc, a la cual podría atribuírsele estas buenas propiedades de difusión. Excepto la aleación $\mathrm{Mg}_{0.8} \mathrm{Cr}_{0.2}$, estas aleaciones satisfacen los requerimientos estándar. El sistema $M g_{0.8} V_{0.2}$ posee una capacidad reversible razonable de almacenamiento pero se ha mostrado que los átomos de hidrógeno absorbidos en su mayoría pueden ser liberados solo a bajas velocidades. Las ideas antedichas, condujeron entonces al interés por la profundización del estudio y la caracterización de los sistemas Mg-Ti hidrurados como potenciales reservorios de hidrógeno (en particular para aplicaciones móviles por la densidad gravimétrica aceptable).

En esta tesis se presenta también un estudio comparativo de las cinéticas de formación de los sistemas $M g_{x} T i_{1-x}$. Al igual que el $\mathrm{Nb}$ y el $\mathrm{V}$, el Ti forma varias fases de hidruros metaestables $\mathrm{TiH}_{x}(0.7<x<1.1)$. Además la fase fluorita fcc del $\mathrm{Ti} H_{2}$ exhibe mucho mejor difusividad del hidrógeno que la estructura rutilo del $\mathrm{MgH} \mathrm{H}_{2}\left(1.7 \times 10^{-13} \mathrm{~m}^{2} \mathrm{~s}^{-1}\right.$ a $600 \mathrm{~K}$ [83]). Luego se espera que favorezca la cinética de difusión del $\mathrm{H}$ durante los coclos de carga y descarga. Como el Mg, el Ti cristaliza a temperatura ambiente en la estructura hcp (S.G. P63mmc). El sistema Mg-Ti es prácticamente inmiscible $\left(\Delta H_{\text {mezcla }}=20 \mathrm{kJmol}-\right.$ atom $)$, -lo que suele 
atribuirse a su diferente valencia- ${ }^{15}$ [84], luego, las aleaciones metaestables e hidruros pueden ser producidas ya sea como películas delgadas, [65, 85] a través de técnicas de deposición de vapor, o geometrías de bulk [86,57] vía molienda mecánica reactiva entre otras $[87,88]$ (rutas fuera del equilibrio). Estas fases metaestables constituyen rutas promisorias para lograr la desestabilización del hidruro. Anastasopol et al. [89] ha reportado una reducción en la entalpía de formación $\left(-45 \mathrm{KJ} / \mathrm{mol} H_{2}\right)$ y entropía $\left(-84 \mathrm{~J} / \mathrm{Kmol} H_{2}\right)$ de hidrogenación de aleaciones Mg-Ti realizadas mediante 'horno de arco', pero la estabilidad térmica a lo largo de los ciclos de carga y descarga resulta problemática, afectando su potencial uso para almacenamiento de hidrógeno. Al modificar las propiedades de hidrogenación del Mg mediante aleación con $\mathrm{Ti}$, es mandatorio la preservación de la estructura Mg-Ti durante el ciclado (absorción/desorción). Se ha reportado la formación del hidruro Mg-Ti-H de única fase por hidrogenación a temperatura ambiente de polvos aleados mecánicamente [90].

La existencia de las interfases entre el $\mathrm{Mg}$ y el $\mathrm{TiH}_{2}$ es clave para facilitar la movilidad de $\mathrm{H}$ en el nano-compuesto. Además, se demuestra que las inclusiones de $\mathrm{TiH}_{2}$ ralentizan el crecimiento de grano de $\mathrm{Mg} / \mathrm{MgH}_{2}$, manteniendo la nano-estructura de los compuestos durante su ciclado. También se han obtenido buenos resultados en cuanto a las propiedades cinéticas y de ciclado para sistemas $\mathrm{Mg}-\mathrm{TiH}_{2}$ sintetizados mediante molienda mecánica reactiva [91, 92, 93, 94]. Ponthieu et al. [24] ha estudiado el sistema Mg-Ti, en particular la composición $\mathrm{Mg}_{0.7} T i_{0.3}$, concluyendo que este puede almacenar de manera reversible hasta $3.7 \mathrm{wt} \%$ a $573 \mathrm{~K}$ sin modificaciones hasta los 100 ciclos.

En un trabajo ya publicado [95], se ha reportado la cinética de formación y la microestructura de los hidruros Mg-Ti producidos en nuestro laboratorio mediante molienda reactiva (molino vibratorio) y siguiendo diferentes rutas. Se ha encontrado que la composición de $\mathrm{Mg}-\mathrm{Ti} \mathrm{H}_{2}$ conduce a una dispersión fina heterogénea de las fases, que tiene buenas propiedades cinéticas de formación sin detrimento significativo de capacidad gravimétrica (una densidad gravimétrica de hidrógeno hasta del 6\%, es bien lograda por los sistemas $M g_{x} T i_{(1-x)}$ con $x \geq 0.7$. En una publicación posterior [96] se focaliza la atención al estudio comparativo de las propiedades de sorción de $\mathrm{H}_{2}$ mediante esas muestras fabricadas por distintas vías. Los resultados de ambos trabajos constituyen parte de este trabajo de Tesis.

\subsubsection{Sistemas con grafito}

El carbono (C) se manifiesta en sus diversas formas: grafito, carbón activado, nanotubos de carbón, fibras de carbono, entre otros. La diversidad de formas estructurales (fulerenos, nanotubos, grafeno, espumas de carbono, carbón tipo $\mathrm{s} p^{1}$, etc) y su alta capacidad de almacenamiento en poros [97], convierten a los sistemas nanoestructurados basados en carbono (C) en materiales interesantes para el desarrollo de reservorios de hidrógeno [98, 99, 100]. Además se investiga y utiliza al carbono como aditivo de materiales formadores de hidruro. Se ha encontrado que los aditivos de carbono exhiben ventajas prominentes sobre otros aditivos sin carbono, tales como nanotubos de nitruro de Boro (BNNTs) o asbestos [101]. En particular el agregado de grafito, una de las formas más económicas disponibles, mejora considera-

\footnotetext{
${ }^{15}$ Sin embargo se ha logrado mediante molienda mecánica una solubilidad sólida extendida de Mg en Ti, Ti(Mg), y
} viceversa, $\mathrm{Mg}(\mathrm{Ti})$. 
blemente las propiedades de sorción de sistemas basados en Mg con aditivos catalizadores, obtenidos por molienda mecánica [102]. Estos sistemas han sido investigados a fin de reducir la temperatura de descomposición del hidruro $\mathrm{MgH}_{2}$ [103] así como también para mejorar las cinéticas de hidruración/deshidruración. En particular también ha sido investigado el efecto de las distintas formas de carbono sobre las propiedades cinéticas de composites Mg-C preparados mediante molienda mecánica reactiva [27].

Por un lado, las propiedades lubricantes del grafito pueden influir en el modo de aglomeración de partículas, influyendo en las características estructurales y en consecuencia en los mecanismos de absorción (vinculado a la superficie de interacción).

Además, si se lograra cubrir las superficies con grafito, este podría cumplir un rol protector evitando la oxidación de dicha superficie u otro tipo de reacciones indeseadas.

Por otro lado, las reacciones de hidruración/deshidruración del sistema $\mathrm{Mg} / \mathrm{Mg} \mathrm{H}_{2}$ son fuertemente exotérmicas/endotérmicas. Así, una de las principales dificultades a superar para la implementación práctica de estos sistemas como reservorios (tanques a escala real basados en $\mathrm{Mg} \mathrm{H}_{2}$ ) consiste en el control del flujo de calor durante la carga y descarga (extracción de calor durante la carga y mantenimiento de la temperatura por encima de la temperatura de equilibrio durante la descarga). Se espera que el uso de una matriz expandida de grafito natural pueda aumentar la velocidad de reacción por las propiedades particulares de conducción térmica del grafito[81], [104].

Otro aspecto interesante que merece ser comentado es la existencia de algunas investigaciones orientadas al desarrollo de sistemas híbridos para el almacenamiento de hidrógeno, es decir combinando materiales basados en carbono y metales.

Mientras que los sistemas basados en la fisisorción (fuerzas intermoleculares débiles) tienen una capacidad limitada sujeta al uso de temperaturas criogénicas, los materiales que almacenan por quimisorción (intercambio electrónico interatómico) poseen mayor capacidad pero tienen cinética limitada y requieren altas temperaturas de desorción. Los sistemas híbridos mencionados se focalizan entonces en el uso de distintos composites combinando la capacidad de absorción química (materiales reactivos con alta superficie específica) con la cinética propia de reservorios por adsorción física $[49,105]$. Un sistema híbrido podría consistir en una dispersión de nanopartículas de un material formador de hidruro inmerso en una matriz de un medio nanoporoso de carbón. Este último provisto de la porosidad precisa, con poros activos para la fisisorción a través de fuerzas intermoleculares (por ejemplo usando carbón activado) $[106,107,108]$. De esta manera la investigación y desarrollo de estructuras carbonáceas es importante en materia de desarrollo de sistemas híbridos como almacenadores de hidrógeno.

En síntesis este trabajo constituye una investigación básicas sobre propiedades cinéticas y termodinámicas de sistemas nanoestructurados Mg-Ti formadores de hidruros preparados por distintas vías o rutas de fabricación. Se estudia el rol del $\mathrm{TiH}_{2}$ en la formación de los materiales y en la catálisis de las reacciones de hidruración y deshidruración del $\mathrm{Mg} / \mathrm{Mg} \mathrm{H}_{2}$. También se investigó la influencia del grafito como aditivo en las propiedades de estos sistemas. 


\section{Resumen de capítulos}

En el Capítulo 2 se pretende dar un panorama sobre los modelos cinéticos existentes, las consideraciones físicas detrás de los mismos, la manera de realizar un análisis cinético para hallar un modelo adecuado, y las limitaciones existentes en la determinación de dichos modelos.

En el Capítulo 3 se describirán el método y las vías de fabricación utilizados, como así también los sistemas fabricados mediante molienda mecánica reactiva.

En el Capítulo 4 se describirán las técnicas de hidruración y deshidruración de materiales en general, y en particular las experiencias realizadas sobre los materiales fabricados durante el desarrollo de la Tesis.

En el Capítulo 5 se mostrará la caracterización estructural realizada sobre las muestras fabricadas y tratadas térmicamente, mediante difracción y microscopía.

En el capítulo 6 se describirán los métodos de fabricación de los sistemas en polvo y las muestras fabricadas. Se presentarán comparativamente las curvas cinéticas de formación de los hidruros obtenidos mediante distintas rutas así como el modelo y los parámetros de ajuste.

En el Capítulo 7 se presentarán resultados de las experiencias de desorción/absorción de $\mathrm{H}_{2}$. Se presentarán los análisis de los tratamientos térmicos realizados sobre las muestras fabricadas antes de ser sometidas a ciclos de carga y descarga de hidrógeno. También se presentarán las curvas cinéticas de deshidruración/hidruración a temperatura constante y a distintas presiones, comparándolas por vías de fabricación.

En el Capítulo 8 se presentarán las experiencias de desorción y absorción de hidrógeno realizadas mediante calorimetría diferencial. Se presentarán resultados para distintas vías de fabricación y para diferentes atmósferas.

En el Capítulo 9 se realizará el análisis de las curvas cinéticas isotérmicas y no isotérmicas obtenidas mediante volumetría. Se mostrarán las características termodinámicas de los sistemas fabricados y la modelización de la cinética mediante componentes de ajuste que indican la existencia múltiples mecanismos de sorción. Esto será complementado con el análisis de los resultados calorimétricos que fueron analizados mediante el método isoconversional, a través del cual se obtuvieron las energías de activación para la deshidruración de los sistemas.

Finalmente en el Capítulo 10 se desarrolla una discusión conclusiva sobre los resultados experimentales y de los análisis realizados. 


\section{Capítulo 2}

\section{Detrás de los modelos cinéticos}

Uno de los factores determinantes para que los sistemas metal/hidrógeno $(\mathrm{MH})$ sean factibles como reservorios de hidrógeno son las propiedades cinéticas de formación y descomposición del material formador de hidruro, lo que es usualmente llamado cinética. Junto al estudio de la cinética del sistema se pueden investigar los mecanismos involucrados en la reacción sólido-gas. La meta es optimizar la velocidad de reacción y las condiciones termodinámicas correspondientes.

En este capítulo se pretende dar un panorama sobre los modelos cinéticos existentes, las consideraciones físicas detrás de los mismos, la manera de realizar un análisis cinético para hallar un modelo adecuado, y las limitaciones existentes en la determinación de los modelos. El tipo de análisis adoptado se deriva principalmente de un análisis cinético generalizado utilizado para estudiar las cinéticas de reacciones en sistemas sólidos y sólido-gas. Estas reacciones pueden involucrar varios mecanismos. Por lo tanto debe distinguirse la cinética homogénea de la cinética heterogénea, comprendiendo, está última un conjunto complejo de procesos durante la transformación Metal $+\mathrm{H}_{2} \Leftrightarrow$ Hidruro. Además, las reacciones pueden ocurrir en condiciones isotérmicas o en condiciones no isotérmicas, lo que debe ser tenido en cuenta por los distintos métodos. Ambos tipos de datos experimentales son complementarios.

\subsection{Dos conceptos necesarios: Factor limitante y nucleación- crecimiento}

Las cinéticas de absorción y desorción de hidrógeno en general responden a una cinética heterogénea. Así, uno de los abordajes más generalizados del problema consiste en considerar la multitud de los procesos en una secuencia de pasos que ocurren en distintas regiones del sistema. La reacción de formación del hidruro (o absorción), se iniciaría en la superficie del sólido seguida de una serie de procesos elementales para finalizar en la difusión del $\mathrm{H}$ en las fases hidruro/metal [109]:

i) llegada de $H_{2}$ a la superficie, ii) disociación de la molécula $H_{2}$, iii) quimisorción del hidrógeno $H$, iv) migración de los átomos de $H$ (protones) de la superficie y subsuperficie al bulk, v) difusión del $H$ al interior del material y vi) nucleación y crecimiento de la fase hidruro.

La secuencia inversa corresponde a la desorción, siendo el último paso la reasociación de los átomos de $H$ para formar la molécula $H_{2}$.

Desde ese enfoque, la estrategia usual es determinar lo que llamamos cinética intrínseca, es 
decir la identificación del mecanismo más lento involucrado durante la reacción, lo que se denomina rate-limiting step (rls) o factor limitante (fl). En la cinética intrínseca se asume que sólo uno de los pasos o mecanismos de la reacción es suficientemente lento comparado con el resto de los procesos tal que puede decirse que controla la reacción entera. El otro enfoque, no excluyente, consiste en estudiar la reacción desde el punto de vista de la nucleación y crecimiento de las fases, teniendo en cuenta la interferencia oimpingement entre núcleos (o granos) al crecer . Tales procesos podrían ocurrir separada o simultáneamente y se ha escrito bastante acerca de los factores que influyen en la formación de núcleos y su crecimiento, por ejemplo si ocurren isotrópicamente o si existen lugares preferenciales (por ejemplo en bordes de grano donde hay una ruptura del orden cristalino).

La primera, y más conocida teoría general sobre la transformación de fases en estado sólido es la teoría JMAK, inicialmente desarrollada por Melvin Avrami (1939 [110]), generalizada por Kolmogorov, Johnson y el mismo Avrami en una serie de publicaciones posteriores [111, 112, $113,114]$. En dicha teoría, se da una expresión general para la fracción de fase real trasformada, digamos $X$, en términos de una fracción de fase 'extendida' $X_{e}{ }^{1}$ y las velocidades de crecimiento y nucleación. En un desarrollo simplificado se puede partir de un volumen $V_{0}$ donde crece una fase que ocupa un volumen $V$. El incremento de la fase transformada $d V$ en un tiempo infinitesimal $d t$ viene dado por:

$$
d V=\left(1-\frac{V}{V_{0}}\right) \times d V_{e}
$$

siendo $d V_{e}$ el cambio en el volumen de fase extendida. Dividiendo por $V_{0}$ e integrando:

$$
X_{0}=1-e^{-X_{e}}
$$

siendo $X_{0}$ la fracción de fase real transformada dentro del volumen $V$.

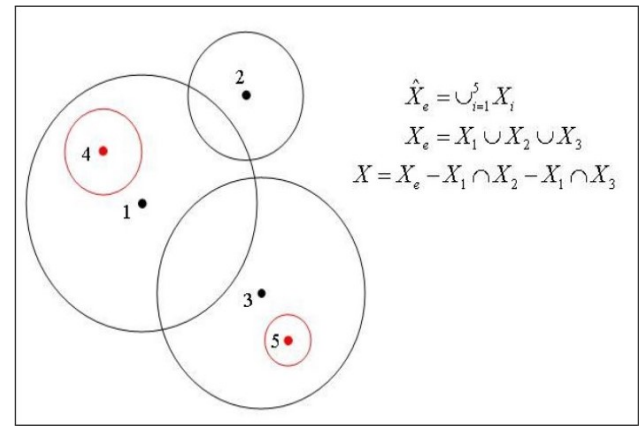

Figura 2.1: Concepto de fracción de fase extendedida.

Las leyes que dan la tasa de nucleación y la velocidad de crecimiento de los núcleos formados están incorporadas en $X_{e}$. La expresión general obtenida por Avrami se desarrolla en el Apéndice A.0.3, ec. A.11 :

\footnotetext{
${ }^{1}$ Es decir la fracción de fase transformada que tendría lugar sin tener en cuenta el impingement o superposición, y por lo tanto la interpenetración de regiones transformadas que representarían regiones ficticias de fase transformada (Figura 2.1).
} 


$$
V(t, \vec{R})=1-e^{-\int_{0}^{t} \tilde{v}\left(t, t^{\prime}\right) \frac{\partial \tilde{N}}{\partial t^{\prime}} d t^{\prime}}
$$

Así, el grado de avance de la reacción en términos de la fracción de volumen transformado deviene en una expresión sencilla en términos de la tasa de nucleación $\frac{\partial \tilde{N}}{\partial t^{\prime}}$ y la ley de crecimiento $\tilde{v}\left(t, t^{\prime}\right)$.

En la literatura suele considerarse como punto de partida el caso más simplificado. En este se supone:

- nucleación aleatoria y homogénea sobre toda la fase no transformada

- crecimiento isotrópico de los núcleos-grano a una velocidad invariante frente a la extensión de la transformación

de esa manera (y cambiando de notación $\frac{V}{V_{0}} \rightarrow \alpha$ ) resulta:

$$
\alpha(t, T)=1-e^{-K(T) t^{n}}
$$

A partir de la ecuación ${ }^{2} 2.1$ se obtiene la clásica expresión para realizar un 'Avrami plot' graficando $\ln (-\ln (1-\alpha))$ vs $t$ :

$$
\ln [-\ln (1-\alpha)]=n \cdot \ln (t)+\ln (K)
$$

La pendiente del gráfico de Avrami brinda el parámetro $n$ que se asocia al tipo de ley de crecimiento de la fase en transformación.

Por ejemplo $n=4$ corresponde al caso de crecimiento tridimensional. En la práctica podrían obtenerse valores no enteros de $n$. La constante K está asociada a la ley de crecimiento de los granos y depende de la temperatura. Es generalmente aceptado que sigue una ley tipo Arrehenius $K(T)=A . e^{-\frac{E_{a}}{k_{B} T}}$. Este factor pre-exponencial se lo asocia a la frecuencia de intentos para que tenga lugar una reacción que requiere de una energía $E_{a}$. El factor exponencial tiene como origen la distribución de Maxwell que da la fracción de moléculas con energía cinética mayor a $E_{a}$.

\section{Comentarios sobre la aplicabilidad del modelo}

Sobre la teoría de JMAK, Málek[116] hace notar que su aplicabilidad práctica a procesos no isotérmicos se restringe a casos particulares donde se satisface la condición de saturación de sitios. Por tanto la teoría presenta en principio limitaciones para describir la cinética de muchísimos de los sistemas reales, y algunos autores sostienen que esta limitación principalmente se da en el caso de procesos no isotérmicos[116].

No obstante, como se muestra en el desarrollo del Apéndice A.0.3, la teoría de JMAK es una descripción probabilístico-geométrica que contempla en forma general las velocidades de crecimiento y tasas de nucleación. Las hipótesis exigidas para el progreso de la reacción son más generales que las que se reportan usualmente en la literatura. Por ejemplo no suele destacarse que el modelo también incluye las casos de formación de núcleos homogéneamente dentro

\footnotetext{
${ }^{2}$ La ecuación 2.1 es la A.13 del Apéndice A.0.3.
} 
de cierta región restringida del material, como puede ser una capa de la superficie o bordes de grano. Esto es importante dado que como se mostrará, en algunos de nuestros sistemas el modelo ha funcionado y por lo tanto nos brinda información del tipo de nucleación que ocurre.

De esta manera, a pesar de las limitaciones del modelo (por ejemplo, anisotropías[117, 118]) se comprende que el uso generalizado de la teoría de JMAK se mantenga vigente en casi todos los análisis cinéticos hallados en la literatura. Paralelamente la ecuación de Johnson-MehlAvrami-Kolmogorov es frecuentemente utilizada para el análisis de datos experimentales correspondientes a cinéticas de recristalización no isotérmicas[116, 119]. En muchos de los análisis cinéticos se asume la necesidad de hacer un análisis cuantitativo de los datos experimentales para verificar si los mecanismos cinéticos se corresponden con los de este modelo y/o para apreciar cuánto se apartan del mismo. [116, 120]. Se han realizado varias investigaciones describiendo la manera de hacer tests robustos y de como aplicarlos[116, 120, 121]. También se han publicado varios trabajos que revisan la teoría y proponen la manera de extenderla en diversas situaciones [119, 122, 123, 124, 125].Se justifica entonces hacer una descripción de la misma (Apéndice A.0.3) dado que, además este análisis permite inferir qué tipo de procesos pueden asociarse con la reacción a través de los exponentes involucrados. Por ejemplo si se trata de procesos de transformación polimórfica, crecimiento controlado por movimiento de la interface, crecimiento controlado por difusión, etc.[115, 126] (ver sección 2.3). A partir de esto se podrán comparar cinéticas isotérmicas y no isotérmicas basadas en este tipo de análisis.

\section{Algunas consideraciones sobre las reacciones sólido-gas}

La cinética de reacción de hidruración ha sido abordada por varios autores con los mismos modelos desarrollados para las reacciones sólido gas con $\mathrm{O}_{2}$ y $N_{2}$ [28]. En general resulta complicada la interpretación de la cinética de los sistemas metal/hidrógeno/hidruro/. Esto se debe a distintas características como la exotermicidad de la formación de hidruro, escasa conductividad térmica de la fase hidrurada, fragilización de los los productos, etc. Además estos sistemas muestran ser muy sensibles a pequeños cambios en la morfología tanto de la superficie como del bulk y a la pureza del sólido y de los gases. Existen de hecho abundancia de datos experimentales que pueden diferir significativamente aún cuando las condiciones de los experimentos sean en apariencia similares. Algunos autores sostienen que la determinación del mecanismo intrínseco debe ser llevada a cabo solo para muestras donde el calor (generado o absorbido) no influya en la cinética, lo cual resulta cierto en muestras suficientemente pequeñas. Las muestras utilizadas en el desarrollo de esta Tesis asumen una situación de este tipo. En un sistema a escala piloto deberán combinarse las ecuaciones cinéticas junto con las ecuaciones de transporte (masa y calor) a fin de simular las condiciones reales, en las que debe tenerse en cuenta la influencia de la transferencia de calor en cada proceso de la reacción, un aspecto insoslayable a la hora de la implementación de estos sistemas como reservorios $[28,127]$. 


\subsection{Modelos y métodos de análisis}

La ecuación más general [128] aceptada para la descripción de la cinética del proceso adquiere la forma:

$$
\frac{d \alpha}{d t}=H(P, T, r) \times A f(\alpha)
$$

denominada ecuación cinética fundamental, siendo $\alpha$ la fracción de fase transformada. La función $f(\alpha)$ describe los mecanismos de la transformación de fase y solo depende del grado de transformación $\alpha$, lo que constituye la hipótesis isocinética[129]. A es un prefactor de normalización. La función $H$ incluye la dependencia con la presión $P$, la temperatura y parámetros de geometría $r$ del sistema. En ciertos casos resulta posible proponer una separación de variables:

$$
\left.\frac{d \alpha}{d t}=A \cdot R(r) \cdot I\left(P, P_{e q}\right) \cdot K(T)\right) \times f(\alpha)
$$

La mayoría de los métodos de análisis parten explícita o implícitamente de la ecuación cinética fundamental para el progreso de la reacción en su forma más simple:

$$
\frac{d \alpha}{d t}=K(T) \times A \cdot f(\alpha)
$$

asumiéndose generalmente un comportamiento tipo Arrhenius para $K(T)$, la cual es independiente del grado de transformación.

$$
K(T)=A \cdot e^{-\frac{E_{a}}{k_{B} T}}
$$

La ecuación 2.5 corresponde tanto a procesos isotérmicos como no isotérmicos. Estos últimos se aplicarán en el caso de experimentos de calorimetría diferencial (DSC). Las consideraciones que hay que hacer sobre esta ecuación en el caso de procesos no isotérmicos se han descrito en la literatura[126].

A partir de la ecuación 2.5, la caracterización de la cinética [28] de un sistema y su interpretación abarca en general los siguientes pasos. En primer lugar la elección de la variable o parámetro experimental que describa el avance de la reacción, por ejemplo la fracción de fase transformada $\alpha[126,128]$. Luego la determinación del modelo cinético que mejor describa su dependencia con el tiempo y la interpretación de los parámetros correspondientes. Por otro lado, es necesario investigar la dependencia de la reacción con $\mathrm{P}$ y $\mathrm{T}$.

Siguiendo esa línea, esquemáticamente se ha adoptado en general el siguiente esquema de análisis de la cinética :

- Hallar la función $\alpha(t)$ que mejor ajuste los datos experimentales.Esto en general se hace a través de la función $f(\alpha)$.

- Obtener la energía de activación asociada al factor $K$ (ec. 2.6) a partir de algún método confiable. Siguiendo las expresiones anteriores uno de los más conocidos es el método de Arrhenius, graficando $\ln (K) v s .1 / T$. 
- La dependencia de la velocidad de reacción con la presión ${ }^{3} \mathrm{P}$, lo que permite distinguir entre distintos modos de nucleación.

Para hallar $\alpha(t)$ (o alternativamente $\alpha(T)$ ), la expresión más ampliamente usada es:

$$
g(\alpha):=\int_{o}^{\alpha} \frac{d \alpha^{\prime}}{f\left(\alpha^{\prime}\right)}=\int_{o}^{t} H d t^{\prime}=k . t
$$

válida estrictamente (en principio) para el caso en que la presión y la geometría no varíen durante la transformación $(k=A$. $H)$. Se origina del caso particular de procesos isotérmicos a partir de la ecuación 2.5 y también se corresponde con un caso particular de JMAK: de las ecuaciones 2.1 y 2.2 se deduce la forma de $g(\alpha)$ directamente. Se comprende entonces por qué la ecuación 2.7 se usa generalizadamente para explorar el mecanismo de nucleación y crecimiento al que responde el sistema.

Los modelos suelen darse en términos de $g(\alpha)$ o alternativamente en términos de $f(\alpha)$. Varios de los modelos se han reportado y descrito en la bibliografía [23, 28, 116, 130, 131, 132]. En el Apéndice A.0.1 se da una lista de modelos.

Se podría decir que este es un esquema convencional el cual se ha generalizado para determinar o inferir los mecanismos correspondientes a la cinética en estudio.

Veremos que hay cuestiones sin resolver aún acerca del valor de la energía de activación, que resulta de la superposición de varios mecanismos involucrados en la transformación.

\subsection{Análisis formal de la cinética}

\section{Limitaciones de los análisis cinéticos. Análisis formal vs. análisis convencional}

Los análisis cinéticos convencionales se basan entonces en la ecuación cinética fundamental 2.5, asumiendo un comportamiento tipo Arrhenius (ec.2.6) para hallar la energía de activación y el modelo apropiado $f(\alpha)$. En forma creciente, se ha ido remarcando en la literatura que la determinación de los parámetros cinéticos de las reacciones de estado sólido y sólido-gas a partir de este tipo de análisis, resulta confusa y ambigua. Esto es así dado que en un análisis cinético convencional varios modelos cinéticos permiten lograr buenos ajustes. Así, los parámetros obtenidos suelen responder a situaciones más ideales que realistas y en consecuencia resulta difícil explicar el origen de la discrepancia con los datos experimentales. Se puede decir que se ha extendido el uso, poco crítico, del enfoque cinético adoptado, es decir soslayando las hipótesis subyacentes sobre el sistema y los mecanismos posibles de reacción. Por ejemplo, ya se ha advertido [133] que los parámetros de activación obtenidos siguiendo la ecuación fundamental representan cantidades aparentes de las cuales no se puede dar una interpretación mecanicista directa, por lo que no deben ser usados para interpretaciones teóricas. No obstante, tales parámetros permiten el modelado semiempírico para predecir cinéticas en otros regímenes de temperatura y/o calentamiento en el caso de experimentos no isotérmicos (por ejemplo corridas calorimétricas DSC). Frente a este

\footnotetext{
${ }^{3}$ Realmente el parámetro más representativo que debe ser considerado es $\Delta P=P-P_{e q}$ que depende de T, y es lo que suele denominarse 'driving force' o fuerza impulsora. $P_{e q}$ es la presión de equilibrio de absorción/desorción.
} 
contexto Baitalow [121] advierte entonces la necesidad de focalizarse en realizar lo que denomina un análisis cinético formal, en contraposición a los análisis convencionales. Es decir un análisis mediante el cual expresar la velocidad de la reacción como función del tiempo y la temperatura usando funciones empíricas o semiempíricas. Los parámetros así obtenidos serían útiles para aplicaciones prácticas, como predecir el progreso de la reacción en función del tiempo y la temperatura, correlacionar las cinéticas de reacción con las propiedades de la muestra, etc. Un análisis formal de la cinética del sistema permite también una mejor discriminación entre los modelos cinéticos. En un primer paso se determinarán entonces los parámetros de activación a través de algún método confiable, principalmente la energía de activación. En un segundo paso, una vez establecido el modelo cinético mediante la energía de activación, pueden ajustarse los parámetros asociados al modelo mediante un proceso de regresión no lineal. Según Baitalow este abordaje constituye la mejor manera de hacer un análisis formal ya que permite obtener sin ambigüedad datos cinéticos. Algunos autores [134] han desarrollado análisis para determinar un valor confiable de la energía de activación para luego determinar el mejor modelo cinético que se ajusta a las curvas experimentales y por lo tanto también los parámetros correspondientes. Debe entenderse por 'confiable' a aquellos valores de energía obtenidos, que preserven las hipótesis iniciales detrás de la ecuación fundamental: la hipótesis de variables separables y la hipótesis isocinética. Los valores de $E_{a}$ pueden depender fuertemente del tipo de método utilizado y por ello resulta conveniente comparar los valores obtenidos por diversos métodos. También se han reportado energías de activación que dependen del grado de transformación $\alpha$ y en otros casos, que dependen del rango de velocidades de calentamiento cuando se trata de experimentos no isotérmicos. Así pueden llegar a identificarse distintas energías de activación que se asociarían con distintos procesos. Si bien la ecuación fundamental contempla en principio reacciones homogéneas, se ha extendido su uso para interpretar reacciones heterogéneas. Desde el enfoque presentado, debe adoptarse entonces un método para hallar la energía de activación. Aquí serán descritos y adoptados los métodos isoconversional y de Kissinger. En el caso de procesos isotérmicos, un método adoptado es el de gráfico de tiempo reducido, es decir la fracción transformada $\alpha$ vs. $t_{r e d}$, siendo $t_{r e d}=\frac{t}{t_{0.5}}$, con $t_{0.5}$ el tiempo correspondiente a la mitad de la transformación total. Si es cierta la hipótesis de separabilidad de variables, el factor pre-exponencial es el mismo y a partir de la ec. 2.7 correspondiente a procesos isotérmicos, se puede notar que las curvas experimentales descritas en términos de la nueva variable $t_{r e d}$ deberían coincidir a distintas temperaturas.

En el caso de procesos no isotérmicos, el análisis adoptado en este trabajo se basa en las siguientes funciones:

$$
\begin{gathered}
y(\alpha)=\frac{d \alpha}{d t} e^{\frac{E}{R T}} \\
z(\alpha)=g(\alpha) \cdot f(\alpha)
\end{gathered}
$$

Usando combinadamente las propiedades matemáticas de estas funciones se pueden identificar los modelos más adecuados para los datos experimentales[120, 135]. Este uso combinado que llamaremos protocolo de Mălek se resume en el esquema de la figura 2.2. Notar que la función $y(\alpha)$ se comporta esencialmente como la función $f(\alpha)$ que contiene la información sobre el mecanismo de la transformación. Esta función suele ser sensible al valor 
de $E_{a c t}$. En tanto que la función $z(\alpha)$ es menos sensible y la expresión adoptada generalmente es:

$$
z(\alpha)=\pi(x)\left(\frac{d \alpha}{d T}\right) \frac{T}{\beta}
$$

siendo $\beta$ :velocidad de calentamiento, $x=\frac{E}{R T} \mathrm{y} \pi(x)$ una función relacionada con la integración ${ }^{4}$ de la ecuación 2.5.

Cabe destacar que siempre es posible hallar un buen ajuste usando el modelo [126]:

$$
f(\alpha)=(1-\alpha)^{m} \alpha^{n}
$$

De esta manera, en el caso de no identificarse las curvas experimentales con ninguno de los modelos planteados, siempre es posible hallar una expresión empírica utilizando este último modelo. Los exponentes indican el grado de influencia de las fracciones transformada y sin transformar en la reacción. Se desarrollará un modelo similar (Biasetti, Meyer y Mendoza Zélis) extendido a reacciones que involucran varios mecanismos. Dicho modelo desarrollado durante el trabajo de Tesis fue satisfactoriamente aplicado a cinéticas de hidruración/deshidruración isotérmicas de los sistemas fabricados.

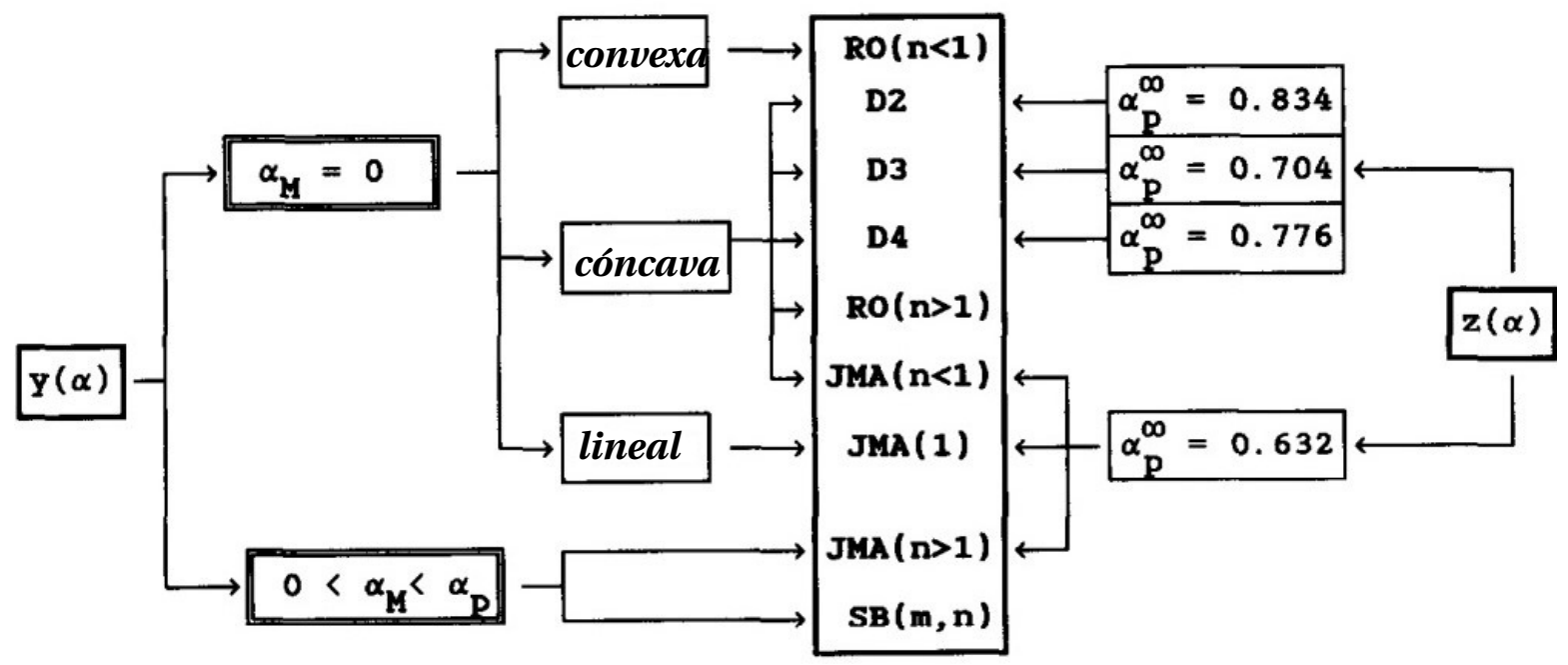

Figura 2.2: Protocolo de Mălek para el análisis isoconversional. El esquema sintetiza el protocolo a seguir en función de las propiedades de las funciones $y(\alpha)$ y $z(\alpha)$ construídas a partir de los datos experimentales y la energía de activación calculada. $\alpha_{M}$ es el valor de $\alpha$ (grado de transformación), para el que la función $y(\alpha)$ toma el máximo valor. Similarmente, $\alpha_{P}$ es el valor de $\alpha$ para el que la función $z(\alpha)$ toma el máximo valor en el intervalo $\epsilon[0,1]$. La columna del medio indica los modelos adecuados de acuerdo a las correspondientes propiedades de las funciones. Los modelos se pueden consultar en la tabla A.1

\footnotetext{
${ }^{4}$ La expresión para este factor depende del tipo de aproximación realizada para integrar, ya que suelen hacerse
} integraciones numéricas. 


\section{Resumen de métodos isoconversionales para la obtención de parámetros cinéticos}

Los métodos isoconversionales se basan en la utilización de la ecuación fundamental 2.5 fijando el grado de transformación $\alpha$. Construyendo curvas del tipo $\ln \left(\frac{d \alpha}{d t}\right)$ vs. $\frac{1}{T}$ para iguales valores de $\alpha$ de varias curvas experimentales cinéticas, y a partir de la ecuación 2.5, pueden obtenerse la energía de activación y los parámetros cinéticos. Los gráficos se construyen con datos experimentales obtenidos a distintas temperaturas -isotermas- o a distintas velocidades de calentamiento. En todos los casos se obtiene la energía de activación como la pendiente de la recta ajustada. El punto esencial - y por ello el prefijo 'iso' - es que cada uno de los puntos del gráfico (asociados a determinada temperatura) correspondan al mismo grado de avance de la reacción. Mencionaremos 4 métodos:

- Método isoconversional isotérmico

En este caso la ecuación 2.5 es fácilmente integrable pudiéndose expresarel tiempo $t$ como función de $1 / T$. Luego se grafica $\ln \left(t_{\alpha}\right)$ vs. $1 / T$ para los tiempos de las isotermas obtenidas correspondientes a un mismo grado de transformación $\alpha$. Se espera en principio una relación lineal para procesos que involucren un único mecanismo. Los parámetros cinéticos pueden obtenerse a partir de la pendiente y ordenada al origen del ajuste. También se conoce como método de Arrhenius.

- Método isoconversional para procesos no isotérmicos con velocidad de calentamiento constante.

En este caso la ecuación fundamental no es integrable directamente, por lo que se utilizan diferentes estrategias:

- Método integral. A partir de usar aproximaciones para realizar la integración, se derivan los métodos de Flyn-Wall-Ozawa (FWO) y Kissinger-Akahira-Sunose (KAS), que dan la expresión:

$$
\ln \left(\frac{\beta}{T^{a}}\right)=u\left(\frac{1}{T}\right)
$$

correspondiendo $a=0$ en el método de FWO y $a=2$ en el método de KAS. $\beta$ es la velocidad de calentamiento y $\mathrm{T}$ corresponde a la temperatura para un mismo grado de transformación en cada una de las curvas experimentales obtenidas. En el Apéndice G se desarrolla la ecuación correspondiente al método de Kissinger

- Método diferencial. En este caso, en lugar de integrar se utiliza la ecuación fundamental transformando la derivada de acuerdo a la velocidad de calentamiento $\frac{d T}{d t}=\beta$, resultando

$$
\ln \left(\beta \frac{d \alpha}{d T}\right)=\ln \left(A_{\alpha}\right)-\frac{E_{\alpha}}{R T}
$$

siendo $A_{\alpha}$ una constante dependiente del grado de transformación considerado, y $E_{\alpha}$ un valor asociado a la energía de activación. Este es el método de Friedman y es sensible a la relación ruido/señal experimental dado que se basa en valores instantáneos de la transformación.

- Método incremental. Es similar al método integral, pero en lugar de realizar la integración en todo el rango de temperaturas durante el experimento, se integra sobre un intervalo conveniente de manera de reducir en gran medida el ruido experimental. 
Simon [133] y Mălek [134] dan argumentos de por qué la ecuación 2.13 brinda el valor más confiable de la energía de activación. Esto tiene que ver con que tiene en cuenta la correlación existente entre los parámetros $A_{\alpha}$ y $E_{\alpha}$, evitando valores aparentes que conduzcan a modelos incorrectos. Incluso se ha reportado que aún cuando la energía pueda depender linealmente de $\alpha$, un cálculo iterativo de la energía muestra que el método de Friedman es el más robusto y confiable[121]. 


\section{Capítulo 3}

\section{Experimental. Parte I: formación de los hidruros}

En este capítulo se describirán los métodos y las vías de fabricación utilizados, como así también los sistemas fabricados mediante molienda mecánica reactiva.

\subsection{Molienda mecánica reactiva}

Los sistemas estudiados fueron fabricados por molienda mecánica reactiva de alta energía. La técnica ha sido vastamente utilizada desde hace varias décadas debido a su bajo costo, eficiencia y versatilidad (existen muchos tipos de molinos y de distintas escalas de producción). Además brinda la posibilidad casi ilimitada de obtención de composites nanoestructurados en una amplia gama de composiciones. Típicamente la molienda mecánica reactiva consiste en la incorporación de los materiales crudos dentro de una cámara o reactor de alta dureza con bolas de dureza, ligeramente menor. Dicho reactor, con el material y las esferas dentro, realiza movimientos oscilatorios, circulares o planetarios, dando lugar a múltiples impactos entre los reactivos, las esferas y el reactor. Las reacciones son inducidas por las fuerzas mecánicas durante los impactos simultáneos entre bola/s,reactivos y pared. Los procesos involucrados durante la molienda han sido des-

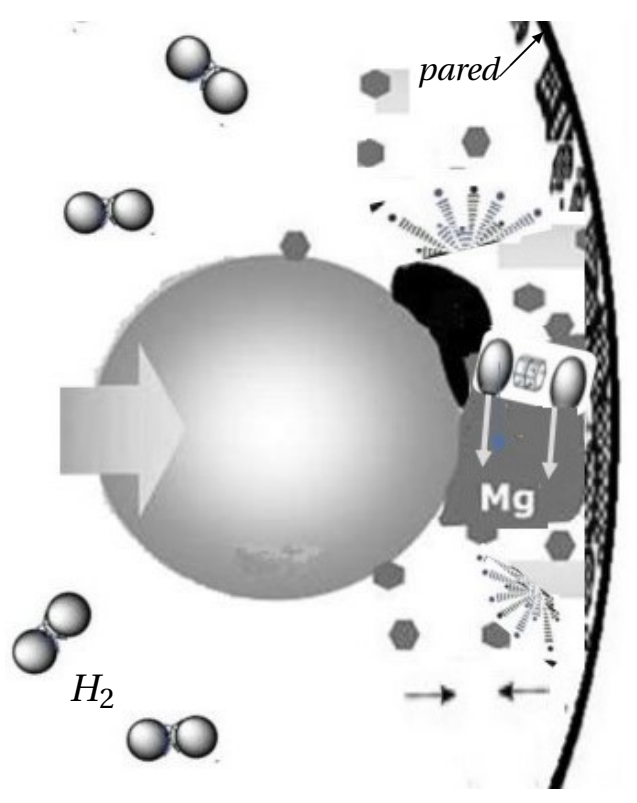

La molécula de $\mathrm{H}_{2}$ se disocia en la superficie del Mg con la asistencia de catalizadores $\left(\mathrm{Ti} / \mathrm{Ti} \mathrm{H}_{2}\right) \mathrm{y}$ de las fuerzas mecánicas que promueven la deformación plástica y la fragmentación durante los impactos bola/material/pared. critos en la literatura [60, 61]. Estos trabajos describen como el desarrollo de las microestructuras nanocristalinas mediante atrición mecánica puede resumirse en tres etapas: i) localización de la deformación en zonas estrechas de intensa tensión de corte (generalmente de naturaleza plástica) con una alta densidad de dislocaciones, ii) destrucción de la dislocación/recombinación/reacomodamiento para la formación de la estructura de cel- 
das/subgranos nanométricos,iii) la orientación de los granos se vuelve aleatoria: bordes de grano de bajo ángulo $\rightarrow$ bordes de grano de alto ángulo (deslizamiento de bordes de grano pudiendo haber rotación)

\section{Fabricación de muestras}

\section{Materiales y monitoreo}

Para este trabajo se utilizó principalmente un molino vibratorio (figura 3.1). Se contó también con la posibilidad de usar un molino planetario (molienda a alta presión) en un laboratorio externo. El molino utilizado resultó de una modificación y adaptación ad hoc realizada a partir de un molino Retsch. La capacidad de la cámara (figura 3.1), las características propias del molido y el material permitían moler hasta aproximadamente $0,5 \mathrm{~g}$ de material. . La mayor eficiencia de molido se obtenía utilizando una frecuencia de vibración de $32 \mathrm{~Hz}$ y una única bola (Diámetro $\phi=12.5 \mathrm{~mm}$ ) con una relación de masas bola:material de 15. Esto había sido estudiado previamente por el grupo.
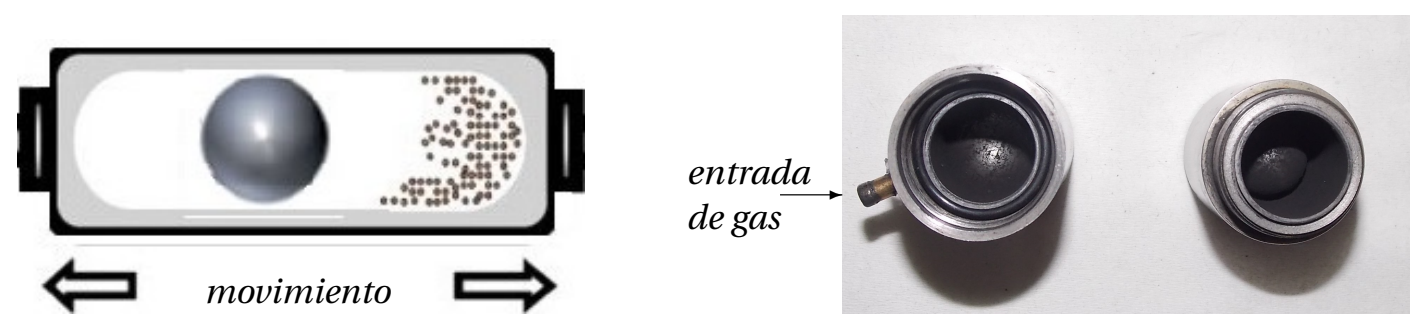

Figura 3.1: Reactor de la molienda abierto mostrado en corte transversal. Se usaba un O-ring a fin de lograr un sellado hermético que permita controlar la presión y preservar la pureza de la atmósfera.

Los composites nanoestructuradas obtenidos se fabricaron a partir de materiales comerciales de alta pureza ${ }^{2}$. Se prepararon muestras con diferentes composiciones atómicas Mg:Ti. Todas las moliendas se realizaron hasta alcanzar un estado estacionario (tipicamente entre 4 a 20 horas) en el cual podía asumirse que no ocurrían más reacciones en las cámara (figura3.2). La preparación y manipulación tanto de los constituyentes como de las muestras molidas siempre se realizó en una cámara de guantes con atmósfera controlada ( $\left.\mathrm{Ar}+\sim 10 \% \mathrm{H}_{2}\right)$, para minimizar el contenido de humedad y de oxígeno. En todos los casos se consiguieron dispersiones heterogéneas nanoestructuradas.

Los reactores cilíndricos del molino contaban con una entrada de gas (figura 3.1) de manera que era posible realizar la molienda bajo distintas condiciones de atmósfera interna. También se contaba con la posibilidad de monitorear la presión $\mathrm{P}(\mathrm{t})$ durante la molienda, permitiendo además el suministro de gas de acuerdo la configuración de valores de presión preestablecida.

\footnotetext{
${ }^{1}$ Se requerían varias moliendas en caso de necesitar mayor cantidad de masa. Superado un cierto factor de llenado del cilindro, la molienda se torna completamente ineficiente, ya que la bola queda fija (atrapada por el polvo) y deja de moler. Esto probablemente se deba a la ductilidad del Mg.

${ }^{2}$ Se midieron patrones de difracción de rayos $\mathrm{X}$ para verificar cualitativamente la pureza.
} 
Con estas facilidades se realizaron moliendas utilizando distintos gases (inertes o reactivos) y distintos valores de presión (entre 1 y 3 bar).

El procedimiento de preparación y molienda fue el siguiente:

i) Incorporar los reactivos con la estequiometria deseada al reactor ${ }^{3}$. Dicha operación se realizaba dentro de la cámara de atmósfera controlada.

ii) Ajustar el reactor en el molino y conectarlo a la línea de gases.

iii) Realizar purgas para obtener la atmósfera deseada dentro del reactor.

iv) Una vez lograda la atmósfera deseada dentro del reactor (generalmente $\mathrm{H}_{2}$ a una presión inicial típicamente de $\sim 2,8$ bar). Se iniciaba la molienda a una frecuencia de $32 \mathrm{~Hz}$.

v) Dicha molienda era monitoreada mediante un sensor de presión conectado al reactor.

vi) Mediante un programa de control se inyectaba nuevamente $\mathrm{H}_{2}$ cuando la presión caía por debajo de un valor predeterminado. Con este mecanismo se lograba una molienda con a una presión aproximadamente constante.

vii)Transcurridos 200 minutos desde la ultima reinyección de gas la molienda se daba por finalizada.

Una vez iniciada la molienda, y luego de un pequeño aumento de temperatura, el progreso de la reacción comenzaba a evidenciarse a los pocos minutos, a partir de la disminución de la presión $P_{\text {reac }}$ en el reactor ${ }^{4}$, debido a la absorción de $H_{2}$ gaseoso por parte de la muestra. En todos los casos se programó mediante el software ad-hoc que al disminuir $P_{\text {reac }}$ por debajo 2,20 bar, se reinyectara gas $\mathrm{H}_{2}$ a través de la apertura/cierre inmediatos de una electroválvula conectada al reservorio de hidrógeno, cuyo volumen era mucho mayor al del reactor. De esa manera la presión era restaurada a su valor inicial consistiendo cada medida en una serie de etapas de absorción ocurridas entre 2,80 a 2,20 bar. Para medir la presión instantánea se empleó un sensor diferencial (sensibilidad $0,5 \mathrm{kPa}$ ). Las curvas cinéticas de formación fueron obtenidas a partir de esta información, reconstruyendo el progreso de la reacción considerando el consumo relativo de hidrógeno [136] durante la molienda, es decir la fracción instantánea $\alpha(t)$ de átomos de $H$ incorporados al material relativa al número de átomos metálicos reactivos. En las condiciones de medida esto se puede calcular mediante:

$$
\frac{N_{H}(t)}{N_{\text {at.Met }}}=\frac{-2 \frac{\Delta P(t) V}{R T}}{N_{M g}+N_{T i}}
$$

La reconstrucción de las curvas cinéticas de formación queda ilustrada mediante la figura 3.2. El volumen fue calculado a partir de las dimensiones de los componentes del sistema (diámetro interno y longitud de las tuberías, volumen del reactor y volumen de la esfera). Asimismo, se realizó una calibración, llevando a cabo moliendas reactivas de metales de fácil hidruración (Ti) en las cuales se conoce la cantidad de $H_{2}$ que absorbe el material. A partir de la disminución de presión producida para diferentes masas molidas se pudo confirmar el valor del volumen del reactor.

\footnotetext{
${ }^{3}$ Los reactores cilíndricos y bolas eran previamente lavados con alcohol y acetona usando el molino.

${ }^{4} \mathrm{El}$ volumen era constante durante la molienda pero dependía del largo de manguera usada, con un valor $24 \mathrm{~cm}^{3}$.
} 
a)

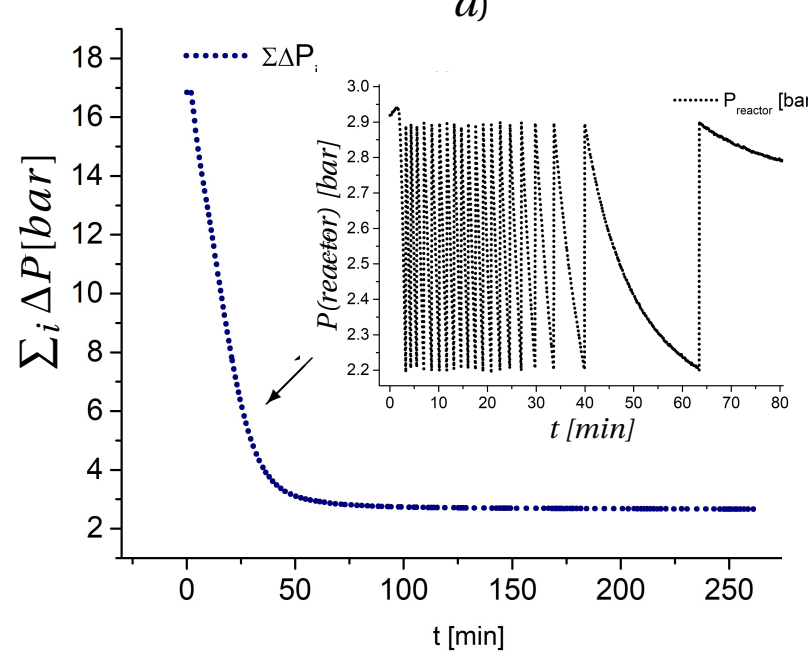

b)

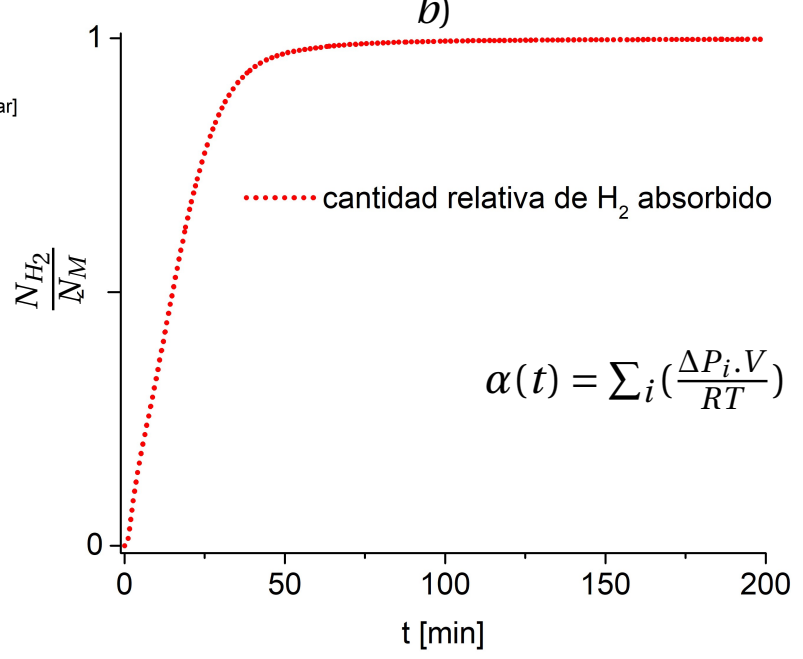

Figura 3.2: La figura $a$ muestra las etapas de apertura y cierre de válvula durante el monitoreo de presión $\mathrm{P}(\mathrm{t})$. A partir de la suma de etapas puede obtenerse la cantidad total de moles de $H_{2}$ absorbidos. A la derecha se muestra el $\mathrm{n}^{\circ}$ de moles de $\mathrm{H}_{2}$ relativos al ${ }^{\circ}$ de moles metálicos (M) reactivos, Mg y Ti, figura $b$. Las curvas cinéticas de formación presentaron, como en este ejemplo, un valor asintótico de acuerdo al valor teórico esperado para la formación de los hidruros

\section{Molino planetario}

Durante mi estadía en el IFE ${ }^{5}$ se utilizó un molino rotatorio Fritsch Pulverisette 6 y un reactor con monitoreo de la presión (Evico), para obtener un compuesto en polvo de $M g D_{2} \mathrm{TiD}_{2}$. La molienda se realizo durante $20 \mathrm{hs}$ a una presión inicial de 20 bar, que se redujo aproximadamente a 14 bar al finalizar la misma.

\subsection{Muestras fabricadas}

Se describen en esta sección las muestras y vías de fabricación. Como material de partida para los sistemas formadores de hidruro $M g-T i$ se utilizó Mg en granallas (99.9\%, alfa Aesar) y Ti en polvo fino $(99.4 \%$ Cerac). Las composiciones atómicas ensayadas fueron:

$$
M g: T i \rightarrow 50: 50 \quad 60: 40 \quad 70: 30 \quad 80: 20 \quad 90: 10 \quad 95: 5
$$

Las muestras con y sin carbono C (grafito) fabricadas en nuestro laboratorio corresponden a las composiciones:

1. $M g_{x}-T i_{1-x}$

2. $\left(M g_{x}-T i_{1-x}\right)_{1-y}-C_{y}$

${ }^{5}$ Institute for energy and tecnology (IFE),Kjeller,Noruega. Molienda que se hizo allí durante una estadía allí en el marco del trabajo de Tesis y de una colaboración de del grupo del Sr. Steffano Deledda,Senior Scientist. 
En el caso del C, se usó grafito en polvo fino comercial (99.9\% Sigma Aldrich). Se ensayaron variaciones en la cantidad relativa de grafito $5 \%$ at. $<y<20 \%$ at.

\section{Vías de fabricación. A, B, C, D y G}

Se describen a continuación las vías de fabricación ensayadas teniendo en cuenta las atmósferas de molienda y los reactivos de partida. A partir de ello se asigna una notación alfabética conveniente a fin de simplificar la referenciación cuando sea necesario en las siguientes secciones.

- Moliendas en molino vibratorio

vía A : Molienda directa de los componentes Mg y Ti en atmósfera de $\mathrm{H}_{2}$.

vía B : Molienda de los componentes Mg y $\mathrm{TiH}_{2}$ en atmósfera de $\mathrm{H}_{2}$

vía C : Molienda de los componentes Mg y Ti en atmósfera de Ar y una posterior molienda de hidruración en $\mathrm{H}_{2}$.

vía G(grafito): Molienda directa en atmósfera de $H_{2}$. Es idéntica a la vía A pero incorporando una fracción de grafito como componente inicial.

- Moliendas en molino planetario

vía $\mathrm{D}$ : Molienda directa de los componentes Mg y Ti en atmósfera de deuterio $D_{2}$ a alta presión.

Se llevaron a cabo una gran cantidad de moliendas con el molino vibratorio. No obstante se presentan nombradas y descritas en las tablas 3.1 y 3.2 las muestras más relevantes para este trabajo, correspondientes a muestras fabricadas por las vías A,B,D y G. Varias de las mismas fueron preparadas en iguales condiciones pero sometidas a distintos tratamientos para caracterización. Algunas de las muestras fueron simplemente fabricadas y caracterizadas por rayos X y/o microscopía. Mientras que a otras además se las sometió a ensayos de hidruración/deshidruración posteriores mediante un equipo volumétrico (Sieverts) y/o calorimetría diferencial (DSC), que serán descritas en las próximas secciones. La nomenclatura utilizada corresponde a las iniciales de los componentes reactivos de fabricación: $\mathrm{M}$ (Mg), T(Ti), C (carbono), seguidas de una numeración de acuerdo al orden de fabricación, siendo independientes las numeraciones de los grupos con y sin grafito. Así, la muestra MT12 es la décimo segunda muestra fabricada con Mg y Ti por vía $A$, mientras que la CMT12 es la décimo segunda muestra fabricada con $\mathrm{Mg}$, Ti y grafito $(\mathrm{C})$.

Todas las muestras fueron preparadas manipulando los materiales en atmósfera controlada de Ar, $\mathrm{O}_{2}<10 \mathrm{p} \mathrm{pm}, \mathrm{H}_{2} \mathrm{O}<0,01 \%$ humedad relativa,-54 punto de rocío y se procuró conservarlas en esas condiciones.

Entre las composiciones, la de proporción Mg:Ti:80:20 fue la mayormente estudiada ya que 
presentaba comparativamente una buena cinética de formación en relación al porcentaje atómico de Ti. Sobre este sistema se realizaron numerosos tratamientos térmicos, ciclos de carga/descarga de hidrógeno, medidas DSC y medidas DSC combinadas con termogravimetría. Luego estas cinéticas fueron comparadas con las cinéticas de los sistemas del tipo 2 con la misma relación Mg:Ti y distintas composiciones de grafito, y=0,05, y=0,10, y=0,20.

\section{Nombre Composite formado Vía de fabricación}

$\begin{array}{lll}\text { MT02 } & \left(\mathrm{MgH}_{2}\right)_{70}\left(\mathrm{TiH}_{2}\right)_{30} & A \\ \text { MT12 } & & B \\ \text { MT04 } & \left(\mathrm{MgH}_{2}\right)_{90}\left(\mathrm{TiH}_{2}\right)_{10} & A\end{array}$

MT13

MT27

MT29

MT34

MT36

MT40

$\left(\mathrm{MgH}_{2}\right)_{80}\left(\mathrm{TiH}_{2}\right)_{20}$

A

MT41

MT42

MT44

MT50

MT15

MT24

MT35

MT37

MT38

$\left(\mathrm{MgH}_{2}\right)_{80}\left(\mathrm{TiH}_{2}\right)_{20} \quad B$

MT45

MT47

MT48

MT31

MT39

$\left(\mathrm{MgH}_{2}\right)_{90}\left(\mathrm{TiH}_{2}\right)_{10} \quad A$

MTD2 $\left(M g D_{2}\right)_{80}\left(T i D_{2}\right)_{20} \quad D$

Tabla 3.1: Se describen las muestras fabricadas por molienda mecánica de sistemas Mg-Ti . Se indican en las columnas los nombres, el composite formado y la vía de fabricación respectivamente. 


\section{Nombre Composite formado Vía de fabricación}

$\begin{array}{ll}\text { CMT04 } & \left(\left(\mathrm{MgH}_{2}\right)_{90}\left(\mathrm{TiH}_{2}\right)_{10}\right)_{90}-\mathrm{C}_{10} \quad G \\ \text { CMT05 }\end{array}$

CMT07

CMT11

CMT16 $\left(\left(\mathrm{MgH}_{2}\right)_{80}\left(\mathrm{TiH}_{2}\right)_{20}\right)_{95}-\mathrm{C}_{5} \quad G$

CMT17

CMT18

$G$

$\begin{array}{ll}\text { CMT06 } & \left(\left(\mathrm{MgH}_{2}\right)_{80}\left(\mathrm{TiH}_{2}\right)_{20}\right)_{90}-\mathrm{C}_{10}\end{array}$

$\begin{array}{ll}\text { CMT09 } & \\ \text { CMT12 } & \left(\left(\mathrm{MgH}_{2}\right)_{80}\left(\mathrm{TiH}_{2}\right)_{20}\right)_{80}-\mathrm{C}_{20} \\ \text { CMT13 } & G \\ \text { CMT14 } & \\ \text { CMT15 }\end{array}$

Tabla 3.2: Se describen las muestras preparadas con grafito Mg-Ti-C por molienda mecánica. Se indican en las columnas los nombres, el composite formado y la vía de fabricación respectivamente. 


\section{Capítulo 4}

\section{Hidruración y deshidruración de los sistemas $\mathrm{Mg}^{-\mathrm{TiH}_{2}}$}

El monitoreo de las reacciones de absorción/desorción de hidrógeno puede hacerse a través de distintas variables experimentales [28, 126]. En general se trata de escoger una variable que sea proporcional al grado de reacción alcanzado $\alpha(t)$. Entre los métodos más ampliamente usados se encuentran la termogravimetría y la volumetría basados en medición directa de una señal que indique el grado de reacción (masa y presión respectivamente). También existen otros métodos que se basan en la caracterización de distintas propiedades del sistema influenciadas por la cantidad de hidrógeno incorporado al mismo. Entre estas podemos mencionar, la resistividad eléctrica, emisión acústica durante la formación del hidruro, estudios de cambios estructurales por medio de difracción de rayos X,observaciones morfológicas para sistemas 'congelados' a distintos grados de reacción [28] y cambios en las propiedades de transmisión óptica $[137,138]$. Por último deben mencionarse las técnicas calorimétricas (DSC, TDS) que se han ido consolidando como métodos eficientes para el estudio de transformaciones de fase. En dichos experimentos se obtiene una cantidad que se asume proporcional a la velocidad de transformación de fase $\frac{d \alpha}{d t}$.

En el desarrollo de esta tesis se ha recurrido principalmente al uso de un dispositivo volumétrico, tipo Sieverts [139, 140]. El volumen del sistema puede fijarse y es conocido, de manera que monitoreando la presión del gas $H_{2}$ en función del tiempo pueden obtenerse los moles de $H_{2}$ incorporados/liberados al/del sistema estudiado. También se han obtenido medidas termogravimétricas que serán reportadas y descritas junto a los experimentos calorimétricos. Deben señalarse dos requerimientos experimentales de importancia en el momento de perturbar al sistema para iniciar la reacción:

- la perturbación debe afectar lo menos posible al resto de los parámetros del sistema y el transitorio en el que se alcanzan las nuevas condiciones de P y T debe ser despreciable respecto al tiempo total que tome la reacción

- debe reducirse lo más posible el transitorio 'ciego' en el inicio de la reacción ya que las primerísimas etapas pueden ser fundamentales para dilucidar los mecanismos de reacción involucrados.

En este último sentido, el monitoreo de la presión resultó el mejor registro in situ de las transformaciones ocurridas. El equilibrio de la presión en el reactor se alcanzaba a partir de 
los 500 milisegundos aproximadamente y se tuvo en cuenta para el diseño un software ad-hoc a fin de automatizar las aperturas y cierres de electroválvulas. Se realizaron también medidas de flujo mediante un fluxímetro de alta precisión conectado al reactor. Dichas medidas sirvieron para medir la capacidad del sistema y las temperaturas de desorción/absorción.

\subsection{Volumetría}

El estudio delas propiedades termodinámicas, por ejemplo a través de curvas de PresiónComposición-Temperatura (PCT), y de cinéticas de hidruración/deshidruración de materiales formadores de hidruro, ha sido desarrollado extensamente a través de aparatos tipo Sieverts. Este dispositivo ya ha sido presentado en varias ocasiones dando lugar a los denominados equipos volumétricos para investigar la cinética de hidruración/deshidruración. Básicamente en un equipo volumétrico (figura 4.1), se mantiene el volumen $V$ constante calibrado y se miden las variaciones de presión, de las cuales se puede calcular el número de moles involucrados en la reacción. Es necesario conocer la temperatura a la que se encuentra dicho volumen para poder utilizar la ecuación de estado de los gases ideales.

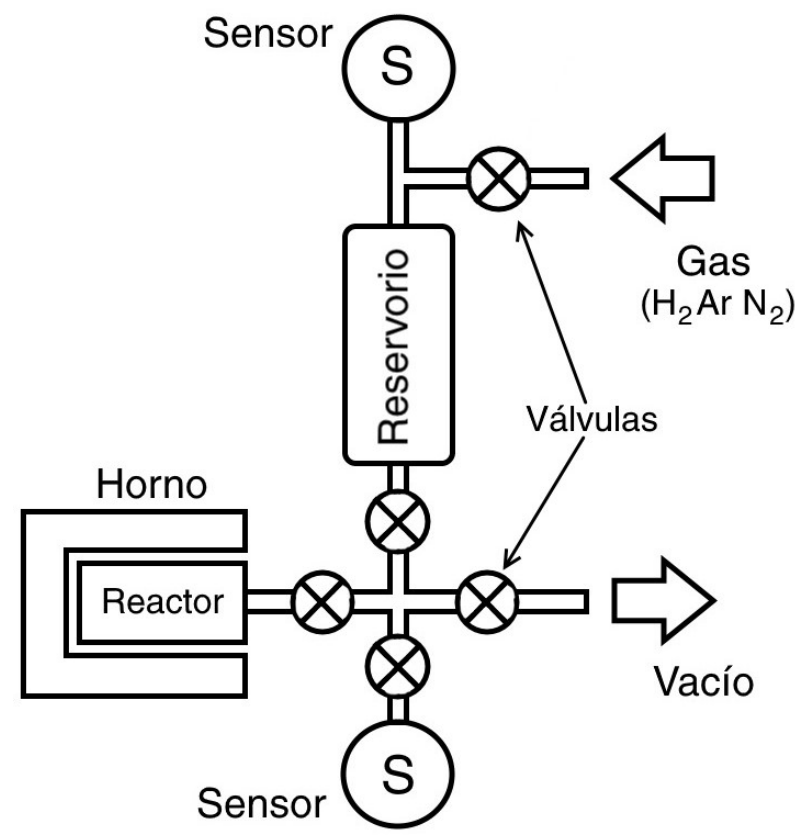

Figura 4.1: Esquema de equipo volumétrico utilizado.

El progreso de la reacción puede registrarse monitoreando ya sea el flujo de gas que ingresa o se expulsa de la cámara de reacción, o el cambio en la presión en el reactor ${ }^{1}$. Los equipos volumétricos han mostrado tener versatilidad y distintas versiones pueden ser encontradas en la literatura, dependiendo del tipo de muestras a tratar (grandes o pequeñas, films delgados o muestras en polvo, etc).

\footnotetext{
${ }^{1}$ Con un sensor electrónico transductor, el cambio en la presión inicial puede ser hasta del $5 \%$.
} 
A fin de optimizar el monitoreo, es importante tener en cuenta que el cambio en la presión es sensible a la relación entre la cantidad de muestra, el volumen del reactor y la propia sensibilidad del sensor. Los cambios de volumen del material al hidrurarse, deben ser despreciables frente al volumen del reactor. De modo que debe encontrarse un compromiso entre el volumen del reactor y de muestra para que el sensor sea capaz de medir los cambios en la presión y con una buena relación señal/ruído. El volumen del reactor debe ser el menor posible para poder medir con precisión los cambios de presión por no tan pequeño para que no sea comparable con los cambios de volumen experimentados por el material hidrurado. Este balance experimental puede resultar más difícil de superar en el caso de películas delgadas donde tanto la cantidad de masa disponible y el volumen del espécimen son despreciables según lo requerido para obtener una buena relación señal/ruido durante el monitoreo.

Por otro lado la existencia de un gradiente de temperatura a lo largo del volumen del reactor y por tanto la inhomogeneidad térmica entre la fase sólida y el gas, implica la necesidad de definir un volumen efectivo (ver Apéndice E)

Se describirán a continuación las experiencias a T variable y a T constante así como las experiencias de carga y descarga de hidrógeno por etapas y las curvas de Presión Composición Isotérmicas (PCT).

\subsection{Cinéticas de absorción y desorción de hidrógeno}

Se realizaron gran cantidad de tratamientos térmicos y distintos tipos de experiencias de absorción/desorción involucrando gran número de ciclos de carga y descarga de hidrógeno. Estas se realizaron sobre el conjunto de muestras mencionado en la sección 3.2, obtenidas por molido mecánico:

- $1 M g_{x}-T i_{1-x}$

- $2\left(M g_{x}-T i_{1-x}\right)_{1-y}-C_{y}$

Para ello se utilizó el equipo tipo volumétrico tipo Sieverts [139, 140] como el que se esquematiza en la figura 4.1.El reactor estaba dentro del horno cilíndrico durante las experiencias para garantizar la homogeneidad de la temperatura. El polvo era colocado dentro de un pequeño cilindro de acero inoxidable, a modo de contenedor o porta muestra, colocándose en los extremos abiertos retazos de lana de cuarzo a modo de filtros, evitando así el derrame del polvo en el volumen de todo el reactor y permitiendo simultáneamente el paso del hidrógeno gaseoso. En función del volumen del cilindro $\left.\left(\sim 0,6 \mathrm{~cm}^{3}\right)\right)$ se tomaron de las muestras, especímenes con masas de $\leq 100 \mathrm{mg}^{2}$. Por otro lado, se requerían masas $>80 \mathrm{mg}$ para un registro de la presión con una buena relación señal/ruido. La temperatura se midió con una resistencia PT 100 en contacto íntimo con uno de los bordes del reactor, muy cercanos al cilindro contenedor de la muestra. La presión instantánea era registrada mediante un sensor diferencial. La configuración de válvulas se adecuaba al tipo de experiencia a realizarse. En casos de requerir evacuar o inyectar gas (por ejemplo en experiencias de desorción o absorción respectivamente) se realizaban aperturas o cierres de forma automática

${ }^{2}$ Estos valores permiten una buena transferencia de calor y circulación de hidrógeno[54]. 
o manualmente. Conociendo los volúmenes del reservorio y el reactor, se pudo controlar y escoger aceptablemente la presión inicial en cada caso. Se usó un volumen calibrado a fin de determinar el volumen de cada parte del equipo (reactor, reservorio, tuberías); luego, realizando medidas a distintas temperaturas se calculó un volumen efectivo del reactor, para cada una de ellas. A partir de las variaciones de presión medidas se pudo obtener el consumo y la liberación de hidrógeno en los ensayos de carga y descarga de hidrógeno de acuerdo a la expresión 3.1 y usando el volumen efectivo $\left[\mathrm{cm}^{3}\right]$ (ver Apéndice $\mathrm{E}$ ):

$$
V_{e f}=13,9+3,5 \times \frac{T_{0}}{T}
$$

\subsubsection{Tratamientos térmicos}

\section{Cinéticas no isotérmicas}

Por un lado se realizaron experimentos de desorción y absorción de hidrógeno (en ese orden), a volumen constante a partir de un estado inicial de carga del espécimen de muestra preparada por molienda. A partir de temperatura ambiente primero se establece una presión de $\mathrm{H}_{2}$ y se programa un incremento de temperatura hasta una temperatura fija suficientemente alta para que pueda superarse ampliamente la presión de equilibrio de desorción. Tipicamente hasta $350^{\circ}-400^{\circ}$ a una velocidad de $\sim 13 \mathrm{~K} / \mathrm{min}$. Luego se apaga la fuente dejando enfriar el sistema hasta la temperatura del ambiente.

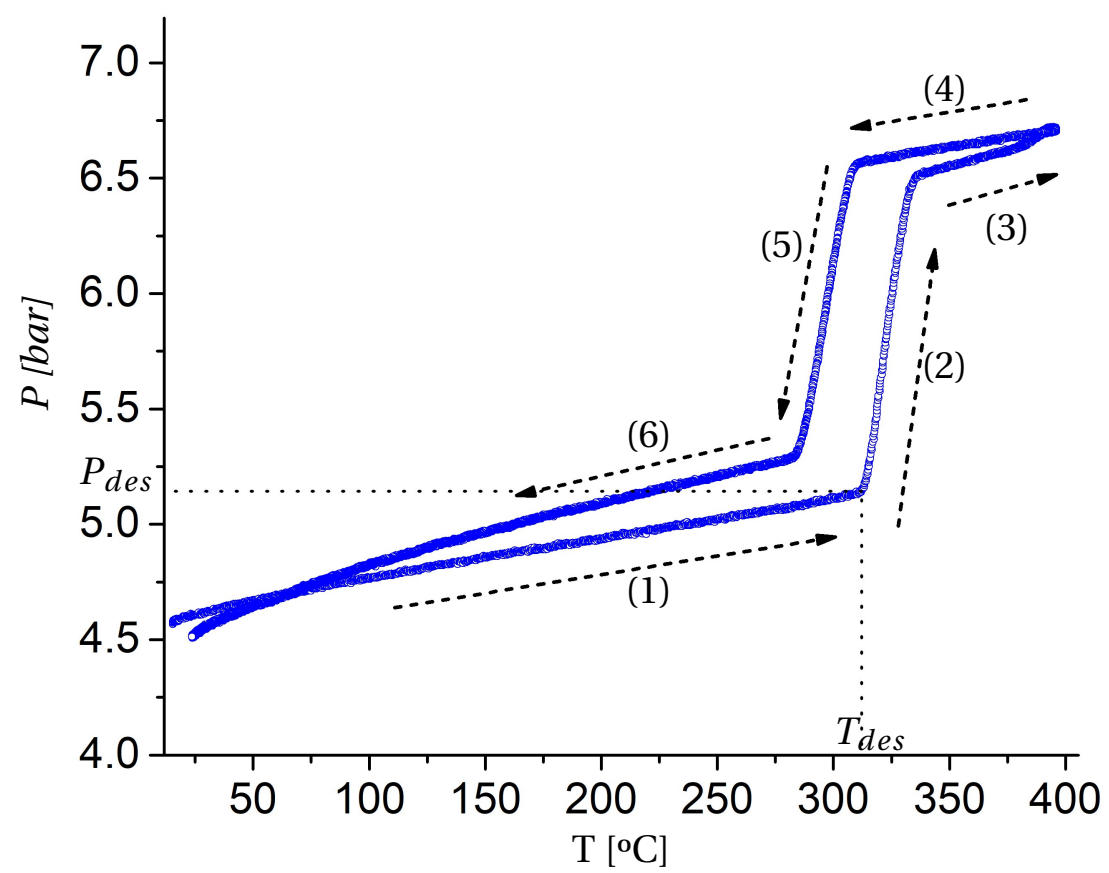

Figura 4.2: Curva típica de T variable correspondiente a los tratamientos térmicos a volumen constante: (1) Calentamiento de la muestra cargada,(2) desorción,(3) calentamiento muestra descargada,(4) enfriamiento muestra descargada,(5)absorción,(6), enfriamiento de muestra re-cargada

A partir de las curvas de presión como función de la temperatura (a volumen constante) 
pueden identificarse claramente las etapas correspondientes a los procesos de desorción, durante el calentamiento, y de absorción, durante el enfriamiento [141] como se puede apreciar en un experimento típico ilustrado en la figura 4.2. También pueden obtenerse las cinéticas como función del tiempo a partir de convertir, como se ha explicado, el cambio en la presión en términos de consumo y liberación de $\mathrm{H}_{2}$.

\subsubsection{Isotermas}

\section{Cinéticas a Temperatura constante}

Se sometieron los especímenes a distintos ciclos de carga y descarga a volumen y temperatura constantes. Se monitoreó el cambio en la presión durante las reacciones cinéticas de sorción en el reactor. Para medir dicha cinética se realizaron una serie de pasos en el equipo volumétrico que se detallan a continuación:

Cinética de desorción:

1) Se fija la temperatura a la cual se desea realizar la cinética (tipicamente entre $240^{\circ} \mathrm{C} \mathrm{a}$ $\left.380^{\circ} \mathrm{C}\right)$.

2) Se parte de una muestra completamente hidrurada y a una presión superior a la $P_{e q}$ para la temperatura elegida, de modo de asegurar que el estado de equilibrio sea la fase hidruro.

3) De manera súbita se evacúa el reactor. Esto se logra mediante la apertura y cierre inmediato de una válvula que conecta el reactor con la bomba de vacío.

4) Esta maniobra genera en el reactor una presión menor a la $P_{e q}$, de modo que el sistema comienza a desorber $\mathrm{H}_{2}$ dando lugar a un aumento de la presión que es registrado en función del tiempo. Para temperaturas relativamente bajas, sucedía que el aumento de la presión era tal que se alcanzaba la $P_{e q}$ (en cuyo caso el sistema dejaba de desorber). En tales circunstancias, se repetía la evacuación, dando lugar a una desorción en etapas.

Cinética de absorción:

1) Se fijaba la temperatura a la cual se deseaba realizar la cinética (en la práctica, generalmente la misma a la que se había realizado la desorción, entre $240^{\circ} \mathrm{C}$ a $380^{\circ} \mathrm{C}$ ).

2) A partir de una muestra deshidrurada y en vacío, de manera súbita se inyecta $H_{2}$ asegurando que la presión resultante en el reactor sea superior a la $P_{e q}$. Esto se logra mediante la apertura y cierre inmediato de una válvula que conecta el reactor con el reservorio.

3) Esta maniobra genera en el reactor una presión mayor a la $P_{e q}$, de modo que el sistema comienza a absorber $\mathrm{H}_{2}$ dando lugar a una disminución de la presión que es registrada en función del tiempo.

Los tiempos involucrados en la apertura y cierre inmediato eran de 0,5 seg, de modo que las cinéticas, así obtenidas solo tienen una pequeña indeterminación durante el primer medio segundo inicial.

Este procedimiento se llevó a cabo para una gran cantidad de valores de $\mathrm{T}$ y $\mathrm{P}$, con el fin de caracterizar las propiedades cinéticas de las muestras en un amplio rango de presiones y temperaturas. En todos los casos, midiendo el cambio de la presión en el reactor puede obtenerse el valor instantáneo del No de átomos de $\mathrm{H}$ absorbidos/desorbidos de acuerdo a la ecuación 3.1. 


\subsection{Calorimetría diferencial (DSC)}

Se realizaron varios experimentos (que denominaremos corridas DSC) tanto en nuestro laboratorio como en laboratorios externos. Se realizaron ensayos con varias muestras variando composición, vías de fabricación, horas de molienda, estado de la muestra, y condiciones atmosféricas: flujo de gas inerte $\left(\mathrm{Ar} \mathrm{o} \mathrm{N}_{2}\right)$ o atmósfera de $\mathrm{H}_{2}$. Para todas las muestras estudiadas, se realizaron experiencias estimulando la desorción a distintas velocidades de calentamiento.Cada corrida a cierta velocidad se realizó con un espécimen fresco $^{3}$. En el caso de las experiencias en atmósfera de $\mathrm{H}_{2}$ se contó con la posibilidad de registrar la señal DSC correspondiente a la absorción durante el enfriamiento, tanto en condiciones de enfriamiento espontáneo como con una velocidad de enfriamiento controlada.

A continuación se describen las experiencias realizadas según los equipos utilizados, indicando las velocidades de calentamiento (y enfriamiento en el caso de $\mathrm{H}_{2}$ ), las condiciones atmosféricas y las muestras correspondientes.

\subsubsection{Calorimetría de absorción y desorción $\left(\mathrm{H}_{2}\right)$}

\section{Università degli Studi Di torino ${ }^{4}$ (UNITO)}

Se utilizó un equipo NETZSCH. Las corridas se realizaron en atmósfera de $\mathrm{H}_{2}$ a una presión prácticamente constante de alrededor de $\simeq 2$ bar. Las velocidades de calentamiento para cada muestra estudiada fueron $1 \mathrm{~K} / \mathrm{min}, 5 \mathrm{~K} / \mathrm{min}, 10 \mathrm{~K} / \mathrm{min}$ y $20 \mathrm{~K} / \mathrm{min}$. También se realizaron corridas para muestras con distintas cantidades de grafito $(0 \%$, $5 \%, 10 \%$ y $20 \%$ ) y también para las dos vías de fabricación $A$ y $B$. En detalle, se tomaron especímenes individuales de las muestras CMT13, CMT18, MT42 y MT48 tablas (ver tabla 3.2). Las corridas calorimétricas correspondientes se indican en la tabla 4.1. Las corridas consistieron en rampas de calentamiento desde temperatura ambiente hasta $400^{\circ} \mathrm{C}$ y el posterior enfriamiento (controlado o espontáneo).

Para la preparación de las muestras se utilizaron crisoles de $A l$, donde se colocaban epecimenes de masas entre 20 a $30 \mathrm{mg}$. Este hecho determinó el valor superior de $400^{\circ} \mathrm{C}$ para la temperatura, ya que se procuró evitar aproximarse a la temperatura del punto eutéctico entre el $M g$ y el $A l$. Todo el proceso se llevó a cabo en atmósfera controlada, dado que el equipo estaba dentro de la una cámara con muy bajos porcentajes de humedad y $\mathrm{O}_{2}$. La calibración de las curvas de calentamiento se realizó con anterioridad. En una primera serie de medidas realizadas durante la estadía en Torino en 2016, se planificaron únicamente las desorciones, por lo cual en dicho conjunto de medidas no se programó la velocidad de enfriamiento. Esto significa que las cinéticas de absorción se midieron con enfriamiento espontáneo, es decir una velocidad de enfriamiento variable. En las siguientes series de medidas, también se programó la velocidad de enfriamiento,

\footnotetext{
${ }^{3}$ Es decir una alícuota de las muestra obtenida por molienda mecánica sin ningún tipo de tratamiento posterior.

${ }^{4}$ Estas medidas se realizaron en el marco de una estadía breve en Torino en una colaboración con el grupo de Marccello Baricco. La preparación de muestras y realización de experimentos las llevé a cabo conjuntamente con la estudiante de Doctorado Erika De Matteis.
} 
para obtener información cuantificable del proceso de absorción. A la vez, en esta segunda serie de corridas ( ver tabla 4.2), se utilizaron programas de calentameinto y enfriamiento continuados sobre un mismo especímen a fin de analizar el ciclado (desorción/absorción). En esta segunda serie hubo excepcionalmente calentamientos por encima de los $400{ }^{\circ} \mathrm{C}$.

Por último se desea mencionar que también se realizaron corridas sobre una muestra de $\mathrm{MgH}$ y $\mathrm{TiH}_{2}$ preparada en el Laboratorio de Calorimetría de nuestro instituto (IFLP). Dichas muestras corresponden a los materiales de partida para la fabricación de las todas las muestras de este trabajo.

Cabe mencionar que en el caso de las experiencias realizadas en laboratorios externos, el transporte de las muestras se realizó habiendo empaquetado las mismas en condiciones de atmósfera controlada (inerte), dentro de la cámara de guantes de nuestro laboratorio.

\subsubsection{Calorimetría combinada con termogravimetría (Ar)}

\section{Institutt for energiteknikk (IFE) ${ }^{5}$}

Se utilizó también en este caso un equipo calorímetro NETZSCH. Las corridas fueron realizadas en flujo constante de $\mathrm{Ar}(50 \mathrm{ml} / \mathrm{min})$. Las velocidades ensayadas para cada muestra fueron similares,(excepto las de menor velocidad): 2, 5, 10 y $20 \mathrm{~K} / \mathrm{min}$.

Similarmente a la serie de medidas realizadas en Torino, se usaron muestras homólogas: CMT14, CMT16, MT44 y MT45 (ver tablas 3.1 y 3.2). Las corridas se realizaron calentando desde temperatura ambiente hasta $400^{\circ} \mathrm{C}$. Las muestras se prepararon en crisoles de $A l$ en cámara de atmósfera controlada pero debían trasladarse inmediatamente al equipo calorimétrico que no estaba instalado dentro de una cámara de atmósfera controlada $^{6}$. Se usaron especímenes de masas entre $\sim 25$ y $\sim 50 \mathrm{mg}$. Las calibraciones correspondientes se realizaron previamente.

Lo interesante del montaje experimental es que se contaba con la posibilidad de combinar las medidas calorimétricas simultáneamente con medidas termogravimétricas. Así, pudieron complementarse los datos calorimétricos con la pérdida de masa durante las desorciones. Esta reducción del peso de la muestra corresponde a la liberación, térmicamente estimulada, de hidrógeno. Aún siendo muy liviano y representando un porcentaje minoritario en el peso de la muestra, los equipos poseen una sensibilidad adecuada para registrar este cambio con una precisión muy buena. De esta manera, la termogravimetría permite identificar si las transformaciones que ocurren están asociadas a una transformación de fase con variación de masa, pudiendo en este caso cuantificar las capacidades de desorción al tener bien identificada el tipo de reacción

\footnotetext{
${ }^{5}$ Estas medidas se realizaron en el marco de una estadía breve en el IFE (Kjeller, Noruega), en una colaboración con el grupo de Stefano Deledda. La preparación de muestras y realización de experimentos las llevé a cabo conjuntamente con Christoph Frommen.

${ }^{6} \mathrm{~A}$ los crisoles sellados manualmente se los trasladaba dentro de un tubo eppendorf a fin de minimizar el contacto con al atmósfera.
} 
que ocurre.Las muestras sobre las que se realizó la serie de medidas en $A r$ en el IFE se describen en la tabla 4.3.

\subsubsection{Calorimetría en distintos gases inertes $\left(\mathrm{N}_{2} \mathbf{y}\right.$ Ar)}

\section{Instituto de Física La Plata ${ }^{7}$}

Se utilizó en este caso un equipo calorímetro SHIMADZU 50. Las corridas fueron realizadas en flujo constante de $A r$ y/o de $N_{2}$ (50 ml/min en ambos casos). Se realizaron series de medidas a varias velocidades: $5,10,20$ y $40 \mathrm{~K} / \mathrm{min}$ (en algunos casos se incorporaron corridas a $30 \mathrm{~K} / \mathrm{min}$ ). Se usaron las muestras CMT12, CMT14,MT44,MT50 y MTD2 (ver tablas 4.4 y 4.5) ${ }^{8}$. Algunas de las corridas se realizaron calentando desde temperatura ambiente hasta $400{ }^{\circ} \mathrm{C}$ y para otras se requirió llegar hasta temperaturas más altas para completar los procesos de desorción. Las muestras se prepararon en crisoles de $A l$ en cámara de atmósfera controlada pero debían trasladarse inmediatamente en un tubo eppendorf al equipo calorimétrico, el cual no estaba instalado dentro de la cámara de atmósfera controlada ${ }^{9}$.Se usaron especímenes de masas entre $\sim 25$ y $~ 50 \mathrm{mg}$. Las calibraciones correspondientes se realizaron previamente.

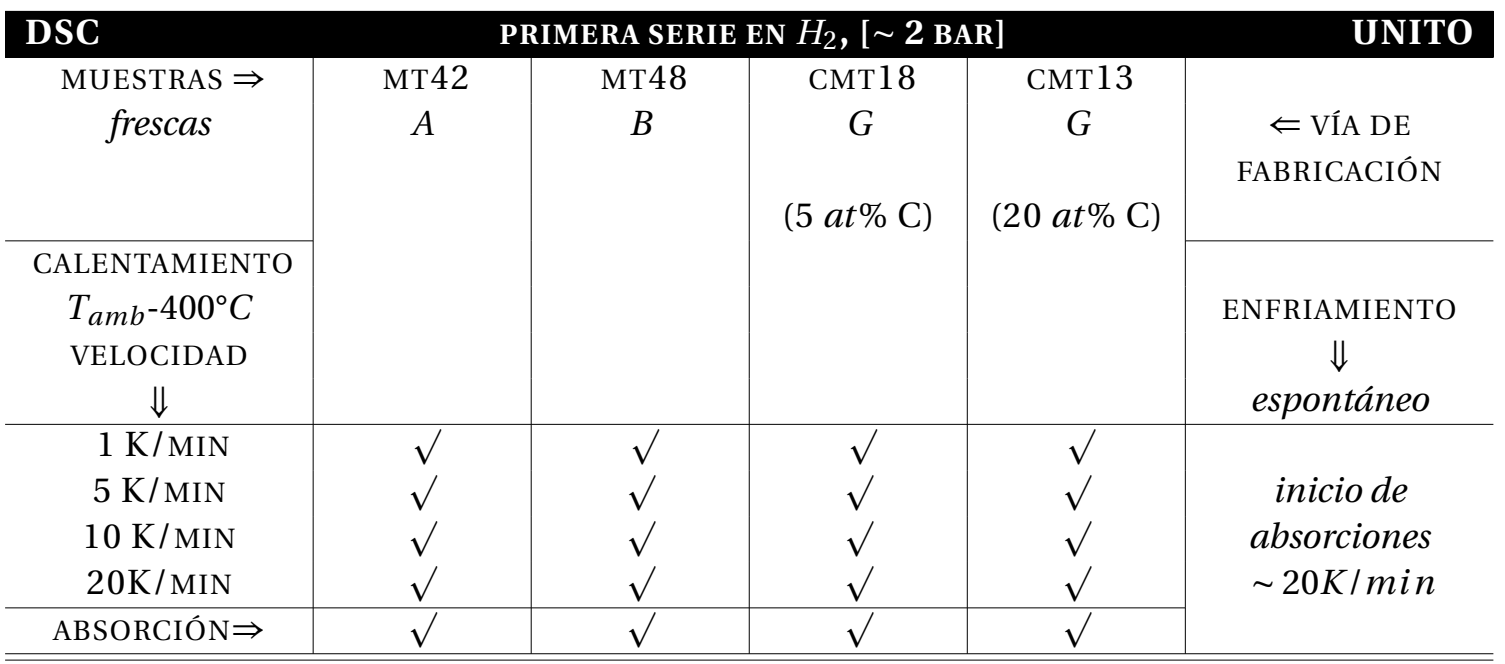

Tabla 4.1: Se describen en la tabla las desorciones/absorciones calorimétricas realizadas en la primera serie de experiencias en atmósfera de $\mathrm{H}_{2}$. Corresponden al primer ciclo de desorción/absorción de muestras frescas hidruradas. Todas fueron empaquetadas en atmósfera controlada para ser transportadas. La preparación para las corridas también se realizó en atmósfera controlada. Para todas las muestras y corridas se pudo identificar el proceso de absorción durante el enfriamiento.

\footnotetext{
${ }^{7}$ Estas medidas las realicé con la colaboración de Caludia Rodríguez Torres, Fabiana Cabrera, Patricia Rivas y Luciana Juncal, quienes están a cargo del uso del equipo perteneciente al IFLP.

${ }^{8}$ Las corridas DSC realizadas en $N_{2}$ se muestran en el Apéndice F, figura F.8.

${ }^{9} \mathrm{~A}$ los crisoles sellados manualmente se los trasladaba dentro de un tubo eppendorf a fin de evitar el posible el contacto con al atmósfera.
} 


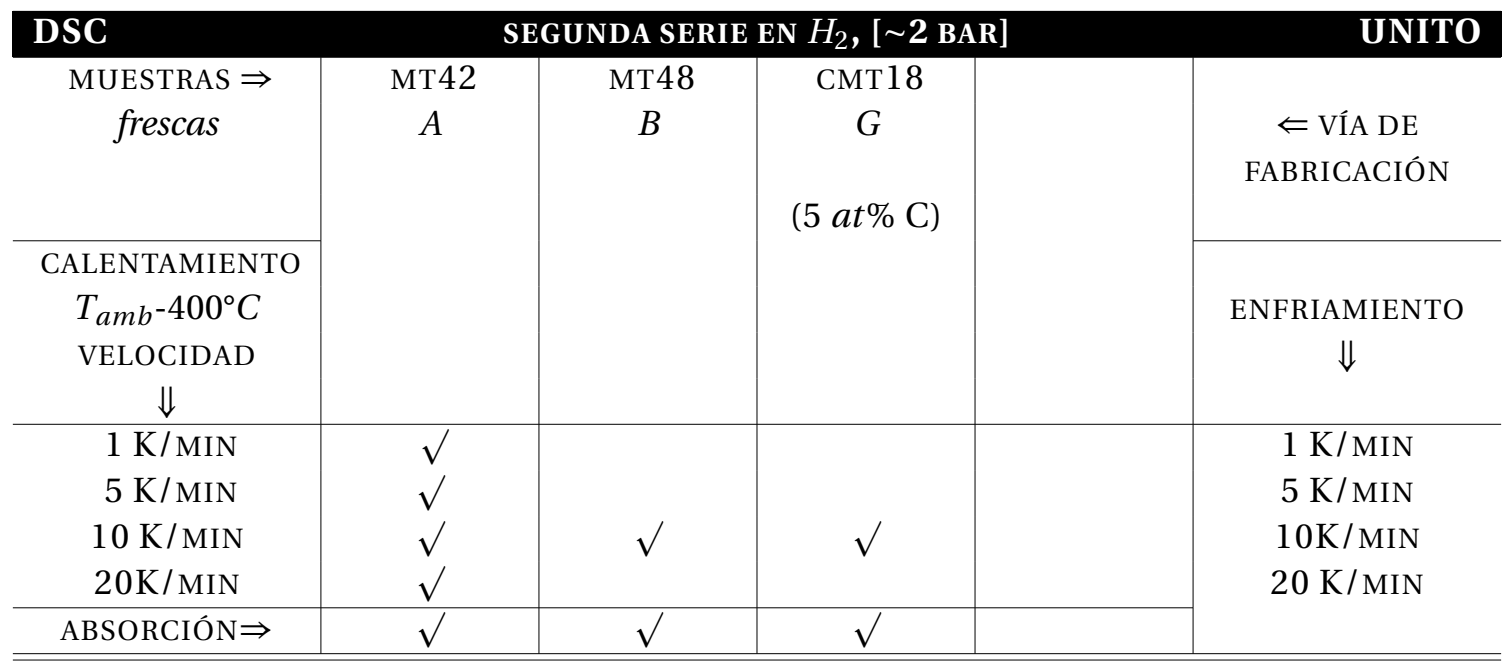

Tabla 4.2: Se describen en la tabla las desorciones/absorciones calorimétricas realizadas en la segunda serie de experiencias realizadas en atmósfera de $\mathrm{H}_{2}$. Corresponden tres ciclos de desorción/absorción de muestras frescas hidruradas. Las muestras son frescas habiéndose conservado en cámaras controladas durante largo tiempo (un año). La preparación para las corridas también se realizó en atmósfera controlada. Los ciclos de absorción durante el enfriamiento programado resultaron similares mientras que el primer ciclo de desorción (activación) se diferenciaba del resto de las desorciones (segunda y tercera)

\begin{tabular}{|c|c|c|c|c|c|}
\hline TERMOGRAVIMETRÍA-DSC & & ESORC & ES EN A & & $\mathbf{I F}$ \\
\hline $\begin{array}{l}\text { MUESTRAS } \Rightarrow \\
\quad \text { frescas }\end{array}$ & $\begin{array}{c}\text { MT } 44 \\
A\end{array}$ & $\begin{array}{c}\text { MT45 } \\
\quad B\end{array}$ & $\begin{array}{c}\text { СMT } 16 \\
G \\
5 a t \% \mathrm{C}\end{array}$ & $\begin{array}{c}\text { СMT } 14 \\
G \\
20 a t \% \mathrm{C}\end{array}$ & $\begin{array}{c}\Leftarrow \text { VÍA DE } \\
\text { FABRICACIÓN }\end{array}$ \\
\hline $\begin{array}{c}\text { CALENTAMIENTO } \\
T_{a m b}-400^{\circ} \mathrm{C} \\
\text { VELOCIDAD } \\
\Downarrow \\
\end{array}$ & & & & & \\
\hline $\begin{array}{c}2 \mathrm{~K} / \mathrm{MIN} \\
5 \mathrm{~K} / \mathrm{MIN} \\
10 \mathrm{~K} / \mathrm{MIN} \\
20 \mathrm{~K} / \mathrm{MIN}\end{array}$ & $\begin{array}{l}\sqrt{ } \\
\sqrt{ } \\
\sqrt{ } \\
\sqrt{ }\end{array}$ & $\begin{array}{l}\sqrt{ } \\
\sqrt{ } \\
\sqrt{ } \\
\sqrt{ }\end{array}$ & $\begin{array}{l}\sqrt{ } \\
\sqrt{ } \\
\sqrt{ } \\
\sqrt{ }\end{array}$ & $\begin{array}{l}\sqrt{ } \\
\sqrt{ } \\
\sqrt{ } \\
\sqrt{ }\end{array}$ & \\
\hline
\end{tabular}

Tabla 4.3: Se describen en la tabla las desorciones/absorciones calorimétricas realizadas en flujo de $A r$. Corresponden al primer ciclo de desorción de muestras hidruradasfrescas. Todas fueron empaquetadas en atmósfera controlada para ser transportadas. La preparación para las corridas también ser realizó en atmósfera controlada y eran trasladadas en el crisol de Al sellado hasta el calorímetro inmediatamente. 


\section{DSC}

DESORCIONES EN AR

IFLP

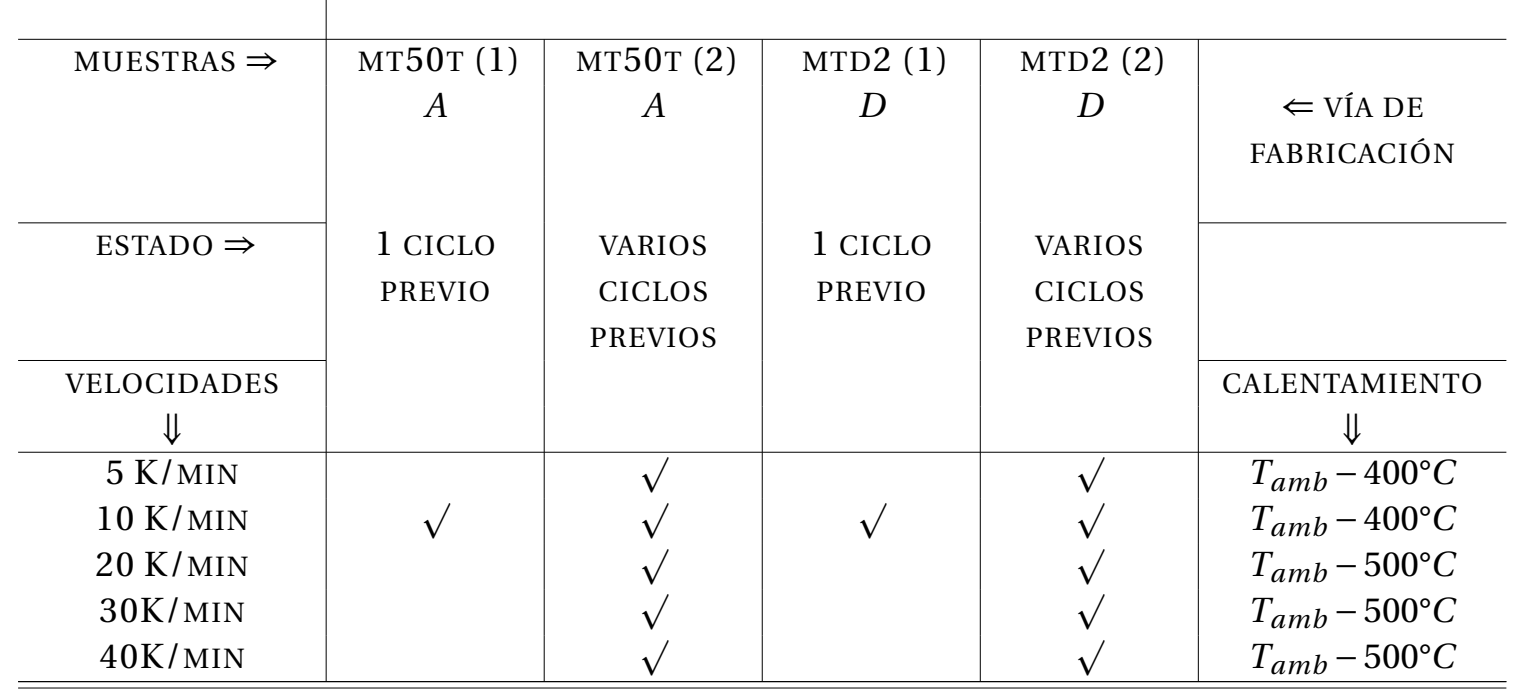

Tabla 4.4: Se describen en la tabla las desorciones calorimétricas realizadas en flujo de $A r$ correspondientes a muestras hidruradas frescas y tratadas, fabricadas por las vías A y D. Se indica el ciclado realizado previamente en el equipo volumétrico.

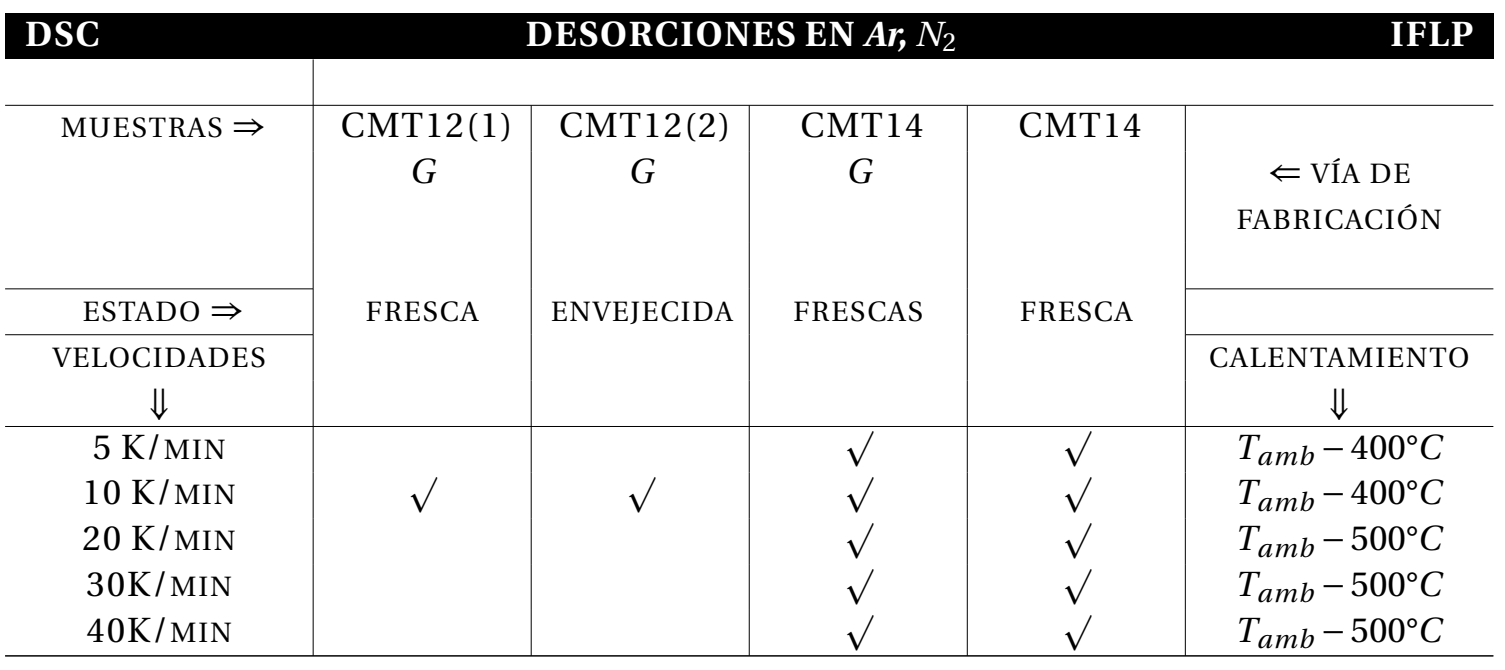

Tabla 4.5: Se describen en la tabla las desorciones calorimétricas realizadas en flujo de $\operatorname{Ar}$ y algunas en $\mathrm{N}_{2}$, correspondientes a muestras homólogas hidruradas fabricadas con grafito y de composición Mg:Ti:80:20. 


\section{Capítulo 5}

\section{Identificación de fases y caracterización estructural}

Este capítulo trata sobre la identificación de fases y la caracterización estructural realizadas sobre los sistemas estudiados. Se mostrarán los patrones de difracción más relevantes y los análisis correspondientes, identificando fases y características estructurales principales en muestras fabricadas por distintas vías, tanto en muestras frescas como tratadas. En las secciones 5.1 y 5.2 se presentan los resultados y análisis de los patrones de difracción de rayos X obtenidos. Luego, (sección 5.3) se presentarán resultados de microscopías SEM y TEM que permitirán una caracterización micro/nanoestructural de las muestras.

\subsection{Patrones de difracción: Rayos $X$ y Neutrones}

Se obtuvieron patrones de difracción para las muestras fabricadas por las distintas vías, tanto frescas como tratadas térmicamente (cicladas). Se usaron distintos equipos ${ }^{1}$. En casi todos los casos se utilizó radiación $\mathrm{Cu} K_{\alpha}$ y una geometría de Bragg en el rango $2 \theta: 20^{\circ}$ hasta $80^{\circ}$, típicamente con pasos de $0,02^{\circ}$ a $0,05^{\circ}$. Los patrones obtenidos en la Universidad de Torino se obtuvieron usando un difractómetro de ánodo rotatorio. Se midieron también patrones de difracción del Mg comercial utilizado y del $\mathrm{TiH}_{2}$ preparado por molienda. En el caso del Mg se pudo identificar la presencia despreciable de $\mathrm{Mg}(\mathrm{OH})_{2}$ y no se detectó MgO. En los casos del $\mathrm{Ti}$ y el $\mathrm{Ti} \mathrm{H}_{2}$ no se detectó la presencia de óxidos ${ }^{2}$.

En la figura 5.1 se muestran los patrones de difracción correspondientes a muestras frescas preparadas por las vías A, B y C, los cuáles revelan la formación de las mismas fases. En todos los casos se identificaron la fase metaestable $\gamma-M g H_{2}$ (ortorrómbica), la fase rutilo $\beta$ - $M g H_{2}$ (tetragonal) y la fase $\delta$ - $T i H_{2}$ (cúbica) ${ }^{3}$. Una proporción minoritaria de óxido $(\mathrm{MgO})$ también fue identificada, la cual se debe al inevitable contacto de la muestra con el aire durante la

\footnotetext{
${ }^{1}$ Philips PW1710 (Lab. Lanadi-IFLP), equipo del Cetmic,y equipo de la Universidad de Torino.

${ }^{2}$ Los patrones de los materiales de partida para la fabricación se presentan en las figuras C.1 del Apéndice C para consulta.

${ }^{3} \mathrm{En}$ los patrones no pudo distinguirse la fase $\epsilon-\mathrm{TiH}_{2}$ (tetragonal) cuya presencia no se descarta por haberse identificado en otras muestras mediante TEM.
} 
medida de difracción que se realizaba abierta a la atmósferá . La fase metaestable $\gamma-M g H_{2}$ como puede notarse siempre constituyó una fase minoritaria presente solo en las muestras frescas. Luego del primer tratamiento esta fase desaparecía.

Comparando los patrones de la vías $A$ y $B$ con el de la via $C$ se puede ver en éste último un corrimiento de los picos de la fase cúbica $\delta$ - $T i H_{2}$ que está asociado a un mayor parámetro de red, probablemente debido al Mg substitucional incorporado durante la molienda. Tal corrimiento, aunque menos notorio, también ocurre para la vía B. En general, los patrones de los sistemas MgTi mostraron fase $\delta$ - $\mathrm{Ti} \mathrm{H}_{2}$ con picos corridos respecto sistema puro $\mathrm{TiH}_{2}$ preparado por molienda. Estos aspectos mencionados se aprecian mejor en las figuras C.2 y C.3 del Apéndice $\mathrm{C}$ en las que se muestran distintos picos ampliados.

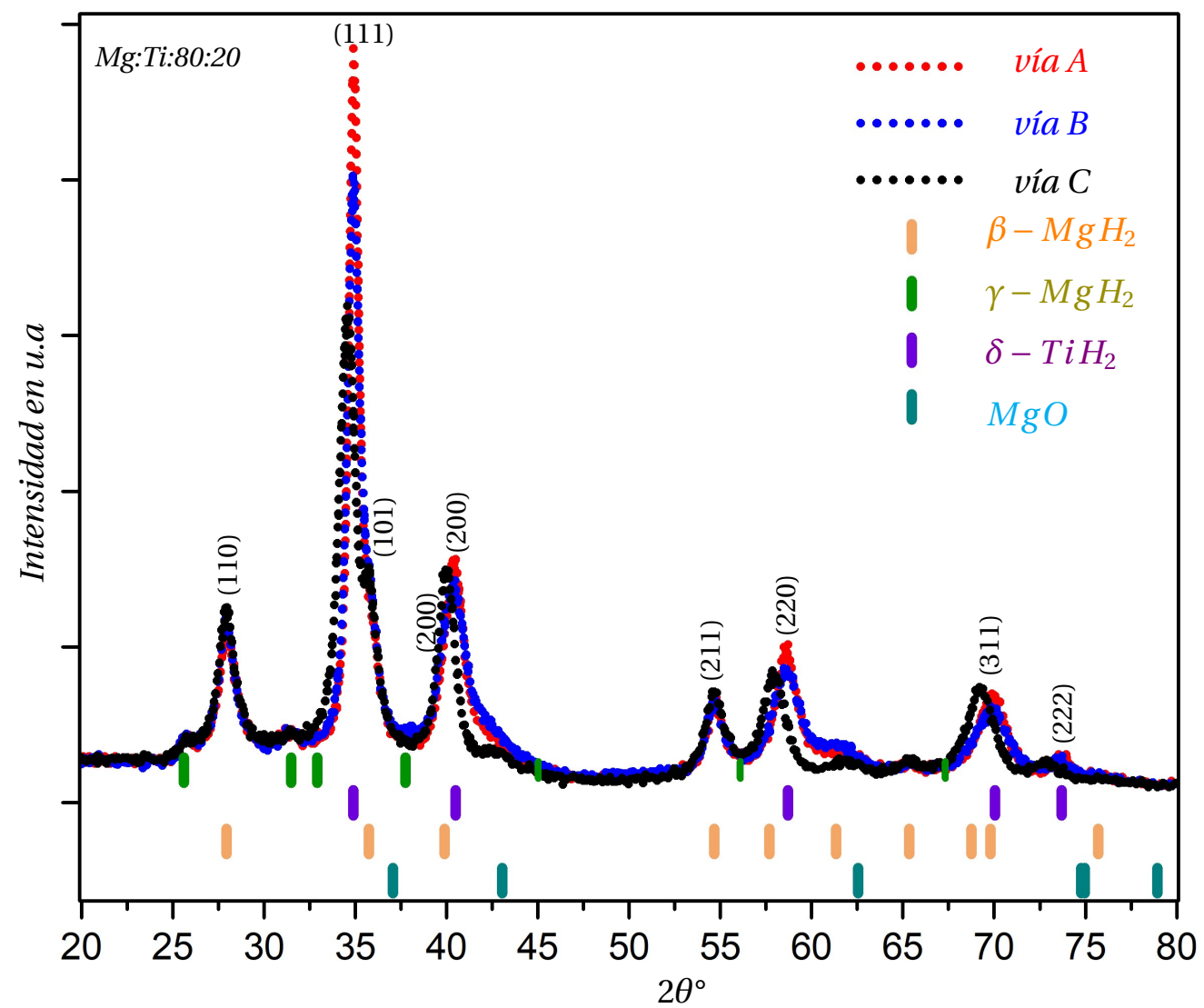

Figura 5.1: Patrones de difracción de rayos X correspondientes a muestras fabricadas por las vías A (MT13), B (MT15) y C (MT19). Se indican los índices $h, k$, $l$ de la fase cúbica $\delta-T i H_{2}$, y de algunos delos máximos de la fase $\beta \mathrm{MgH}_{2}$. El patrón de está ultima vía revela un aumento del parámetro de red de la fase $\delta-\mathrm{TiH}_{2}$. Los picos de altos ángulo de la fase $\gamma \mathrm{Mg} \mathrm{H} 2$ son minoritarios.

Por otro lado, se comparan en la figura 5.2 los patrones DRX de muestras de composición Mg:Ti:80:20, con distinta cantidad de grafito. En la misma se puede apreciar la formación de las fases ya mencionadas y con anchos de picos similares, revelando que el el agregado de grafito, no produce cambios significativos en las dispersiones obtenidas.

\footnotetext{
${ }^{4}$ Esto condujo a la necesidad de tomar mayores recaudos y en posteriores medidas se utilizó cinta adhesiva para evitar el contacto con el aire.
} 


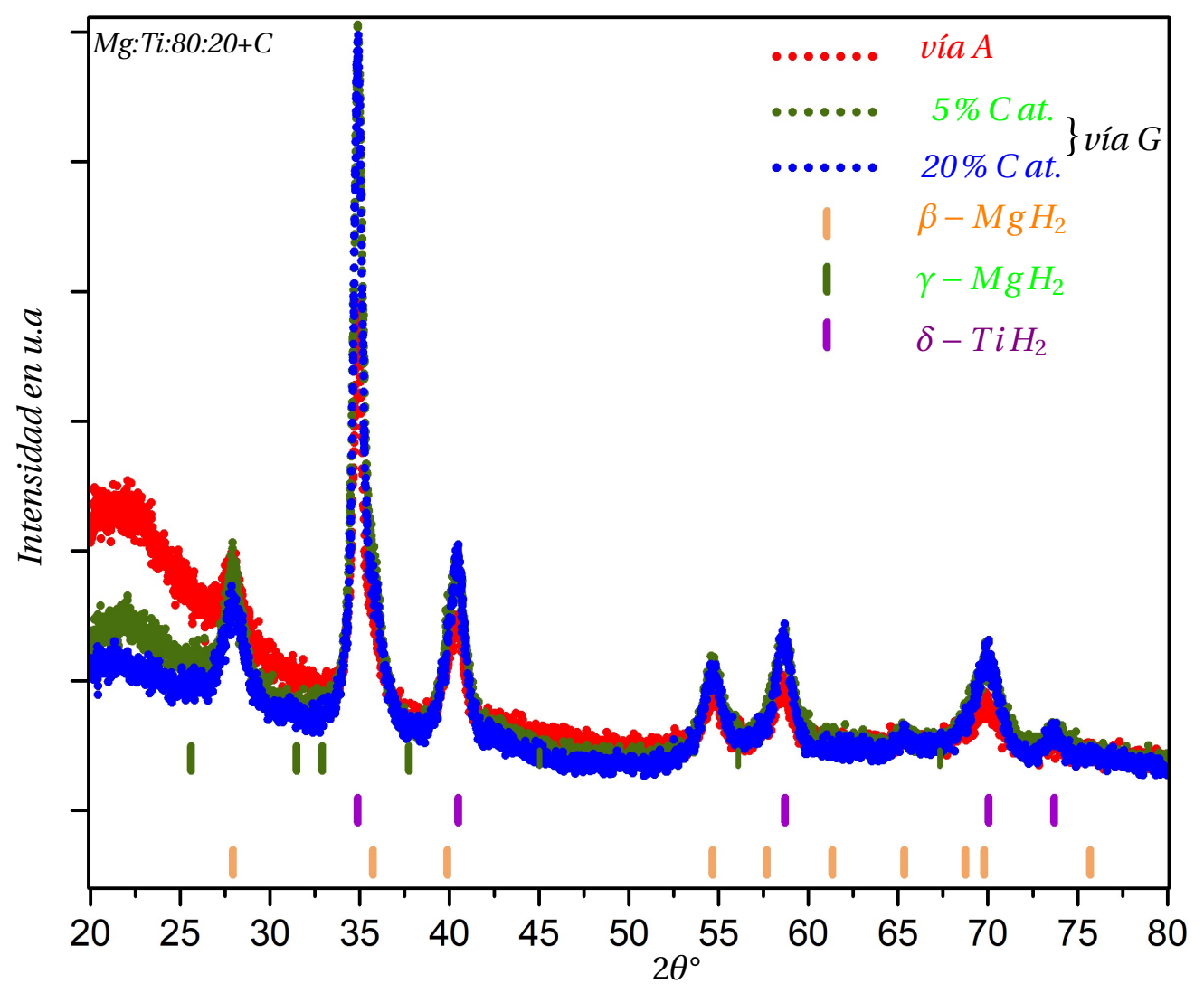

Figura 5.2: Patrones de difracción de rayos $X$ correspondinetes a muestras fabricadas por las vías A (MT13) y G (CMT18, CMT13). EL uso de capilares sellados (portamuestras) evitaba la oxidación durante la medida.

\section{Difracción de neutrones}

La figura 5.3 corresponde al patrón de difracción de neutrones de una muestra deuterada preparada mediante la vía $D$ a alta presión (en comparación con las presiones utilizadas en nuestro laboratorio). Este patrón fue obtenido en el reactor del IFE con una longitud de onda $\lambda=1,5538 \AA$. Las fases principales identificadas son: fase metaestable $\gamma-M g D_{2}$ (ortorrómbica), la fase rutilo $\beta-M g D_{2}$ (tetragonal) y la fase $\delta-T i D_{2}$ (cúbica). Se puede observar que la fase $\gamma-M g D_{2}$ también es minoritaria.

\section{Patrones de muestras frescas y tratadas}

En la figura 5.4 se muestran patrones de difracción de rayos $\mathrm{X}$ de muestras fabricadas por las vías $B$ y $D$, luego de haber sido sometidas a varios ciclos térmicos y ciclos de carga y descarga de hidrógeno. Comparando con los patrones de las mismas muestras pero frescas figuras 5.1 (curva azul) y figura 5.3, se observa claramente un adelgazamiento de los picos asociados a reflexiones de la fase rutilo $\beta-\mathrm{MgH}_{2}$. Esto indica un crecimiento de grano de la fase $\mathrm{MgH}_{2}$. Algo similar ocurre en el caso de los patrones de las muestras con distinta 
cantidad de grafito. Los patrones obtenidos para estas muestras en la Universidad de Torino ${ }^{5}$ son comparados en la figura 5.2. Corresponden a las muestras para dos composiciones con grafito (CMT13 y CMT18) y otra sin grafito (MT42). Las muestras frescas también presentan picos anchos para las fase $\beta-\mathrm{MgH}_{2}$. Luego, al ser tratadas térmicamente los patrones exhiben los picos de esta fase adelgazados. en la figura 5.5 pueden verse patrones de muestras fresca y tratada con $20 \%$ at.C.

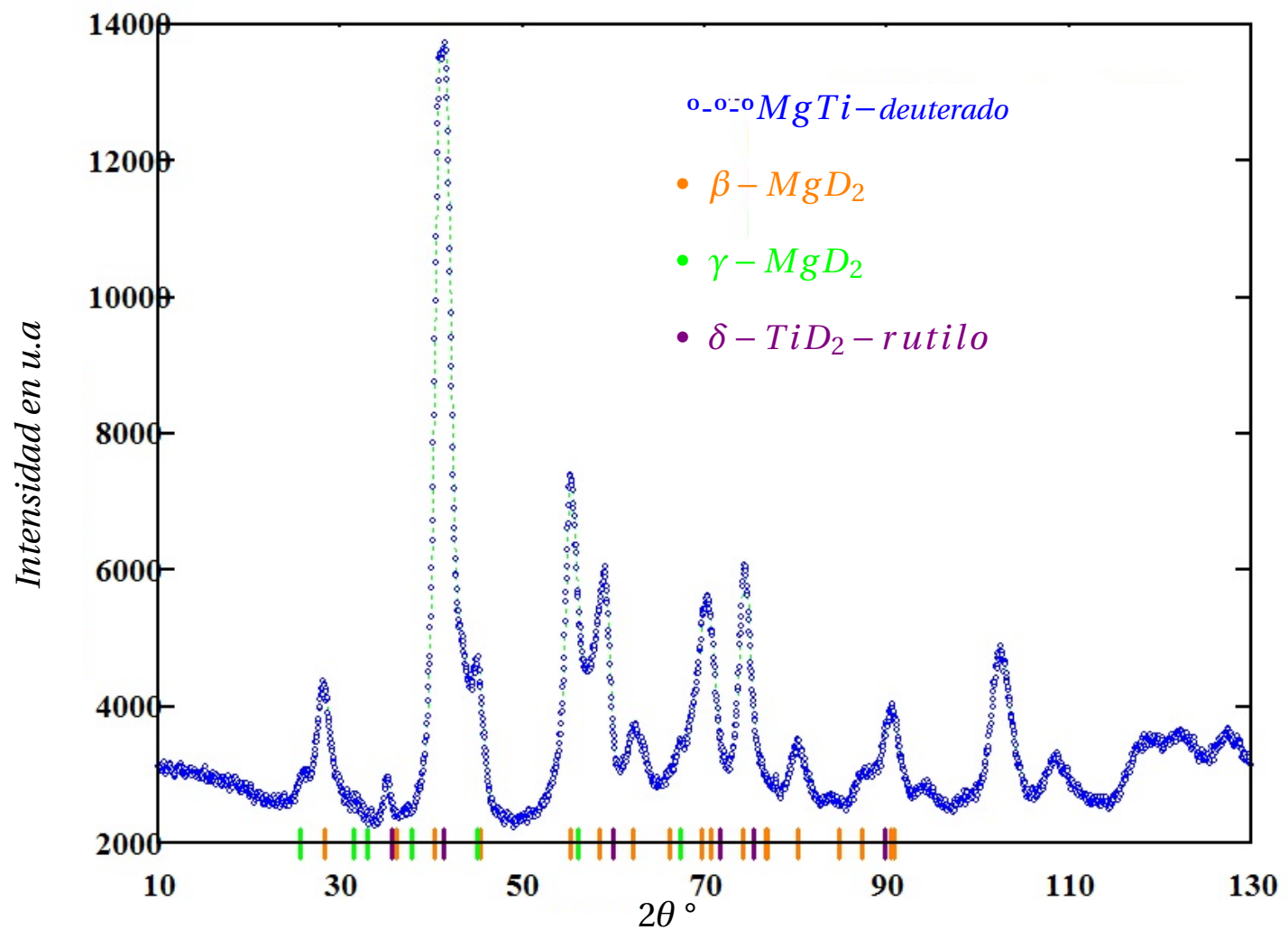

Figura 5.3: Patron de difracción de neutrones obtenido en el reactor del IFE. Corresponde a la muestra fabricada a 20 bar en el molino planetario.

\footnotetext{
${ }^{5}$ Università degli Studi Di Torino durante mi estadía allí.
} 


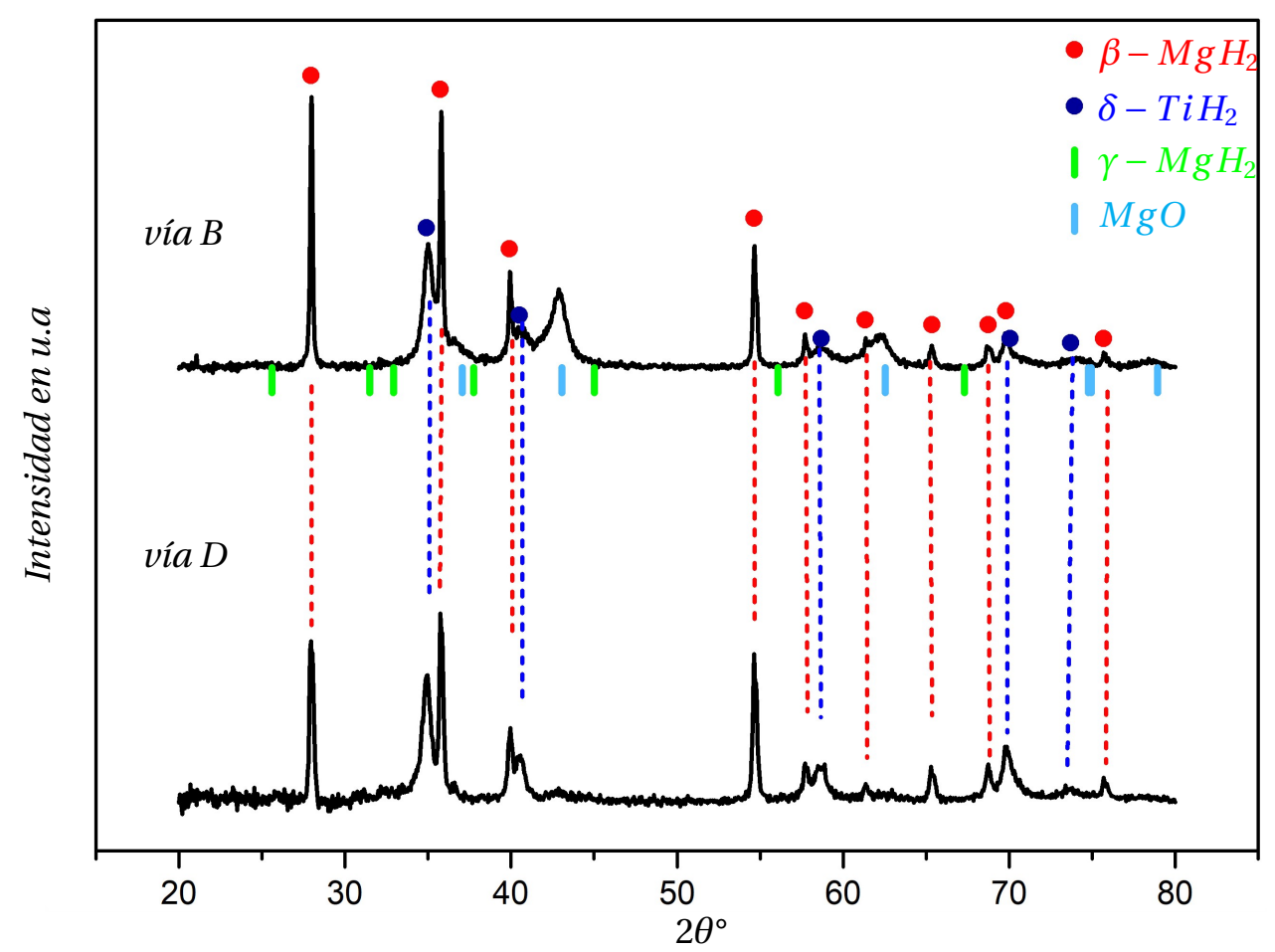

Figura 5.4: Patrones de difracción de rayos $X$ correspondientes a muestras fabricadas por las vías $B$ (MT24) y D (MTD2) luego de haber sido sometida a varios tratamientos térmicos y ciclos de absoroción y desorción de hidrógeno. 


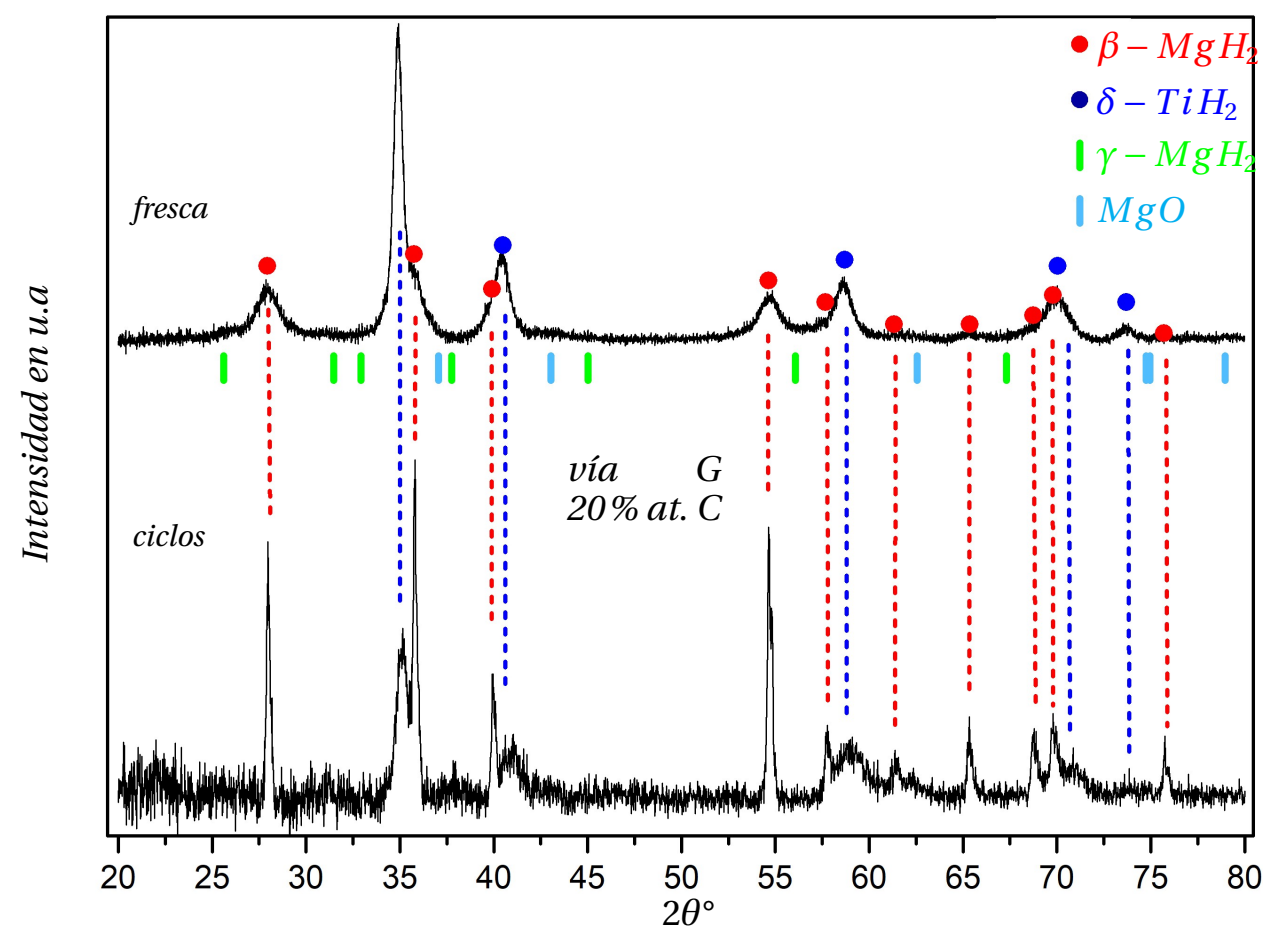

Figura 5.5: Patrones de difracción de rayos $X$ correspondientes a muestras fabricadas por la vía $G$, una fresca (arriba) y otra luego de haber sido sometida a varios tratamientos térmicos y ciclos de absorción y desorción de hidrógeno (abajo). 


\subsection{Análisis de los patrones de difracción}

\section{Microestructura de muestras frescas}

Se utilizaron el código PowderCell y el programa FullProf para hacer ajustes de los patrones de difracción. La identificación de las fases hidruro concuerda con la completitud de las reacciones $\mathrm{Mg} \rightarrow \mathrm{MgH}_{2}$ y $\mathrm{Ti} \rightarrow \mathrm{TiH}_{\sim 2}$, no habiéndose detectado la presencia de las fases de Mg y Ti metálicas.

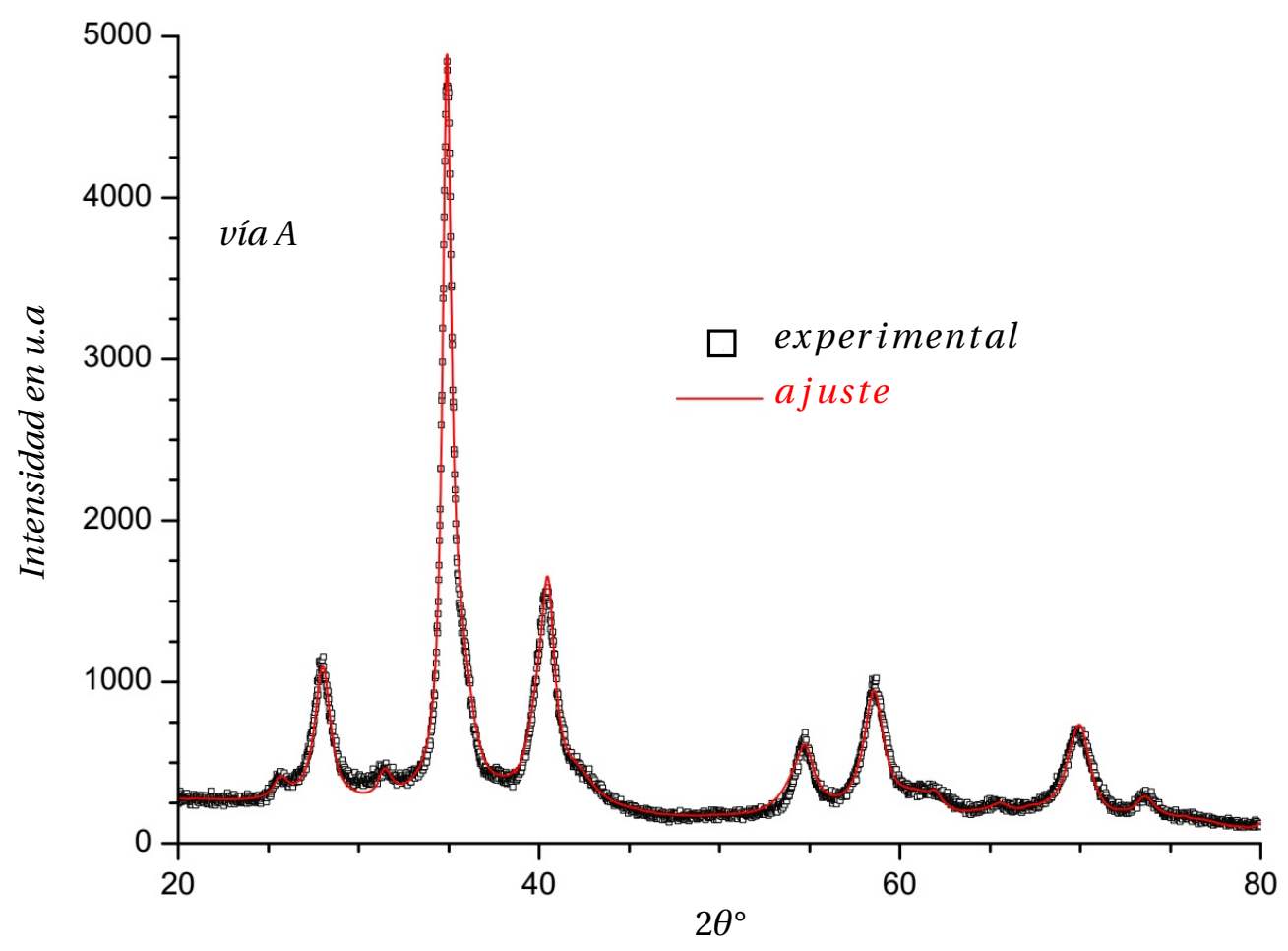

Figura 5.6: Refinamiento del patrón de difracción de una muestra preparada por molienda directa (vía A).

Como se mencionó, una parte minoritaria corresponde a la fase $\mathrm{MgO}$. Aunque en los casos en que se utilizó cinta adhesiva para cubrir la muestra, la cantidad de óxido resultaba mucho menor. La figura 5.6 muestra un patrón para una muestra fabricada mediante la ruta $A$. El ancho a mitad de altura (FWHM) de cada uno de los picos de las fases pudo obtenerse a partir del ajuste y con ello se realizó un análisis de Williamson-Hall. En el caso de las muestras fabricadas mediante las vías $A$ y $C$ el modelo de Scherrer indica una disminución relativa de tamaño de grano para la fase rutilo- $\mathrm{Mg} \mathrm{H}_{2}$ con el incremento en la proporción de Ti en la mezcla. Esto puede ser comprendido dada las propiedades abrasivas de $\mathrm{TiH}_{2}$ que es formado inicialmente durante los primeros minutos de molienda. El análisis de Williamson-Hall a partir de los $F W H M^{\prime} s$ para las muestras de composición 80:20, brindan valores de tamaño de grano similares a los obtenidos por el método de Scherrer y valores típicos de microdeformaciones para aleaciones obtenidas mecánicamente. El incremento en la constante de red para la fase $\delta-\mathrm{TiH}_{2}$ obtenido mediante la ruta $B$ puede atribuirse a la dilución de $\mathrm{Mg}$ en la fase $\delta-\mathrm{TiH}_{2} \rightarrow \mathrm{TiH}_{2}(\mathrm{Mg})$. Los picos de los patrones respondían a un perfil Lorentziano 
excepto en el caso de $\delta-\mathrm{TiH}_{2}$ que respondía más a un perfil PseudoVoightiano. Respecto a las fase metaestable $\gamma-M g H_{2}$, fue hallada usualmente en todas las muestras recién preparadas y no afecta la capacidad de hidrogenación de los sistemas. Dicha fase desaparece, transformándose en la fase rutilo una vez realizados el primer tratamiento térmico o el primer ciclo de descarga-carga.

En la tabla 5.1 se reportan los resultados de la identificación de fases y el refinamiento de parámetros correspondiente a un patrón de difracción de muestra fresca. En la tabla 5.2 se comparan los parámetros obtenidos mediante un refinamiento Rietveld ${ }^{6}$, entre una muestra tratada y otra sometida a ciclos de carga y descarga.

\begin{tabular}{|c|c|c|c|c|c|c|}
\hline Via & Fase & Parámetro & de red [nm & & $\mathbf{L}[\mathbf{n m}]$ & [wt.\%] \\
\hline$A$ & $\begin{array}{l}\beta-\mathrm{MgH}_{2} \\
\gamma-\mathrm{MgH}_{2} \\
\delta-\mathrm{TigH}_{2} \\
\mathrm{MgO}\end{array}$ & $\begin{array}{l}a: 0,4501_{3} \\
a: 0,4452_{8} \\
a: 0,4456_{2} \\
a: 0,4253_{2}\end{array}$ & $b: 0,5420_{4}$ & $\begin{array}{l}c: 0,3043_{5} \\
c: 0,5109_{2}\end{array}$ & $\begin{array}{l} \\
\sim 7 \\
\sim 13 \\
\sim 17 \\
\sim 6\end{array}$ & $\begin{array}{l} \\
\sim 43 \\
\sim 6 \\
\sim 40 \\
\sim 11\end{array}$ \\
\hline$B$ & $\begin{array}{l}\beta-\mathrm{MgH}_{2} \\
\gamma-\mathrm{MgH}_{2} \\
\delta-\mathrm{TiH}_{2} \\
\mathrm{MgO}\end{array}$ & $\begin{array}{l}a: 0,4515_{9} \\
a: 0,4606_{3} \\
a: 0,4581_{2} \\
a: 0,4250_{5}\end{array}$ & $b: 0,5357_{6}$ & $\begin{array}{l}c: 0,3035_{2} \\
c: 0,4991_{2}\end{array}$ & $\begin{aligned} & \sim 8 \\
& \sim 6 \\
& \sim \sim 10 \\
& \sim 13\end{aligned}$ & $\begin{array}{l}\sim 48 \\
\sim 7 \\
\sim 38 \\
\sim 7\end{array}$ \\
\hline C & $\begin{array}{l}\beta-\mathrm{MgH}_{2} \\
\gamma-\mathrm{MgH}_{2} \\
\delta-\mathrm{TiH}_{2} \\
\mathrm{MgO}\end{array}$ & $\begin{array}{l}a: 0,4513_{2} \\
a: 0,4537_{1} \\
a: 0,4446_{3} \\
a: 0,4306_{5}\end{array}$ & $b: 0,5356_{2}$ & $\begin{array}{l}c: 0,3021_{5} \\
c: 0,4954_{3}\end{array}$ & $\begin{array}{l} \\
\sim 9 \\
\sim 7 \\
\sim 14 \\
\sim 3\end{array}$ & $\begin{aligned} & \sim 46 \\
& \sim 7 \\
& \sim 27 \\
\sim & \sim 20\end{aligned}$ \\
\hline
\end{tabular}

Tabla 5.1: Parámetros obtenidos en los ajustes realizados sobre patrones de difracción de muestras frescas fabricadas por distintas vías (A, B y C). Se realizaron con el con el código Powdercell.

${ }^{6}$ Como fueron publicados en (96). 


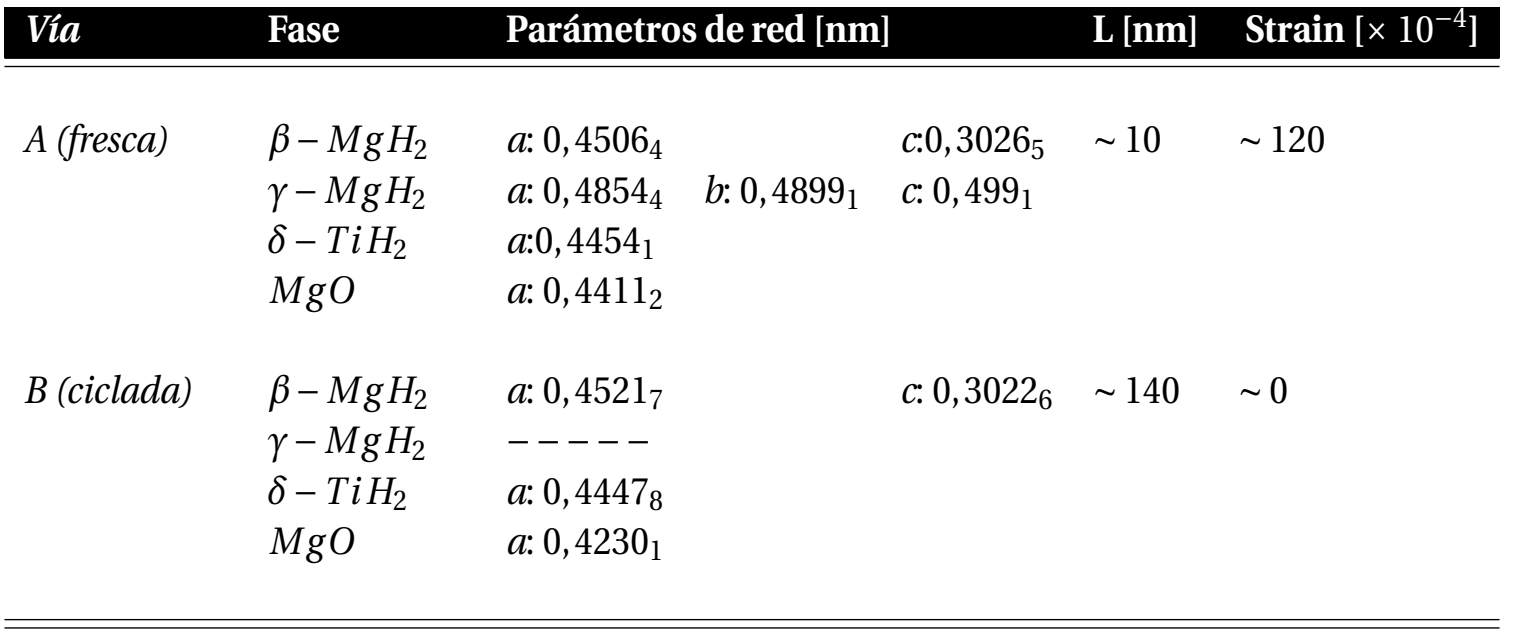

Tabla 5.2: Tabla de parámetros de refinamiento Rietveld realizado con el FullProf sobre una muestra fresca y otra tratada fabricada por distintas vías.

\subsection{Caracterización microscópica}

Se presentan en esta sección los resultados y el análisis de la caracterización microscópica. Se recurrió tanto a Microscopía Electrónica de Barrido (SEM) como a Microscopía Electrónica de Transmisión (TEM). Se contó con el acceso a diversos equipos a través del Sistema Nacional de Microscopía (Apéndice D).

Como objetivo general se pretende contribuir a la caracterización específica de los sistemas estudiados (identificación y descripción de las características micro y nanoestructurales, morfológicas, y composicionales) e intentar vincular dichas características con sus propiedades cinéticas. Por otro lado, como objetivos específicos, se pretende: identificar tamaños y morfologías de partículas, conglomerados de partículas y monocristales, así como también identificar fases y su grado de dispersión.

Se realizaron observaciones sobre un amplio conjunto de muestras caracterizándolas comparativamente de acuerdo a composición Mg:Ti, la vía de fabricación y el estado de la muestra. Se enfatizó el estudio de la composición Mg:Ti:80:20 teniendo en cuenta sus propiedades cinéticas.

\section{Sobre microscopías SEM y TEM}

Si bien los principios de funcionamiento, modos de operación y resolución alcanzada con las distintas técnicas microscópicas son diferentes, además de depender del equipo utilizado, se aprovechó el uso complementario de las técnicas para realizar un análisis microestructural. La microscopía electrónica de barrido permite un análisis morfológico más o menos superficial dependiendo del volumen de interacción de los electrones con la muestra, pudiendo alcanzar dicho volumen o gota de interacción, hasta $1 \mu \mathrm{m}$ de profundidad para los microscopios utilizados en esta Tesis. Otra característica importante es la apariencia tridimensional de la imagen de la muestra.

La microscopía electrónica de transmisión en cambio, puede brindar información del in- 
terior (bulk) del material (partículas), a expensas de que estas no excedan cierto espesor $(<\sim 100-300 \mathrm{~nm})$. Además, la microscopía TEM puede alcanzar altas resoluciones $(\leq 1 \mathrm{~nm})$ y permite obtener información sobre la estructura, orientación cristalina y defectos.

Ambas técnicas cuentan con un sistema dispersivo en energías, para análisis cuali/cuantitativo de la composición de la muestra (sistema de microanálisis EDAX por sonda de electrones y espectrómetro de rayos X dispersivo en energías EDS). El análisis de rayos X emitidos por la muestra como resultado de la interacción entre el haz de electrones y la muestra, puede proporcionarnos información cualitativa y cuantitativa de su composición en pequeños microvolúmenes $\left(\sim \mu \mathrm{m}^{3} \mathrm{o} \mathrm{nm}^{3}\right)$. La técnica, en nuestro caso, permite analizar los elementos de la tabla periódica con $Z>5$. La combinación con un espectrómetro de pérdida de energía de los electrones (EELS) permite la obtención de mapeos composicionales en áreas seleccionadas de observación, lo cual nos brinda información cualitativa de la distribución de elementos químicos(mapeos elementales).

En el caso de SEM, fue necesario metalizar las muestras depositando una capa delgada de $\mathrm{Au}$, de modo de asegurar una buena conducción de electrones. Mientras que la preparación de muestras para observación por TEM consistió en la disolución de una pequeña alícuota de muestra en solventes no reactivos (tolueno o acetona), para luego depositar una gota en grillas de $\mathrm{Cu}$ recubiertas de carbono Formvar (resistentes a los solventes utilizados).

Al realizar un análisis comparativo de las imágenes de ambas técnicas, debe tenerse en cuenta que las partículas y aglomerados observados pueden mostrarse de manera distinta según la microscopía utilizada justamente debido a las diferencias en la preparación de la muestra.

\section{Resultados}

Se presentarán los resultados de acuerdo a las categorías mencionadas en la sección introductoria anterior, complementando las numerosas imágenes obtenidas mediante SEM y TEM. De esta manera puede asumirse una caracterización representativa de las muestras, lo que podría constituir una limitación de la microscopía en general cuando se cuenta con una única observación.

Se tomaron fotografías en distintos rangos de magnificación. Se pueden clasificar en baja (hasta $10.000 \times)$, media $(10.000 \times$ a $\sim 50.000 \times)$ y alta $(100.000 \times-200.000 \times)$ magnificación. De menor a mayor magnificación las imágenes revelan distintas características, desde la conformación de lo que se denominarán conglomerados principales observados a magnificaciones bajas, hasta la conformación de conglomerados menores de partículas pequeñas, mostrando tamaños y morfologías diferentes al ser observadas a magnificaciones altas. Algunas imágenes obtenidas serán presentadas adicionalmente en el Apéndice D mostrándose en esta sección imágenes representativas de los observado. Cualitativamente la distribución de tamaños revelada por las imágenes de baja magnificación abarca un amplio rango. No obstante, la identificación de partículas individuales no resulta sencilla por la presencia de conglomerados polimórficos y complejos sumado al altísimo grado de superposición de las partículas, lo que puede observarse directamente en todas las imágenes SEM. Incluso en las imágenes TEM, en menor medida esto también ocurre. Por ello un análisis cuantitativo resulta complejo de realizar. 


\subsubsection{Muestras de composición $\left(\mathrm{MgH}_{2}\right)_{80}-\left(\mathrm{TiH}_{2}\right)_{20}$, preparada por Vía A}

Se presentarán las imágenes de menor a mayor magnificación ilustrando en ese orden las características a distintas escalas. En la figura 5.7 se muestran imágenes de baja magnificación correspondientes a distintas muestras de composición $\left(\mathrm{MgH}_{2}\right)_{80}-\left(\mathrm{TiH}_{2}\right)_{20}$ preparadas por molienda directa. En la figura 5.8 se presentan una serie de fotografías de distinta magnificación mostrando distintos tipos de conglomerados. Ambas figuras (5.7 y 5.8) ilustran los rasgos más representativos y destacados de la estructura y morfología de los conglomerados principales y menores. Estas revelan la diversidad morfológica y de tamaños de los tipos de conglomerados y partículas que se forman.
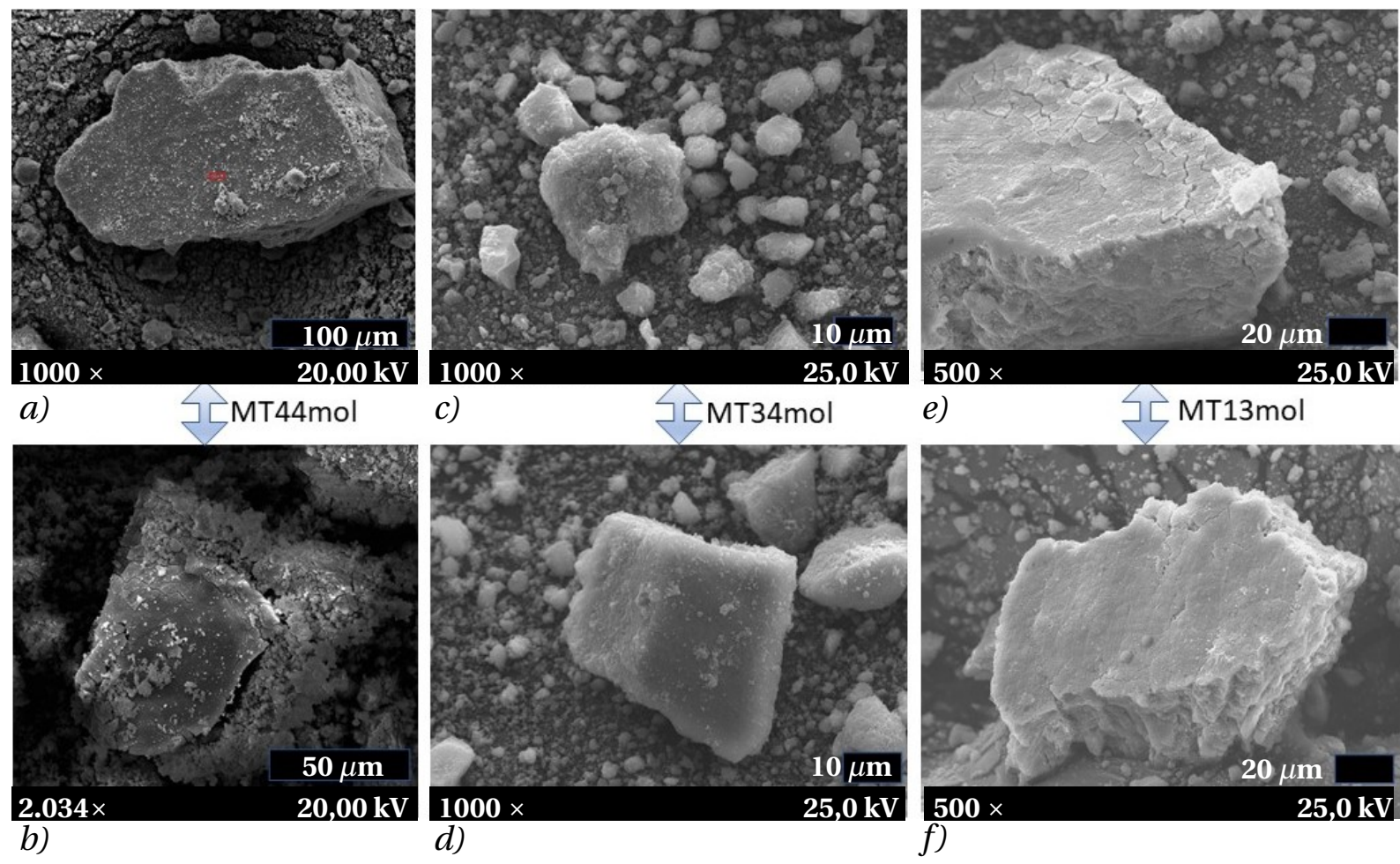

b)

d) f)

Figura 5.7: Serie de imágenes a bajas magnificaciones mostrando tamaños y características morfológicas de los conglomerados principales y menores. Se comparan muestras frescas homólogas (fabricadas por la vía A).

La serie de la figura 5.7 revela a simple vista que este tipo de sistemas presentan una distribución amplia de tamaños de conglomerados principales cuyo rango estimado podemos definirlo entre $\sim[10 \mu \mathrm{m}-500 \mu \mathrm{m}]$. Los mismos pueden presentar una morfología tipo poliédrica irregular con bordes en general filosos. Estos se presentan, en distinto grado, cubiertos por conglomerados más pequeños de partículas, exponiendo zonas lisas, aparentemente compactas al ser observadas a magnificaciones bajas. Sin embargo, en algunas imágenes (5.7e,$b$ y $f$ ) ya puede observarse un grado importante de agrietamiento que es confirmado por imágenes de mayor magnificación (figuras $5.8 d$ y 5.9a). También se observan numerosos conglomerados tipo racimos irregulares y partículas $\leq 10 \mu \mathrm{m}$ dispersos y separados de los conglomerados principales, como se observa en las figuras $5.7 c$ - $d$ y 5.8. Estas características se repiten a lo largo de las distintas muestras, incluso al comparar alícuotas de muestra obtenidas directamente del polvo desprendido del reactor, como del obtenido por raspado de las paredes (figuras $(5.7 c \mathrm{y} d)$. 
a)

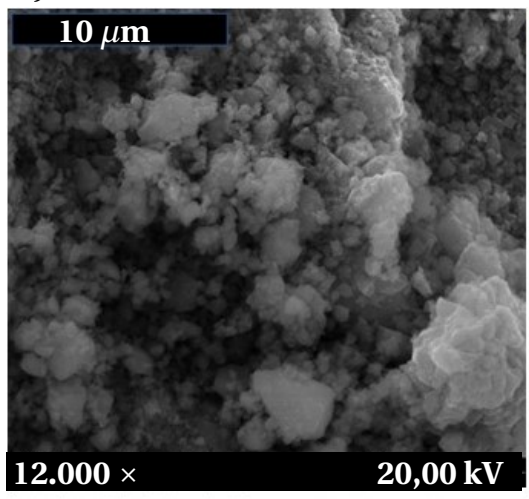

b)

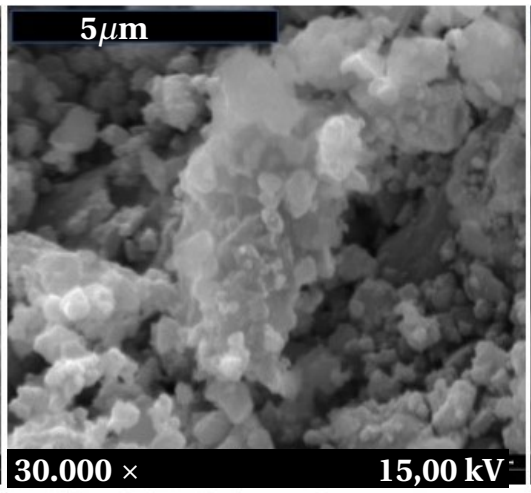

c)

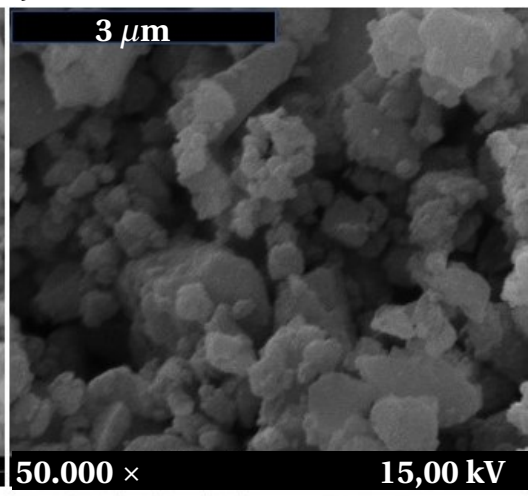

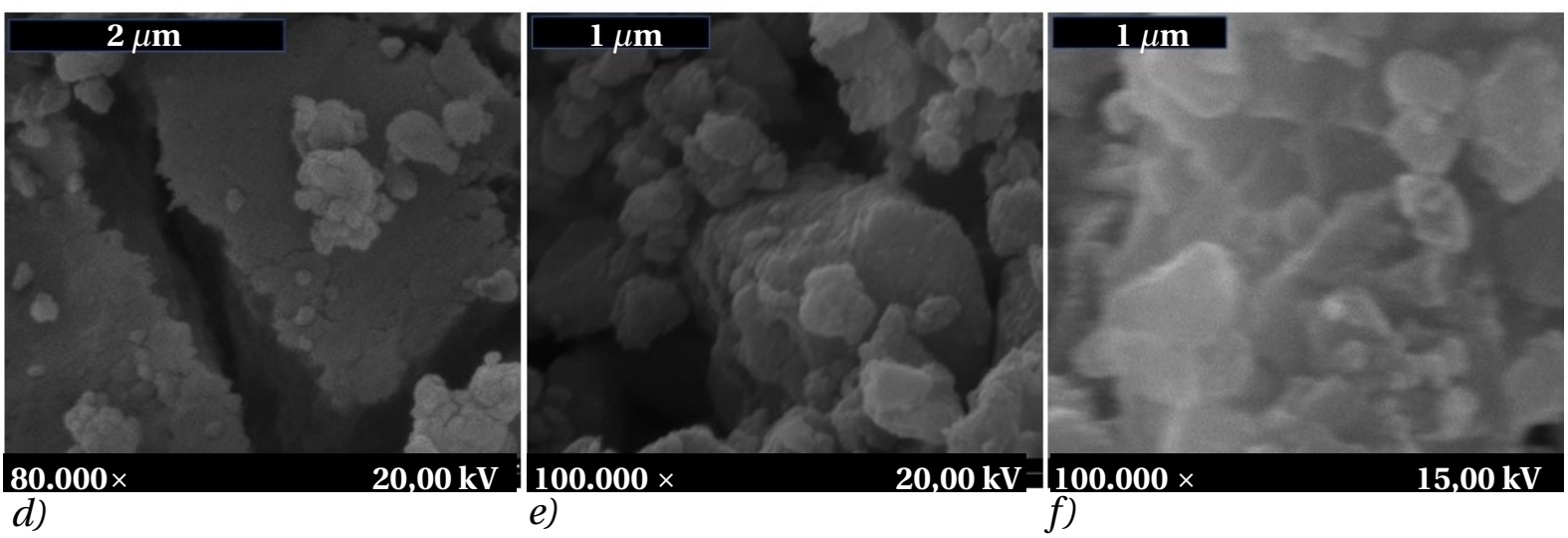

Figura 5.8: Serie de imágenes a baja, media y alta magnificación mostrando las regiones de partículas dispersas y/o adosadas a zonas de partículas mayores de apariencia compacta

Las fotografías de mayor magnificación $(10.000 \times$ a $200.000 \times)$ revelan la existencia de lo que se definirán como conglomerados menores y de partículas en el rango de tamaños $\sim[3 \mu \mathrm{m}-10 \mu \mathrm{m}]$. Estos conglomerados menores pueden ser semejantes morfológicamente a los conglomerados principales. Por ejemplo los hay de forma poliédrica, lo cuales también pueden estar cubiertos en distinta medida por partículas y o conglomerados más pequeños aún. Esto se ilustra por ejemplo en las figuras $5.7 e, b$ y $5.8 d$, e y $5.9 \mathrm{~b}$. Los conglomerados menores pueden conformar parte de los conglomerados principales, como se aprecia en las figuras mostradas, o pueden simplemente estar dispersos. Tanto estas figuras como las imágenes de alta magnificación SEM (5.9a, D.2), tomadas sobre zonas de estas partículas, permiten distinguir las partículas más pequeñas que las conforman. Por otro lado también en esa escala intermedia $(\sim[3 \mu m-10 \mu m])$ se presentan conglomerados más suaves tipo racimo 5.8. Por lo tanto podremos hablar de conglomerados menores y de conglomerados/partícula. Este último término adquiere sentido cuando se observan las fotografías de las partículas y conglomerado más pequeños por TEM (figuras 5.10, 5.11).Estas corresponden a imágenes representativas de los denominados conglomerados/partícula, por constituirse a partir de un aglutinamiento indefinido. Debe mencionarse que se ha observado al preparar las muestras para observación TEM, que gran parte de la muestra se deposita en el fondo de la solución, correspondiendo esto a las partículas y conglomerados grandes (de mayor masa). Debe considerarse la posibilidad de un desmembramiento parcial de estos conglomerados principales en la solución. Así, mediante microscopía TEM solo podemos identificar las partículas y conglomerados de menor tamaño, que denominaremos conglomerados menores y/o 
conglomerado/partícula.

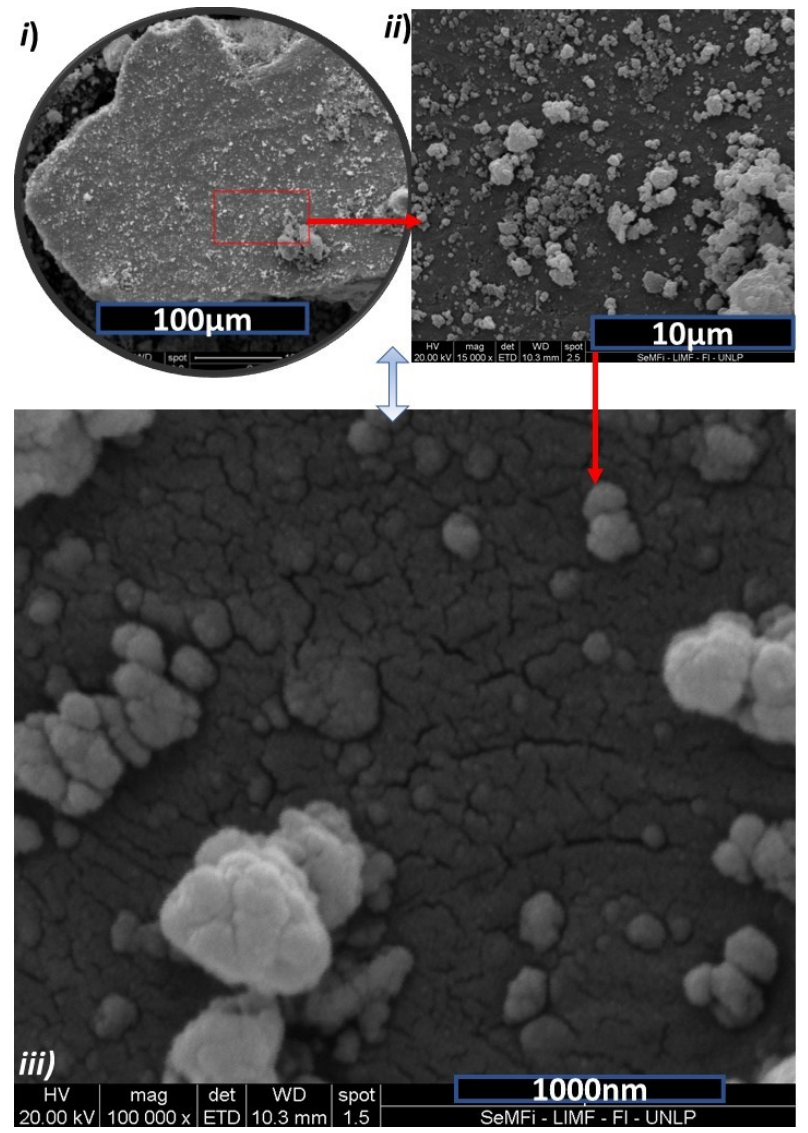

(a) Amplificación de zona compacta indicada en la fotografía $i$

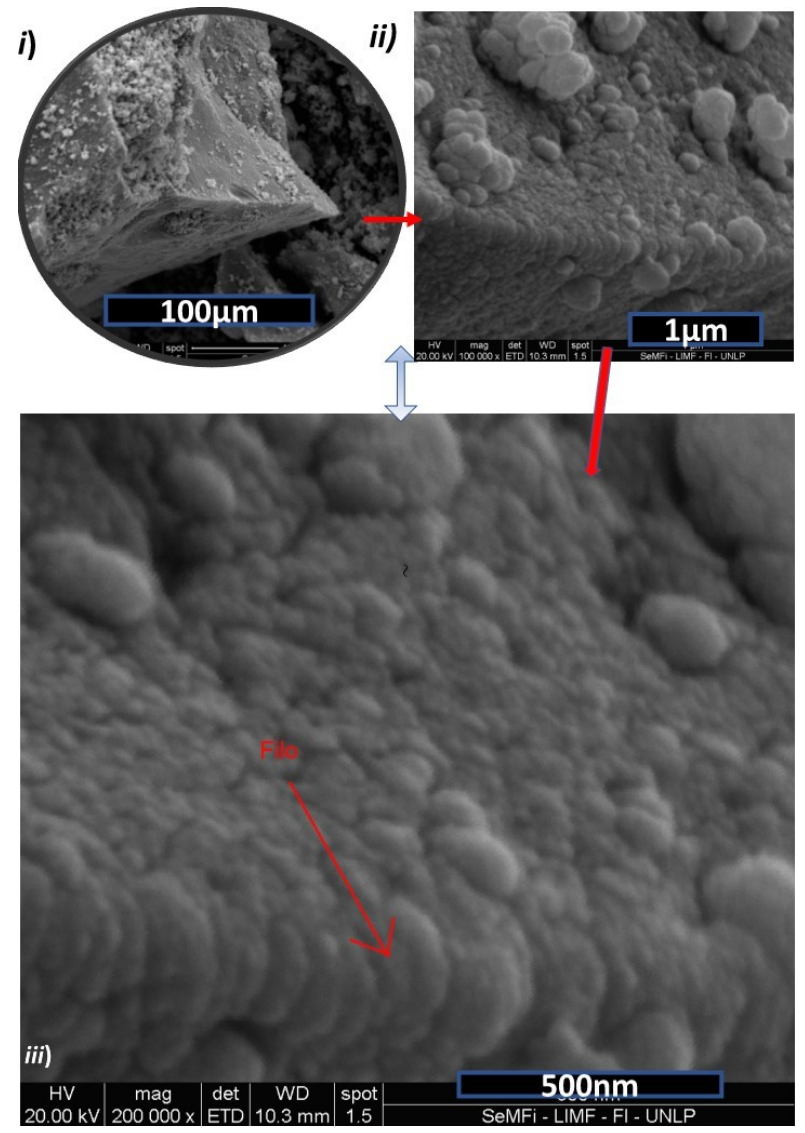

(b) Magnificación de una zona de borde del borde de la partícula de la fotografía $i$

Figura 5.9: Fotografías SEM de muestras fabricadas por la vías A. En cada subfigura se muestran fotografías de una misma región a magnificación creciente de $i \rightarrow i i i$, como indica el sentido de las flechas rojas, siendo la $i i i$ la de máxima magnificacion, $200.000 \times$.

A partir de la descripción desarrollada, se puede esquematizar la existencia de tres escalas estructurales de tamaños :

- conglomerados principales $\sim[10 \mu \mathrm{m}-500 \mu \mathrm{m}]$

- conglomerados menores y partículas $\leq 10 \mu \mathrm{m}$ ]

Los tipos de configuraciones estructurales observadas mediante SEM a distintas magnificaciones pueden resumirse de la siguiente manera. A bajas magnificaciones se identifican distintos tipos de estructuras y morfologías. En general se observan: conglomerados principales con formas irregulares poliédricas con zonas "compactas ” y/o zonas "agrietadas" eventualmente con partículas y/o conglomerados/partícula adosadas sobre los mismos, y conglomerados menores con formas más suaves tipo racimo y partículas pequeñas dispersas. Las zonas agrietadas pueden observarse a distintas escalas, dando lugar a la existencia de microgrietas, distinguidas a bajas magnificaciones (figuras $5.7 e, b \mathrm{y} f$ ) y nano-grietas (distinguidas a altas magnificaciones (figura 5.9a). 
Tanto a media como a alta magnificación pueden identificarse también zonas compactas y agrietadas. Se pueden observar regiones de aglutinamiento de partículas redondeadas (compatibles con tamaños de cristales), sobre las que se siguen distinguiendo pequeñas partículas y conglomerados/partículas dispersos.

\section{Microscopía TEM}

En la figura 5.10 se muestran fotografías obtenidas mediante microscopía TEM (CNEA) para una muestra fabricada mediante la vía A. El tipo de aglutinamiento así como los tamaños y formas observados resultan representativos de las muestras fabricadas por esta vía ${ }^{7}$.

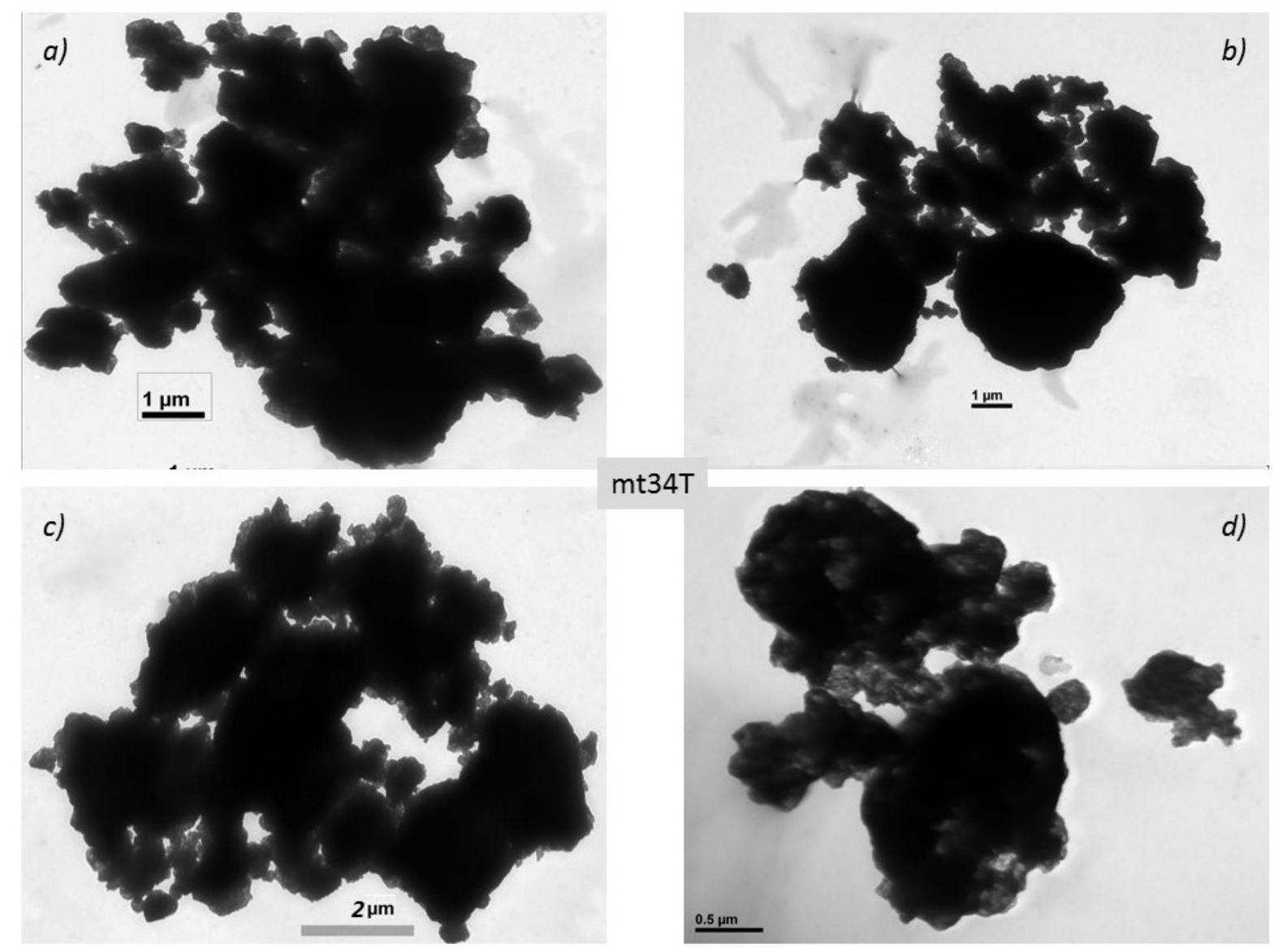

Figura 5.10: Partículas y conglomerados/partícula observados a baja magnificación por TEM. Puede apreciarse el notorio aglutinamiente de partículas y subpartículas. Estos conglomerados no exceden los $10 \mu m$ de diámetro promedio mientras que las subpartículas que lo conforman raramente exceden los $\sim 5-6 \mu \mathrm{m}$.

Las fotografías TEM a mayor magnificación se muestran en la figura 5.11. Allí se indican distancias representativas. Estas partículas corresponden al rango de tamaños $\sim 1-10 \mu m$. En la figura de mayor magnificación, 5.11c, pueden apreciarse más detalles de las partículas a esa escala, distinguiéndose manchas oscuras regulares distribuídas más o menos homogéneamente. Si bien en la observación TEM las regiones más oscuras pueden corresponder a

${ }^{7}$ En el ApéndiceD se muestran más fotografías tomadas que muestran la representatividad de estas características. 
contrastes de espesor, la clara regularidad de las manchas negras en el rango de $\sim 30$ a $80 \mathrm{~nm}$ se atribuyen a regiones de partículas más densas en nuestro caso del $\mathrm{TiH}_{2}$. Esto es soportado también con la información obtenida por las imágenes de mapeo elemental obtenidas por TEM (figura 5.22), la cual que permitió identificar la presencia de Ti en dichas regiones oscuras.
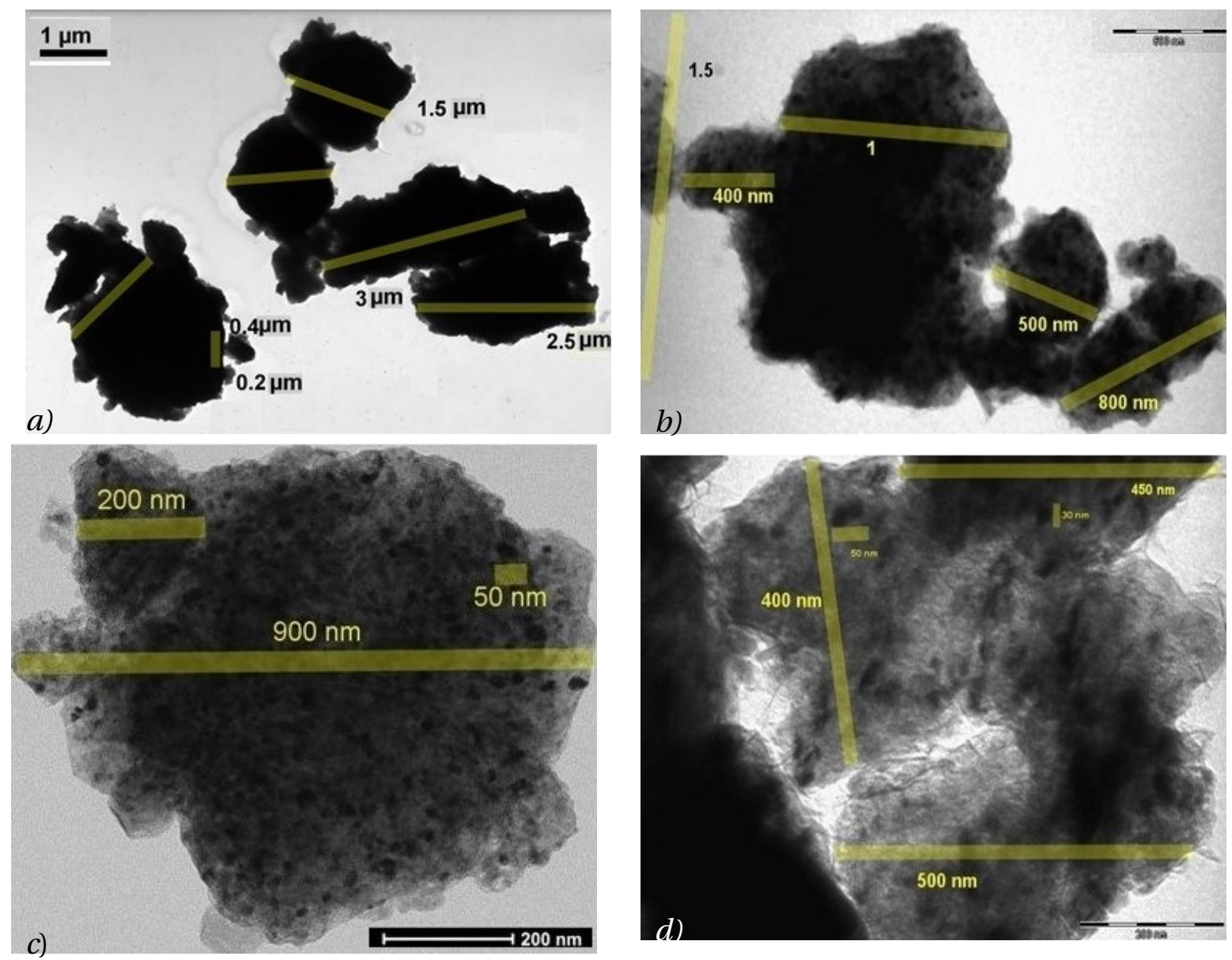

Figura 5.11: Imágenes obtenidas mediantte microscopía TEM (CNEA,Y-Tec), correspondientes a muestras fabricadas por la vía A. La morfología de las partículas y la gran regularidad de las manchas oscuras indican que estas regiones negras probablemente corresponden a partículas de fase más densa conformando una estructura de microdispersión.

Se tomaron fotografías de alta resolución TEM sobre distintas regiones (ÁREAS) de la partícula observada en la figura 5.11c. Estas ÁREAS abarcan parte del centro y del borde de la partícula (figura 5.12). En la figura 5.13 se han individualizado en amarillo las distintas regiones cristalinas de una de las áreas mostradas en la figura 5.12 (ÁREA 3). Allí, como en la figura 5.14, se presentan fotografías ampliadas del ÁREA 3, a fin de mostrar en mayor detalle algunas de las familias de planos cristalinos observados. En las distintas zonas se puede percibir un alto grado de cristalinidad, observándose claramente distintas familias de planos cristalinos orientados en varias direcciones sin una orientación relativa preferencial. Pueden observarse también regiones de Moiré (franjas con distancias mayores), que corres- 
ponden a la superposición de varios cristales con diferentes orientaciones atravesados por el haz de electrones transmitido .
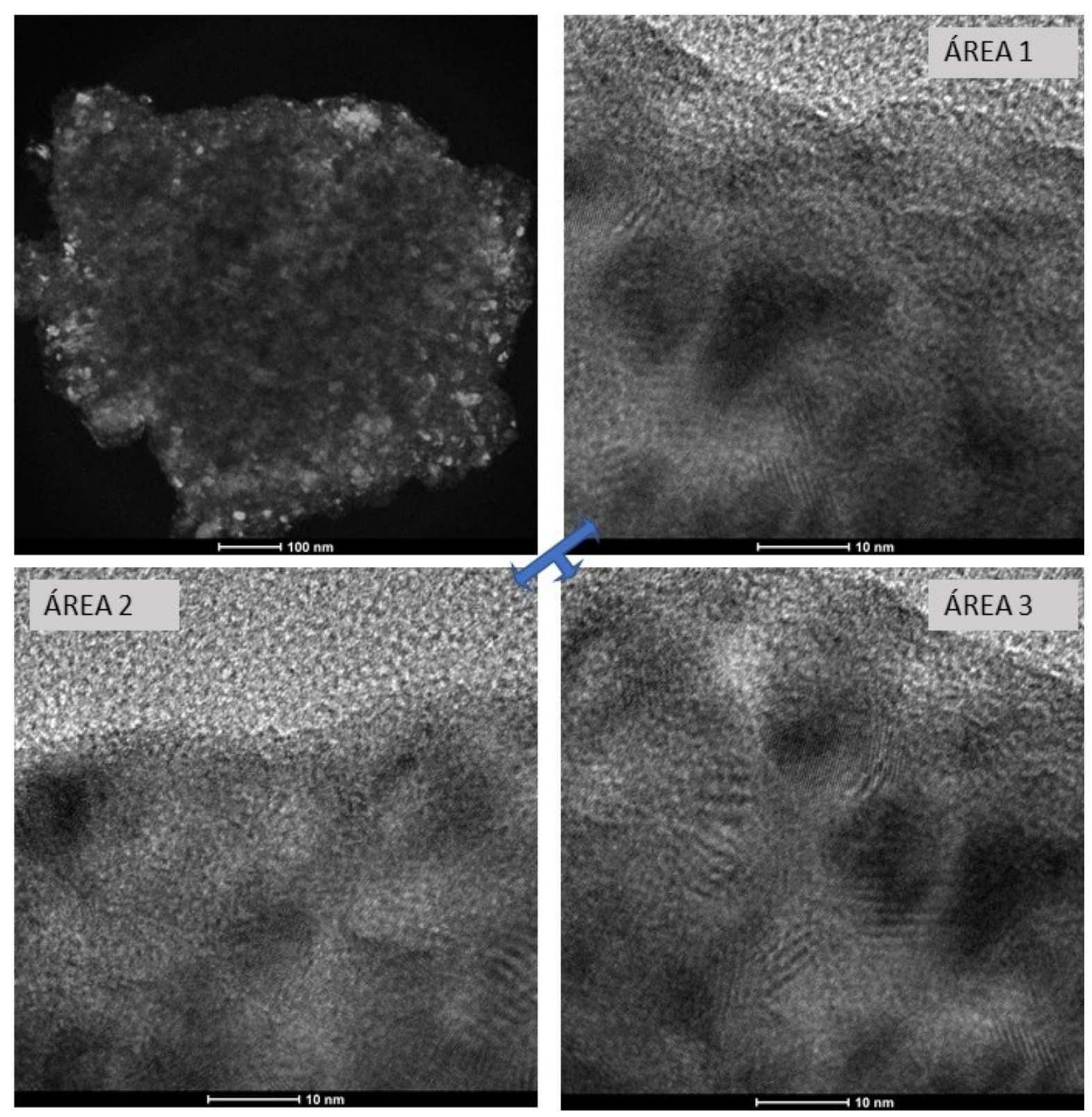

Figura 5.12: $a$ ): Imágen de campo oscuro correspondiente a la partícula observada en la figura 5.11. $b), c), d)$ : Forografías de alta resolución tomadas sobre tres áreas distintas. 

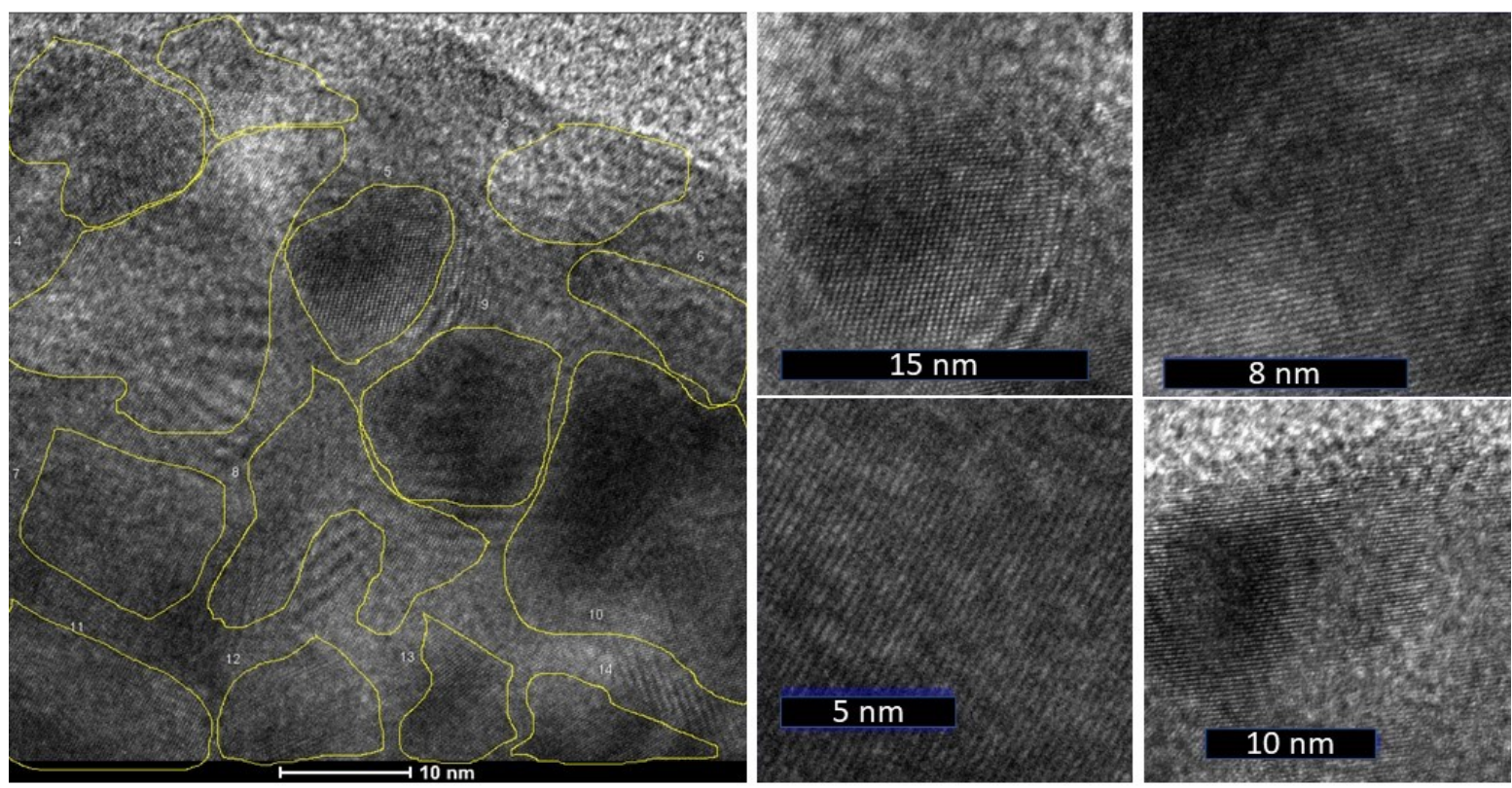

Figura 5.13: Se han delimitado aproximadamente, a la izquierda, las zonas correspondientes a granos con familias de planos cristalinos orientados de manera distinta. Se muestran amplificadas para percibir mejor los planos a la derecha.

La medición de las distancias interplanares mediante el software ImageJ (como se ilustra en la figura 5.14) brinda valores coherentes con las fases presentes identificadas mediante DRX, sin embargo el grado de precisión y la comparación con las distancias interplanares reportadas en la literatura ${ }^{8}$ no es suficiente para poder distinguir las fases $\mathrm{Mg} \mathrm{H}_{2}$ y $\mathrm{TiH}_{2}$. Resulta necesario el uso complementario de las Transformadas de Fourier (FFT) calculadas sobre estas regiones y de los patrones de difracción (figura 5.17).

En la figura 5.15a puede identificarse un entramado compacto asociado a múltiples familias de planos, correspondiendo estos probablemente a distintas fases. En la fotografía 5.15 b) pueden identificarse claramente distintas familias de planos cristalinos. En cambio, en las fotografías 5.15 c) y d) se puede identificar una única familia de planos.

\footnotetext{
${ }^{8}$ Se ha utilizado por ejemplo la base de datos PDFWin.
} 


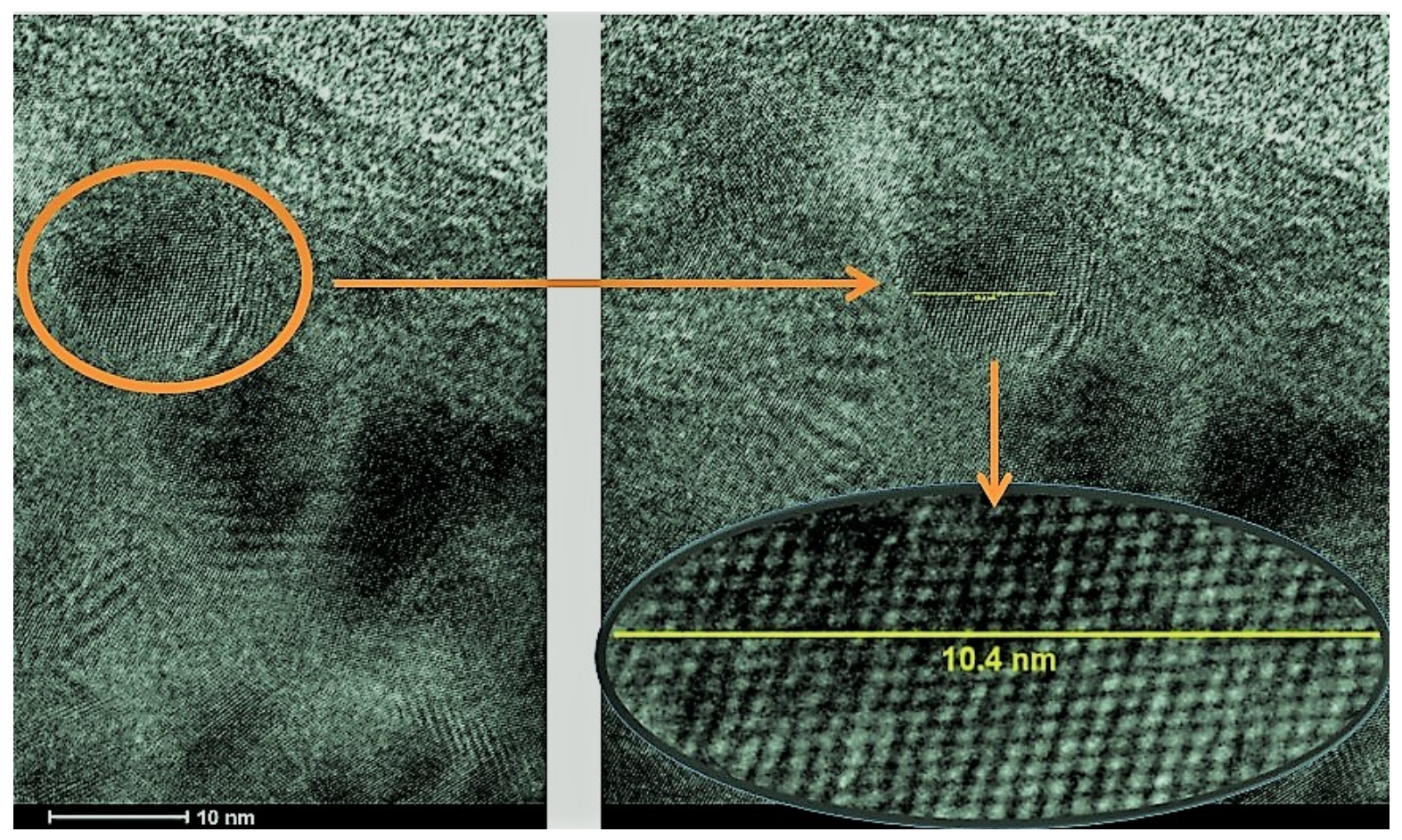

Figura 5.14: Se muestra amplificada (izquierda) las zona correspondientes a varios conjuntos de planos cristalinos. Se muestras amplificadas a la derecha la región de un conjunto en particular para percibir mejor los planos (derecha). Así es posible medir las distancias interplanares y estimar las posibles fases presentes. 

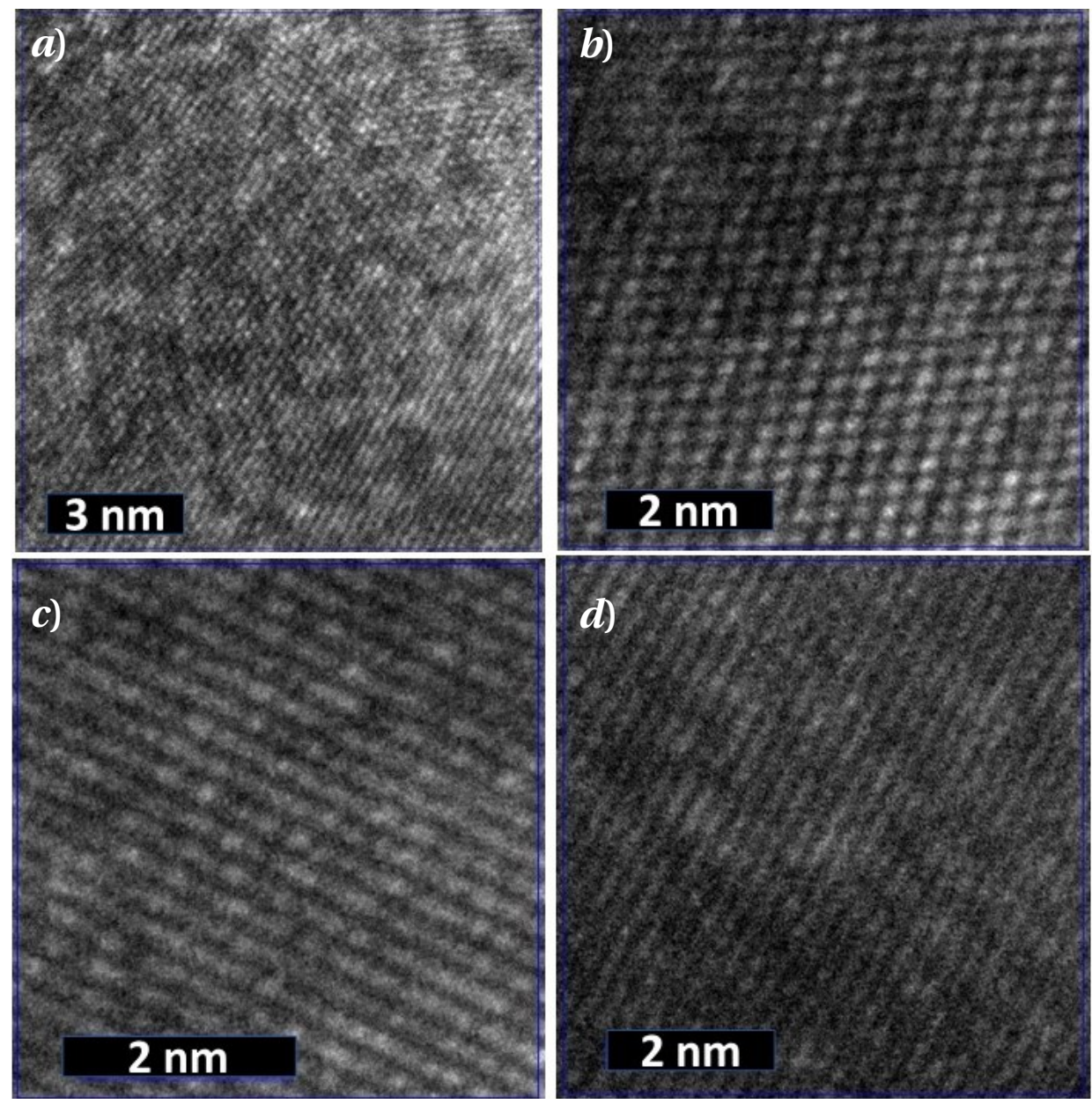

Figura 5.15: Distintas familias de planos cristalinos. Se muestran amplificadas para percibirlos más claramente. 

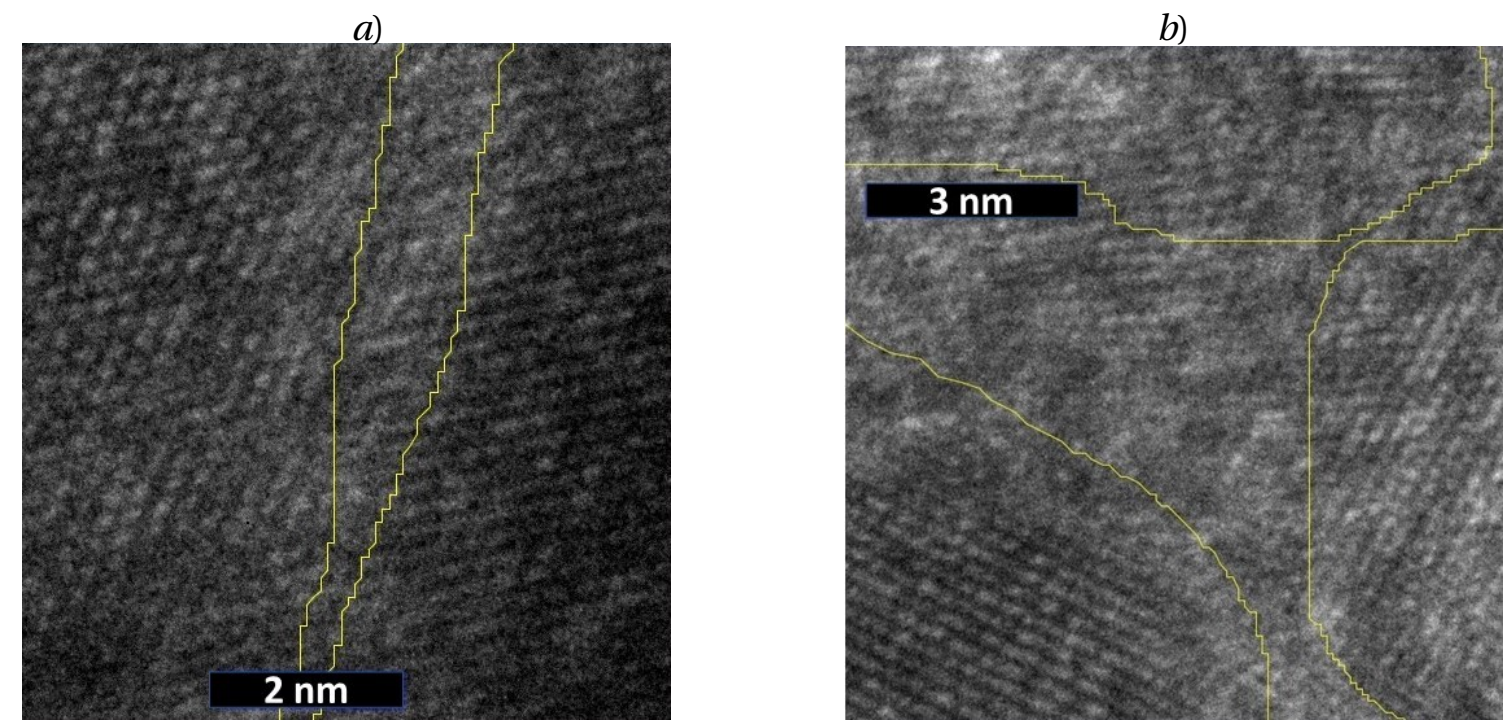

Figura 5.16: Se indicaron aproximadamente distintas regiones halladas tipicamente a lo largo de las muestras observadas mediante TEM a alta resolución. Al amplificar las fotografías, se identificaron numerosas regiones de este tipo asociadas probablemente a bordes de grano.

En en la figura 5.16 se muestran las fotografías amplificadas asociadas a las regiones de bordes de grano. A lo largo de las muestras, tanto con grafito como sin grafito resultaron abundantes y diversas las regiones de este tipo.

En la figura 5.17 se muestran dos patrones de difracción distintos y las respectivas imágenes de campo oscuro. Fueron obtenidos para una muestra fabricada por la vía A (MT50), luego de haber sido sometida a varios tratamientos térmicos. Los anillos de difracción revelan la alta cristalinidad de la muestra. En el caso de las muestras con grafito los patrones resultaban menos nítidos. 

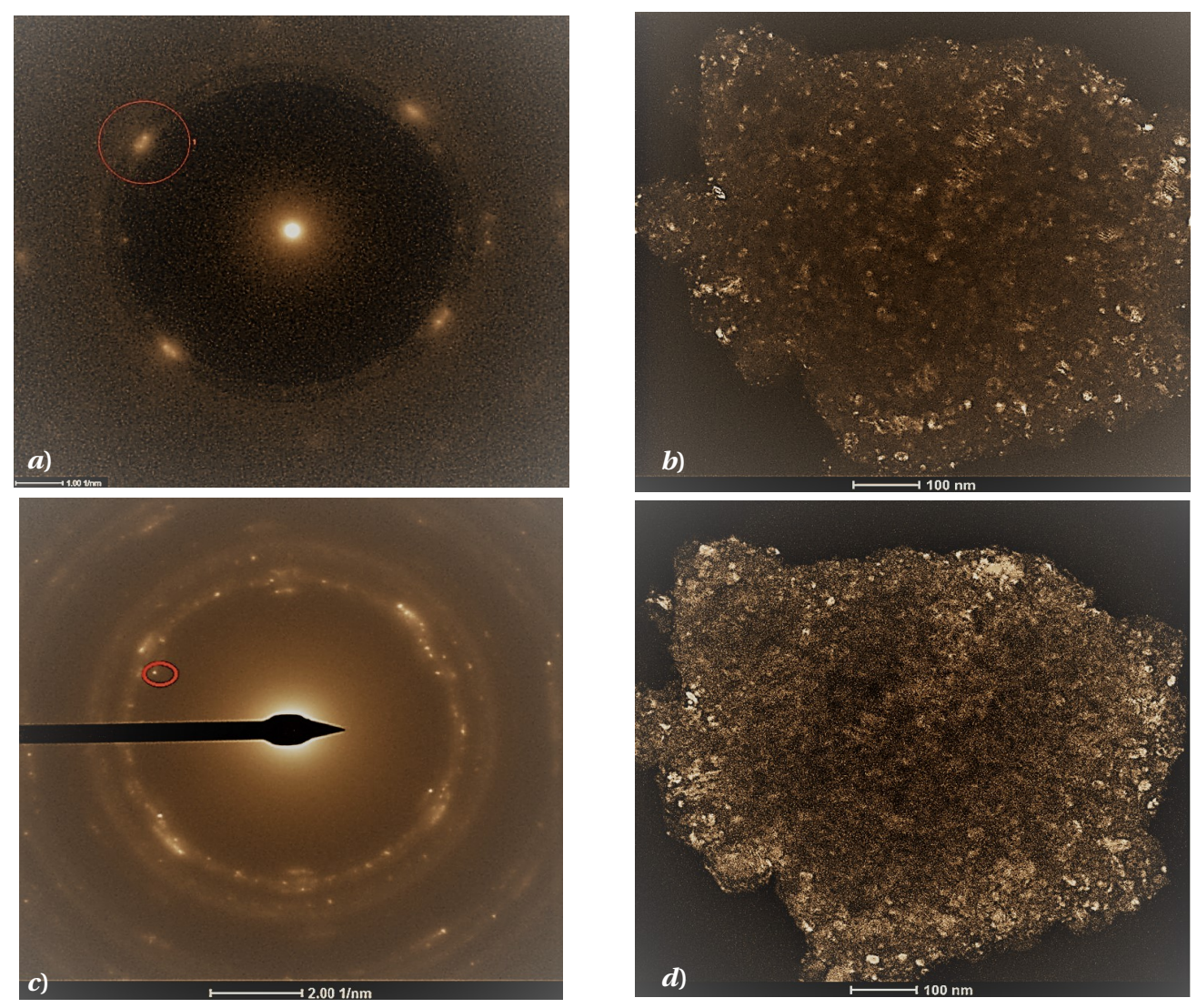

Figura 5.17: a) y c): Patrones de difracción obtenidos por TEM .Corresponden a una muestra preparada por la vía A luego de varios ciclos de absorción/desorción de hidrógeno. b) y d): Corresponden a las imágenes de campo oscuro (DF) asociadas a los patrones de difracción. Se pueden apreciar los tamaños de los cristales.

\section{Muestras con agregado de grafito}

Las características estructurales y morfológicas observadas mediante SEM sobre muestras del tipo $\left(\mathrm{MgH}_{2} \mathrm{TiH}_{2}\right)_{1-y}-\mathrm{C}_{y}$ a bajas magnificaciones no presentan grandes diferencias con las muestras que no contienen grafito. En esta sección se muestran las fotografías obtenidas por TEM correspondientes a una muestra preparada mediante la vía $G$ con agregado de de grafito, $20 \%$ at. (figura 5.18). Las muestras con grafito podrían presentar una inhomogeneidad más notoria en la dispersión de las fases, como se puede observar a través de las manchas oscuras (esto se observó para distintas muestras con grafito. Por otro lado las fotografías de alta resolución tomadas sobre zonas de esta partícula (figura 5.19, izquierda) muestran diferencias aparentes con las muestran sin grafito: las zonas cristalinas pueden distinguirse con mayor dificultad. Sin embargo los patrones de DRX obtenidos para estas muestras con grafito son similares a los de las muestras sin grafito. Todo esto indica que el grafito estaría

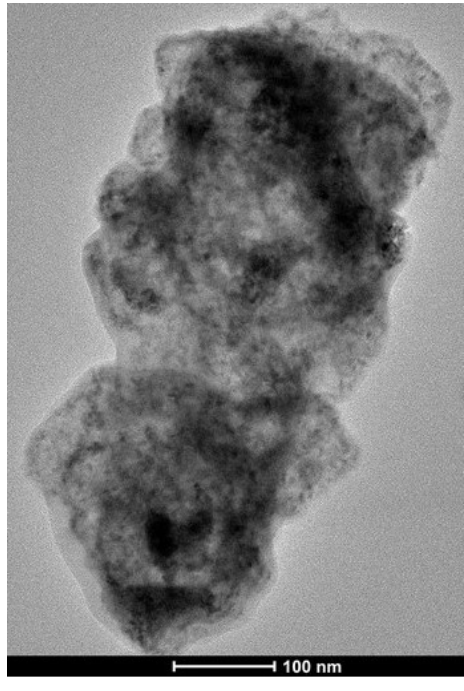

Figura 5.18: Imagen TEM. Partícula con grafito luego de ciclos. 
formando un recubrimiento homogéneo sobre las partículas y conglomerados. Las fotografías en las que se podían observar las regiones externas de la partícula (y por lo tanto parte de la grilla de Formvar carbón sobre la que estaba depositada), presentaban un aspecto tipo amorfo similar a las regiones en las que no resultaba difícil distinguir los planos cristalinos. Amplificando las regiones y mediante la transformadas de Fourier (FFT) en una zona específica podía identificarse la presencia de fases cristalinas. Esto se ilustra en la figura 5.19 y ocurría típicamente a lo largo las partículas con grafito observadas.

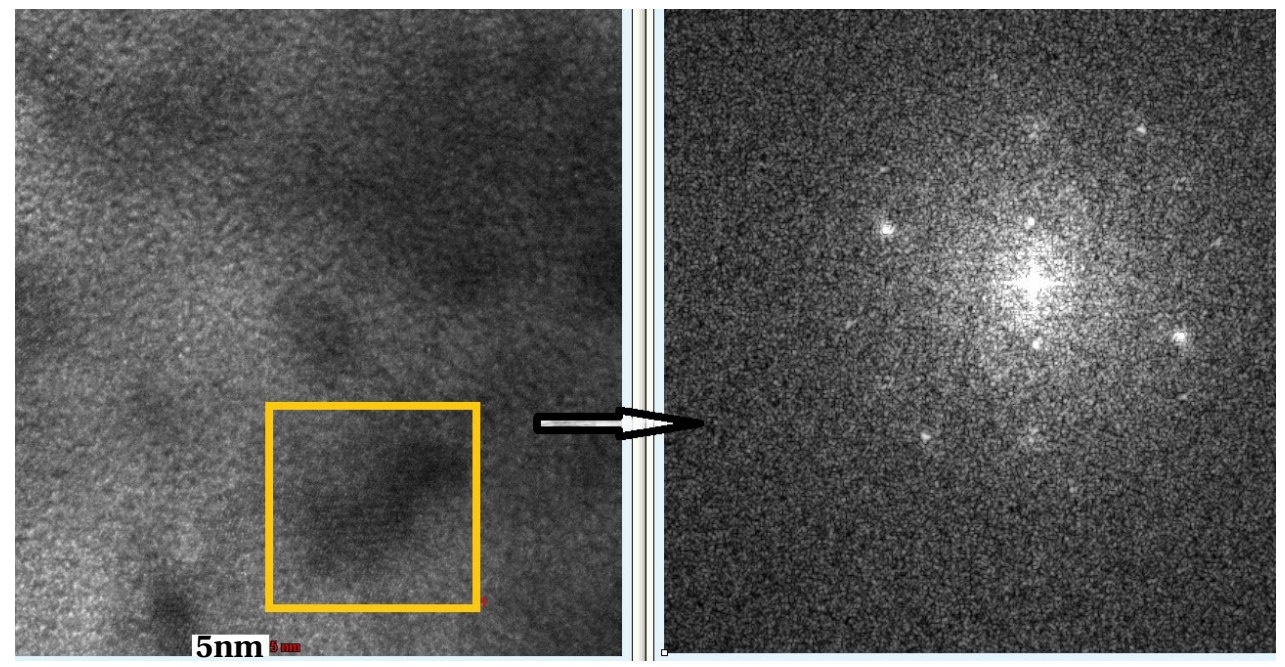

Figura 5.19: Izquierda: Imágen de alta resolución TEM (Y-Tec) de un área seleccionada (amarillo) de la partícula de la figura 5.18. La FFT calculada sobre este área nanométrica se muestra a la derecha.

\section{Mapeos elementales y análisis semi-cuantitativo. Dispersión de fases}

Se realizaron numerosos mapas composicionales (mapeos elementales) y a distintas escalas $^{9}$, así como los respectivos análisis cuantitativos (EDAX). En esta sección se muestran imágenes representativas (otras se muestran en el Apéndice D). Los mapas composicionales, muestran cualitativamente una distribución homogénea de los elementos presentes (Mg,Ti) observando tanto a baja (figura 5.20), como a media magnificación (figura 5.21). En dicha figura el mapeo se realizó como lo indica la figura, en una partícula de tamaño típico como las observadas por TEM. Esto revela que las muestras preparadas conforman un sistema heterogéneo de fases finamente disperso a escalas micrométricas. En las figuras mencionadas se reportan también los análisis cuantitativos correspondientes a los mapeos. Se hace notar que la relación $M g: T i$ se mantiene fiel a la proporción de partida para la fabricación $M g$ : $T i$ : $80: 20$. Estos son algunos de los numerosos análisis semicuantitativos realizados y en todos los casos se mantuvo la composición de partida (dentro de la precisión indicada del instrumento $\sim 1-10 \%$ ). Por otro lado, los espectros EDAX siempre revelaron la presencia de $\mathrm{O}$ formando la fase $\mathrm{MgO}$ minoritaria, habitualmente distribuida en las superficies de los conglomerados y partículas. Se muestran algunos mapeos y reportes EDAX adicionales en

\footnotetext{
${ }^{9} \mathrm{~A}$ baja y media con SEM y a alta con TEM.
} 

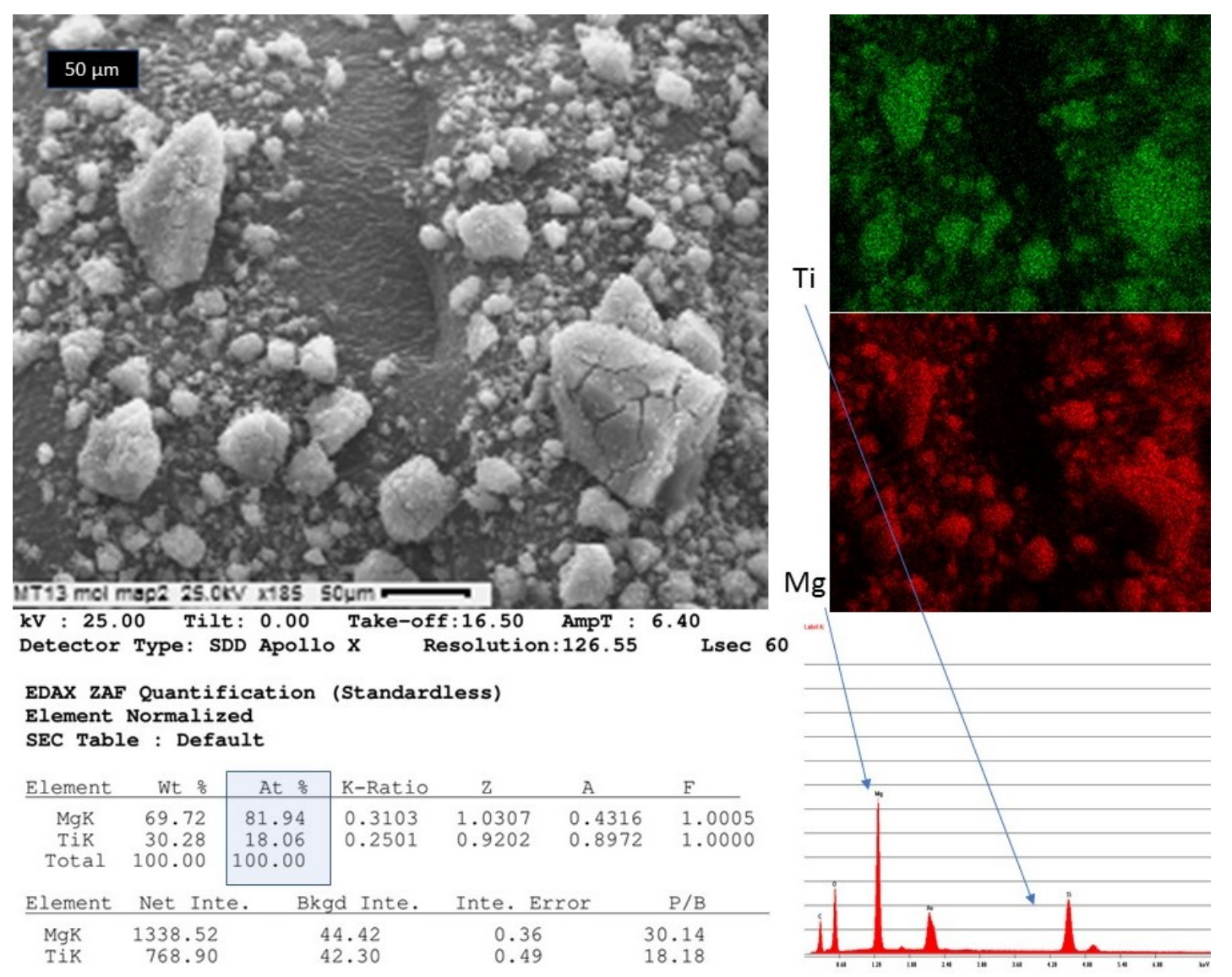

Figura 5.20: Mapping elemental de baja magnificación y análisis por EDAX. Obtenida mediante SEM sobre una muestra molida fresca Mg:Ti:80:20 (vía A).

el Apéndice D. Los mapeos elementales de alta magnificación se obtuvieron por TEM para muestras con y sin grafito. Estos se presentan en las figuras 5.22a y 5.22b. En esta escala de observación ya es posible la distinción espacial de las fases. Se muestran representaciones elementales de las regiones correspondientes a cada elemento identificado. Se cuenta así con información nanométrica sobre la manera en que el $\mathrm{TiH}_{2}$ está disperso en la matriz de $\mathrm{MgH}_{2}$. Se puede observar que la dispersión de la fase $\mathrm{TiH}_{2}$ se manifiesta más definidamente en la muestra con grafito que en la muestra sin grafito. 


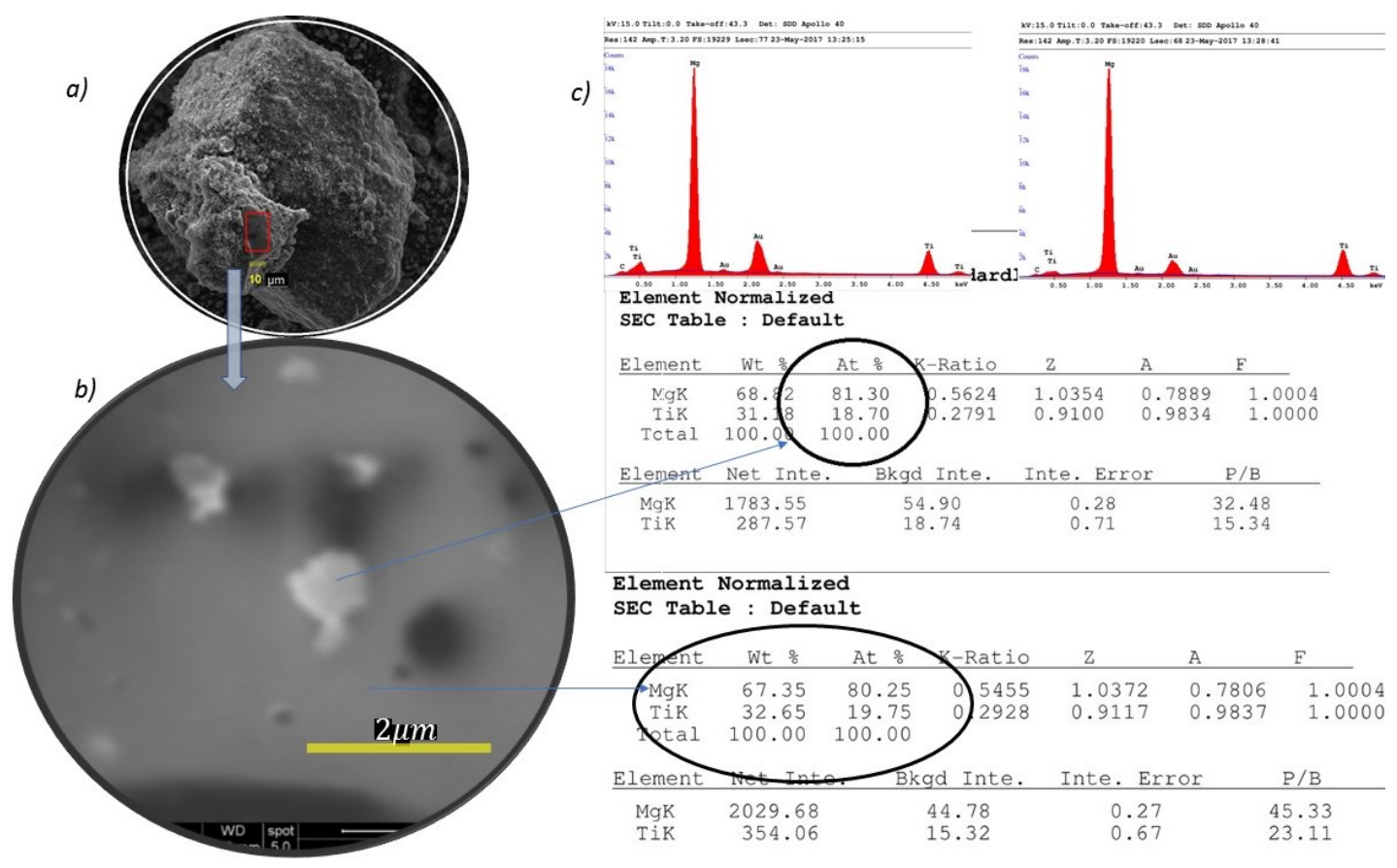

Figura 5.21: Análisis EDAX realizado mediante SEM con la mayor magnificación posible, 50.000×. En esa escala la dispersión de Ti y Mg sigue siendo fina.

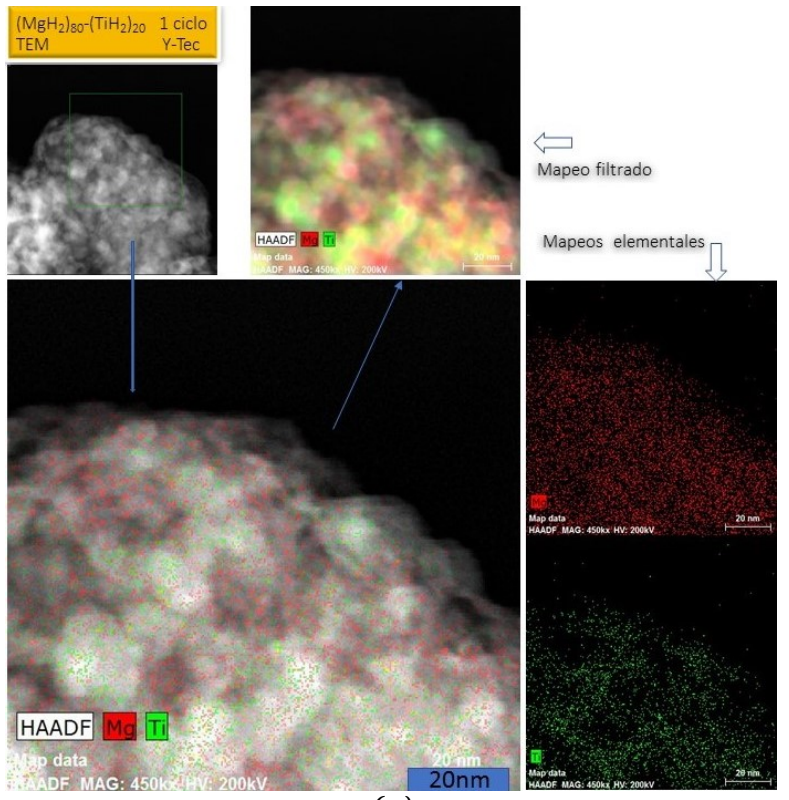

(a)

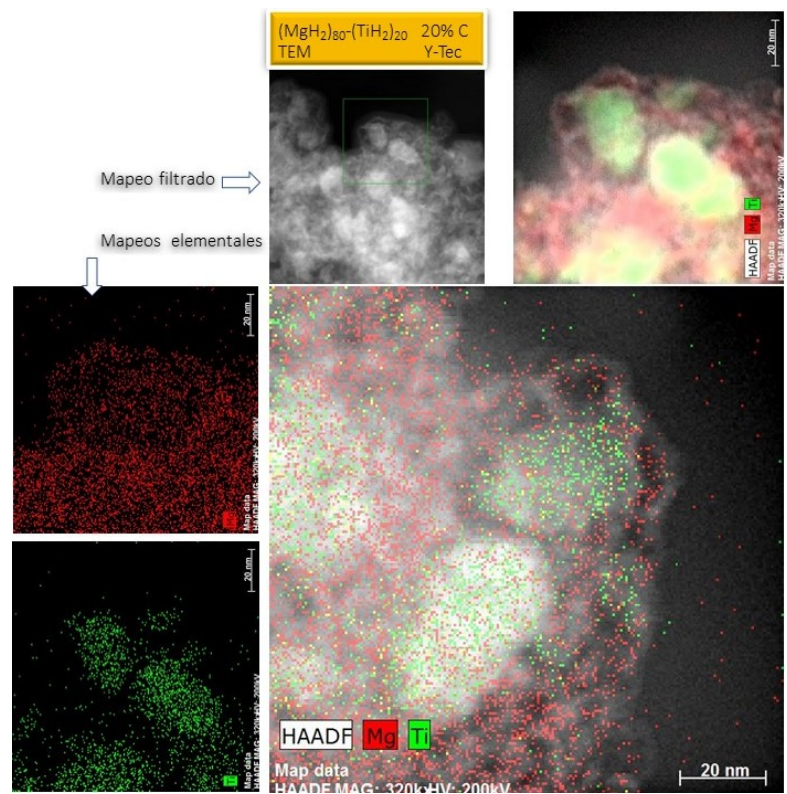

(b)

Figura 5.22: Mapeo elemental obtenido mediante TEM para una muestra Mg:Ti:80:20, sin grafito, habiendo sido sometida a 1 ciclo de absorción/desorción de hidrógeno. En rojo se aprecia al Mg y en verde al Ti. En esta escala recién pudo apreciarse la segregación de fases asociadas a estos elementos. 


\subsubsection{Vías de fabricación}

En esta sección se presentan las fotografías de mayor magnificación obtenidas mediante microscopía SEM para muestras de proporción $M g: T i: 80: 20$ fabricadas mediante las vías A, B, C y D. Las imágenes de baja magnificación de estos sistemas (ver Apéndice D) presentan comparativamente en esa escala de observación características estructurales-morfológicas semejantes y comparables, como fueron descritas en las sección 5.3.1.

\section{Sistema MgTi $H_{2}$ preparado por la vía $B$}

Las muestras fabricadas por la vía B observada a media magnificación (SEM) revela también algunas características similares a las observadas en sistemas fabricados por la vía directa $(A)$. Por ejemplo, la figura 5.23 corresponde a una fotografía de una muestra preparada por la vía $B$ tomada sobre una región compacta de un conglomerado principal. Se observan también para esta ruta de fabricación partículas y conglomerados menores tipo racimo depositados sobre la superficie de partículas grandes. Además, puede observarse en esta escala un grado de agrietamiento que aún puede apreciarse mejor con fotografías de alta magnificación sobre la misma zona (figura $5.24 B$ ). Esto indica que las muestras preparadas por la via $B$ presentan también la constitución de un agrietamiento a escalas nanométricas. Este tipo de características estructurales ya se habían observado en muestras preparadas por la vía $A$ (ver por ejemplo la figura 5.9a). Se adjunta a la figura 5.23 un análisis por EDAX realizado sobre las zonas indicadas en rojo (E). El mismo revela que en esa escala se mantiene la proporción nominal Mg:Ti similar a la de fabricación, es decir 80:20.

Las fotografías $a$ ) y $b$ ) de la figura 5.24 revelan

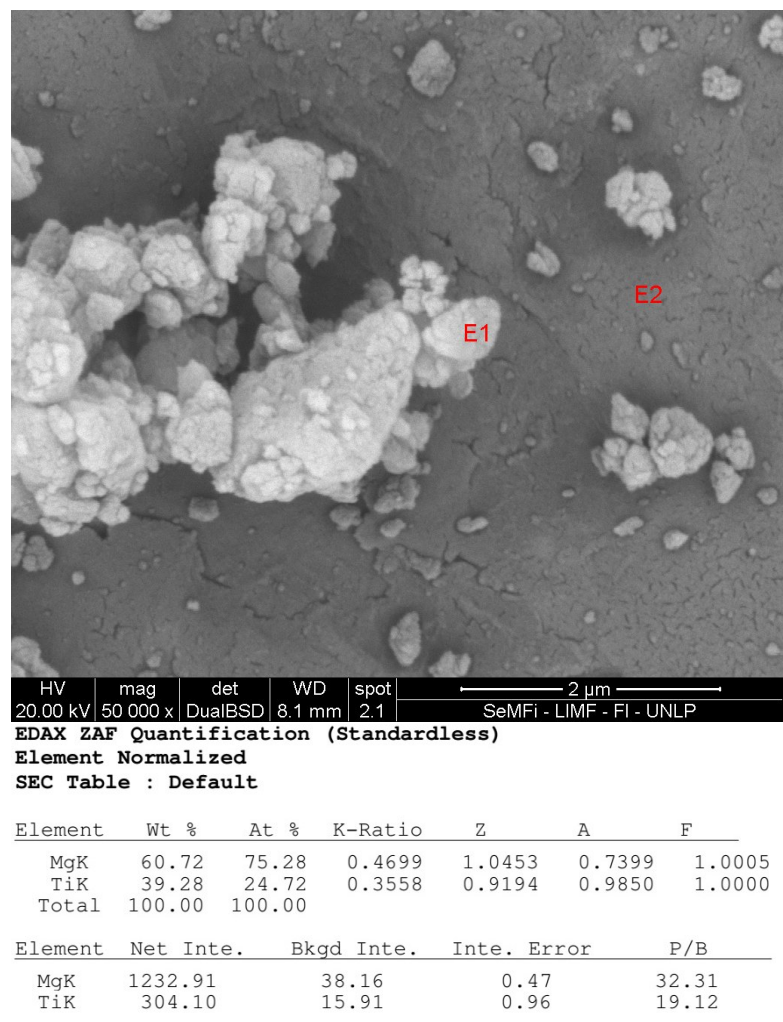

Figura 5.23: Imagen a media magnificación obtenida por SEM. Corresponde a una muestra fabricada por la vía B. Se realizaron análisis Edax en distintos tipos de regiones (E1,E2) resultando composiciones similares a la de partida Mg:Ti: 80:20. En el reporte se indica solo uno de los valores siendo el otro muy similar. que el el grado de agrietamiento luce diferente para las vías de fabricación A y B. Esto podría estar asociado a diferencias en el proceso de crecimiento de grano, así como en la disponibilidad de superficies frescas y de bordes de grano como regiones de ingreso/egreso del hidrógeno. 


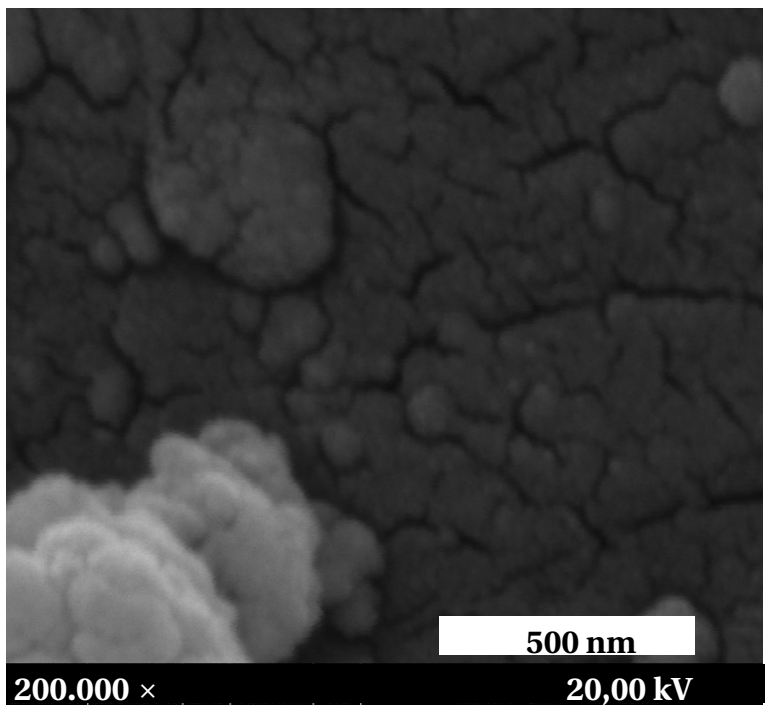

a)

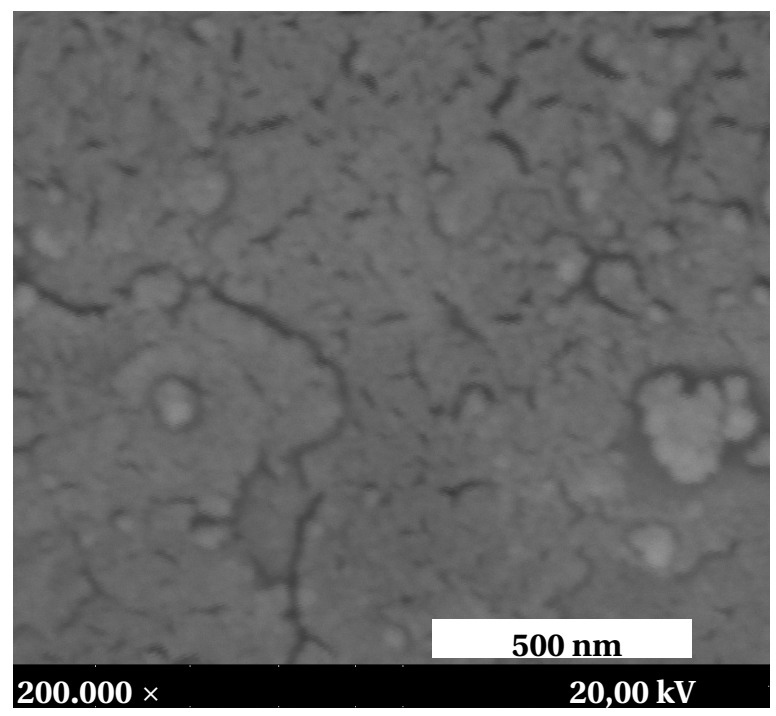

b)

Figura 5.24: Comparación de imágenes SEM a alta magnificación. Muestras preparadas por las vías A ( $a$ ) y B (b). Se observa que este tipo nanoestructuras tipo agrietamiento (nanogrietas) se presentan en ambas rutas pero con posibles diferencias respecto al tamaño y distribución de las grietas.

\section{Sistema MgTi-deuterado preparado a alta presión}

En las figuras 5.25 y 5.26 se muestran imágenes a distinta magnificación comparando características estructurales típicas identificadas en las muestras preparadas por la vías $A$ y $D$. Las muestras presentadas en estas fotografías fueron previamente sometidas a ciclos de absorción y desorción de hidrógeno.

En la figura 5.25 se muestran imágenes de la muestra MTD2 con magnificación creciente $a \rightarrow b \rightarrow d$, de una región de estructura compacta y agrietada (microgrietas) al ser observada a baja magnificación (a). Este tipo de estructura se había identificado para las muestras fabricadas por la vía A y se muestra comparativamente en la misma figura $5.25 c$ a magnificaciones crecientes como indican las flechas azules.

Similarmente, en la figura 5.26 se muestran imágenes de la muestra MTD2 con magnificación creciente $a \rightarrow b \rightarrow d$, de una región de estructura compacta al ser observada a baja magnificación $(a)$. Este tipo de estructura también se había mostrado para las muestras fabricadas por la vía A que se muestran comparativamente en la misma figura $5.25 c$ a distintas magnificaciones.

\section{Sistema MgTi $H_{2}$ preparado por la vía $G$}

Finalmente en la figura 5.27 se muestran fotografías a baja y alta magnificación obtenidas para la muestra CMT14 con $20 \%$ at . de grafito. Los conglomerados principales obtenidos mediante esta vía (G) presentaban una tendencia a aglutinar sobre sus superficies mayor cantidad de conglomerados menores. Además en la imagen de alta magnificación se observa la regularidad y la suavidad de las partículas más pequeñas, pudiéndose notarse las subpartículas que lo conforman, probablemente cristales. 


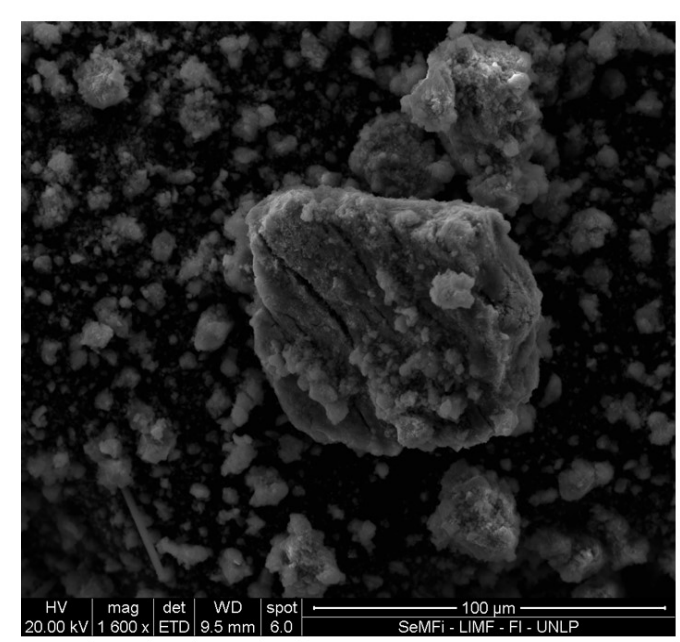

a)
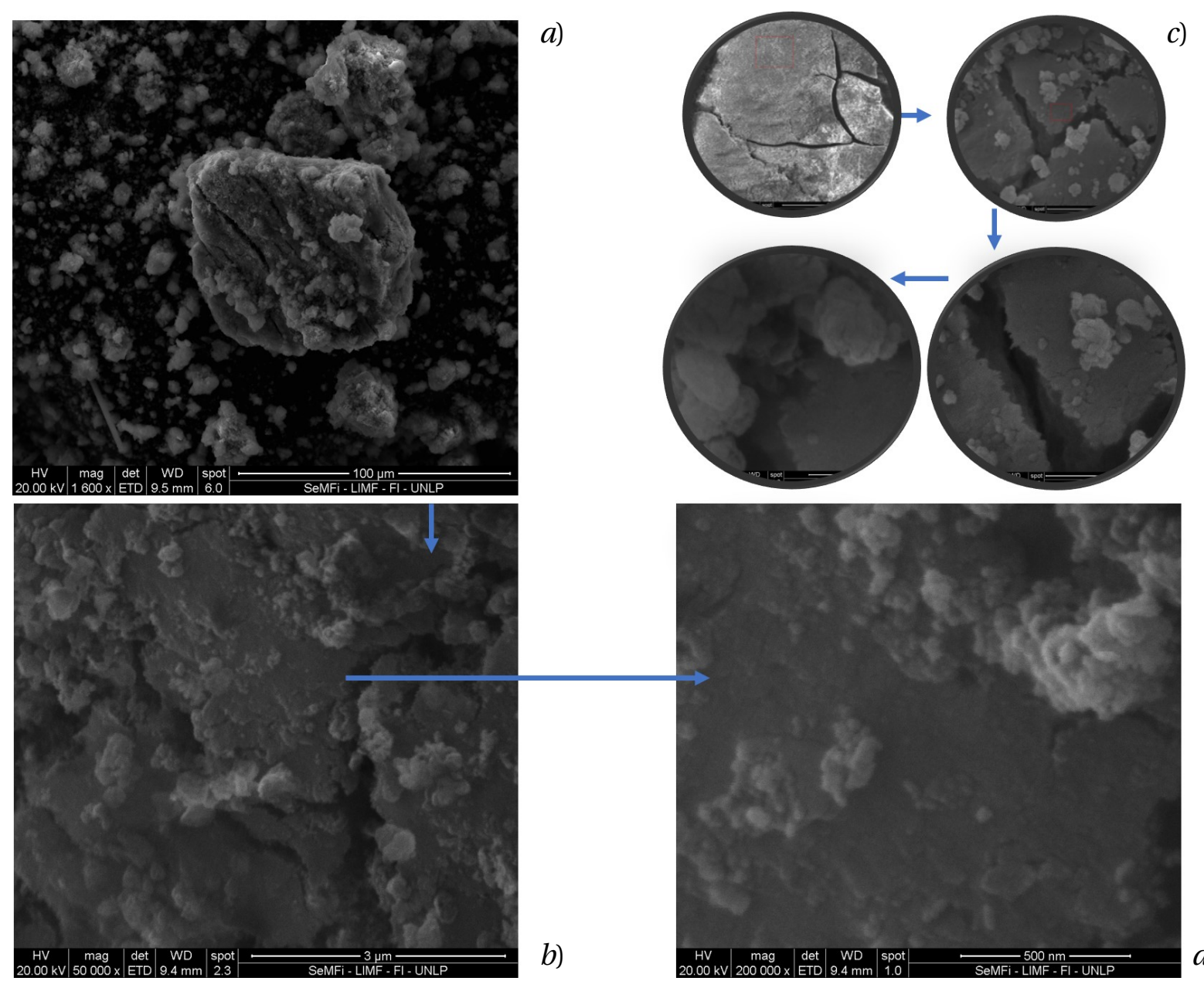

d)

Figura 5.25: Comparación de imágenes SEM de estructuras agrietadas. Comparación de fotografías a distinta magnificación sobre una región típica compacta con microgrietas al ser observada a baja magnificación $a$. Corresponden a muestras fabricadas por las vías A $(c)$ y $\mathrm{D}(a, b, d)$. 


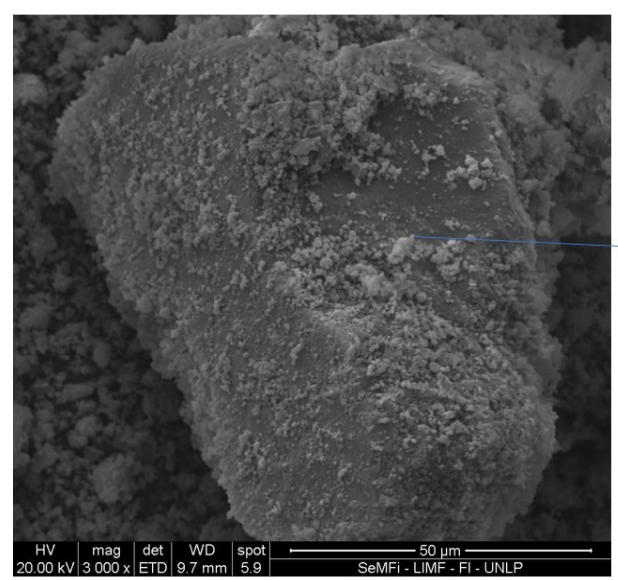

\section{a)}

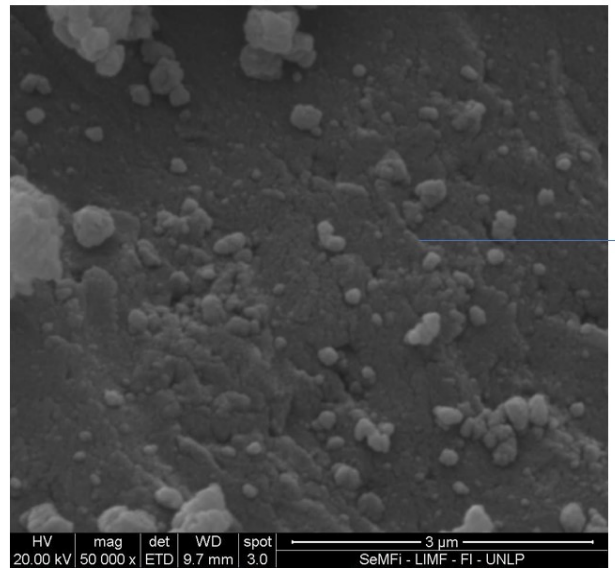

b)
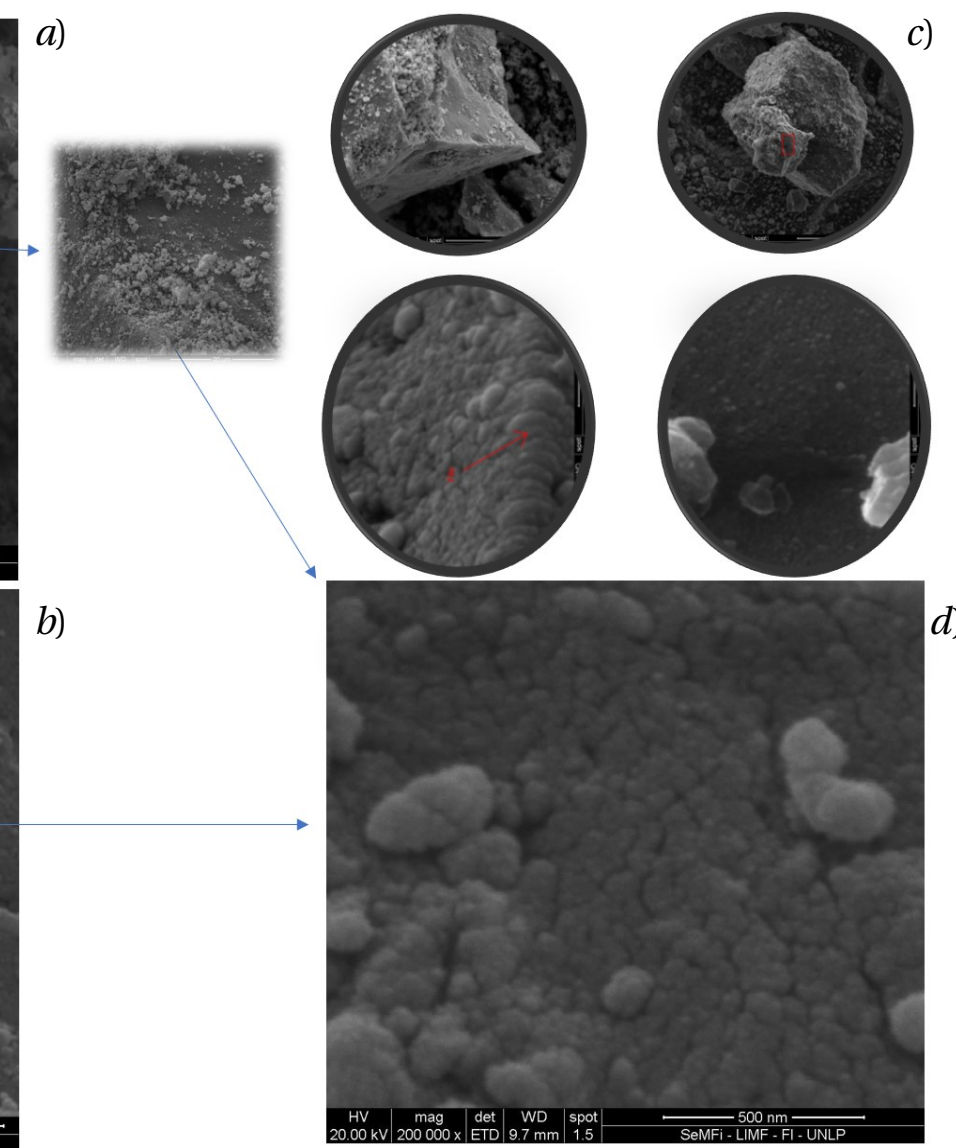

Figura 5.26: Comparación de imágenes SEM obtenidas a distinta magnificación sobre una regiones típicas en apariencia compacta a baja magnificación. Corresponden a muestras fabricadas por las vías A (c) y D $(a, b, d)$. 


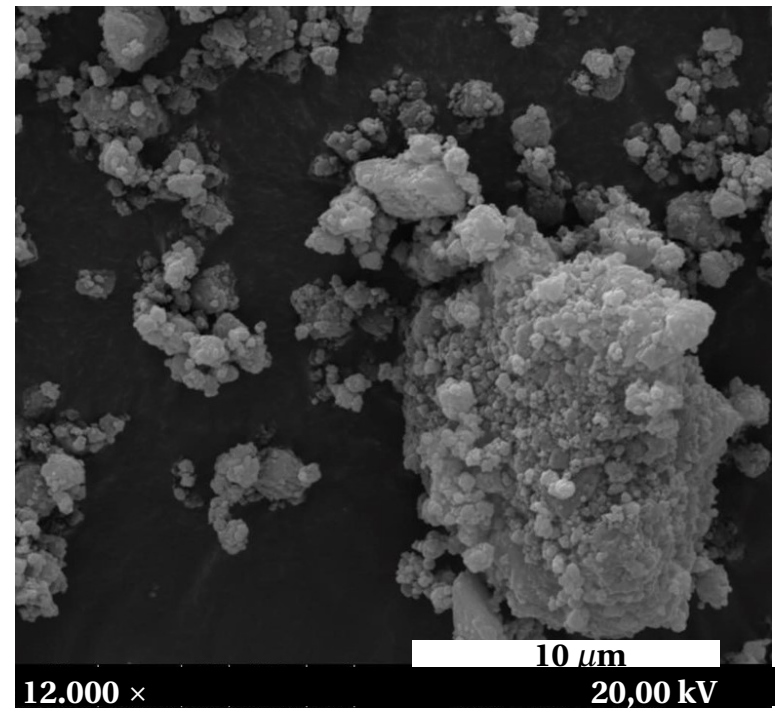

a)

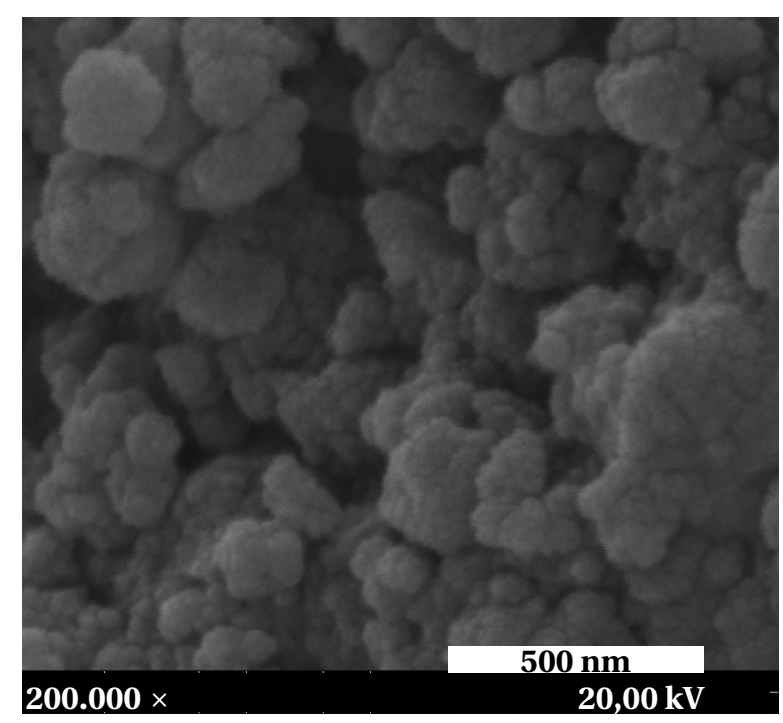

b)

Figura 5.27: Imágenes SEM a baja y alta magnificación tomadas sobre una muestra preparadas por la vía G con $20 \%$ at. de grafito.

\subsubsection{Muestras frescas y tratadas}
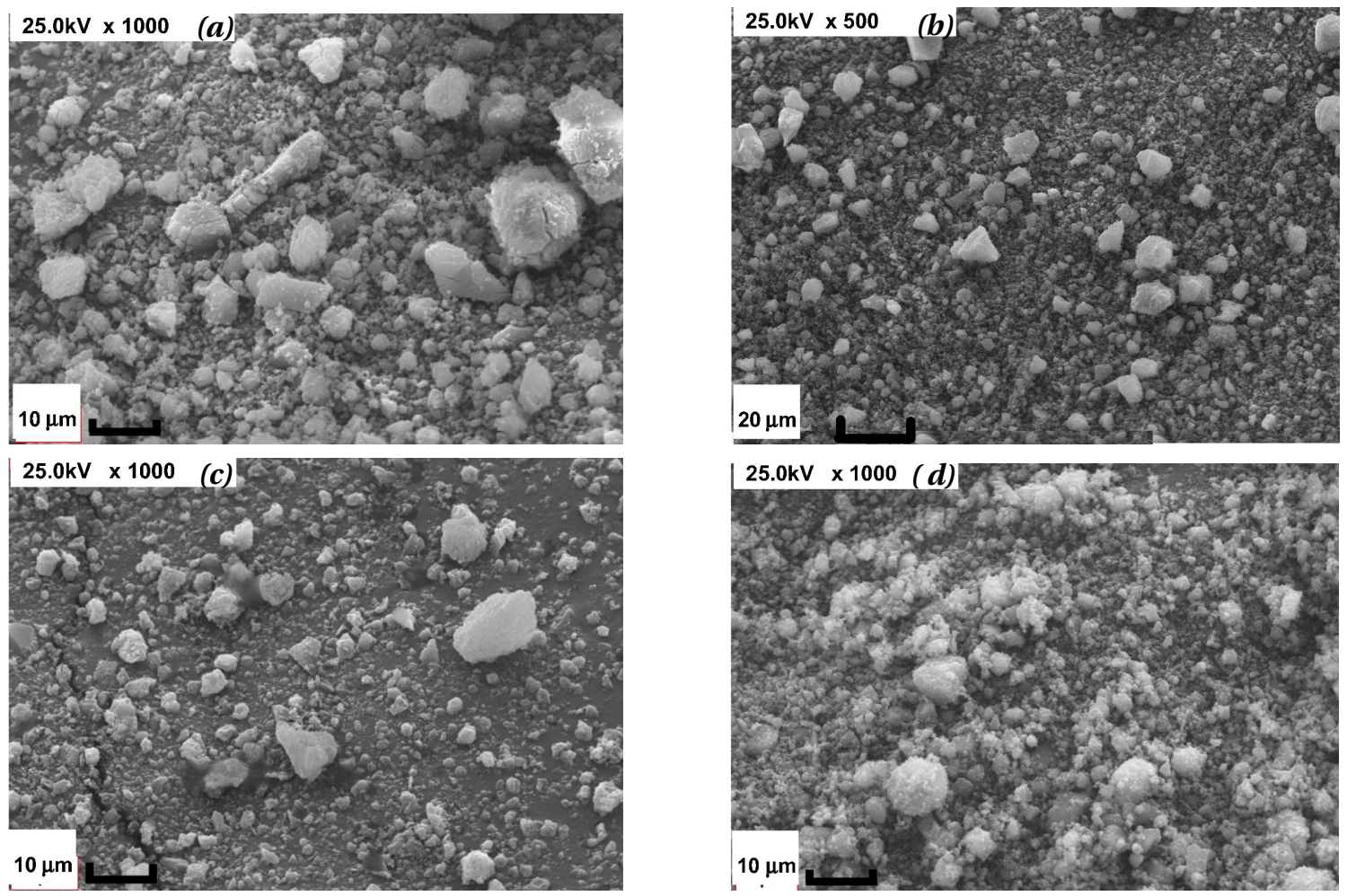

Figura 5.28: Imágenes SEM comparando muestras fabricados por distintas vías, A $(a, c)$ y B $(b, d)$. Se comparan a la vez las muestras frescas (arriba) y tratadas (abajo) para cada ruta de fabricación. 
En la figura 5.28 se muestran imágenes de muestras frescas y muestras tratadas térmicamente correspondientes a las vías A y B. No se aprecian diferencias evidentes en la conformación de aglomerados y tamaños de partícula. Lo mismo ocurría al comparar muestras fabricadas por vía A con la vía G. 


\section{Capítulo 6}

\section{Resultados Parte I: Cinéticas de formación}

Este capítulo tiene por objeto:

Presentar los resultados de las curvas cinéticas de formación de los hidruros. Se presentarán comparativamente de acuerdo a las composiciones Mg:Ti ensayadas y a las vías de fabricación A, B, D y G. Se mostrarán así los tiempos típicos de formación, lo que resulta de interés para la fabricación de un potencial reservorio.

Caracterizar y modelar las curvas cinéticas. Se presentará aquí el análisis de las cinéticas de formación, focalizado en la composición Mg:Ti:80:20. Se mostrará que las mismas responden a un modelo logístico y que es posible describir la formación de cada fase mediante una componente de ajuste asociada a la misma (Biasetti, Meyer y Mendoza Zélis, [95]).

Ilustrar la reproduciblidad de las cinéticas propias del método de fabricación utilizado. De esta manera los parámetros ajustados adquieren valor empírico para caracterizar la formación de estos sistemas.

Las cinéticas de formación fueron obtenidas mediante el procedimiento descrito en el Capítulo 3. Dada la gran cantidad de moliendas realizadas (tablas 3.1 y 3.2), se mostrarán los resultados más representativos agregando en el Apéndice B resultados complementarios para consulta.

\subsection{Cinéticas de formación de los hidruros}

\subsubsection{Sistemas $M g_{x} T i_{1-x}$}

El monitoreo del consumo de hidrógeno durante las moliendas permitió controlar el estado de carga de H logrado, verificando una formación de hidruros completa dentro de las expectativas estequiométricas, esto se corresponde con las reacciones:

$$
\begin{gathered}
\mathrm{Mg}+\mathrm{H}_{2} \rightarrow \mathrm{MgH}_{\simeq 2} \\
\mathrm{Ti}+\mathrm{H}_{2} \rightarrow \mathrm{Ti} H_{\sim 1.9}
\end{gathered}
$$




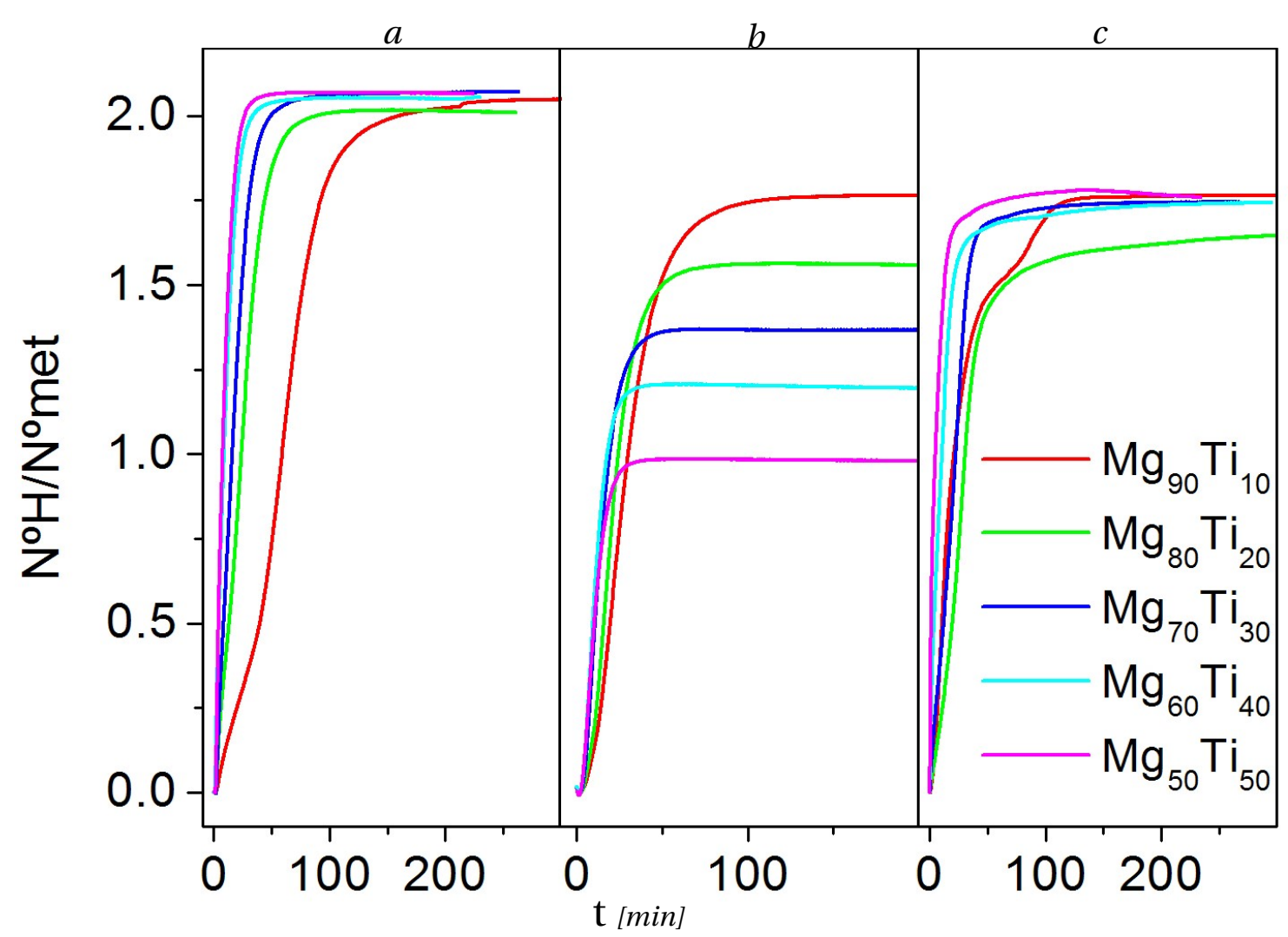

Figura 6.1: Curvas cinéticas de formación de los composites hidrogenados preparados por molienda reactiva (molino vibratorio) de acuerdo las vías A (figura $a$ ), vía B (figura $b$ ) y vía C (figura $c$ ).

En la figura 6.1 se muestran algunas de las cinéticas de formación de nanocomposites Mg:Ti obtenidos mediante las rutas de fabricación A, B y C. Las curvas representan el grado de transformación relativo en función del tiempo, es decir muestran el $\mathrm{n}^{\circ}$ de moles de $\mathrm{H}$ consumidos a tiempo $t$ relativos al $\mathrm{n}^{\circ}$ de moles de especies metálicas reactivas $N_{H} / N_{M}$. Es por esto que las curvas de la figura no saturan todas a la relación estequiométrica final del composite formado. En el caso de la vía $B$ (figura 6.1b) se normaliza al número total de átomos metálicos $(\mathrm{Mg}+\mathrm{Ti})^{1}$, de manera que se comprende porqué las curvas con menor proporción de Mg saturan a un valor menor.

Por otro lado, en cada serie de curvas de la figura 6.1, queda evidenciada la dependencia de las curvas cinéticas con la proporción atómica Mg:Ti. Se puede ver claramente como el aumento relativo de Ti reduce los tiempos de formación de los productos finales.

Al variar Mg:Ti de 50:50 a 90:10 las cinéticas correspondientes a la vía B saturan aproximadamente a los valores respectivos $\sim 2 x$. Esto se corresponde con la formación del hidruro $\mathrm{Mg} \mathrm{H}$ ${ }^{2}$. En las figuras $6.1 a$ y $6.1 b$, se puede percibir cualitativamente que las curvas de las vías $A$ y $B$ tienen un perfil distinto desde el inicio de la transformación. Esto responde al hecho de que

${ }^{1}$ Como el $\mathrm{TiH}_{2}$ ya fue formado previamente en esta ruta de fabricación, las curvas saturan a un valor menor a 2. Si se normalizaran solo al $n^{\circ}$ total de moles de especies reactivas $(\mathrm{Mg})$, saturarían cerca del valor $\sim 2$ como en la figura 6.1 $a$.

${ }^{2}$ En ese caso $N_{H}=2 . N_{M g}$, por lo tanto $\frac{N_{H}}{N_{M}}=\frac{N_{H}}{N_{M g}+N_{T i}}=\frac{2 \cdot N_{M g}}{74}=\frac{2 \cdot N_{M g}}{N_{M g}+N_{T i}}=2 . x$. 
en un caso deben formarse dos fases $\left(\mathrm{Mg} \mathrm{H}_{2}\right.$ y $\mathrm{Ti} \mathrm{H}_{2}$, vía A), mientras que en el otro caso (vía B) solo ocurre la formación de $\mathrm{MgH}_{2}$ catalizada por la fase preexistente $\mathrm{TiH}_{2}$. Finalmente, comparando las cinéticas por vías de fabricación, se observa que la vía C (figura $c$ ) presenta cinéticas incompletas en relación a la estequiometría esperada para la capacidad óptima $\left(N_{H} / N_{M}=2\right)$. Esto mostró que la vía C de fabricación resultaba ineficiente para obtener materiales hidrurados con óptima capacidad de almacenamiento. Más aún, las cinéticas de absorción y desorción de hidrógeno a las que fueron sometidas las muestras fabricadas por esa vía, no revelaron mejoras en la cinética.

En la próxima sección se compararán las velocidades de formación $\frac{d \alpha}{d t}$ a fin de caracterizar las cinéticas de cada una de las fases principales.

\section{Velocidad de transformación y ajustes}

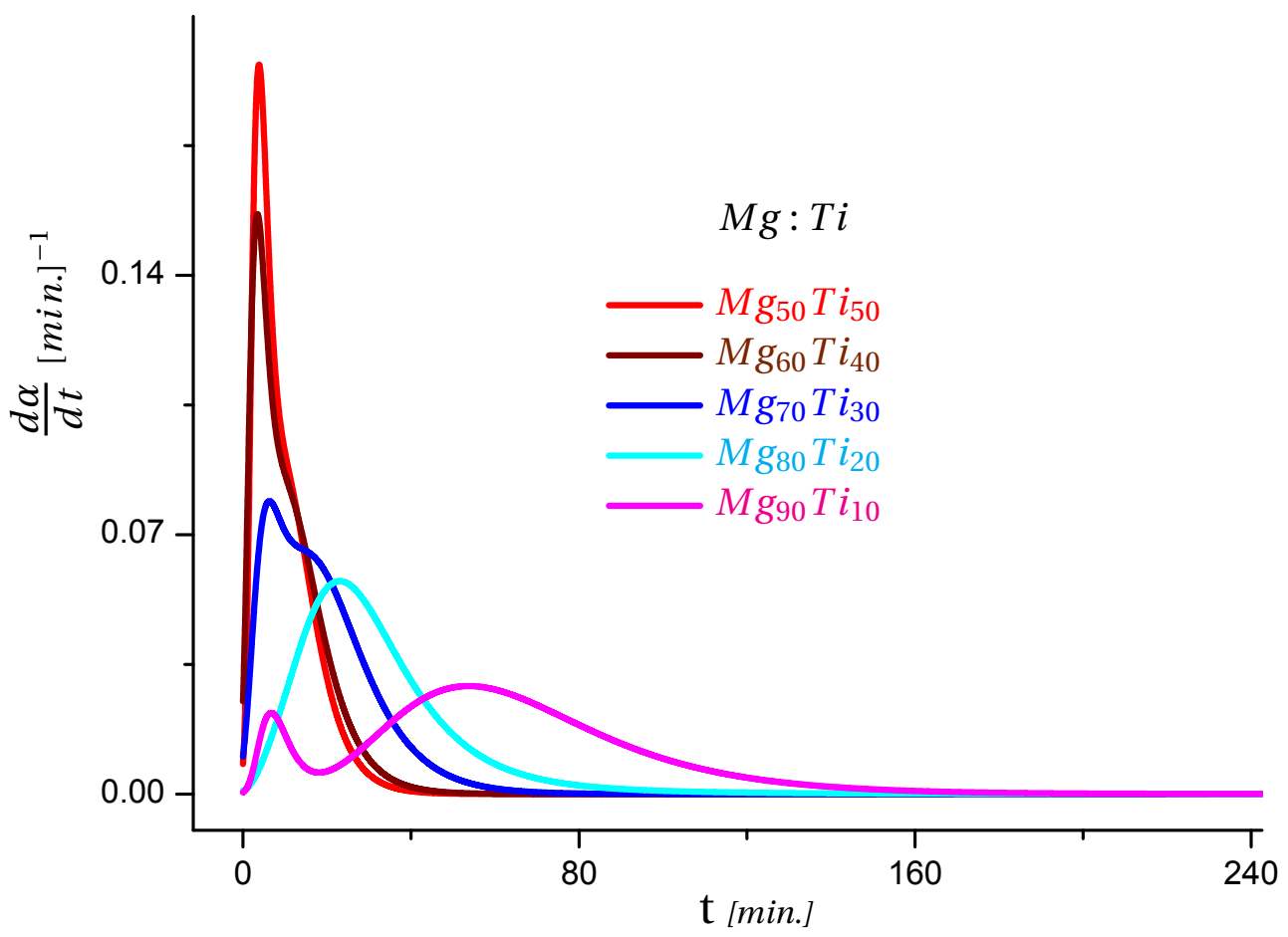

Figura 6.2: Velocidades de transformación en función del tiempo correspondientes a las curvas cinéticas de formación de los composites Mg-Ti preparados mediante la vía A.

A fin de comprender mejor el proceso de transformación durante la formación de los hidruros, se calcularon las derivadas de las curvas cinéticas de formación ${ }^{3}$. Estas son ilustradas en la figura 6.2, que corresponden a las muestras obtenidas por la ruta $A^{4}$. Las curvas

${ }^{3}$ La densidad de puntos y la buena relación señal/ruido permiten obtener curvas derivadas satisfactorias para el análisis.

${ }^{4}$ Se muestra en la figura B.3a del Apéndice B la derivada de la cinética de formación para una muestra fabricada por la ruta B de proporción Mg:Ti:80:20. 
derivadas presentan en general dos máximos más o menos distinguibles lo que indica la existencia de dos etapas principales en la formación de las fases. La primera se asocia con la formación de la fase $\mathrm{Ti} \mathrm{H}_{2}$ debido a la menor entalpía de formación en relación al $\mathrm{Mg} \mathrm{H}$, cuya formación se asocia entonces a la segunda etapa (segundo pico). Se observa que en las muestras de composición 80:20 no se pueden resolver los picos respectivos

Las curvas cinéticas de formación son de tipo sigmoidal. Este comportamiento, se da como consecuencia del agotamiento de reactivos que influye en desacelerar la transformación. La ecuación diferencial de la tasa instantánea de transformación $d \alpha / \alpha$ es entonces función del tiempo y puede ser descrita por la siguiente ecuación diferencial:

$$
\frac{d \alpha}{\alpha}=k(t) . d t
$$

siendo $k(t)$ la tasa instantánea de crecimiento relativa al número de átomos capaces de absorber hidrógeno en el sistema. La transformación de fase (hidruración) implica una disminución del número de átomos metálicos reactivos. Además, $k(t)$ debe anularse para tiempos largos hacia el fin de la transformación. Modelos típicos de tasas de crecimiento de tipo $k(t)=a t^{n}$ no ajustaban satisfactoriamente los datos experimentales. Los mejores ajustes se obtuvieron asumiendo un decrecimiento exponencial para la tasa instantánea $k(t)$. Para esta propuesta, la solución general de la ecuación logística 6.1 es la función de Gompertz:

$$
\alpha(t)=a \cdot e^{-e^{-k(t-\tau)}}
$$

A fin de modelar las dos etapas de transformación observadas en el caso de la ruta A, y asumiendo la independencia de las etapas de formación, se adoptó una forma funcional de dos componentes aditivas identificando cada etapa con una componente:

$$
\alpha(t)=a_{1} \cdot e^{-e^{-k_{1}\left(t-\tau_{1}\right)}}+a_{2} \cdot e^{-e^{-k_{2}\left(t-\tau_{2}\right)}}
$$

Para los ajustes se tuvieron en cuenta las condiciones estequiométricas mencionadas:

$$
a_{1}+a_{2}=N_{\max }
$$

siendo $N_{\max }$ el máximo valor de átomos de hidrógeno relativo al número de átomos metálicos (obtenido experimentalmente), y los valores asintóticos de las componentes $\left(a_{1} \mathrm{y} a_{2}\right) \mathrm{de}$ acuerdo a las fracciones de hidruro que representan en el producto final:

$$
a_{1}=2 x
$$

En el caso de la ruta $B$ una sola componente debe ser suficiente para lograr un buen ajuste dado que el $\mathrm{TiH}_{2}$ ya está previamente formado y no sufre transformaciones de fase durante la molienda. Los ajustes correspondientes a las cinéticas de formación mediante la vía A se muestran en la figura 6.3. Los tiempos asociados a la máxima velocidad del proceso $\frac{d \alpha_{i}}{d t}{ }_{\text {máx. }}=a_{i} . k_{i} / e$ se corresponden con los parámetros $\tau_{i}$ y permiten una primera caracterización de la cinética. Los valores de $\tau_{i}$ asociados a cada componente, así como los demás 
parámetros de ajuste, se reportan en la tabla 6.1 (en el apéndice se muestran gráficos con ajustes de otras series de cinéticas incluyendo también muestras fabricadas por la vía B, figuras B.1 y B.2 y los parámetros respectivos, tabla B.1). De esa manera se muestra cuantitativamente una notable reducción de los tiempos característicos con el incremento de la proporción de Ti.

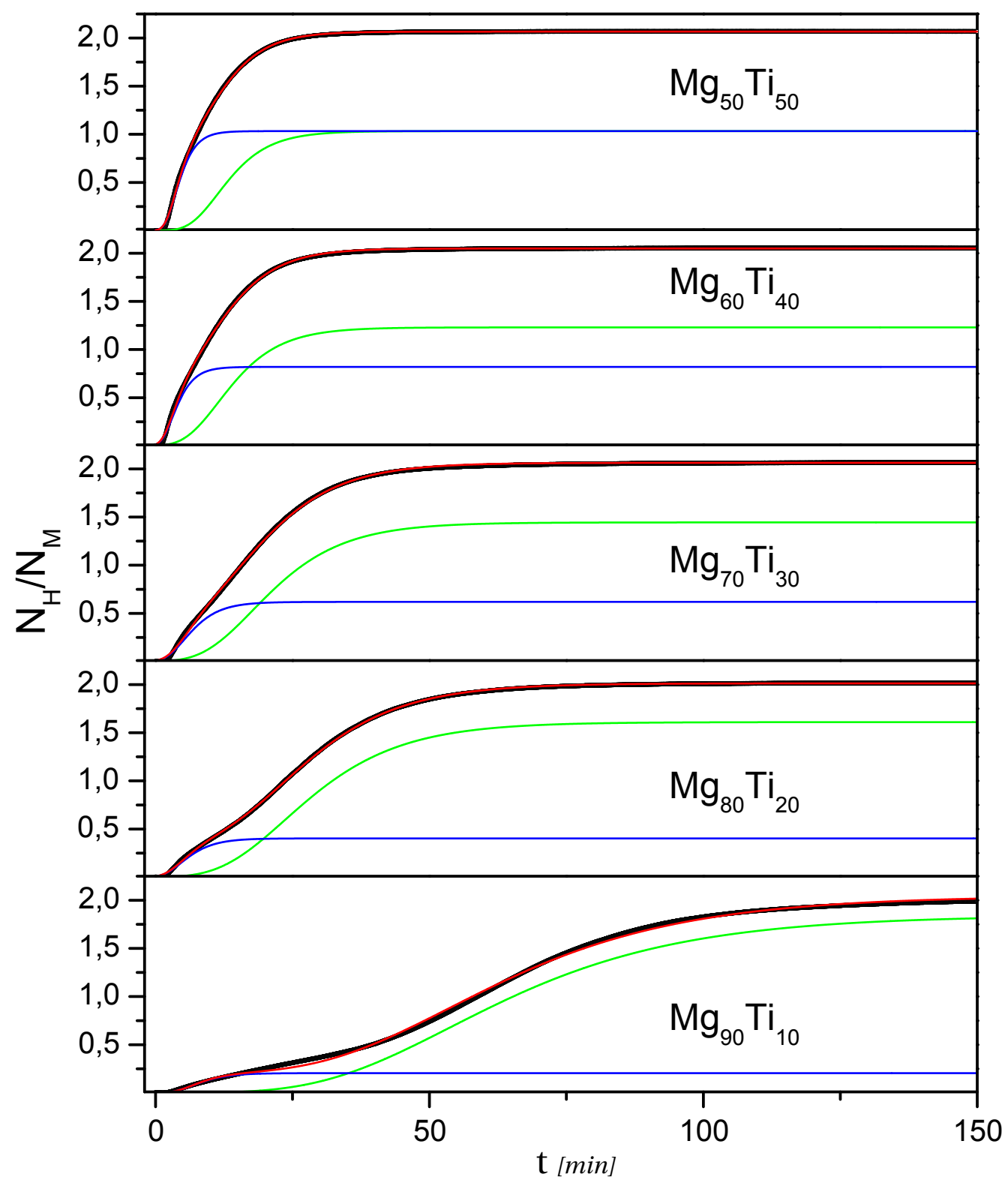

Figura 6.3: Componentes de las cinéticas de formación, vía A. Las figuras muestran las componentes de ajuste de acuerdo a las ecuación 6.1.1. La línea roja corresponde al ajuste (suma de componentes) y la línea negra la curva experimental. 


\begin{tabular}{|c|c|c|c|}
\hline \multicolumn{4}{|c|}{ Parámetros ajustados para las curvas cinéticas } \\
\hline \multirow{3}{*}{$\begin{array}{c}\text { Mg:Ti } \\
\qquad \\
\quad \\
90: 10\end{array}$} & \multicolumn{3}{|c|}{ [parámetros de ajuste] $\left[k_{i}\right]=\frac{1}{\min } ;\left[\tau_{i}\right]=\min$} \\
\hline & \multicolumn{2}{|c|}{ ruta $\mathrm{A}$} & \multirow{2}{*}{$\begin{array}{l}\text { ruta B } \\
a_{1}: 1,5789(6)\end{array}$} \\
\hline & $a_{1}: 1,84$ & $a_{2}: 0,20$ & \\
\hline & $k_{1}: 0,0426(2)$ & $k_{2}: 0,13(2)$ & $k_{1}: 0,0721(2)$ \\
\hline & $\tau_{1}: 53,9(1)$ & $\tau_{2}: 4,9(6)$ & $\tau_{1}: 22,65(4)$ \\
\hline \multirow[t]{3}{*}{$80: 20$} & $a_{1}: 1,6$ & $a_{2}: 0,4$ & $a_{1}: 1,560(3)$ \\
\hline & $k_{1}: 0,0933(2)$ & $k_{2}: 0,426(1)$ & $k_{1}: 0,1060(2)$ \\
\hline & $\tau_{1}: 23,58(2)$ & $\tau_{2}: 4,63(2)$ & $\tau_{1}: 16,97(2)$ \\
\hline \multirow[t]{3}{*}{$70: 30$} & $a_{1}: 1,44$ & $a_{2}: 0,6$ & $a_{1}: 1,3665(4)$ \\
\hline & $k_{1}: 0,195(6)$ & $k_{2}: 0,286(6)$ & $k_{1}: 0,1470(6)$ \\
\hline & $\tau_{1}: 17,75(5)$ & $\tau_{2}: 5,25(5)$ & $\tau_{1}: 11,10(2)$ \\
\hline \multirow[t]{3}{*}{$60: 40$} & $a_{1}: 1,23$ & $a_{2}: 0,8$ & $a_{1}: 1,2001(2)$ \\
\hline & $k_{1}: 0,162(1)$ & $k_{2}: 0,461(7)$ & $k_{1}: 0,1986(7)$ \\
\hline & $\tau_{1}: 11,47(4)$ & $\tau_{2}: 3,14(2)$ & $\tau_{1}: 11,10(2)$ \\
\hline \multirow[t]{3}{*}{$50: 50$} & $a_{1}: 1,033$ & $a_{2}: 1,033$ & $a_{1}: 0,9821(2)$ \\
\hline & $k_{1}: 0,193(1)$ & $k_{2}: 0,489(5)$ & $k_{1}: 0,2025(7)$ \\
\hline & $\tau_{1}: 11,34(3)$ & $\tau_{2}: 3,64(1)$ & $\tau_{1}: 8,43(1)$ \\
\hline
\end{tabular}

Tabla 6.1: Se presentan en esta tabla los parámetros ajustados de la(s) componente(s) de Gompertz para dos series de cinéticas (vías A y B).

\section{Repetitividad de las cinéticas}

La realización de un gran número de moliendas permitió verificar la notable repetitividad del método de fabricación. Particularmente se muestran en la figura 6.4 las cinéticas de formación de composites $\left(\mathrm{Mg} \mathrm{H}_{2}\right)_{0.8}-\left(\mathrm{TiH}_{2}\right)_{0.2}$ fabricados por las vías A (figura 6.4a) y B ( figura 6.4b) . Se prepararon en distintos momentos del desarrollo de la Tesis y en iguales condiciones.

La figura 6.4 ilustra la similutud de los tiempos de molienda requeridos para las vías A y B. Esto se debe a la rapidez en la formación del $\mathrm{TiH}_{2}$ y un mayor tiempo requerido para la formación de $\mathrm{MgH}_{2}$ durante la molienda reactiva en la vía A. Esto respalda la propuesta descrita de separación en componentes para describir las cinéticas de formación de estos sistemas. Los parámetros de ajuste de las cinéticas de muestras homólogas presentadas en las figuras $6.4 a$ y $6.4 b$, variaban relativamente poco ( 10 a $20 \%$ ) de manera que los parámetros obtenidos pueden considerarse representativos. En el Apéndice B se muestran ajustes sobre curvas cinéticas de muestras semejantes a fin de ilustrar esto. La exacta y reproducible descripción de las cinéticas de formación de los hidruros, para el método de fabricación utilizado mediante un modelo predictivo simple, pueden considerarse uno de los logros destacados de este trabajo. 
También se presentan en dicho Apéndice la cinética típica de formación de $\mathrm{TiH}_{2}$ preparado en el molino vibratorio para la fabricación de los composites mediante la vía B B.3b.

(a)

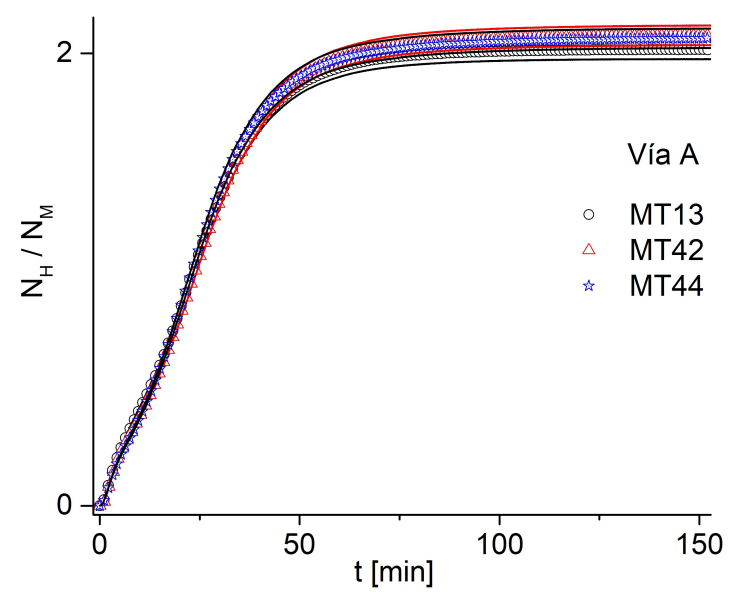

(b)

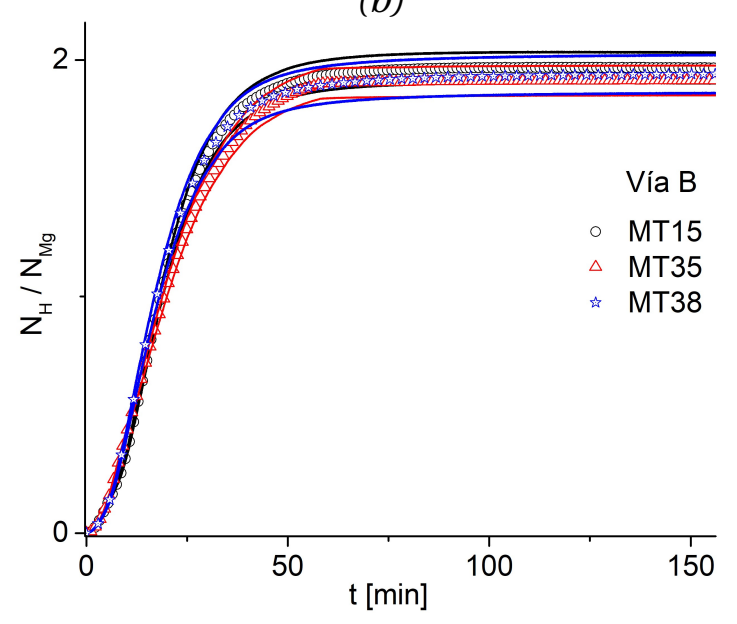

Figura 6.4: Comparación de cinéticas de formación para muestras de igual proporción Mg:Ti:80:20, preparadas por la misma ruta de fabricación A (figura a) y B (figura b). Se representa el número de moles de $\mathrm{H}$ incorporados (absorbidos) relativo al número de moles de material reactivo. Esto es, $\mathrm{M}=\mathrm{Mg}+\mathrm{Ti}$ en el caso $a$ y $\mathrm{M}=\mathrm{Mg}$ en el caso $b$. Se incluyeron las barras de error experimental.

\subsubsection{Sistemas fabricados con grafito}

Se comparan en la figura 6.5 las curvas cinéticas de formación de muestras con y sin agregado de carbono. Las cinéticas también presentan una notable repetitividad para una misma estequiometría $x: y$. Por otro lado, los tiempos de molienda se duplican aproximadamente variando de $0 \%$ a $20 \%$ la proporción de grafito.

Se destaca además la similitud entre los tiempos característicos para la formación de la fase $\mathrm{TiH}_{2}$ en todas las curvas cinéticas, independientemente del contenido de grafito. Esto se puede apreciar en la primera etapa de cada una de las curvas: todas coinciden en los primeros minutos ( 10 min. ) que están asociados a la formación de $\mathrm{TiH}_{2}$, mientras que para la etapa siguiente (formación del $\mathrm{MgH}_{2}$ ) las cinéticas dependen del contenido de grafito. Esto revela la influencia del mismo en los efectos de los impactos bola/pared/reactivo (Mg) mientras que prácticamente no afecta la formación de la fase de menor entalpía $\mathrm{TiH}_{2}$. Aún así la dependencia de la cinética de formación de $\mathrm{MgH}_{2}$ es despreciable para bajo contenido de grafito (5\%) (curvas verde y negra de la figura $6.5 \mathrm{~b}$ ).

El grafito no participa de manera reactiva durante la molienda mecánica ${ }^{5}$. No obstante actúa como agente lubricante, probablemente debido a su estructura de capas débilmente acopladas que se pueden desacoplarse, por ejemplo mediante deslizamientos, e interponerse en las colisiones entre los productos reactivos (figura 6.6).Esto explica en parte la ralentización de las cinéticas de formación. No obstante es llamativo que no afecte prácticamente la formación

${ }^{5}$ La realización de moliendas con grafito puro en atmósfera de hidrógeno durante 5 horas aporta evidencia de que efectivamente el grafito no forma parte del material reactivo. 
del $\mathrm{TiH}_{2}$.
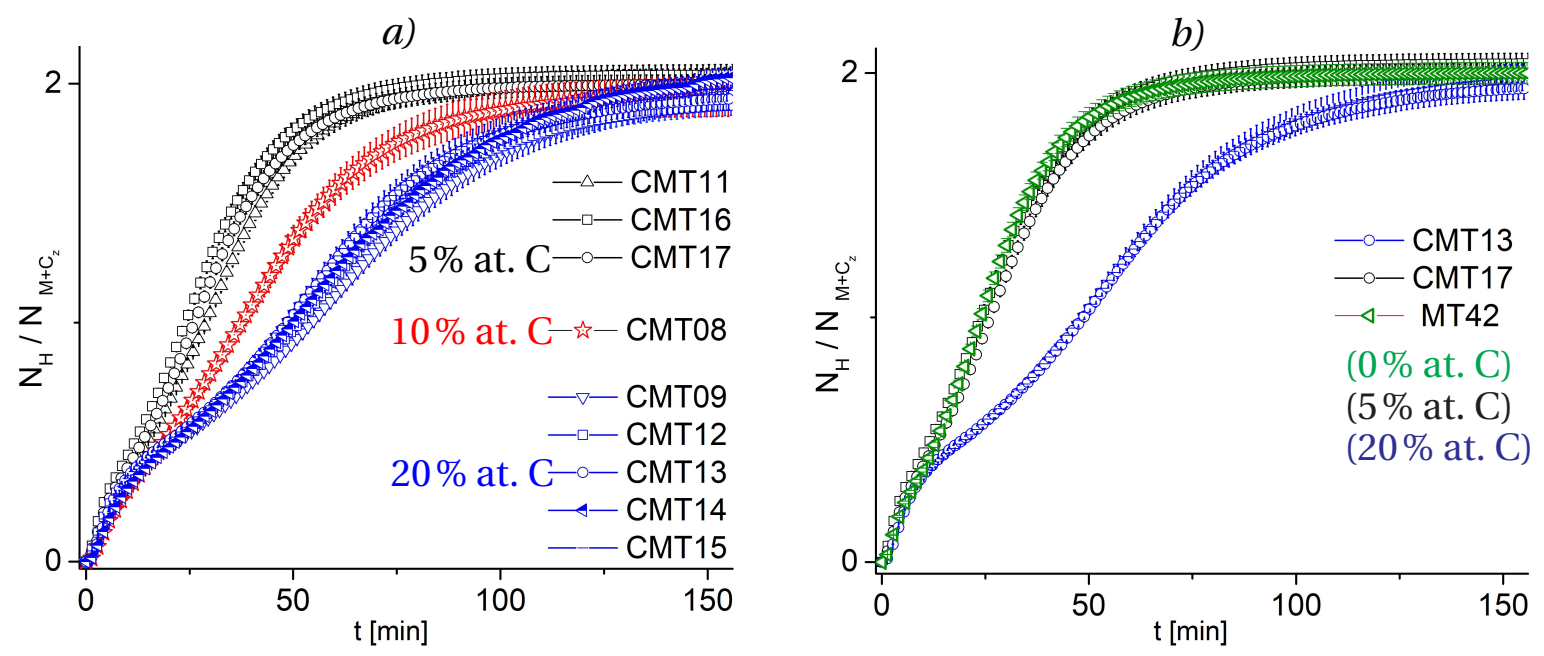

Figura 6.5: Curvas cinéticas de formación de composites hidrurados Mg:Ti:80:20 con distinto contenido de grafito. La proporción atómica de grafito incorporada a la molienda se respresenta con un mismo color. $a$ ) Cinéticas de muestras con 5\%, $10 \%$ y $20 \%$ at. de C. b) Cinéticas de muestras con 0\%, $5 \%$ y $20 \%$ at. de C.
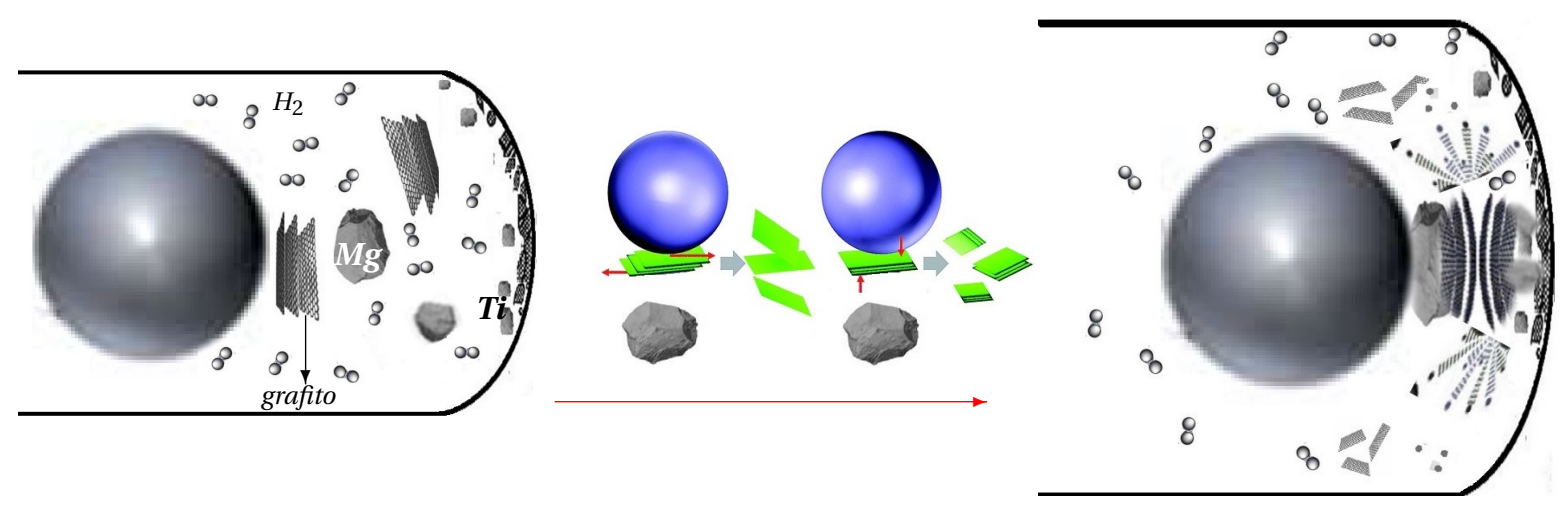

Figura 6.6: Representación esquemática. Molienda con grafito.

El grafito molido presenta un tamaño muy pequeño comparado con el grafito comercial según se pudo identificar mediante difracción de rayos X. Esto es compatible con que efectivamente el grafito actúa como lubricante y logra ocupar una gran parte de las regiones del sistema, quedando bien disperso entre las partículas de las fases hidruradas y probablemente formando una cobertura importante sobre las partículas. 


\section{Capítulo 7}

\section{Resultados parte II: Cinéticas en equipo volumétrico.}

Este capítulo tiene por objeto presentar los resultados más representativos del conjunto de experiencias de desorción/absorción de $\mathrm{H}_{2}$ realizadas en el equipo volumétrico. En la primera sección se presentarán los tratamientos térmicos a volumen constante realizados sobre las muestras recién fabricadas. En la segunda sección se presentarán curvas cinéticas de deshidruración/hidruración a temperatura constante. Estas fueron realizadas a distintas presiones y temperaturas. Se compararon las cinéticas de acuerdo a las condiciones correspondientes y de acuerdo a las vías de fabricación A, B, D y G. Se mostrarán además experiencias de desorción y absorción realizadas en varias etapas como se describió en la sección experimental 4.2.2 del capítulo 4 .

\subsection{Tratamientos térmicos}

EL procedimiento descrito en el capítulo 4 para el tratamiento térmico de las muestras, fue aplicado como primer paso a cada espécimen que fuera sometido posteriormente a ciclos de carga y descarga de hidrógeno. La figura 7.1 muestra una serie de tratamientos a distintas presiones iniciales realizados sobre una muestra de composición $M g: T i: 80: 20$ fabricada mediante la ruta A. Este primer tipo de tratamiento se llevaba a cabo a una velocidad de barrido $\frac{d T}{d t} \sim 13 \mathrm{~K} / \mathrm{min}$ hasta alcanzar una temperatura entre 380 y $400^{\circ} \mathrm{C}$. Típicamente se realizaron entre 3 a 8 tratamientos antes de comenzar con los ciclos de carga y descarga de hidrógeno a $\mathrm{T}$ constante. No obstante se observó que a partir del segundo tratamiento térmico los sistemas mostraban alcanzar un

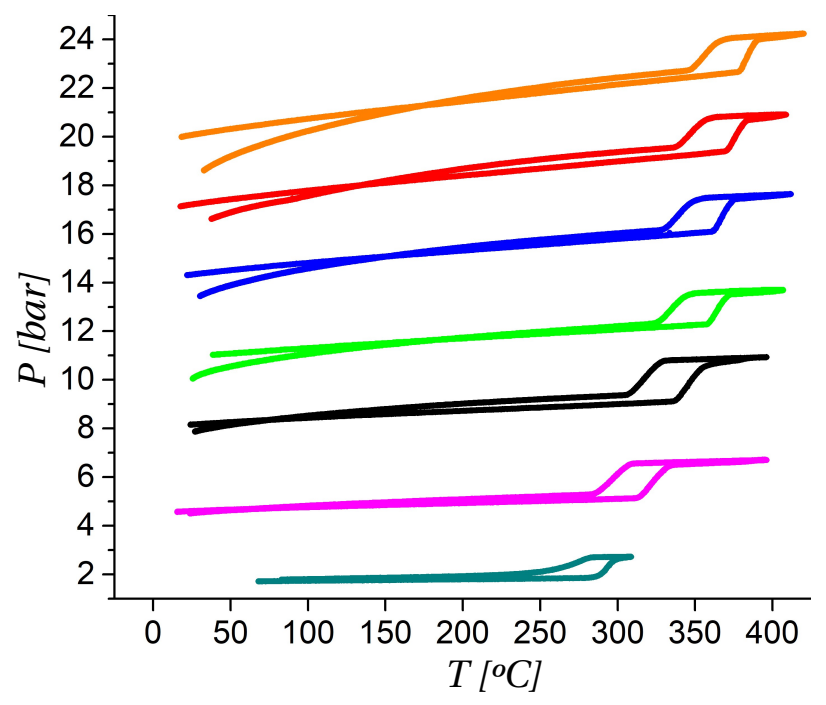

Figura 7.1: Algunos de los tratamientos realizados sobre la muestra MT13 (tabla 3.1). Trazando una envolvente de los puntos de inicio de desorción, se obtiene una curva exponencial que se corresponde con una curva de equilibrio $\mathrm{P}(\mathrm{T})$. 
régimen de absorción/desorción repetitivo. Esto se debe a la recuperación de defectos junto con una reconfiguración microestructural, que ocurre durante el primer tratamiento. De hecho, los patrones de difracción revelaron que el tamaño de grano ya crecía con el primer tratamiento, por lo tanto las muestras molidas (frescas), requerían solo un ciclo para alcanzar un régimen estacionario.

\section{Vías A y B}

En las figuras 7.2 a) y 7.2 b) se comparan tratamientos realizados sobre muestras preparadas por las vías A y B respectivamente. El primer ciclo (1) revela un aspecto diferente hacia el final de la desorción (algo que se puede apreciar también para otras muestras en las figuras $7.5 a$ y $7.6 b$ ). Esto se asoció al reacomodamiento de la microestructura mencionado arriba. En el caso de la muestra MT50 (vía A,molida durante $20 \mathrm{hs}$ ) puede verificarse la repetitividad entre ciclos correspondientes a distintos momentos de la historia de la muestra (ciclos 2 y 30 , figura $7.2 a$ ).

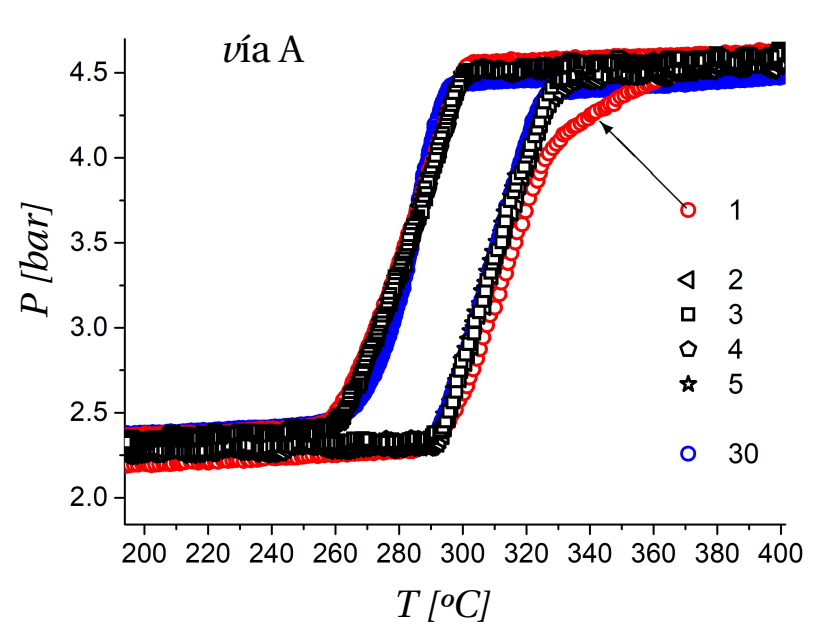

a)

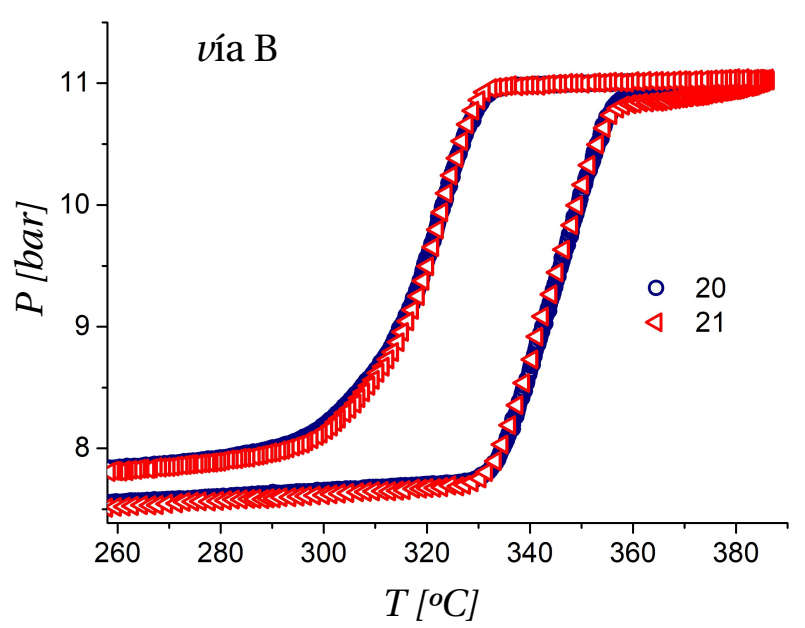

b)

Figura 7.2: a) Se comparan los primeros tratamientos con el ciclo no 30 para muestra fabricada por via A (MT50). b) Se comparan dos tratamientos consecutivos realizados sobre una muestra fabricada por vía B

(MT24).

A partir de este tipo de experiencias fue posible obtener las entalpías de los procesos de absorción y desorción a través de la construcción del gráfico de Vant't Hoff. También fue posible construir la curvas cinéticas de sorción no isotérmicas utilizando el volumen efectivo y la ecuación de estado.

Para estimar las presiones y temperaturas de equilibrio se tomaron las intersecciones a las rectas tangentes de las regiones (1)-(2) (desorción) y (4)-(5) (absorción) (de acuerdo a lo ilustrado en la figura 4.2). Teniendo las presiones de equilibrio $P_{e q}^{d e s}$ y $P_{e q}^{a b s}$ y las temperaturas correspondientes se construyeron los gráficos de Van’t Hoff a fin de estimar las entalpías $\Delta H_{d e s}, \Delta H_{a b s}$ y la entropía $\Delta S$. Podían observarse pequeñas variaciones de las presiones de desorción para tratamientos realizados en distintas instancias de la historia de ciclado, lo cual se ilustra en la figura 7.2. En la parte $a$ de la figura 7.3 se muestra una gráfico de Van’t Hoff 
construido para muestras fabricadas por la vía A ( elaborado a partir de las curvas ilustradas en las figuras E.1 y 7.1). En la parte $b$ se comparan ajustes de las presiones de desorción $P_{\text {des }}$ correspondientes a las vías A y B. En este caso se aprecia bien la semejanza de las presiones de desorción para ambas vías. Se tomó $P_{0}=1$ bar .

a)

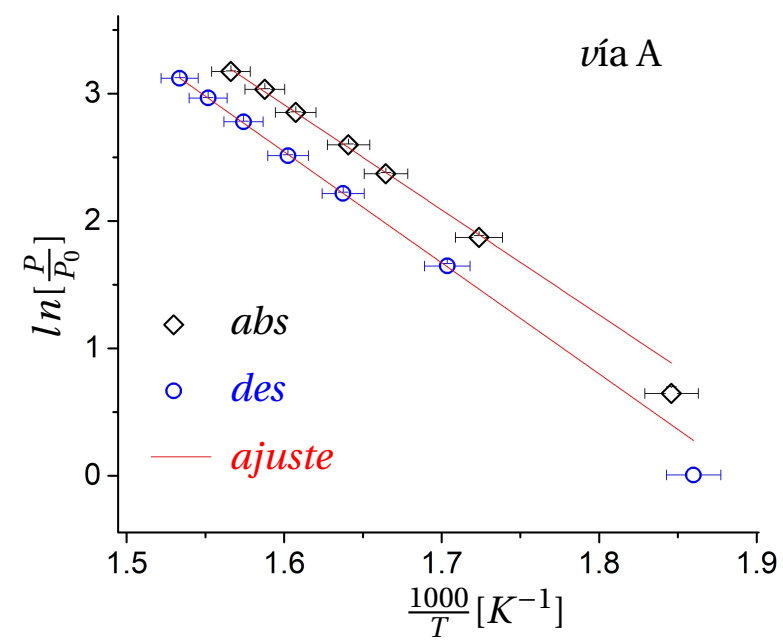

b)

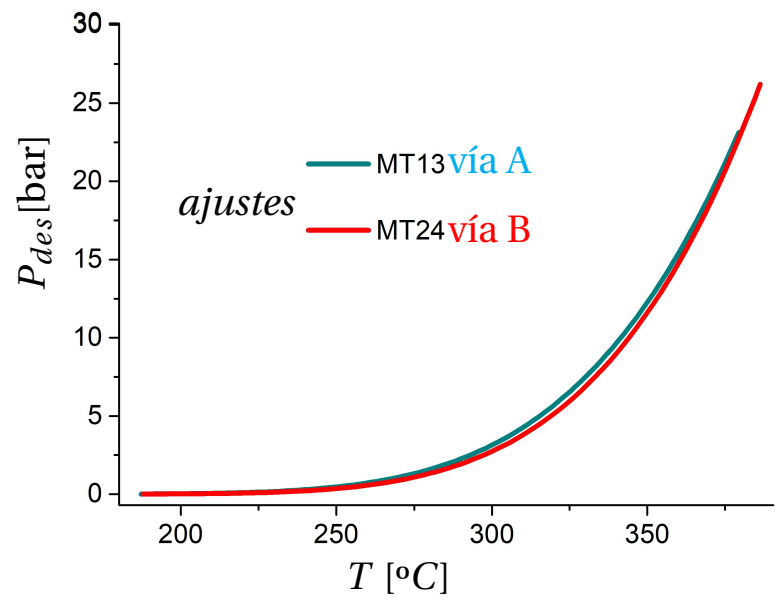

Figura 7.3: Se muestran los ajustes de Vant'Hoff para las presiones y temperaturas de absorción y desorción obtenidas mediante las curvas de los tratamientos realizadas sobre muestras fabricadas por las vía A (MT13(a)). Los ajustes exponenciales obtenidos para la presión de desorción $P_{d e s}$ de ambas vías resultaron similares (b).

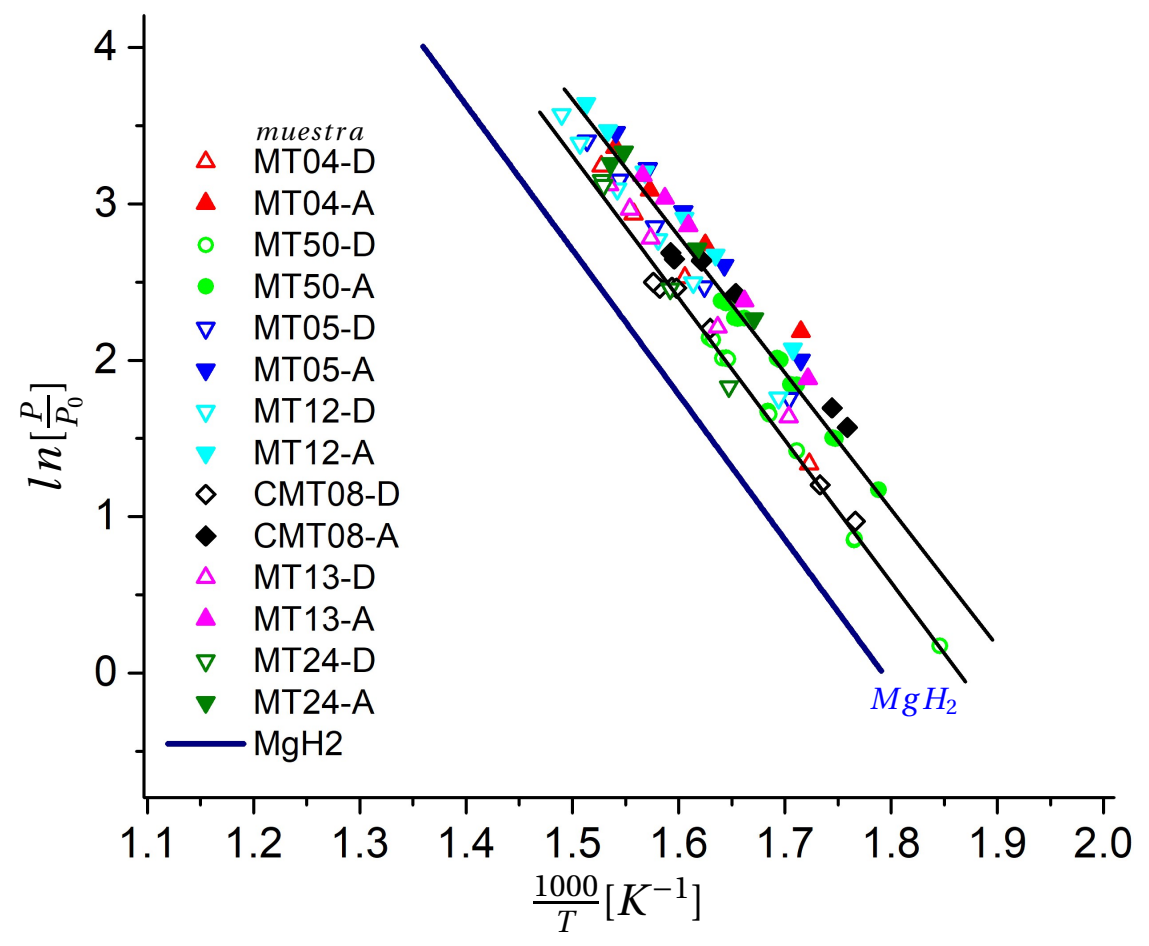

Figura 7.4: Gráficos de Vant'Hoff correspondientes a la presión de desorción, para distintas rutas de fabricación y distintas composiciones. Se destaca la linealidad y semejanza de los valores obtenidos. Eventualmente puntos asociados a primeros ciclos podían desviarse del comportamiento general. 
En la figura 7.4 se muestran los gráficos de Van’t Hoff para la desorción, correspondientes a más muestras, incorporando incluso algunas con distintas composiciones (). Se puede observar la similitud de las propiedades termodinámicas, y además, una leve disminución de la temperatura de desorción comparado con el $\mathrm{MgH}_{2}$ comercial sin aditivos.

En la tabla 7.1 se presentan los resultados de las entalpías y entropías calculadas. Estas resultaron muy similares para muestras fabricadas por distintas vías y composiciones. Los valores obtenidos están de acuerdo a lo reportado generalmente en la literatura.

Tabla 7.1: Tabla de entalpías obtenidas a partir de los gráficos de Van’t Hof. Corresponden a distintas vías de fabricación y distintas composiciones. Se incluyen los errores de ajuste y las entropías.

\begin{tabular}{|c|c|c|c|c|c|c|c|c|}
\hline Muestra & $-\Delta H_{\text {des }}$ & $e r r_{\Delta H_{d e s}}$ & $\Delta S_{\text {des }}$ & $e r r_{\Delta S_{\text {des }}}$ & $-\Delta H_{a b s}$ & $e r r_{\Delta H_{a b s}}$ & $\Delta S_{a b s}$ & $e r r_{\Delta S_{a b s}}$ \\
\hline & {$[\mathrm{kJ} / \mathrm{mol}]$} & & [J/K.mol] & & {$[\mathrm{kJ} / \mathrm{mol}]$} & [J/K.mol] & & \\
\hline MT04 & 75 & 3 & 141 & 6 & 61 & 4 & 122 & 6 \\
\hline MT50 & 76,7 & 0,8 & 143 & 2 & 69 & 2 & 134 & 3 \\
\hline MT05 & 71,8 & 0,7 & 137 & 1 & 70,0 & 0,8 & 137 & 1 \\
\hline MT12 & 72,8 & 0,9 & 138 & 2 & 66,7 & 0,4 & 131,2 & 0,7 \\
\hline CMT08 & 75 & 2 & 140 & 3 & 65 & 1 & 127 & 2 \\
\hline MT13 & 73,5 & 0,7 & 138,7 & 0,9 & 70 & 2 & 137 & 2 \\
\hline MT24 & 72 & 1 & 162 & 2 & 72 & 2 & 140 & 3 \\
\hline
\end{tabular}

\section{Muestra deuterada}

La figura 7.5 muestra una serie de tratamientos realizados a baja presión, sobre la muestra deuterada fabricada a alta presión en un molino planetario (MTD2) (tabla 3.1). Los primeros tratamientos realizados fueron naturalmente en atmósfera mixta $\mathrm{H}_{2}+\mathrm{D}_{2}$ dada la naturaleza de la muestra. Estos primeros tratamientos difieren de los tratamientos realizados posteriormente una vez evacuado totalmente el $D_{2}$. La evacuación del mismo se logró mediante ciclos de desorciones en vacío y absorciones en hidrógeno repetidamente. Al reemplazar D por $\mathrm{H}$, la temperatura de desorción se incrementa pero los ciclos térmicos mantienen la repetitividad. 


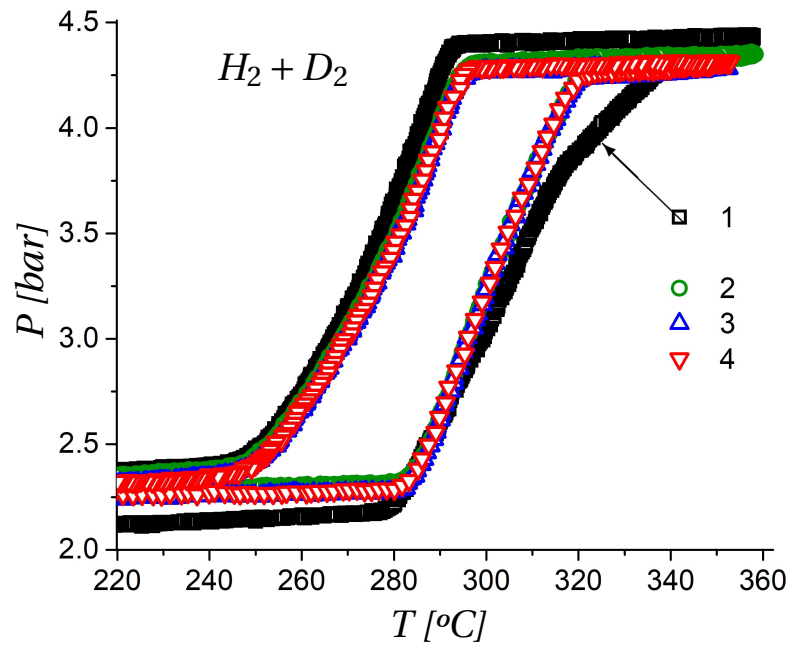

a)

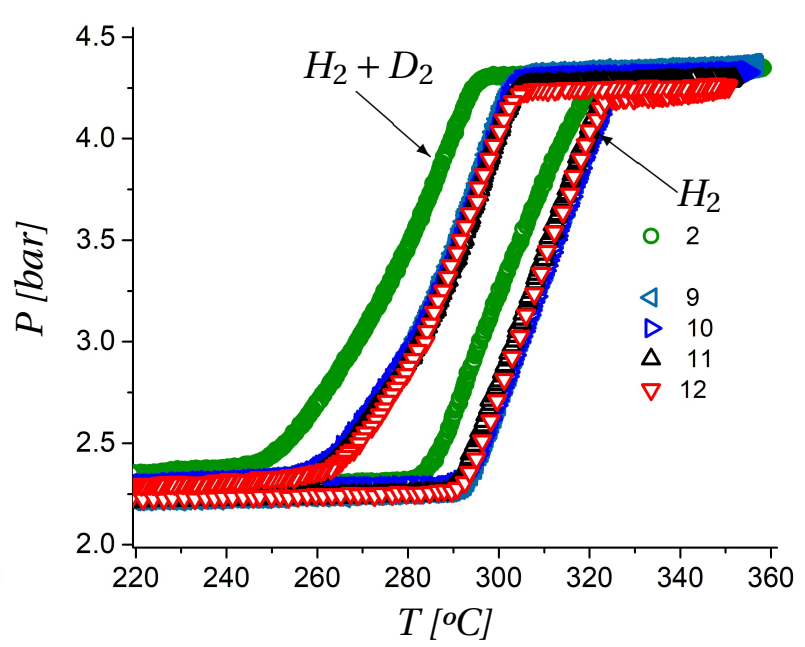

b)

Figura 7.5: a) Primeros tratamientos ( 1 a 4) de un especimen deuterado fabricado por vía D. Las sorciones se llevaron a cabo en atmósfera mixta por la liberación de $D_{2}$ en el ciclo no 1 , que se distingue del resto hacia el final de la desorción. b) Se comparan los tratamientos llevados a cabo en atmósfera pura de $H_{2}(9,10,11$ y 12), con el ciclo nº 2 realizado en atmósfera mixta.

\section{Muestras con grafito}

Las muestras con grafito presentaron propiedades termodinámicas similares a los hidruros sin grafito. Por otro lado se pueden construir las curvas cinéticas no isotérmicas, que corresponden a las curvas obtenidas a partir de los tratamientos térmicos realizados descritos en la sección 4.2.1. Esto se hace descontado previamente las rampas de calentamiento y enfriamiento en el que la presión cambia por cambio de la temperatura sin absorción ni liberación de hidrógeno. Se pudieron obtener las cinéticas no isotérmicas entonces utilizando la ecuación 3.1 y teniendo en cuenta el volumen efectivo, obteniendo obteniendo así la dependencia temporal de la reacción $\alpha(t)$. La figura 7.6 muestra las cinéticas de desorción comparando muestras con (CMT11) y sin grafito (MT50,MT34). La parte $a$ ilustra la similitud de las curvas experimentales para ambas vías y la parte $b$ permite apreciar la similitud, a partir del segundo ciclo, entre las cinéticas de desorción de una muestra fabricada por la vía A y la fabricada por vía $G$. 


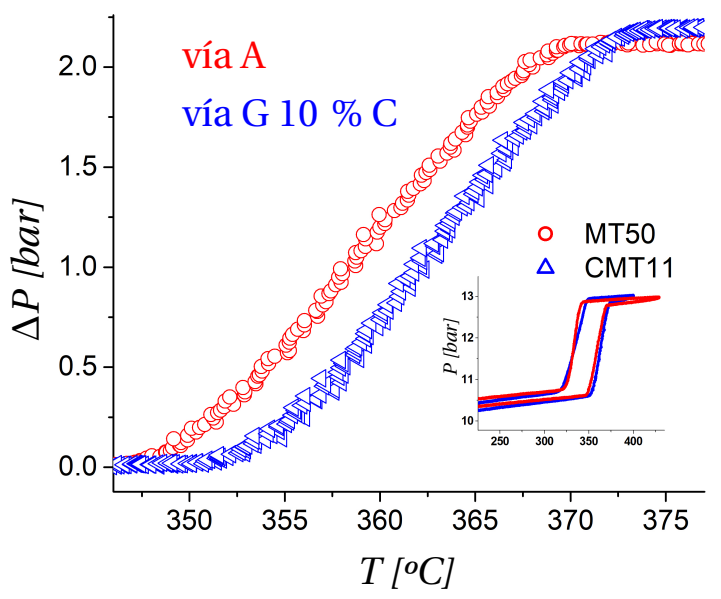

a)

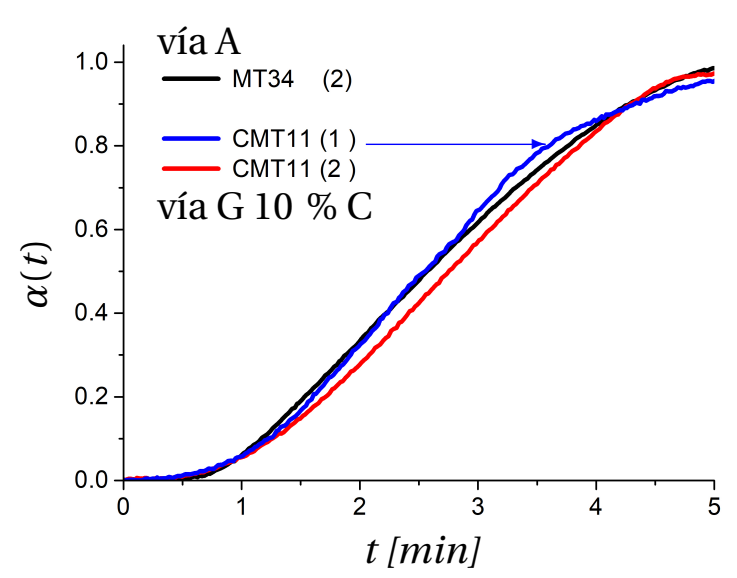

b)

Figura 7.6: $a$ ) Se comparan las cinéticas de desorción no isotérmicas (correspondientes gráfico inserto), entre dos muestras fabricadas por las vías A y G. En este caso se muestra la dependencia con la temperatura T, que se incrementa a velocidad constante. Considerando que la velocidad de calentamiento y presiones fueron similares pero no idénticas, las cinéticas pueden considerarse semejantes. b) Comparación de cinéticas de desorción no isotérmicas de dos muestras con y sin grafito respectivamente. Nuevamente se observa que el primer tratamiento se diferencia hacia el final de la desorción siendo la curva más suave.

\section{Cinéticas de absorción y desorción en el equipo volumétrico}

En las siguientes secciones se presentará parte del conjunto de curvas cinéticas de absorción y desorción de hidrógeno a temperatura constante. Estas fueron obtenidas de acuerdo a lo descrito en la sección 4.2. En primer lugar se compararán curvas de absorción y desorción

obtenidas para muestras fabricadas por distintas vías, de acuerdo a la presión y a la temperatura. Luego se describirán y mostrarán algunos ensayos típicos de absorción y desorción en etapas.

\subsection{Isotermas de sorción}

\subsubsection{Comparación de cinéticas de muestras fabricadas por vías A y B}

Se mostrarán a continuación las curvas de absorción y desorción de hidrógeno comparando la cinética de la vía A con las demás vías. 
- $290^{\circ} \mathrm{C}-265^{\circ} \mathrm{C}-240^{\circ} \mathrm{C}$

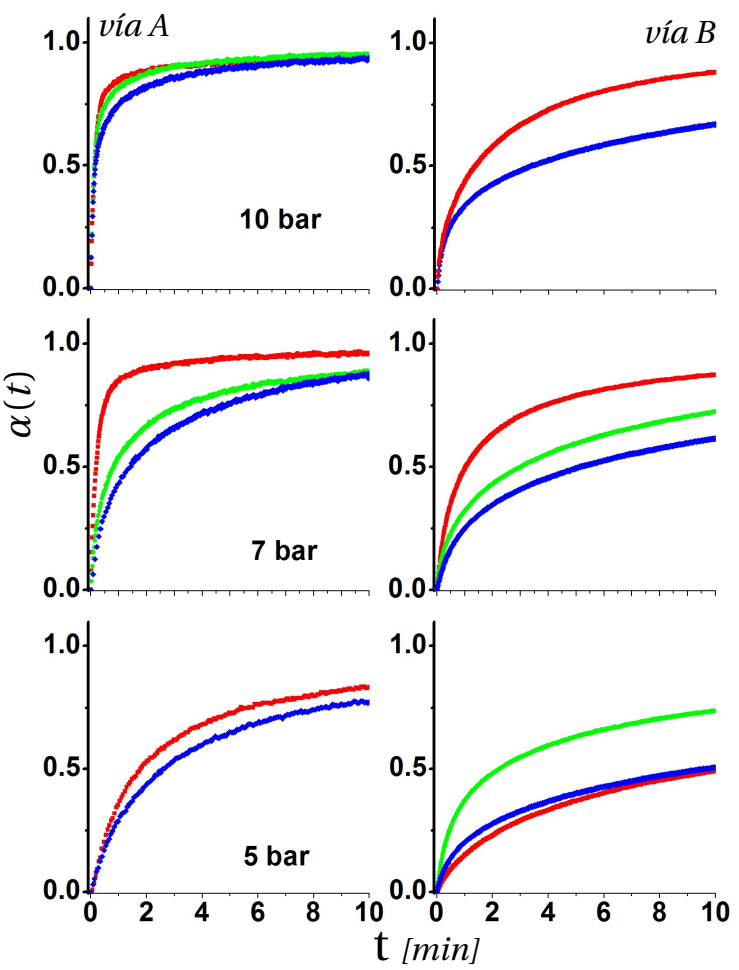

a)
- 10 bar -7 bar 4 bar
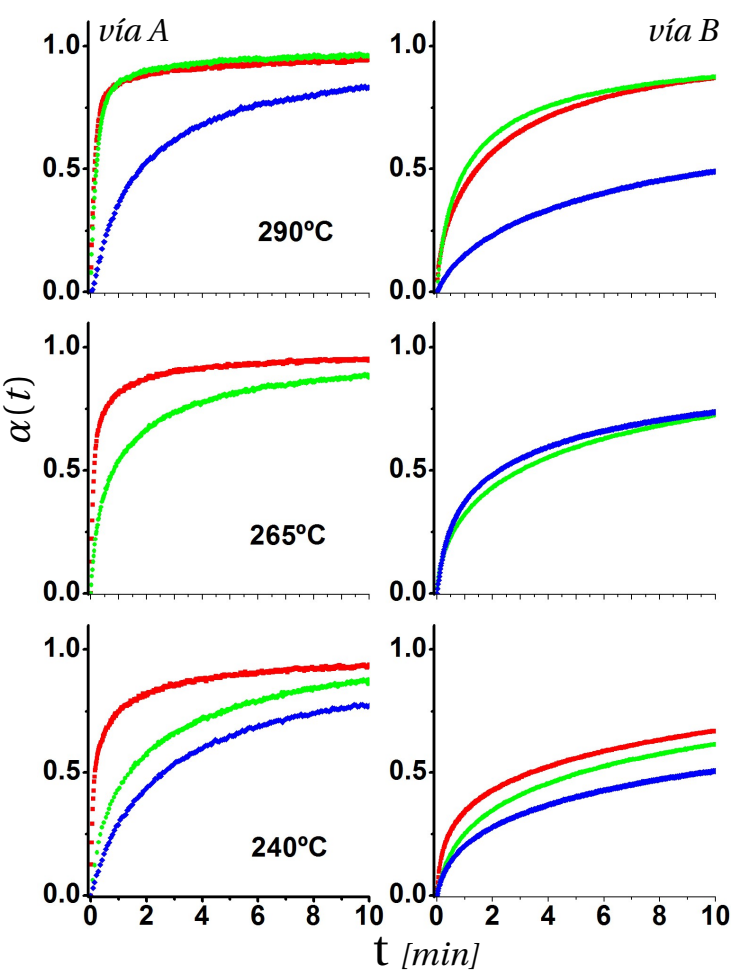

b)

Figura 7.7: Comparación de curvas cinéticas de absorción de muestras fabricadas por las las vías A y B. a): Para una dada presión inicial se comparan las curvas cinéticas de cada vía a distintas temperaturas. $b$ ): Para una dada temperatura se comparan las curvas cinéticas de absorción a distintas presiones iniciales, indicadas en la figura (arriba). A medida que disminuye la fuerza impulsora $\frac{\Delta P}{T}$ las cinéticas de la vía B son comparativamente más lentas.

Se presentan en la figura $7.7 a$ y $b$ las curvas cinéticas de absorción correspondientes a dispersiones hidruradas Mg-Ti, de composición Mg:Ti:80:20. Las curvas muestran el progreso de la reacción durante los primeros 10 minutos. El mismo está representado por la cantidad de átomos incorporados a la muestra relativo al número de átomos metálicos reactivos, de acuerdo a la ecuación 3.1. Las figuras se corresponden con muestras fabricadas mediante las rutas A y B. Las absorciones se realizaron luego de someter las muestras a algunos tratamientos térmicos como fue descrito en la sección anterior. Las curvas se comparan para una dada presión inicial y distintas temperaturas (figura 7.7 a), así como para una dada temperatura y distintas presiones iniciales (figura 7.7 b). Se muestran cinéticas a partir de $240^{\circ} \mathrm{C}$ y 5 bar. Cabe destacar que, en general las muestras pueden absorber hidrógeno apreciablemente a partir de $\simeq 240^{\circ} \mathrm{C} \mathrm{y} \sim 2$ bar. Se puede apreciar que las cinéticas de la muestra fabricada por vía B (MT24) son más lentas, resultando mas rápidas las de la ruta A (MT13).

Lo señalado anteriormente se puede apreciar aún mejor en la figura 7.8 donde se comparan las cinéticas de absorción de dos muestras fabricadas por las vías A y B respectivamente para una determinada presión: en condiciones similares, las cinéticas de las muestras fabricadas por la vía A resultan más rápidas que las cinéticas de muestras fabricadas por vía B. Además las muestras preparadas con $\mathrm{TiH}_{2}$ poseen una mayor sensibilidad de la cinética con la tem- 
peratura. Estos comportamientos resultaron una tendencia general para distintas presiones (incluso comparando las cinéticas de desorción). En el apéndice se agrega la figura E.2 que refuerza estos aspectos observados. Se destaca también la similitud de las pendientes en los instantes iniciales, que resultan sensibles a la presión $P_{i}$ a la cual iniciaban las absorciones. Las curvas se diferencian a medida que el grado de transformación $\alpha(t)$ avanza.

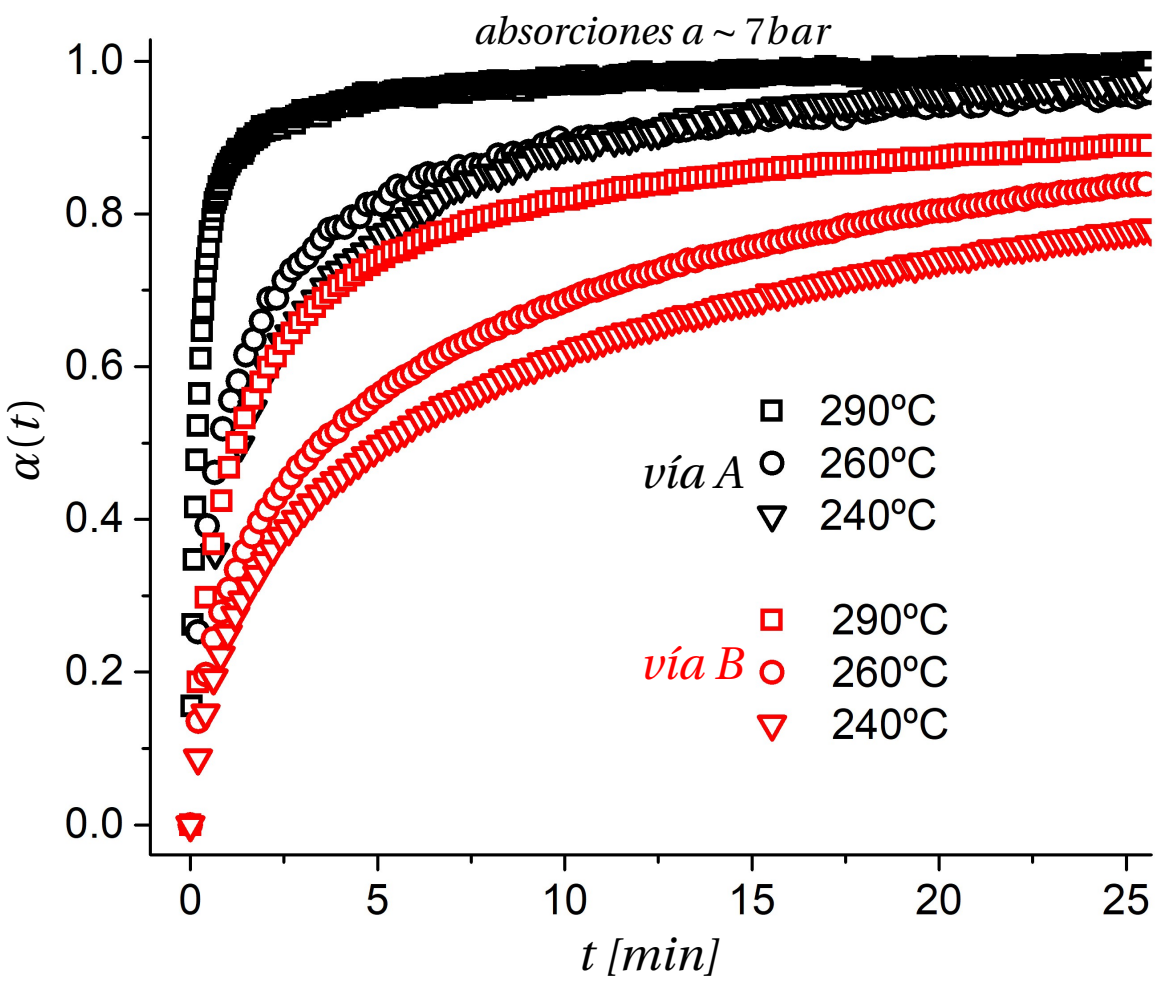

Figura 7.8: Comparación de cinéticas de absorción de las muestras MT13(vía A) y MT24(vía B). Se realizaron a una presión de $\sim 7$ bar y a distintas temperaturas: $240^{\circ} \mathrm{C}, 260^{\circ} \mathrm{C}$ y $290^{\circ} \mathrm{C}$. Las cinéticas de las muestras fabricadas por la vía A resultan mejores que las cinéticas de muestras fabricadas por vía B. Se destaca la similitud de las pendientes en los instantes iniciales.

Algunas de las cinéticas de desorción correspondientes a las muestras mencionadas son comparadas para distintas temperaturas en la figura 7.9.

En el caso de las desorciones las cinéticas se encuentran normalizadas. La velocidad inicial de las cinéticas $\left(\left.\frac{d \alpha}{d t}\right|_{t_{0}}\right)$ de las muestras fabricadas por la vía A, dependían aproximadamente en forma lineal con la temperatura ${ }^{1}$, mientras que en el caso de las muestra fabricada por vía $B$, se destaca una mayor sensibilidad de la cinética con la disminución de la temperatura. En la figura 7.9 se observa claramente esta dependencia, habiendo incluso un cambio de concavidad para temperaturas menores a $290^{\circ} \mathrm{C}$. Dicho cambio de concavidad puede asociarse con una etapa de nucleación de la fase metálica. Esta sensibilidad con la temperatura, fue observado arriba para el caso de las curvas de absorción al comparar las cinéticas entre las distintas rutas de fabricación.

\footnotetext{
${ }^{1}$ Esto es válido para un rango acotado y para $\mathrm{T}<300^{\circ} \mathrm{C}$ (figura E.3).
} 


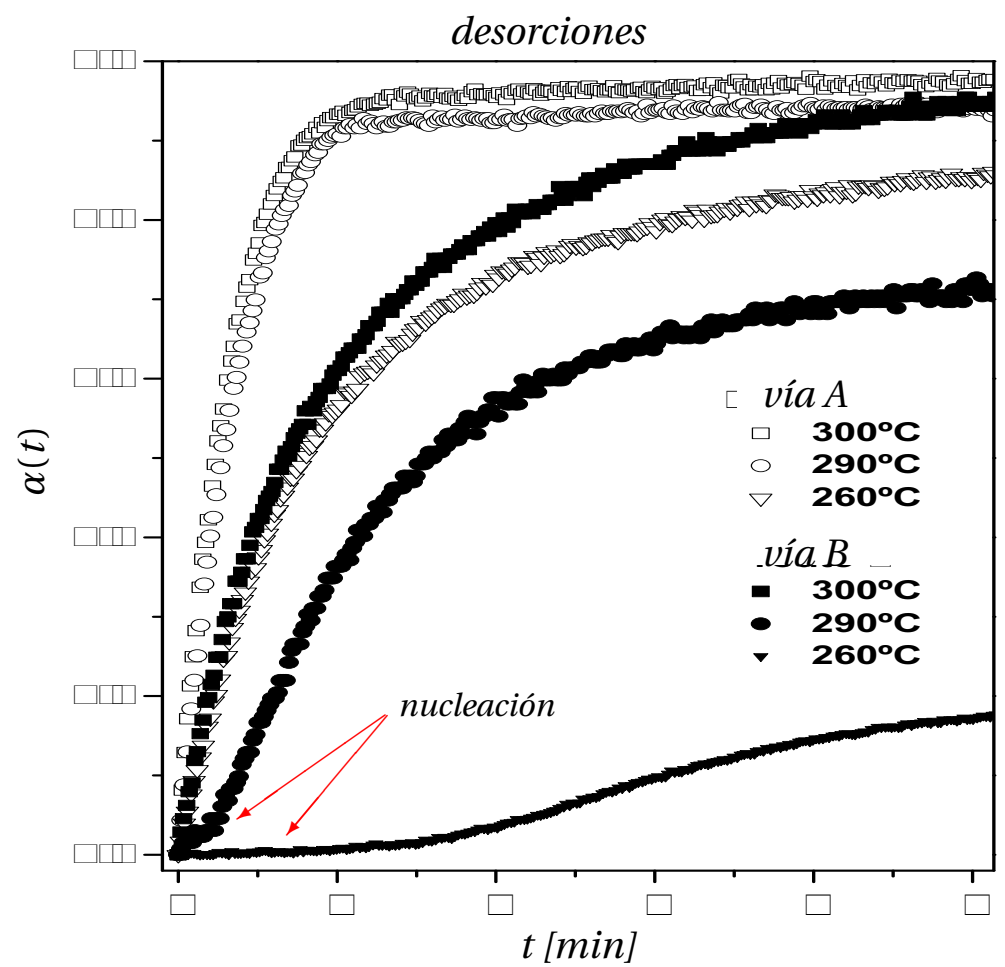

Figura 7.9: Se comparan cinéticas de desorción de las muestras MT13(vía A) y MT24(vía B) a distintas temperaturas. Se realizaron a una presión de $\sim 100 \mathrm{mbar}$ y a $260^{\circ} \mathrm{C}, 290^{\circ} \mathrm{C} \mathrm{y} 300^{\circ} \mathrm{C}$. Las cinéticas de las muestras fabricadas por la vía A resultan más rápidas que las cinéticas de muestras fabricadas por vía B.

\subsubsection{Comparación con cinéticas de muestra deuterada}

En al figura 7.10 se comparan etapas de cinéticas de desorción de muestras fabricadas por las vías A (MT50) y D (MTD2), empleando un tiempo de molienda de 20 hs en ambos casos. En la figura $a$ se muestran la primera etapa de desorción de una muestra fabricada por vía $\mathrm{D}$ junto a la primera etapa de desorción de las primeras dos desorciones ( 1 y 2) de una muestra fabricada por vía A. En la figura $b$ se comparan las tres primeras etapas de deosrción para amabas vías. Se destaca la similitud de la cinética de muestras fabricadas a muy diferentes presiones, en distinta atmósfera y con distintos molinos.

\subsubsection{Comparación de cinéticas de muestras con grafito}

En la figura 7.11 se comparan las cinéticas de absorción correspondientes a muestras con y sin grafito. Se muestran las cinéticas realizadas a una presión inicial típica y cubriendo el intervalo usual de temperaturas en el que se realizaban las absorciones y desorciones. De esta manera se ilustra la similitud en la velocidad de las cinéticas, mostrando que el agregado de grafito (hasta $20 \%$ at.) no afecta la cinética. Contrariamente las cinéticas de desorción se diferencian entre muestras con y sin grafito. Sin embargo, la figura 7.12, muestra que el agregado de hasta un $10 \%$ at. de grafito, preserva la cinética. 
a)

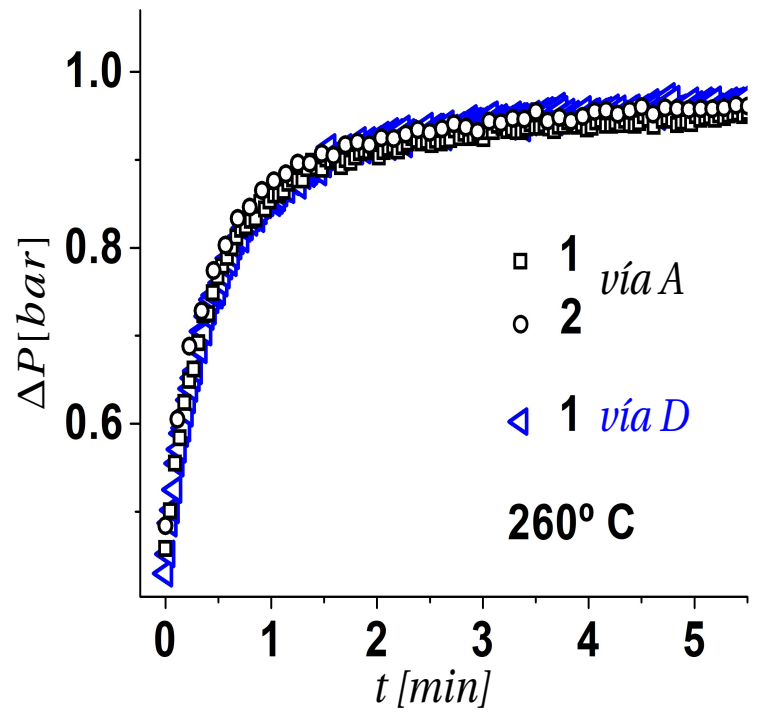

b)

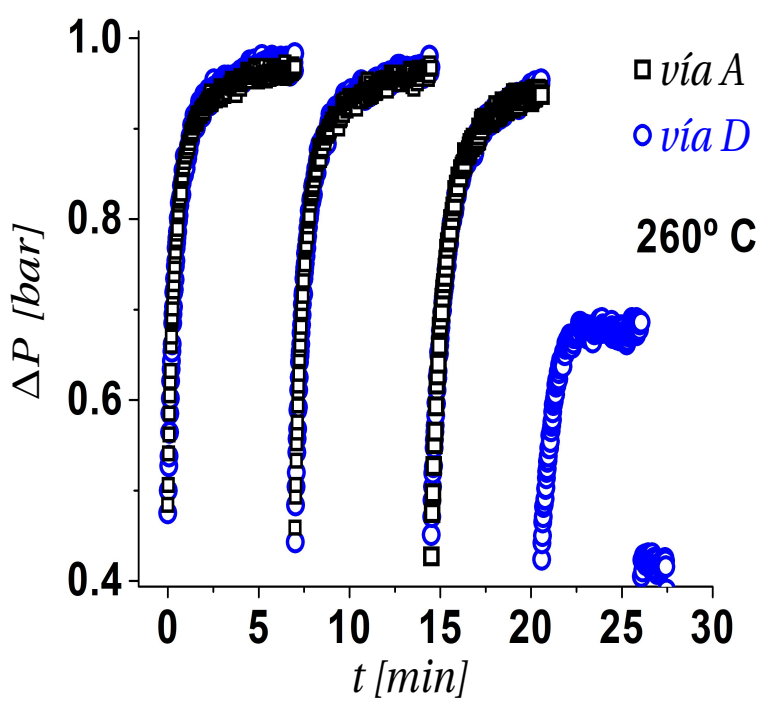

Figura 7.10: Se comparan la cinética de desorción de muestras fabricadas por las vías A (MT50) y D (MTD2), molidas 20 hs pero con distintos molinos y distintas presiones. a): primera etapa de desorción realizada sobre los espécimentes. $b$ ) Comparación de las priemras etapas de desorción de los especímenes.
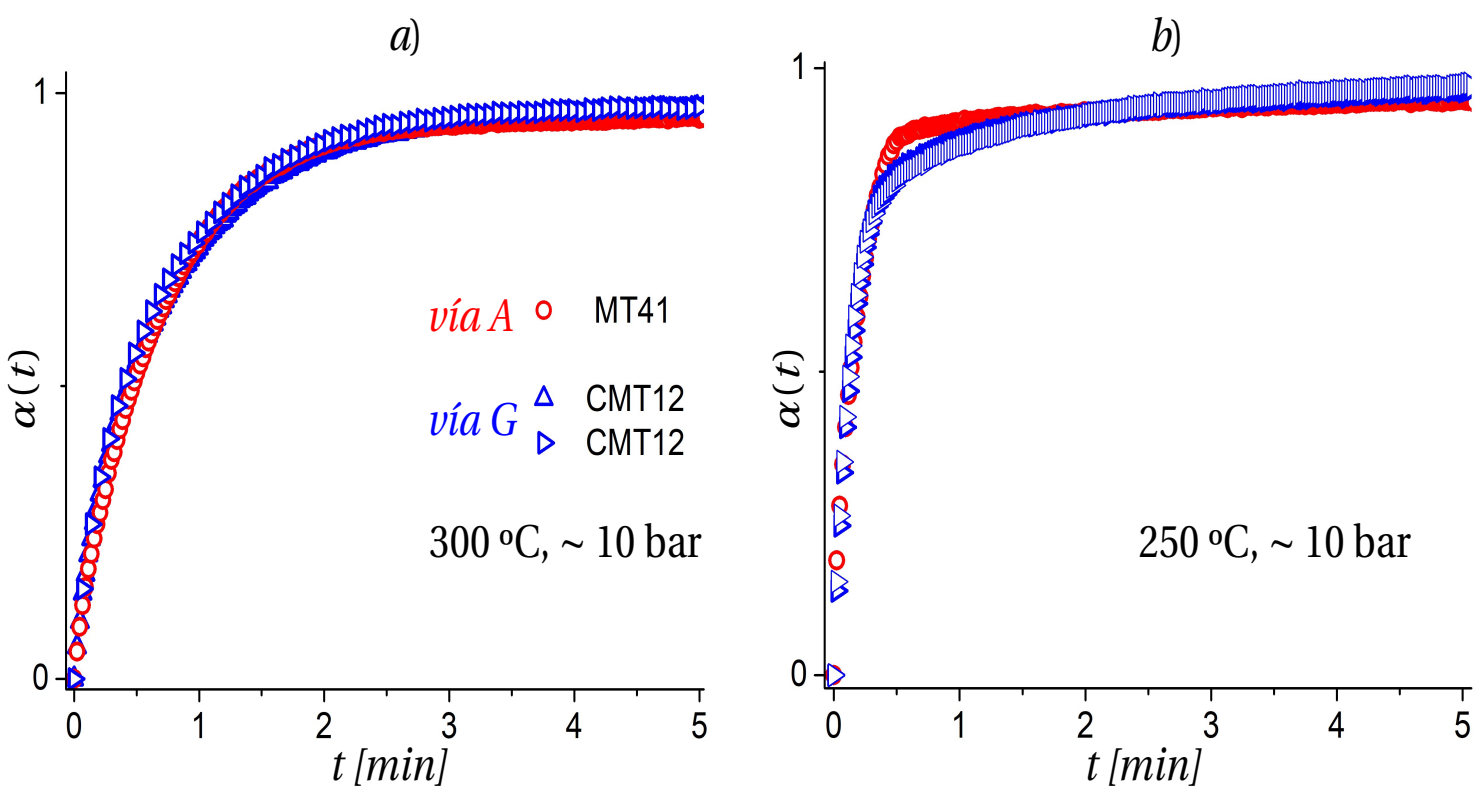

Figura 7.11: Se comparan las cinéticas de absorción de muestras de composición Mg:Ti:80:20 con y sin grafito para dos temperaturas distintas, $300^{\circ} \mathrm{C}$ en $a$ ) y $250^{\circ} \mathrm{C}$ en $b$ ). Las absorciones fueron todas iniciadas a 10 bar de presión y las curvas están normalizadas. 


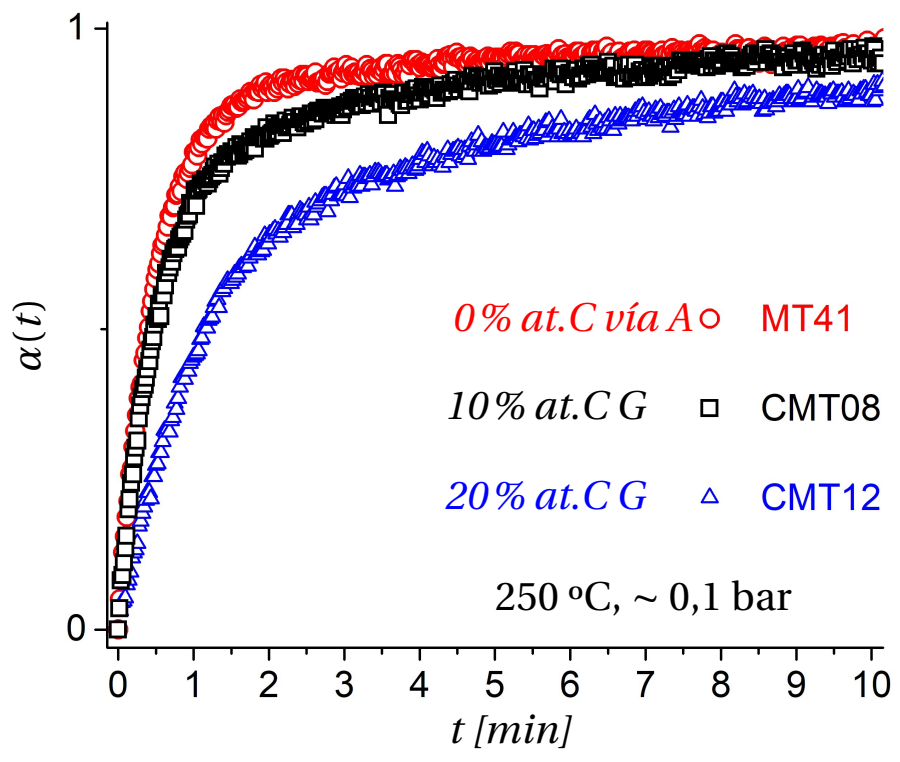

Figura 7.12: Se comparan la primera etapa de desorción de muestras de composición Mg:Ti:80:20 con y sin grafito, a $250^{\circ} \mathrm{C}$. Las desorciones fueron todas iniciadas a $\sim 0,1$ bar de presión y las curvas están normalizadas.

\subsubsection{Absorciones y desorciones en etapas}

\section{Desorciones}

En esta sección se presentan algunos resultados de experiencias de cinéticas realizadas en etapas. Las desorciones realizadas en etapas eran necesarias para completar la descarga a temperaturas $\leq 280^{\circ} \mathrm{C}$. Esto es porque se alcanzaba la presión de equilibrio antes de completar la descarga como se aprecia en la figura (7.13), la cual corresponde a cinéticas de desorción en etapas para una muestra fabricada por la vía A (MT41).

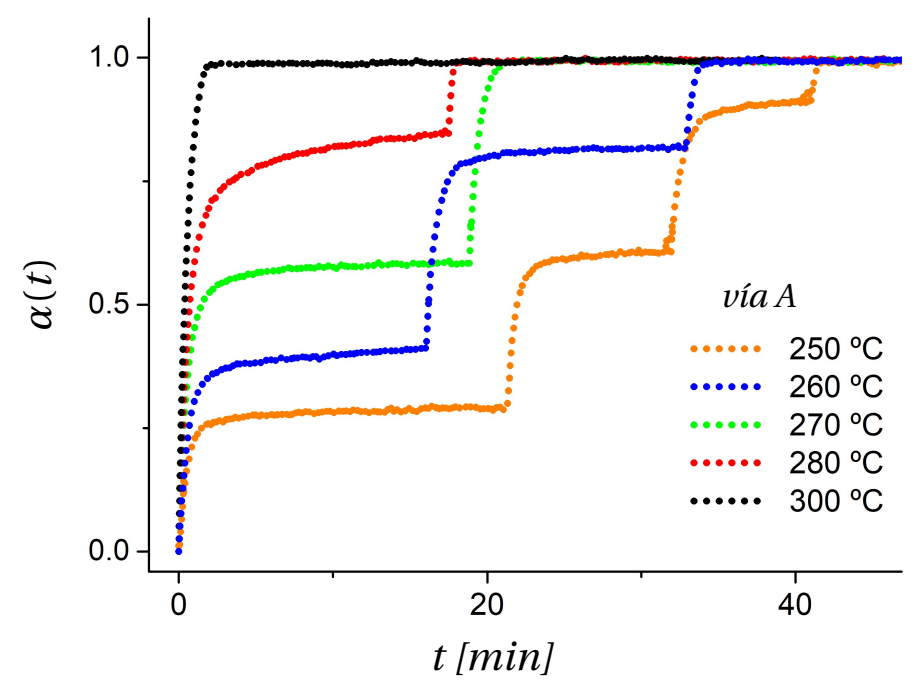

Figura 7.13: Experiencias típicas de desorción en etapas realizadas con el reactor inicialmente en vacío. Al llegar a la presión de equilibrio se abría y cerraba inmediatamente la válvula para bajar la presión y reobtener así la fuerza impulsora $(\Delta P / T)$. Se muestran curvas de desorción en etapas para distintas temperaturas correspondientes a una muestra fabricada por la vía A (MT41). 
Se puede notar a simple vista que las pendientes iniciales de cada etapa variaban -aunque ligeramente- al iniciarse cada etapa. Se compararon entonces las etapas de desorción para una dada muestra y una temperatura determinada. También se compararon las etapas de desorción en similares condiciones para distintas vías de fabricación. En la figura 7.14 se comparan las primeras etapas de desorción a $240^{\circ} \mathrm{C}$ para muestras fabricadas por las vías A y B. A bajas temperaturas, la primera etapa de desorción difiere notablemente de las siguientes etapas (y es claramente más lenta para la vía B como se había observado para temperaturas más altas, figura 7.9 ).

a)

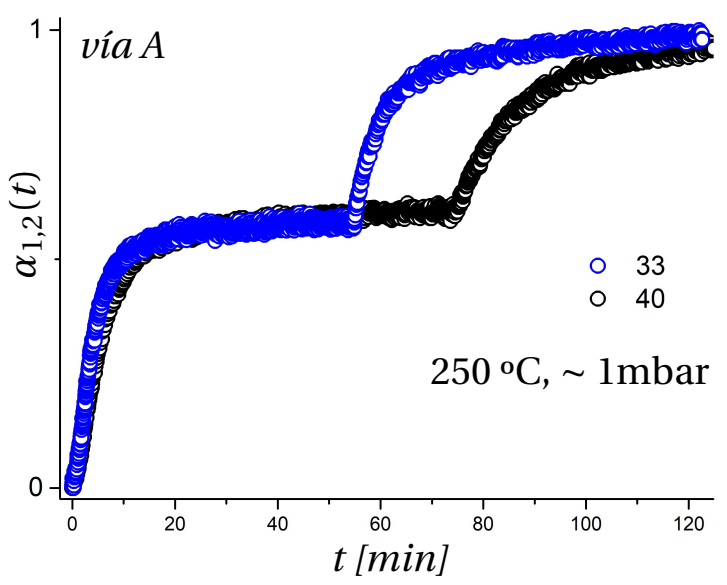

b)

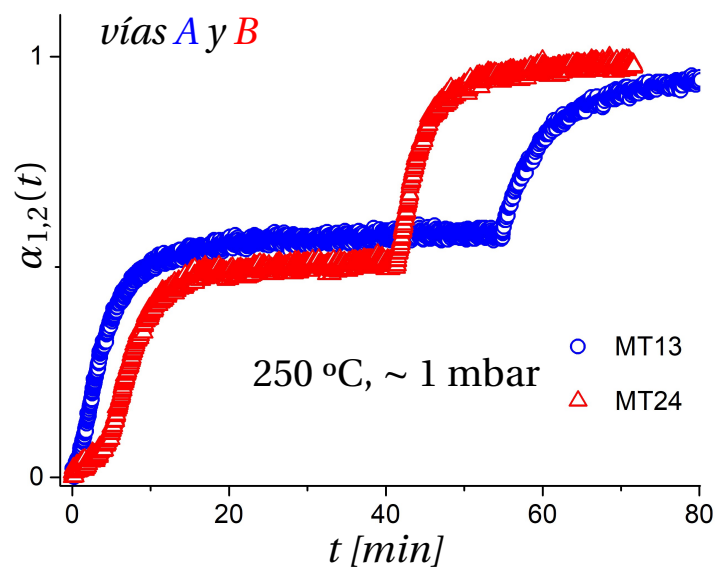

Figura 7.14: Cinéticas de desorción en etapas a $240^{\circ} \mathrm{C}$, vías A y B. Se muestran las primeras dos etapas ( 1 y 2 ) curvas cinéticas de desorción (normalizadas). a): Cinéticas correspondientes a dos ciclos distintos (33 y 40) de una muestra fabricada por la vía A. La cinética se conserva hasta el ciclo 40. b): Primeras dos etapas de desorción correspondientes a una muestra fabricada por la vía A (MT13) y otra fabricada por la vía B (MT24). Se observa que la primera etapa es más lenta para la vía B y las siguientes etapas tienen una cinética similar.

En la figura 7.15 se comparan las 4 etapas de desorción requeridas para la descarga completa de una muestra fabricada por la vía A. Cada etapa de desorción se inicia con el reactor en bajo vacío. En al figura $7.15 b$ se puede apreciar bien como en cada etapa la velocidad de transformación disminuye ligeramente. A diferencia de las muestras con grafito que presentaban una notable similitud entre las cinética de cada etapa de desorción, como se ilustra en la figura 7.16 b. Aparentemente la cantidad de grafito se manifiesta asociada al grado de similitud de las cinéticas. Por ejemplo las muestras con $10 \%$ at. de $\mathrm{C}$ presentaban mayor similitud entre las etapas con respecto a las muestras sin grafito (fabricadas por la vía A), pero no eran tan similares como las muestras con $20 \%$ at. de C (figura E.5). 
a)

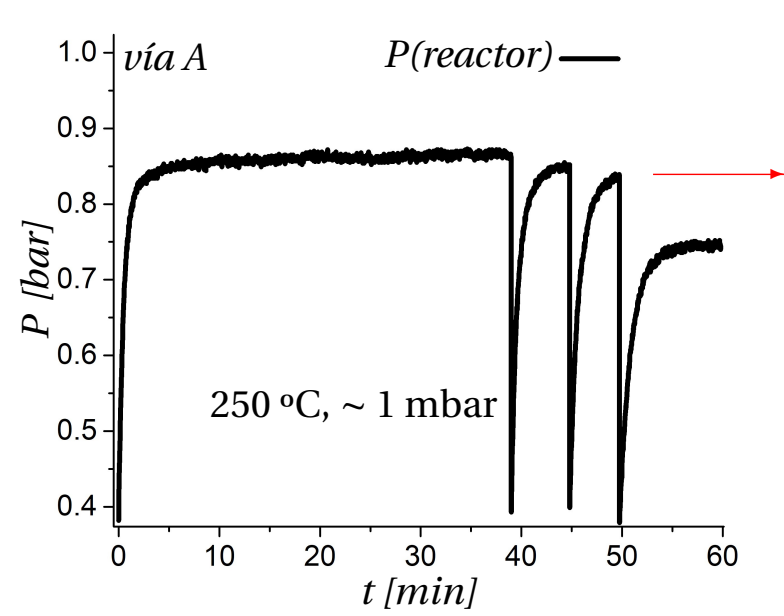

b)

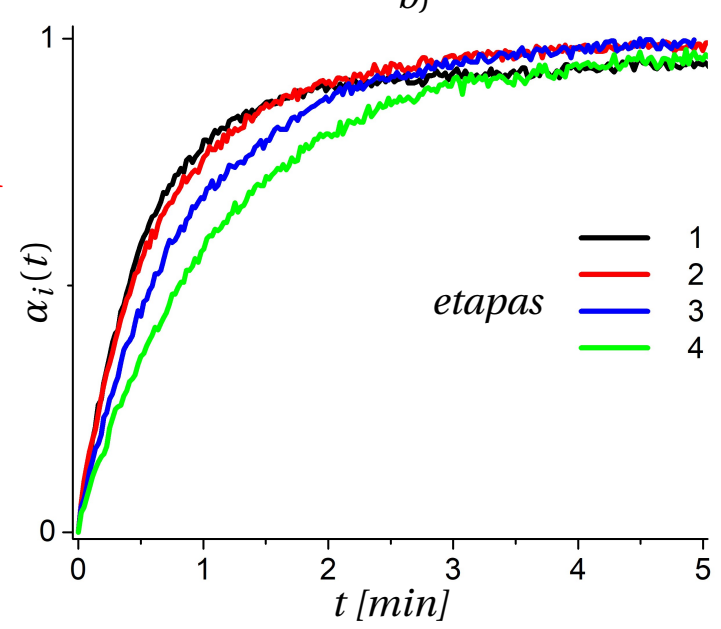

Figura 7.15: Cinética de desorción en etapas a $250^{\circ} \mathrm{C}$, vía A (MT41). La presión inicial de vacío así como en el inicio de cada etapa era de $\sim 1$ mbar. $a$ ): Se muestra la medida de la presión en el reactor en función del tiempo $b$ ): Se muestran la fracción transformada correspondiente a cada etapa de desorción $(1 \rightarrow 4)$. A medida que avanza la reacción la cinética de cada etapa es ligeremente más lenta.

a)

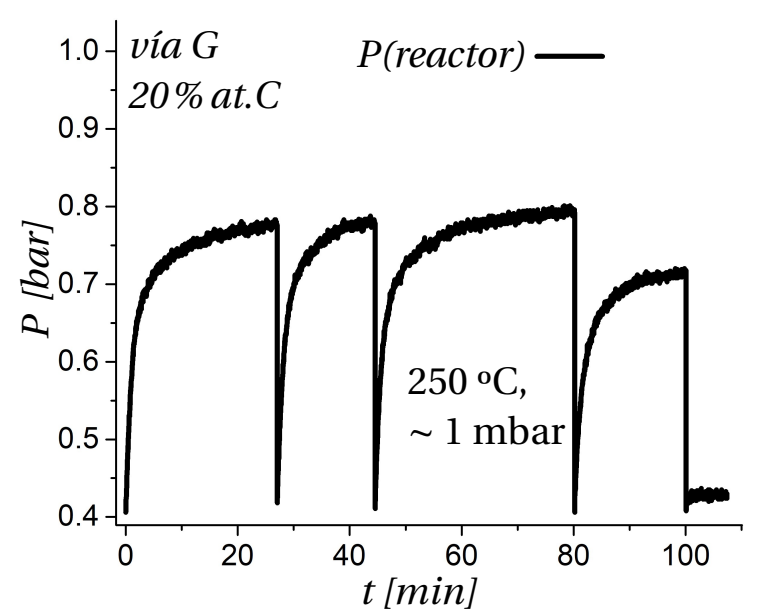

b)

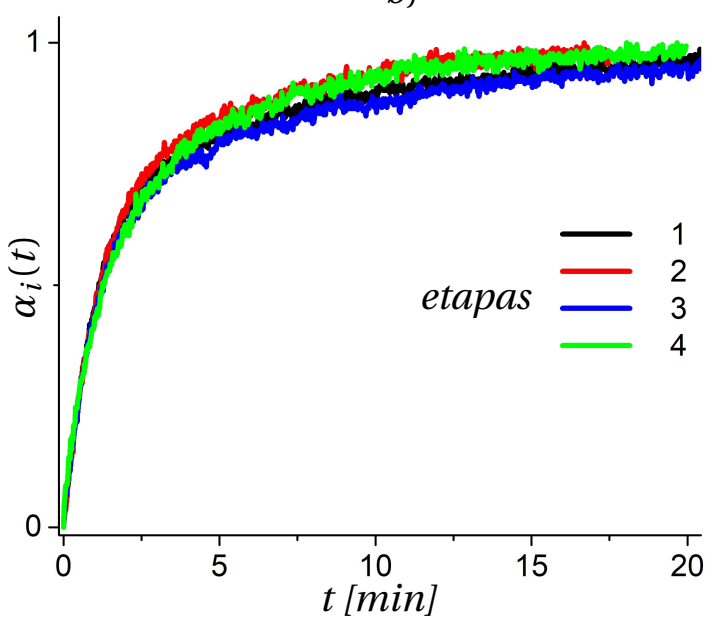

Figura 7.16: Cinética de desorción en etapas a $250^{\circ} \mathrm{C}$, vía G (CMT12). La presión inicial de vacío así como en el inicio de cada etapa era de $\sim 1$ mbar. $a$ ): Se muestra la medida de la presión en el reactor en función del tiempo b): Se muestran la fracción transformada correspondiente a cada etapa de desorción $(1 \rightarrow 4)$. Las muestras con grafito presentaban una notable similitud entre cada una de las etapas de desorción.

\section{Absorciones}

En las figuras 7.17 y 7.18 se muestran algunas experiencias de carga de hidrógeno en etapas para muestras con 10 y $20 \%$ at. de grafito respectivamente. Las absorciones se iniciaban a una presión de 5 bar. Luego, para para distintos grados de transformación alcanzados, se 
re-inyectaba gas estableciendo rápidamente una presión de 15 bar. Las regiones más suaves corresponden al período previo a re-inyecar gas. Los valores asintóticos de esas primeras etapas iniciadas a 5 bar corresponden a la presión de equilibrio alcanzada, por lo cual era necesario aumentar la presión notablemente ( y por lo tanto la fuerza impulsora) de manera de acelerar la absorción. Las figuras correspondientes ampliadas $(7.17 b$ y $7.18 b)$ permiten apreciar la etapa de nucleación de fase hidruro $\left(\mathrm{MgH}_{2}\right)$ dentro del primer minuto. Luego se observa una etapa de crecimiento que presenta aspectos diferentes para muestras con distinto contenido de grafito. En el caso de las muestra con $20 \%$ at. de grafito el crecimiento responde a un comportamiento del tipo $\alpha=k t$. En esta etapa de crecimiento en el que la presión y temperatura ofrecen una fuerza impulsora ${ }^{2} \frac{\Delta P}{T}$ no demasiado alta comparativamente a la segunda etapa, se observa que las trayectorias de las curvas pueden diferir. Esto revela la sensibilidad de la etapa de crecimiento con la presión (dependencia con los núcleos formados). Finalmente al establecer una presión mayor la transformación se acelera notablemente con pendientes muy similares en todas las experiencias.

Por último en la figura 7.19 se incluye una curva de absorción en etapas para la misma muestra con $20 \%$ at. de grafito realizada en etapas de menor presión: 5, 6 y 7 bar. La misma se presenta comparada con algunas de las curvas mostradas en la figura 7.18. Se resalta que aún para presiones menores en las etapas posteriores ( 6 y 7 bar) la transformación adquiere nuevamente una velocidad similar a la inicial al restaurarse la fuerza impulsora, mostrando que la fase hidruro formada no afecta notablemente la cinética de absorción.

a)

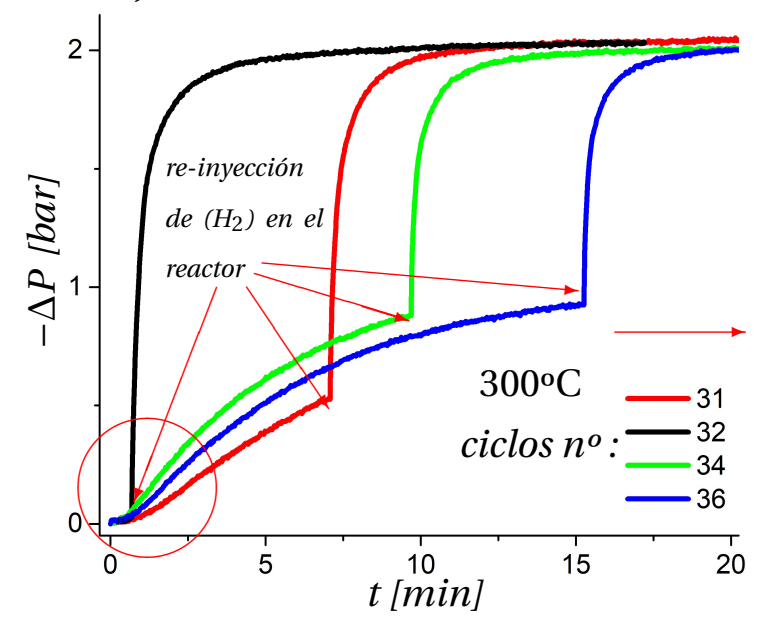

absorciones en etapas: 5 y 15 bar

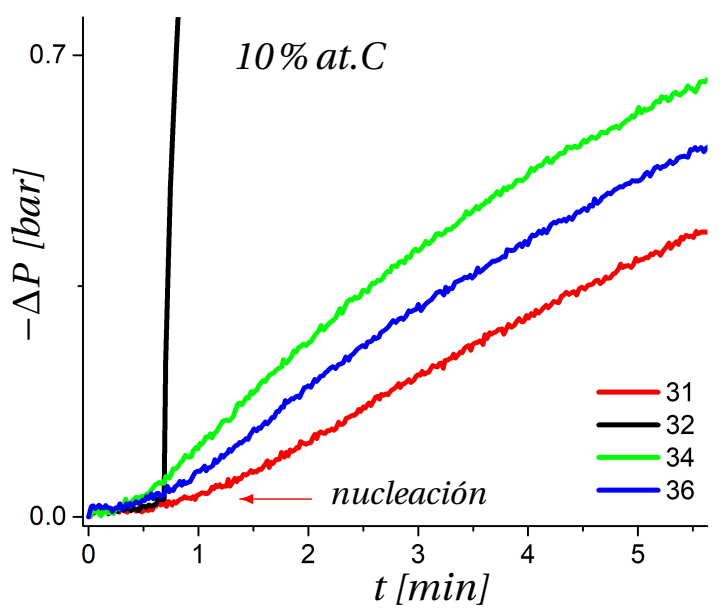

Figura 7.17: Cinética de absorción en etapas a $300^{\circ} \mathrm{C}$, vía G (CMT08). Las etapas de absorción se iniciaron en 5 y 15 bar respectivamente. $a$ ): Se muestran las cinéticas mediante el cambio en la presión $-\Delta P$ en función del tiempo. A diferentes tiempos luego de haber tenido expuesta la muestra $\sim 5$ bar, se re-inyectaba en el reactor con gas $\mathrm{H}_{2}$ de manera de establecre una presión de 15 bar.b): Se muestra amplificada la región de los primeros minutos a fin de apreciar la zona de nucleación y crecimiento inicial.

$2 \frac{\Delta P}{T}$ es una manera generalizada de cuantificar la fuerza impulsora de la reacción al apartarse las variables $\mathrm{P}$ y $\mathrm{T}$ de las condiciones de equilibrio. 
a)

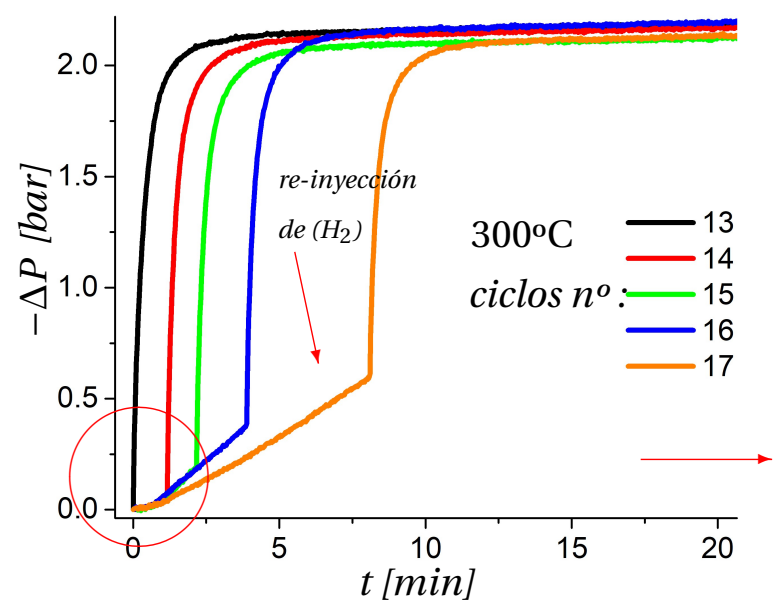

b)

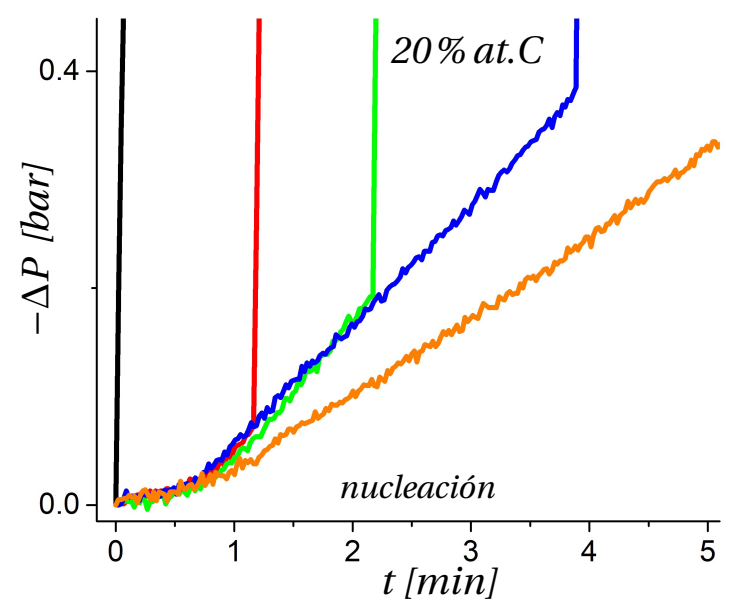

Figura 7.18: Cinética de absorción en etapas a $300^{\circ} \mathrm{C}$, vía G (CMT12). Las etapas de abosorción se iniciaron en 5 y 15 bar respectivamente. $a$ ): Se muestran las cinéticas mediante el cambio en la presión - $\Delta P$ en función del tiempo. A diferentes tiempos de haber tenido expuesta la muestra $\sim 5$ bar, se re-inyectaba en el reactor gas $\mathrm{H}_{2}$ en distinto tiempos, de manera de establecer una presión de 15 bar. b): Se muestra amplificada la región de los primeros minutos a fin de resaltar los procesos de nucleación y crecimiento asociados a esa etapa inicial.

a)

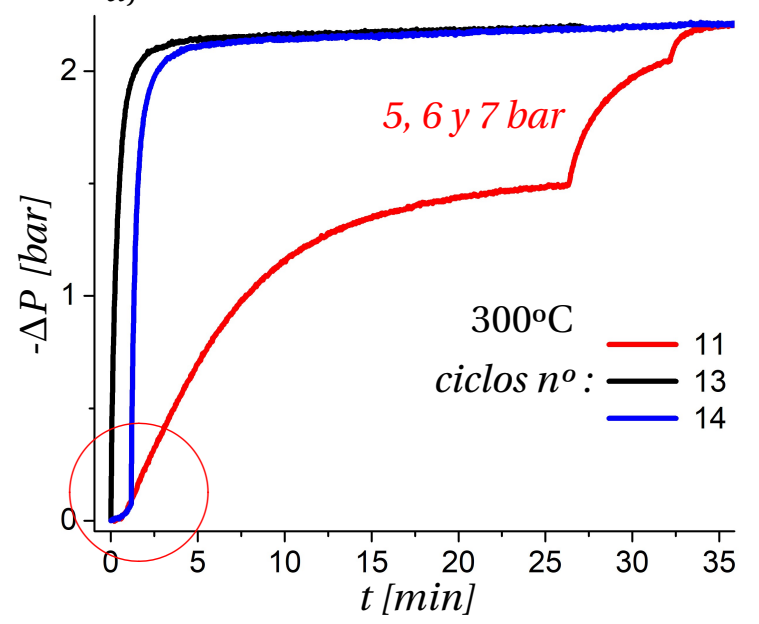

b)

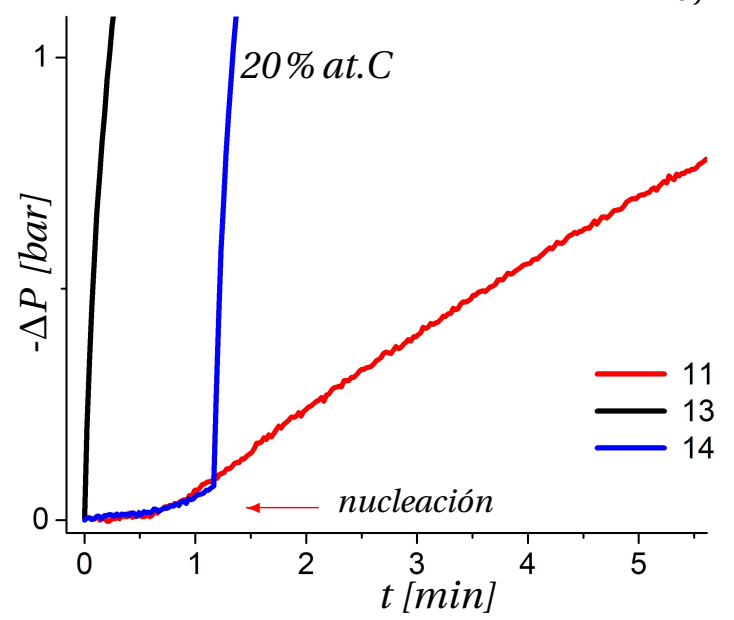

Figura 7.19: a) Cinéticas de absorción en etapas representadas mediante el cambio en la presión - $\Delta P$ en función del tiempo. Se comparan cinéticas de absorción en etapas a $300{ }^{\circ} \mathrm{C}$ para una muestra fabricada por la vía G (CMT12). Fueron realizadas a distintas presiones respectivamente: 15 bar (negra), 5 y 15 bar (azul) y 5,6 y 7 bar (roja). b) Se muestra amplificada la parte de las curvas de la figura $a$ ) correspondiente a los primeros minutos de absorción. 


\section{Capítulo 8}

\section{Resultados Parte III: Calorimetría Diferencial}

Este capítulo tiene como objetivo presentar los resultados principales obtenidos mediante las medidas calorimétricas descritas en la sección 4.3 del Capítulo 4. Se mostrarán primeramente las desorciones calorimétricas realizadas en atmósfera de hidrógeno (UNITO). Luego se mostrarán los resultados de calorimetría diferencial combinados con termogravimetría realizadas en atmósfera de Ar a flujo constante (IFE). Finalmente se mostrarán los resultados principales obtenidos en el laboratorio de calorimetría de IFLP en flujo de Ar. Esta última serie incluye corridas realizadas tanto con muestras frescas como sobre muestras previamente sometidas a varios ciclos de carga de hidrógeno en el equipo volumétrico, lo que permitió conocer si las características observadas para muestras frescas, se conservaban en muestras tratadas.

\subsection{Calorimetría diferencial en $\mathbf{H}_{2}$}

\subsubsection{Sobre los barridos DSC}

Las corridas DSC descritas en la sección experimental 4.3 corresponden a muestras:

- con distinto contenido de grafito, $0 \%, 5 \%$, y $20 \%$,

- fabricadas por distintas vías $(A, B, G y D)$

- frescas y tratadas (variando la cantidad de ciclos térmicos antes del barrido o corrida)

Las corridas (barridos) se realizaron sobre especímenes de las muestras indicadas en las tablas del capítulo 4. Se muestran los resultados de acuerdo al orden en que fueron presentados en la sección experimental, es decir según los laboratorios en las que fueron realizadas, lo que implica condiciones particulares de medida (atmósferas de trabajo, diferencias en los programas de calentamiento, etc).

En todas las corridas realizadas en atmósfera de $\mathrm{H}_{2}$ de la primera serie, la presión inicial fue $P \simeq 2$ bar y se mantuvo en un rango acotado durante cada corrida, dado que las masas utilizadas eran pequeñas y el volumen de la cámara en donde ocurrían los procesos era relativamente grande. Las diferencias entre las presiones iniciales de diferentes corridas, aunque 


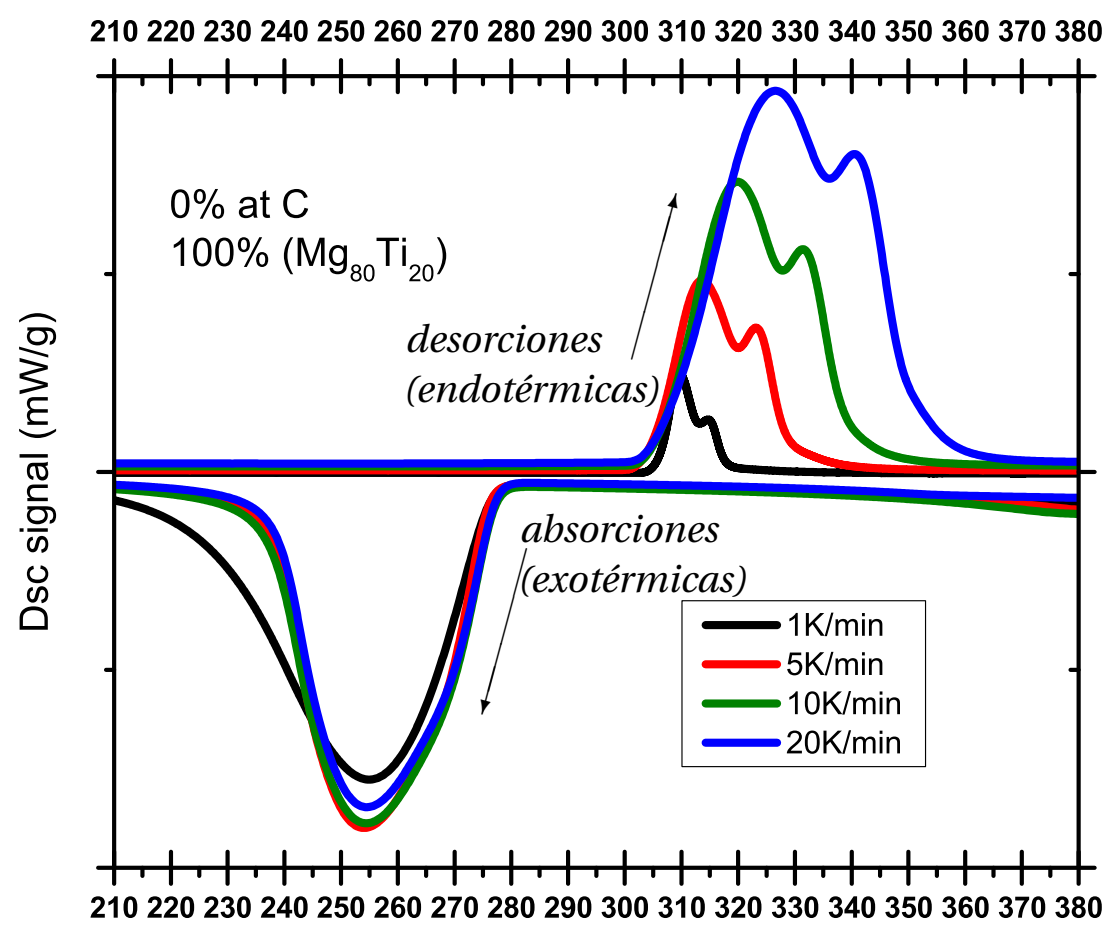

Figura 8.1: Medidas DSC $\left(y^{+}\right)$sobre la muestra prepatrada hidrurada MT42 de composición $\mathrm{Mg}_{80} \mathrm{Ti}_{20}$. Se muestran también los picos exotérmicos $\left(y^{-}\right)$de las absorciones, cuyos máximos prácticamente coinciden.

no superaron el 30\%, debieron ser tenidas en cuenta en el análisis.

La figura 8.1 corresponde a una serie de corridas realizadas en la UNITO en atmósfera de $H_{2}$ sobre muestras hidruradas de composición $\mathrm{Mg}_{80} \mathrm{Ti}_{20}$ preparadas por molienda directa (vía A). Las curvas representan la señal DSC $\left[\frac{m W}{m g}\right]$ en función de la temperatura $\mathrm{T}\left[{ }^{\circ} \mathrm{C}\right]$. La señal representa la potencia por unidad de masa requerida para mantener la velocidad de calentamiento (enfriamiento) programada en la corrida ${ }^{1}$. Se indican en colores las distintas velocidades de calentamiento empleadas. Los enfriamientos para toda esta serie fueron espontáneos. ${ }^{2} \mathrm{Se}$ destaca la estructura de doble pico en las curvas de desorción. En contraposición, las curvas de absorción presentan una forma aparentemente simple. Sin embargo una ampliación en la zona de las curvas de absorción ya revela que la estructura es más compleja (en la segunda serie de medidas realizadas en atmósfera de $\mathrm{H}_{2}$, con enfriamiento programado, esto se observa claramente). Entre los resultados obtenidos en esta primera serie de corridas en atmósfera de $\mathrm{H}_{2}$, la estructura de picos múltiples y la serie de absorciones durante el enfriamiento fue lo que impulsó principalmente la planificación de la segunda serie de medidas en $H_{2}$ (tabla 4.2). Las desorciones calorimétricas graficadas en función de la temperatura típicamente tienen el aspecto de la figura 8.1: las corridas a velocidades de calentamiento mayor presentan en general un corrimiento hacia temperaturas más elevadas, que suele asociarse a procesos que

\footnotetext{
${ }^{1}$ La representación de la señal en función del tiempo se mostrará más adelante, la cual será útil para calcular la cantidad de hidrógeno desorbido y hacer un análisis de la cinética.

${ }^{2}$ Enfriamiento espontáneo, con un inicio de rampa de $-40 \mathrm{~K} / \mathrm{min}$.
} 
se denominan térmicamente activados. Este corrimiento de las curvas DSC puede apreciarse principalmente en términos de los picos, pero también pueden compararse las temperaturas de inicio de la desorción estimulada, $T_{\text {des }}$ y los perfiles de las curvas. De acuerdo a la ecuación 2.5, y considerando una relación lineal entre el calor involucrado en la reacción y la velocidad de transformación ${ }^{3}$, la temperatura de los picos o máximos, (llamémosla $T_{m}$ ), se corresponden con la situación de velocidad máxima de reacción $\Rightarrow \frac{d \alpha}{d t}$ máx. , siendo $\alpha(t)$ el grado de transformación de la reacción. El incremento en las áreas observado se debe a un incremento en la potencia disipada al incrementarse la velocidad de calentamiento programada:

$$
\frac{d Q}{d t}=\frac{d Q}{d T} \cdot \frac{d T}{d t}
$$

siendo $\frac{d T}{d t}=\beta$ la velocidad de calentamiento constante en cada ensayo dada por $T(t)=$ $T_{0}+\beta t$.

La representación de las curvas DSC en función del tiempo, en lugar de la temperatura, tiene el aspecto de la figura 8.2 (correspondiente a la misma serie que la figura 8.1). Se aprecian las curvas corridas en tiempos. Esto resulta natural considerando que la velocidad $\beta$ es distinta en cada caso, por lo que las temperaturas asociadas al inicio y transcurso de los procesos se alcanzan en momentos distintos. En esta representación se puede percibir que las áreas son iguales, las cuales están asociadas a la cantidad de hidrógeno desorbido. El grado de transformación $\alpha(t)$ se puede obtener a partir de las integrales normalizadas de las curvas $D S C$ vs $t$.

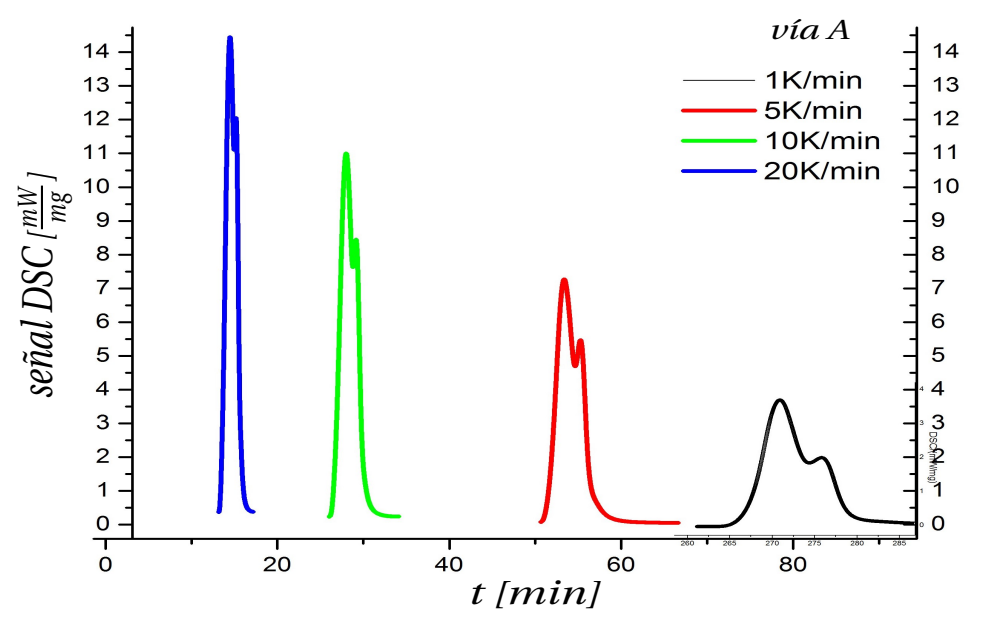

Figura 8.2: La representación en función del tiempo muestra que las áreas se conservan. La curva correpsondiente a $1 \mathrm{~K} / \mathrm{min}$ está corrida manteniendo la escala para compararla con el resto de las curvas

Los valores de las áreas en esta serie (MT42, Serie I) resultaron iguales dentro del intervalo de incerteza $1450_{100} \mathrm{~J} / \mathrm{g}$.

${ }^{3} d Q_{r}=m \Delta H_{r} X_{\max } \cdot \frac{d \alpha}{d t} d t$ 


\subsubsection{Desorciones DSC en $\mathrm{H}_{2}$}

\section{Primeras desorciones de muestras frescas}

En la figura 8.3 se muestran comparativamente los gráficos de las primeras desorciones realizadas a distintas velocidades. Corresponden a muestras con distinta cantidad de grafito y/o fabricadas por distintas vías $A, B, G$ (muestras MT42, MT48, CMT13 y CMT18 de la tabla 4.1). En primer lugar se hace notar que la presencia de picos dobles perfectamente distinguibles, para el caso de la muestra preparada por hidrogenación directa, vía A (MT42) se modifica con el agregado de grafito como se puede percibir en la figuras $8.3 a, c$, $d$ : un pequeño porcentaje de grafito $(5 \%)$ cambia drásticamente la estructura atenuando el proceso asociado al primer pico, o dicho de otra manera, la distinguibilidad de los picos se reduce notablemente. En el caso de las muestras preparadas por la vía B (MT48) se puede observar que hay solamente picos simples para cada velocidad, pese a tener la misma estequiometría que la muestra MT42.

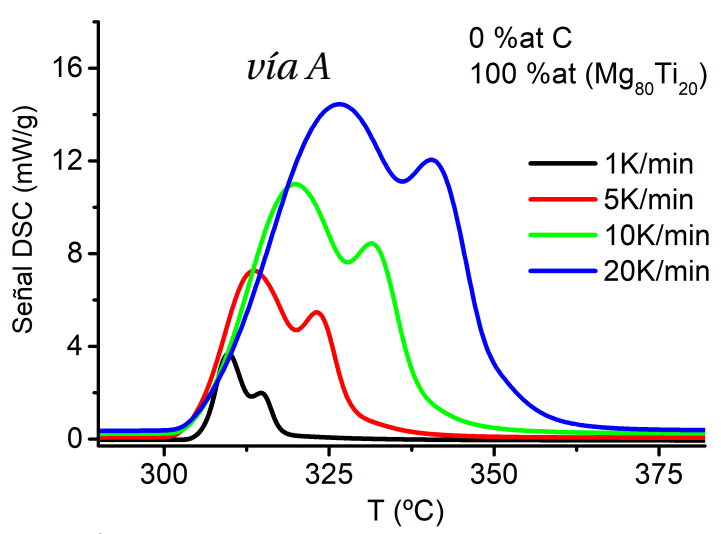

a)

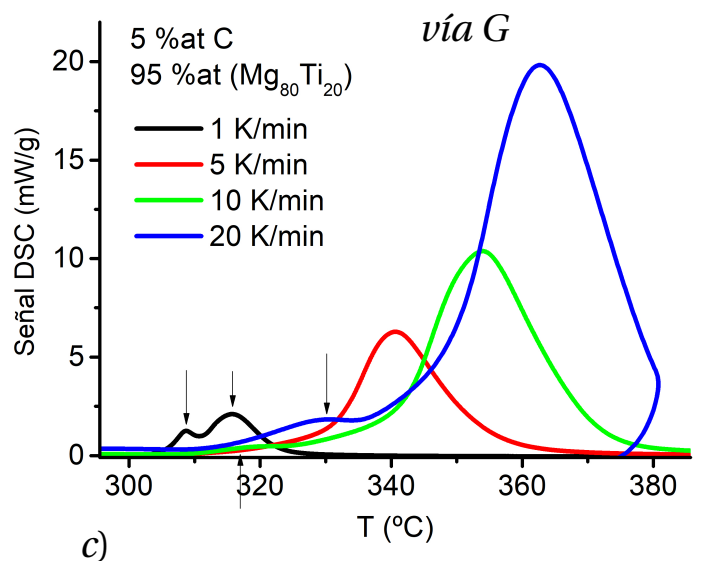

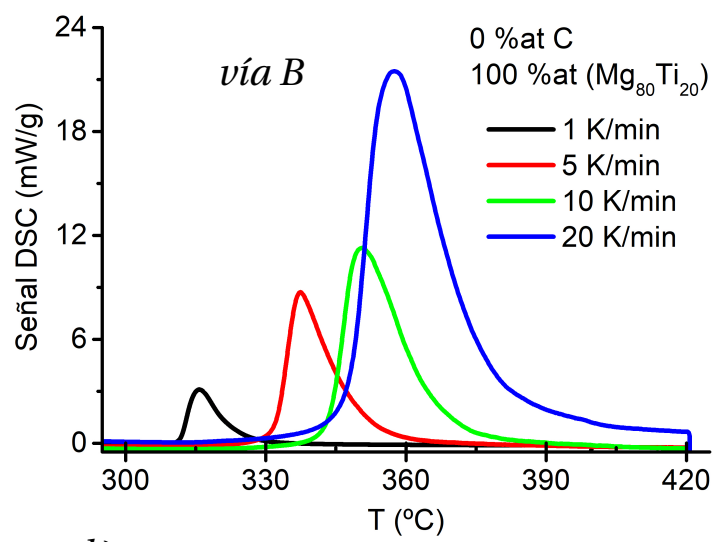

b)

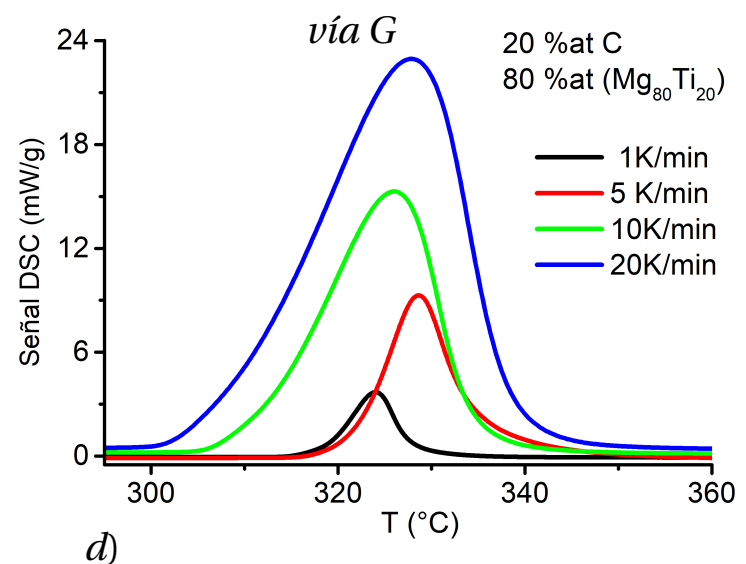

d)

Figura 8.3: Las figuras muestran los barridos de desorción DSC para el conjunto de las distintas velocidades de calentamiento y para muestras con distinta cantidad de grafito (figuras $a, c, d$ ) y fabricadas por distintas vías (figuras $a, b$ ). Los especímenes utilizados tenían una masa entre 20 y $30 \mathrm{mg}$. 
Respecto a las temperaturas de inicio de la desorción, $T_{d e s}$, puede observarse que coinciden en el caso de los sistemas Mg-Ti directamente preparados (vía A). Las presiones en este caso fueron similares en cada corrida. En tanto que para el resto de las muestras hubo leves diferencias en la presión inicial para las distintas corridas, lo cual se vincula con la variación de las las temperaturas de desorción. Esto se ilustra en las figuras F.1, F.2 y F.3 del Apéndice F.

\subsubsection{Absorciones DSC en $\mathrm{H}_{2}$}

\section{Primera absorción luego de una desorción}

Las curvas de absorción de hidrógeno se muestran en la figura F.9 (Apéndice F). Fueron medidas durante el enfriamiento luego de las medidas de desorción DSC realizadas en hidrógeno. En las figuras se especifican las velocidades de calentamiento respectivas a las corridas DSC de desorción previamente realizadas. Se comprobó (con alguna excepción) que las velocidades de enfriamiento fueran las mismas para todos los casos. Los enfriamientos comenzaban con una pendiente de $\sim 40 \mathrm{~K} / \mathrm{min}$ pero al iniciarse la absorción las velocidades de enfriamiento eran de $\sim 19 \mathrm{~K} / \mathrm{min}$, finalizando en $\sim 12 \mathrm{~K}$ min. Algunas de las medidas aparecen incompletas porque fueron detenidas antes de que los procesos de absorción finalizaran. Contrariamente a los picos de desorción, en este caso son picos simples. En el caso de $\mathrm{Mg}_{80} \mathrm{Ti}_{20}$ directamente preparado, las curvas se superponen, siendo las temperaturas de pico $T_{m}$, prácticamente idénticas (tabla G.2). Las otras muestras presentan temperaturas de absorción $T_{a b s}$ y de pico $T_{m}^{a b s}$ corridas. Las temperaturas de inicio de absorción $T_{a b s}$, solo coinciden para el caso de las muestras MT42 y CMT18. Esto último también estuvo relacionado con el hecho que las presiones de partida no fueron las mismas para las distintas corridas, de manera que pequeñas variaciones de presión inicial (y según la muestra), afectaba la temperatura de equilibrio del sistema, modificando la temperatura de inicio de la absorción. Las muestras con grafito resultaron más sensibles a estas variaciones de presión inicial.

\subsubsection{Ciclos de absorción y desorción en $\mathrm{H}_{2}$. Segunda serie}

Por otro lado, en la figura 8.4, se presentan las curvas de desorción/absorción de la segunda serie de corridas realizadas en atmósfera de $\mathrm{H}_{2}$, con el mismo equipo en la UNITO. Corresponden a la muestra MT42 en la que se identificaron los picos dobles durante la primera serie. Las corridas de esta segunda serie son ciclos continuados de desorción/absorción realizados a las mismas velocidades de calentamiento que la primera serie, pero esta vez programando la velocidad de enfriamiento igual a la velocidad de calentamiento. Se observa que la primera desorción se diferencia notablemente de la segunda y tercera, las cuales son muy similares. Esto ocurre para todas las velocidades. Nuevamente las presiones fueron levemente diferentes entre cada ciclo y también respecto a la primera serie de medidas (ver figura F.3. La estructura de doble pico en las desorciones ya no se distingue. En cambio, para las absorciones, se puede percibir una estructura compleja de dos o más picos. Para apreciarlo mejor se muestran juntas en la figura 8.5 todos los ciclos de absorción realizados a distintas velocidades. Además, la estructura de las curvas calorimétricas de absorción (exotérmicas) resulta análoga a la de las desorciones (endotérmicas) de la misma muestra pero realizadas en la primera serie de medidas (figura 8.3).

Los ciclos de desorción se muestran en las figuras 8.6a y 8.6b. Tanto en los ciclos de absorción 
como de desorción se observa una diferencia sistemática entre las curvas de cada ciclo, las cuales no se superponen exactamente. Se indica con una flecha el sentido en el que se incrementa el $n^{\circ}$ de ciclo correspondiente.
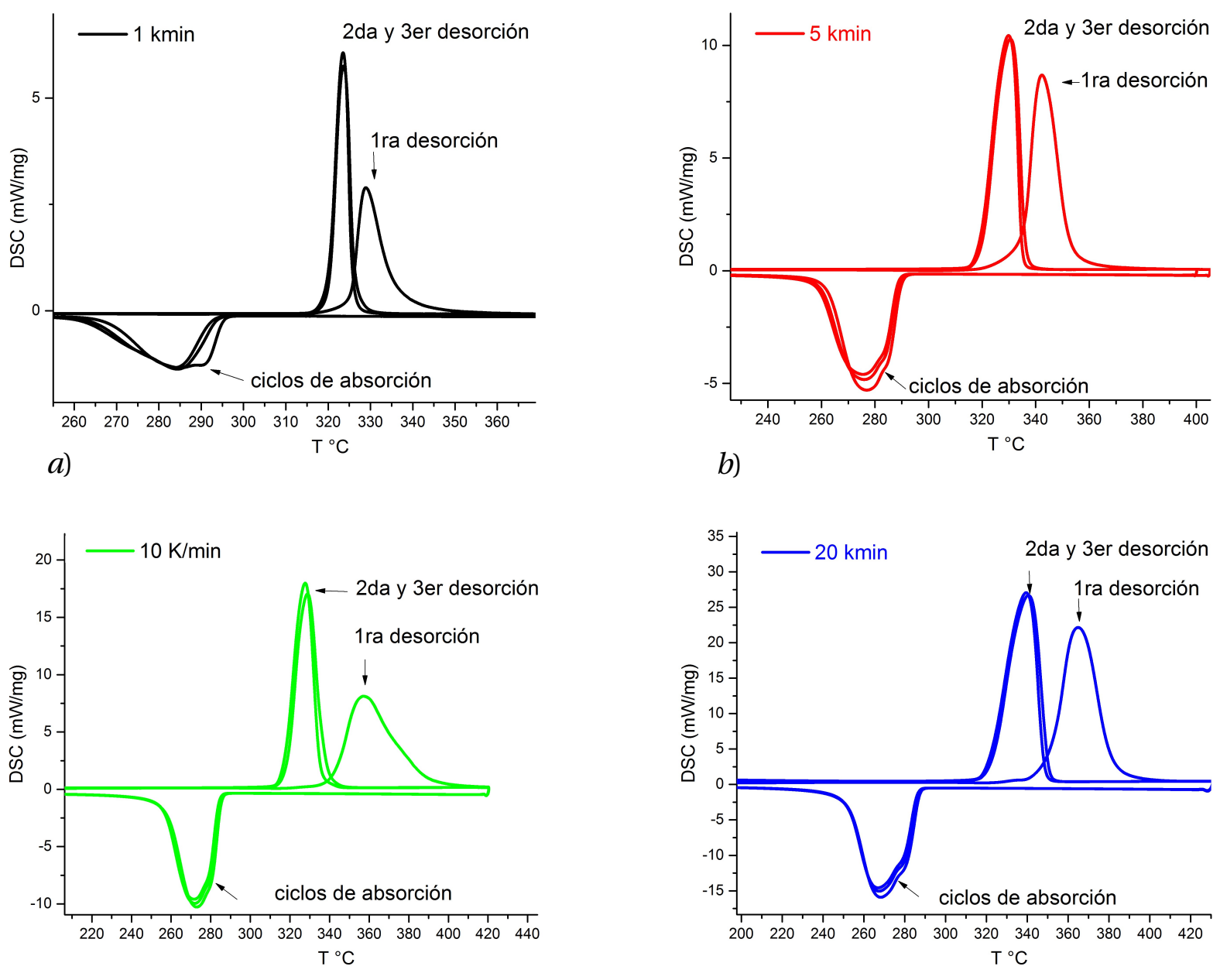

c)

d)

Figura 8.4: Ciclos de absorción/desorción calorimétricos. Segunda serie. Se muestran separadamente los ciclos (3), de absorción/desorción realizados a distintas velocidades de calentamiento/enfriamiento: $1 \mathrm{~K} / \mathrm{min}$ $(a), 5 \mathrm{~K} / \mathrm{min}(b), 10 \mathrm{~K} / \mathrm{min}(c), 20 \mathrm{~K} / \mathrm{min}(d)$. 


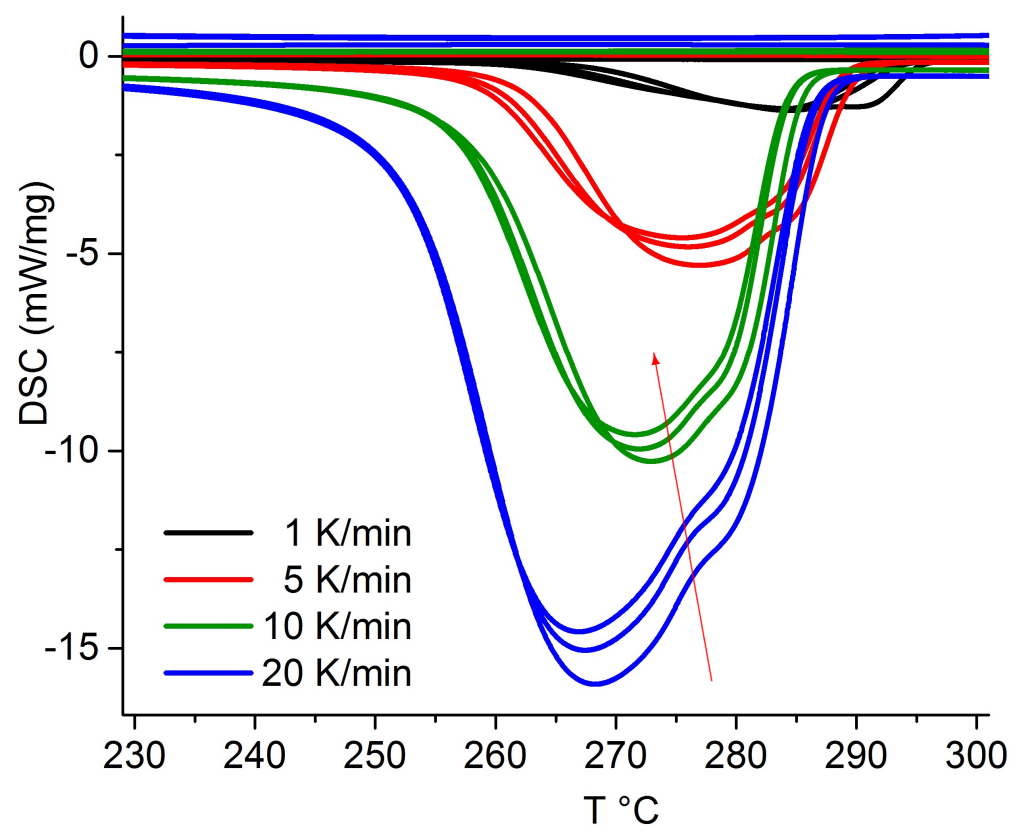

Figura 8.5: Segunda serie de corridas DSC en $\mathrm{H}_{2}$ con enfriamiento programado, realziadas con la muestra MT42. Se muestran los tres ciclos de absorción para cada velocidad de enfriamiento. En cada ciclo se observa un ligero y progresivo cambio de las cinéticas (indicado con el sentido de la flecha).
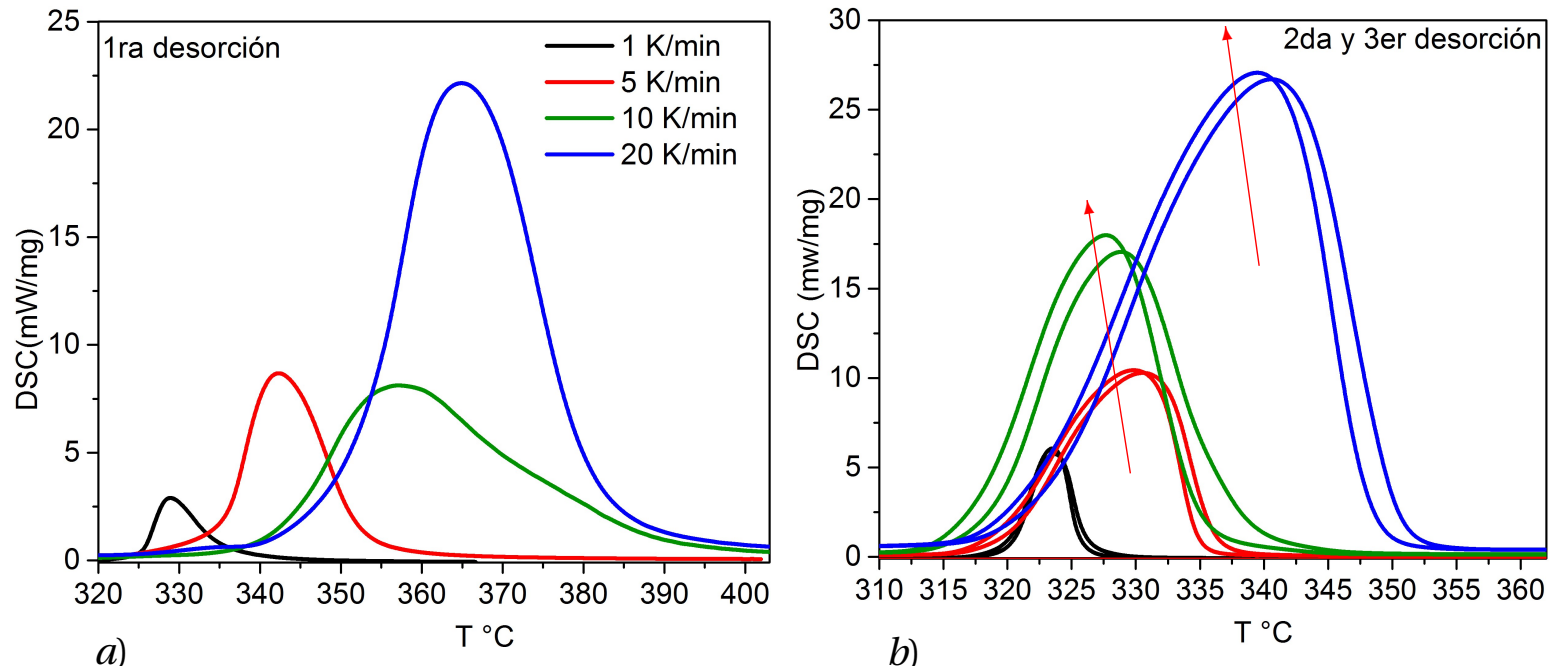

Figura 8.6: Comparación de ciclos de desorción DSC. Segunda serie de corridas en $\mathrm{H}_{2}$ realizadas con la muestra MT42. En cada ciclo se observa un ligero y progresivo cambio de las cinéticas (indicado con el sentido de la flecha). 


\subsection{Calorimetría en $A r$ combinada con termogravimetría}

A continuación se muestran las medidas termogravimétricas combinadas con calorimetría. Se hicieron sobre muestras semejantes a las utilizadas en las medidas de la sección anterior (ver tabla 4.3). Las medidas calorimétricas se muestran comparadas con las medidas termogravimétricas respectivas en cada subfigura de la figura 8.7. Las líneas punteadas ilustran la coincidencia entre las temperaturas de desorción $T_{\text {des }}$ de cada corrida con la temperatura donde se registra el inicio de pérdida de masa de cada espécimen. Si bien la finalización de los procesos es más difícil de determinar, cualitativamente se observa que también coinciden la finalización de la desorción con la finalización de la pérdida de masa.
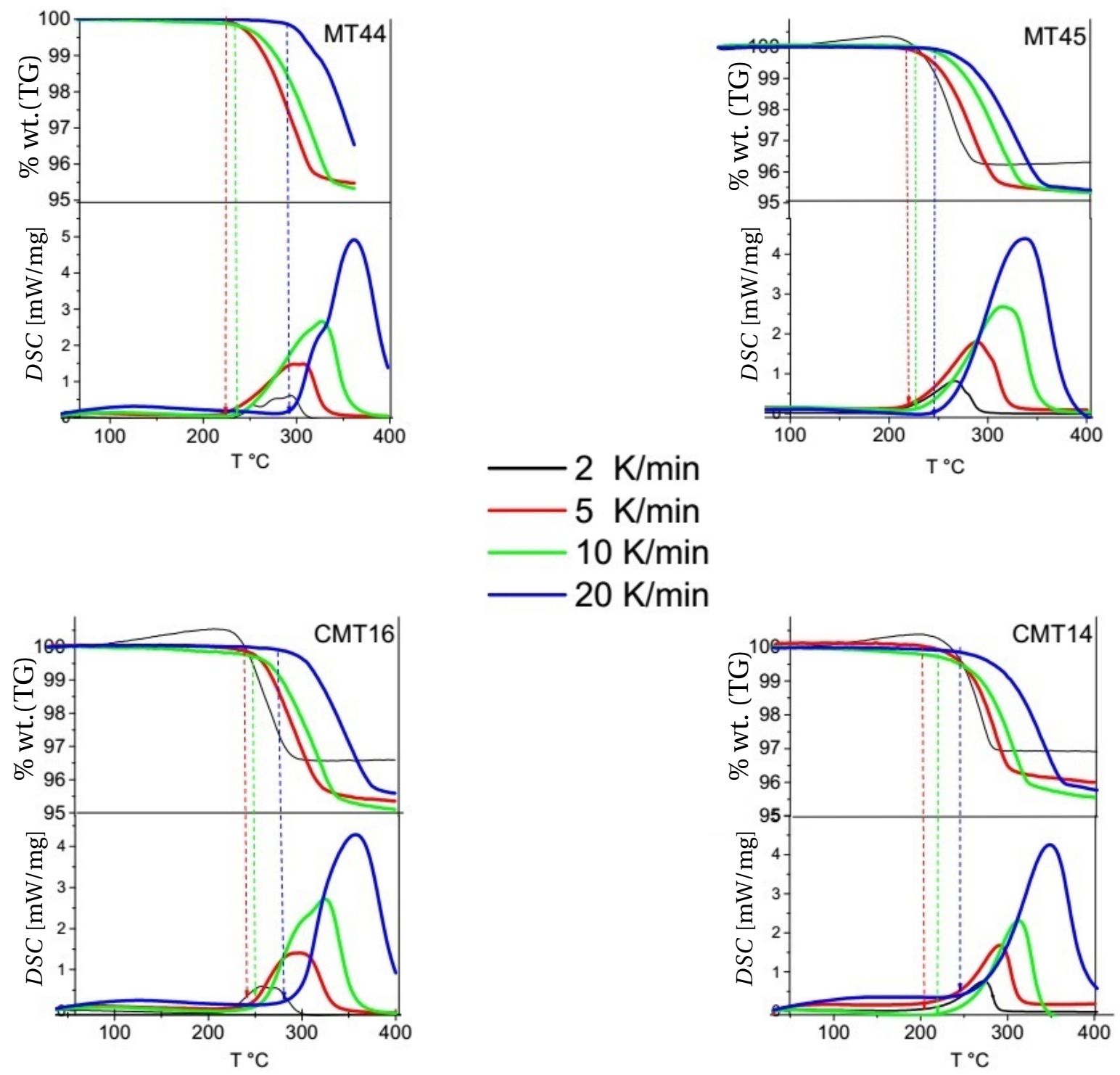

Figura 8.7: Medidas termogravimétricas en flujo de Ar, combinadas con calorimetría. Se comparan las corridas calorimétricas de cada muestra con las medidas termogravimétricas respectivas, indicando los inicios de las desorciones (líneas punteadas). Las corridas a baja velocidad (2K/min) se incluyeron en un trazo más fino. 
Las temperaturas de desorción para estas corridas en flujo de Ar resultan en general mas bajas que las corridas realizadas en $\mathrm{H}_{2}$, lo que resulta natural por la ausencia de presión parcial de $\mathrm{H}_{2}$ que contribuye un flujo ingresante de hidrógeno a las muestras. Los hombros de desorción eran cercanos a $200^{\circ} \mathrm{C}$. Las corridas presentan el corrimiento típico de sistemas térmicamente activados. La pérdida de peso medida (capacidad) de las muestras fue en general de $\sim 4,65 \%$ del peso de la muestra ( ver figura F.4). Las corridas a $20 \mathrm{~K} / \mathrm{min}$ tienen una zona de recuperación de defectos más pronunciada. Las corridas correspondientes a la velocidad $2 \mathrm{~K} / \mathrm{min}$ presentaron un comportamiento distinto debido a una posible oxidación como mostraron las medidas termogravimétricas (en la figura F.5 del apéndice F se muestran todas las corridas a $2 \mathrm{~K} / \mathrm{min}$ juntas y puede verse un aumento de masa antes de la desorción). Comparando con las corridas en $\mathrm{H}_{2}$ puede notarse que en general se mantiene cualitativamente la estructura de picos para las vías de fabricación (excepto la vía B). En las figuras 8.8a y $b$ se muestran amplificadas las corridas en Ar para las muestras fabricadas por las vías $\mathrm{B}$ y G a fin de apreciar mejor la estructura de las curvas. En el caso de la vía B, (muestra MT45) puede distinguirse ahora la existencia de una estructura compleja, aunque no llegan a resolverse los picos.

A fin de ilustrar esta tendencia, se comparan en la figura F.6 del Apéndice F las medidas

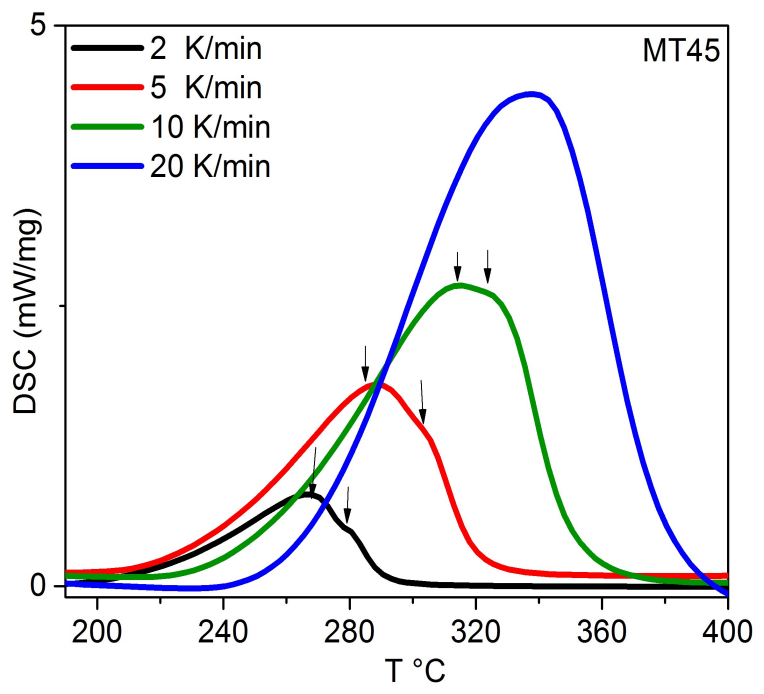

a)

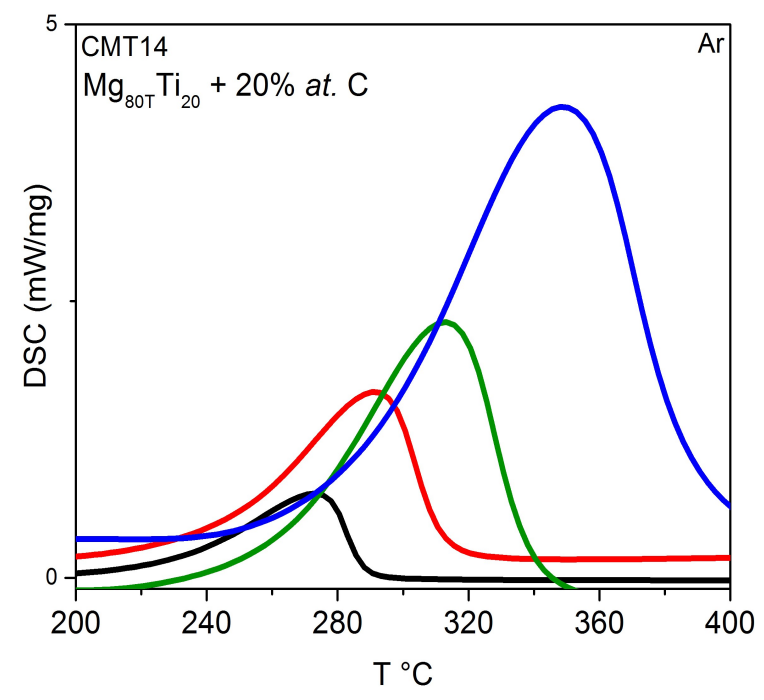

b)

Figura 8.8: Desorciones DSC en Ar correspondientes a las muestras fabricadas por las vías B $(a)$ y G $(b)$. Independientemente de la atmósfera circundante las muestras con grafito siempre presentaron curvas simples mientras que para la vía B esto era dependiente de las condiciones atmosféricas.

TG-DSC para la velocidad 5/Kmin correspondientes a las muestras fabricadas por las vías A y B.

A modo de completitud se agrega en el apéndice una figura (F.7) que revela la pérdida de un pequeño porcentaje de peso del $\mathrm{TiH}_{2}$ fabricado mediante molienda mecánica reactiva con el molino vibratorio. 


\subsubsection{Calorimetría diferencial en $\operatorname{Ar}$ y $N_{2}$}

\section{Desorciones para muestras frescas y tratadas}

Se presentan en la figura 8.9 los resultados de las medidas DSC realizadas en flujo de Ar $(50 \mathrm{ml} / \mathrm{min})$ en el IFLP. Se realizaron sobre especímenes frescos y sometidos a varios ciclos de carga y descarga de hidrógeno (tablas 4.4 y 4.5). Las masas utilizadas fueron de 5 a $15 \mathrm{mg}$ y las velocidades de calentamiento programadas de 5, 10, 20, 30 y $40 \mathrm{~K} / \mathrm{min}$

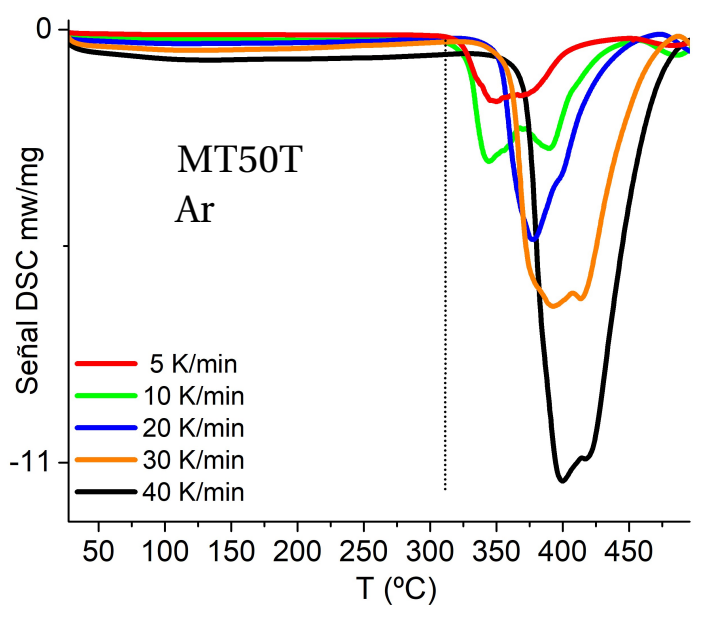

a)

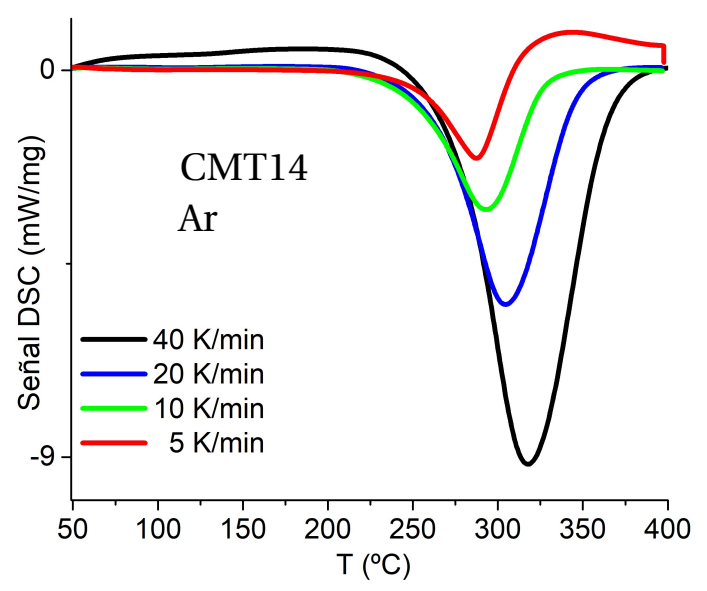

c)

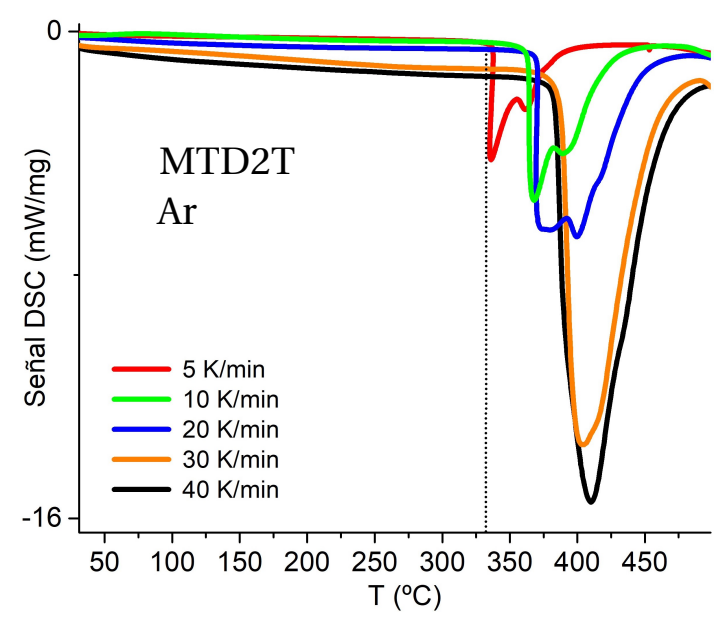

b)

Figura 8.9: Corridas DSC realizadas en Ar sobre muestras frescas y tratadas,IFLP. $a, b$ : Se muestran respectivamente las corridas realizadas en Ar sobre muestras tratatadas, fabricadas por las vías A(MT50T) y D(MTD2T). $c, d$ : Se muestran respectivamente las corridas realizadas en flujos de Ar y $N_{2}(50 \mathrm{ml} / \mathrm{min})$, sobre especímenes frescos de la misma muestra con $20 \%$ at. de grafito (CMT14). 
En las figuras $a$ y $b$ se muestran respectivamente las corridas realizadas en Ar sobre muestras fabricadas por las vías A y D. Ambas fueron sometidas a los mismos ciclos de carga y descarga de hidrógeno previamente a las corridas. A la muestra fabricada por la vía D se la sometió a algunos ciclos más a fin de evacuar el deuterio incorporado químicamente durante la molienda. Se destaca la existencia de múltiples picos como se observó para muestras frescas semejantes sometidas a desorciones calorimétricas en $H_{2}$. Sin embargo las temperaturas de desorción son algo superiores.

En las figuras $c$ y $d$ se muestran respectivamente las corridas realizadas en flujos de $\operatorname{Ar}$ y $N_{2}$ (50 $\mathrm{ml} / \mathrm{min}$ ), sobre especímenes frescos de la misma muestra con $20 \%$ at. de grafito (CMT14). La estructura de las curvas preserva la forma simple observada para la misma muestra en las corridas realizadas en otros equipos, en $\mathrm{Ar}$ (IFE) y en $\mathrm{H}_{2}$ (UNITO). Una vez más se manifiesta la existencia de una estructura simple para muestras con $20 \%$ at. de grafito. Las corridas en Ar y $N_{2}$ mostradas en las figuras 8.9, se comparan en un mismo gráfico en el Apéndice F (figura F.8).

Finalmente en la figura 8.10 se comparan curvas de desorción calorimétrica realizadas sobre

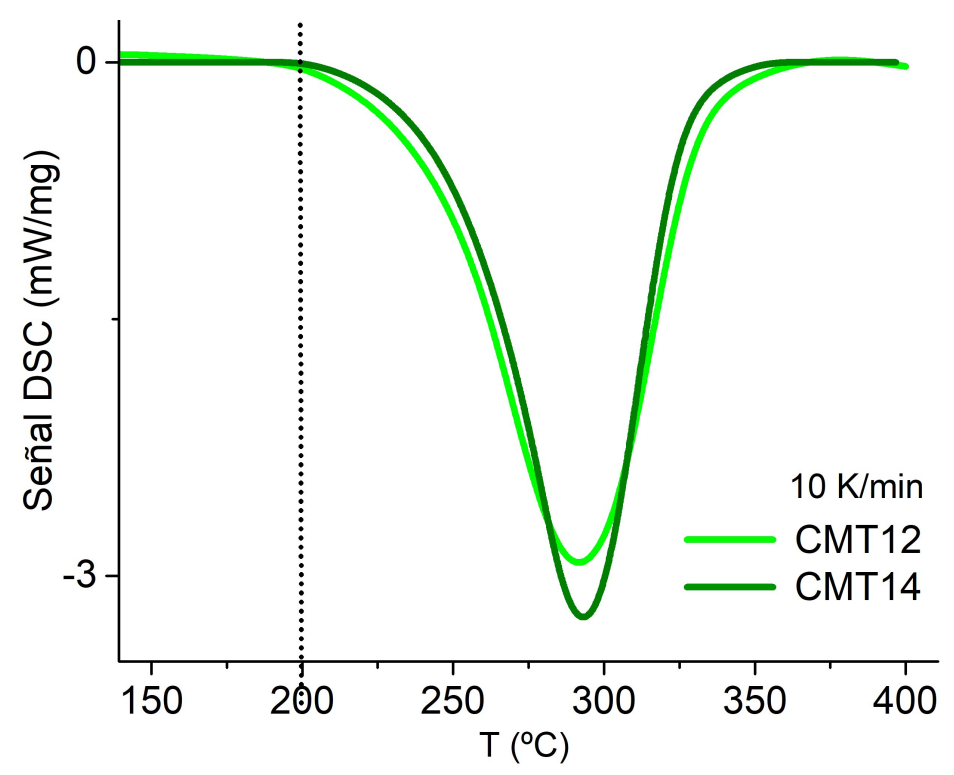

Figura 8.10: Se comparan curvas desorción calorimétrica realizadas sobre especímenes de muestras distintas (CMT12 y CMT14) pero fabricados por la misma vía, ambos con $20 \%$ at. de grafito. Las corridas fueron realizadas en flujo de Ar a una velocidad de calentamiento de $10 \mathrm{~K} / \mathrm{min}$ usando masas similares (13 y $15 \mathrm{mg}$ ).

especímenes de muestras distintas (CMT12 y CMT14), ambos con $20 \%$ at. de grafito. Las corridas fueron realizadas en flujo de Ar a una velocidad de calentamiento de $10 \mathrm{~K} / \mathrm{min}$ usando masas similares (13 y $15 \mathrm{mg}$ ). A ambas curvas se les sustrajo la línea de fondo medida posteriormente a cada corrida. El hombro de desorción es cercano a $\sim 200^{\circ} \mathrm{C}$. Se destaca que siendo muestras con distinto grado de envejecimiento manifiestan comportamientos iguales. 


\section{Capítulo 9}

\section{Análisis}

La evidencia experimental revela la existencia de múltiples procesos asociados a las cinéticas de hidruración de los sistemas fabricados. A su vez, estos procesos dependen de la vía de fabricación. En la primera parte de este capítulo se discutirán los ajustes realizados a las curvas cinéticas obtenidas en el equipo volumétrico. En la segunda, se mostrará el análisis realizado sobre las curvas calorimétricas, reportando las energías de activación obtenidas y las funciones que describen los procesos involucrados.

\subsection{Cinéticas de absorción y desorción isotérmica}

Las curvas cinéticas a temperatura constante mostraron que los mecanismos de sorción son sensibles a la vía de fabricación, y, naturalmente, a las condiciones de presión y temperatura. Particularmente las cinéticas realizadas en etapas revelaron que la velocidad de transformación puede mantenerse mientras se preserve la fuerza impulsora $\frac{\Delta P}{T}$, manteniéndose la velocidad en cada etapa sin cambios notables (figuras 7.14 a 7.19). Esto incluso era comparativamente más evidente para el caso de las muestras fabricadas por la vía B, cuya etapa de nucleación era más lenta (figura 7.14). Este comportamiento se ilustra mejor mediante la aplicación de la ecuación de Avrami 2.2. En la figura 9.1 se muestran típicos gráficos de Avrami (a) construidos mediante la aplicación de la ecuación 2.2 sobre las curvas cinéticas respectivas $(b)$. Las curvas corresponden a procesos de absorción a distintas temperaturas (alta y baja) obtenidas con el equipo volumétrico. El eje de ordenadas corresponde al intervalo amplio acotado en el intervalo $\alpha \in[0,15 ; 0,95]$ [130] a fin de eliminar la regiones de ruido que corresponden generalmente a las colas de las curvas. Se comparan los gráficos de Avrami para las muestras fabricadas por las vías A y B. Claramente las muestras fabricadas por la vía B requerían una re-inyección de gas en el reactor (restauración de la fuerza impulsora $\frac{\Delta P}{T}$ ) para recuperar la velocidad inicial de la reacción. Además, los gráficos revelan que para mayores temperaturas y manteniendo la presión, (y por lo tanto reduciendo la fuerza $\frac{\Delta P}{T}$ ) se hace más evidente la existencia de diferentes regiones (diferentes pendientes). La diferenciación entre las regiones a partir de los gráficos de Avrami es más notoria para las muestras fabricadas por la vía A, mientras que para la vía B la transición es más suave. Esto concuerda con la posibilidad de resolver de manera distinta los procesos superpuestos como se observó mediante calorimetría diferencial. 


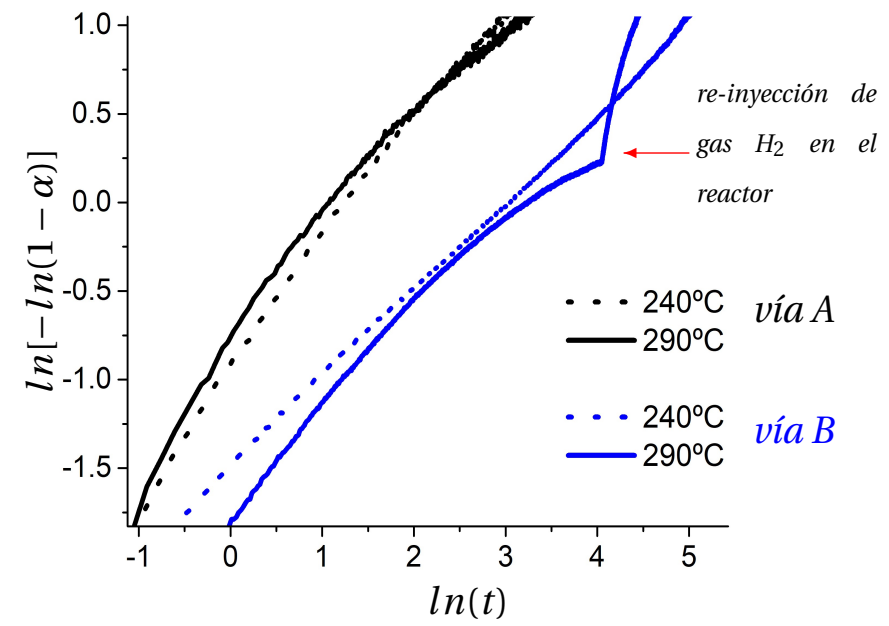

a)

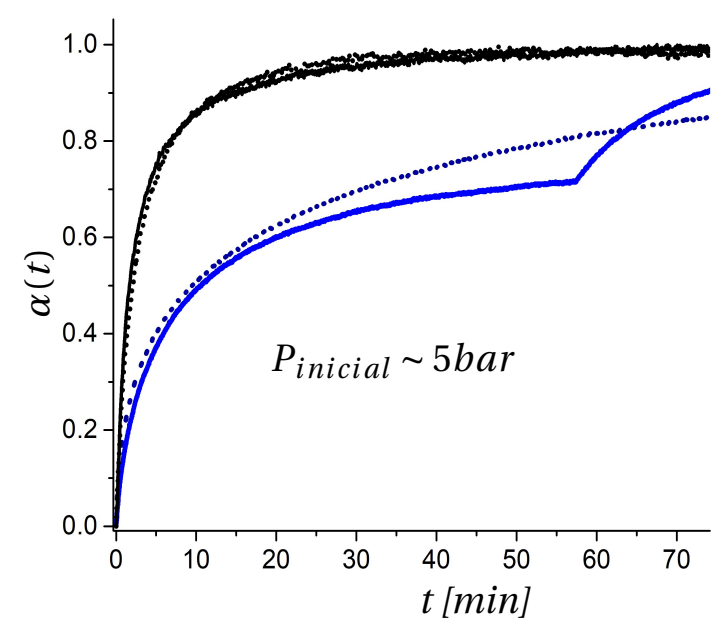

b)

Figura 9.1: Se comparan los gráficos de Avrami (a) para las muestras MT13 (vía A) y MT24 (vía B). Se graficaron en las regiones de $\alpha \in[0,15 ; 0,95]$. En $b$ se muestran las cinéticas respectivas.

En cuanto a las cinéticas de desorción, se muestran en la figura 9.2 los gráficos de Avrami (a) de las distintas etapas de desorción $(b)$ a $250^{\circ} \mathrm{C}$ de una muestra fabricada por la vía A.

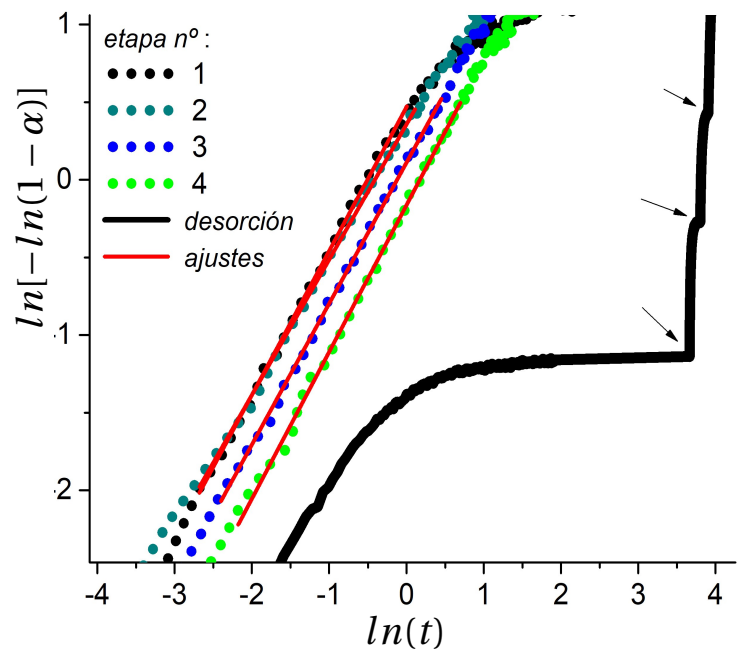

a)

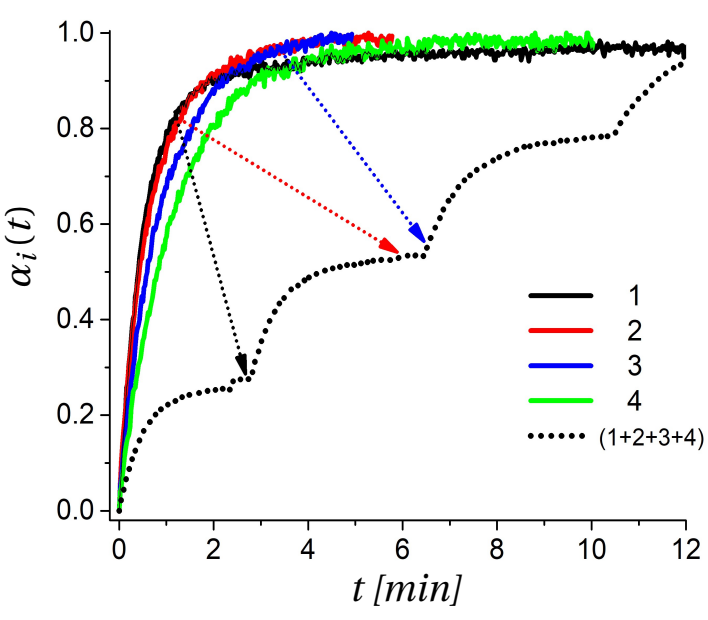

b)

Figura 9.2: Se comparan la respectivos gráficos de Avrami (a) junto a las etapas de desorción $(b)$ de la muestra MT41 (figura7.15). La desorción completa se indica en trazo grueso negro: etapas de desorción $(1 \rightarrow 4)$ realizadas a $250^{\circ} \mathrm{C}$. Se graficaron en las regiones de $\alpha \in[0,15 ; 0,95]$.

Las pendientes obtenidas para cada etapa son semejantes $(\sim 0,9)$ durante gran parte de la transformación, diferenciándose hacia el final de cada etapa (algunos valores calculados: $n_{1}=0,50, n_{2}=0,71, n_{3}=0,98, n_{4}=0,94$ ). Por otro lado el gráfico de Avrami de la desorción completa, muestra que al reducirse la fuerza impulsora (que en el caso de las desorciones sería 
$\frac{-\Delta P}{T}$ ), por aumentar la presión y aproximarse a la presión de equilibrio, la pendiente de la curva cambia notablemente, hasta una próxima etapa iniciada por evacuación del reactor y restablecimiento de la fuerza impulsora. Esto ocurría también, como se describió, para las absorciones.

Así, en términos generales los gráficos de Avrami presentan una pendiente $n=n(\alpha)$, es decir, es variable con el grado de transformación.Cada régimen estaría asociado a una región recta cuya pendiente está dada por el exponente $n$. Los gráficos mostrados evidencian la existencia un régimen complejo de mecanismos de sorción: la existencia de uno o varios regímenes, así como la distinción de los mismos (curvas mas o menos suaves), es dependiente de fuerza impulsora relativa $\Delta P / T$. Por ejemplo para mayores valores de $\Delta P / T$, como en el caso de la cinética a $240^{\circ} \mathrm{C}$ y 5 bar, (figura 9.1a), los gráficos de Avrami son rectas, mientras que al disminuir $\Delta P / T$ (o aumentando T para una misma $P_{i}$ ) dichos gráficos tienden a curvarse y/o presentar regímenes diferenciados. Adicionalmente se muestran en el Apéndice E gráficos de Avrami correspondientes a curvas cinéticas realizadas a otras presiones y temperaturas (figuras E.7 y E.8) que ilustran y respaldan estas observaciones. En ellas se pueden apreciar las observaciones recién mencionadas. Se muestran en las figuras 9.3 y 9.4 las dependencias del parámetro $n(\alpha)$ correspondientes a distintas curvas cinéticas. En particular se hace notar que los valores de $n(\alpha)$ para las absorciones de la vía B son comparativamente menores desde el comienzo, $\sim 0,6$, y disminuyen suavemente, mientras que los valores obtenidos para las absorciones de la vía A son $\sim 0,8$. El valor $\sim 0,6$ se asocia a un proceso de difusión como limitante y el valor de $\sim 0,8$ asociado a un régimen más complejo [142]. En el Apéndice 4.2 se incluyen más gráficos mostrando la dependencia del exponente de Avrami con el grado de transformación para curvas cinéticas realizadas a otras presiones y correspondientes a las vías A, B y a dos composiciones (80:20 y 90:10). (figuras E.9 y E.10).
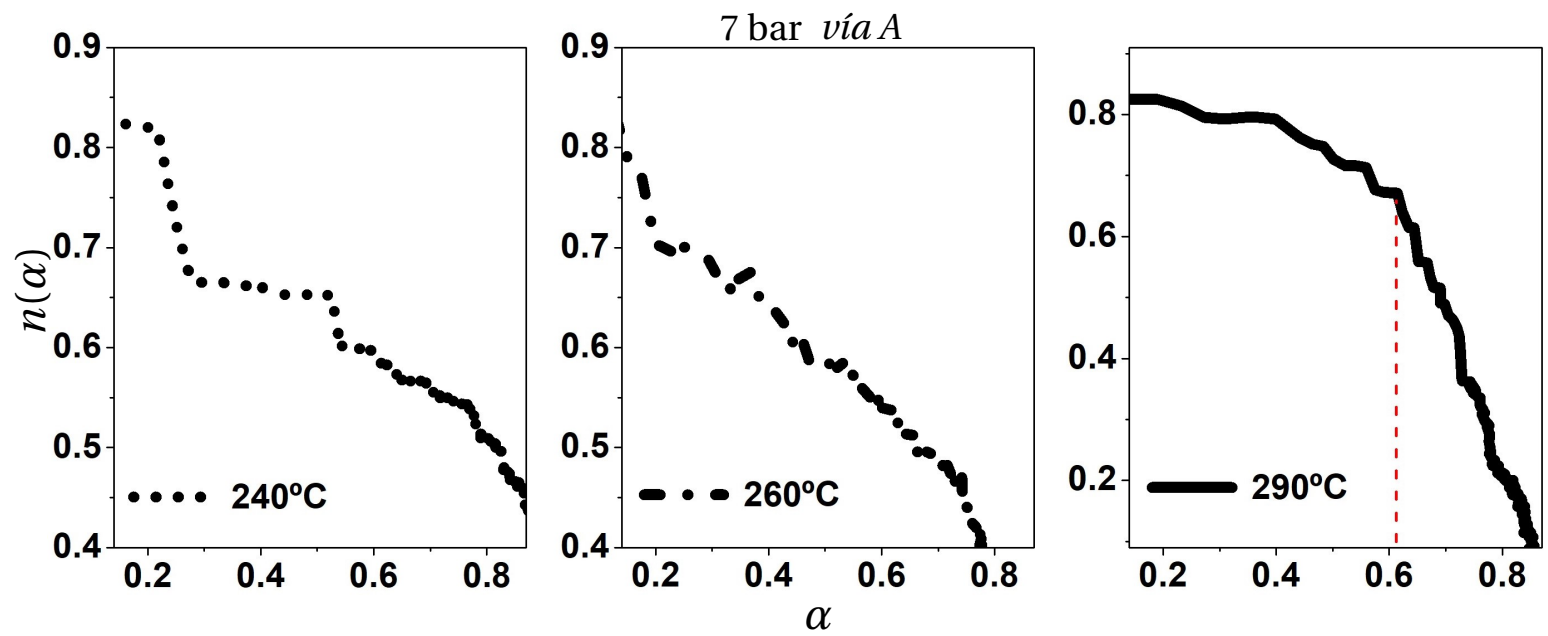

Figura 9.3: Típicos exponentes de Avrami calculados para curvas de absorción de muestras fabricadas por la Vía A. Corresponden a cinéticas de la muestra MT13 a 7 bar, Las curvas muestran que al reducir la fuerza impulsora inicial $\left(240^{\circ} \mathrm{C} \rightarrow 290^{\circ} \mathrm{C}\right)$, los regímenes se distinguen más marcadamente. 

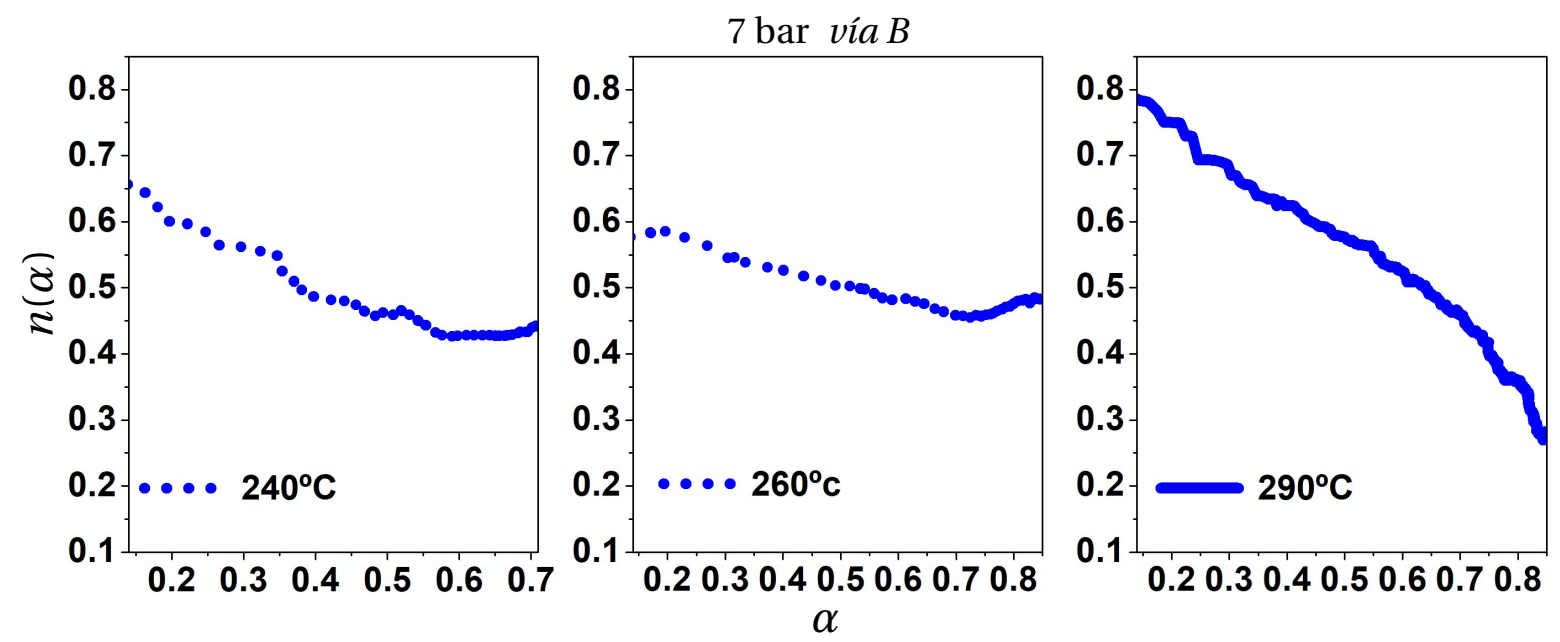

Figura 9.4: Exponentes de Avrami calculados para curvas de absorción a 7 bar, Vía B (MT24). Las curvas muestran que al reducir la fuerza impulsora inicial $\left(240^{\circ} \mathrm{C} \rightarrow 290^{\circ} \mathrm{C}\right)$ en el caso de la vía $\mathrm{B}$, el régimen de mecanismos es complejo pero se distinguen tan marcadamente como en el caso de la vía A.

La existencia de varios mecanismos involucrados manifestados en dos regímenes principales, también se manifiesta a través de las derivadas de las cinéticas no isotérmicas (obtenidas de las curvas de tratamientos térmicos). Como se muestra en la figura 9.5 a partir de las derivadas de curvas de desorción/absorción, se pueden distinguir al menos dos procesos principales para las cinéticas realizadas a ciertas presiones. Aunque con mayor relación señal/ruido, esto puede asociarse a lo observado en las curvas no isotérmicas obtenidas mediante calorimetría diferencial.

\section{Ajustes de las cinéticas}

La dependencia de la cinética con el grado de transformación, como se observó a través de los gráficos de Avrami, indica entonces la necesidad de proponer un modelo que involucre mecanismos múltiples, posiblemente correlacionados, dependientes del grado de avance de la transformación. Partiendo del modelo de Sěstak-Berggren, se puede obtener una solución analítica para $\alpha(t)$ proponiendo una correlación para los exponentes $p$ y $q$ dada por $p+q=2$ (ver Apéndice A.0.2). La solución con ese vínculo resulta ser la función de Hill [143]:

$$
\alpha(t)=\frac{t^{n}}{k^{n}+t^{n}}
$$

que permite describir la cinética de absorción teniendo en cuenta la dependencia de la velocidad de la transformación con la fase transformada y la fase sin transformar, esto es:

$$
\frac{d \alpha}{d t}=A \alpha_{112}^{p} \cdot(1-\alpha)^{q}
$$




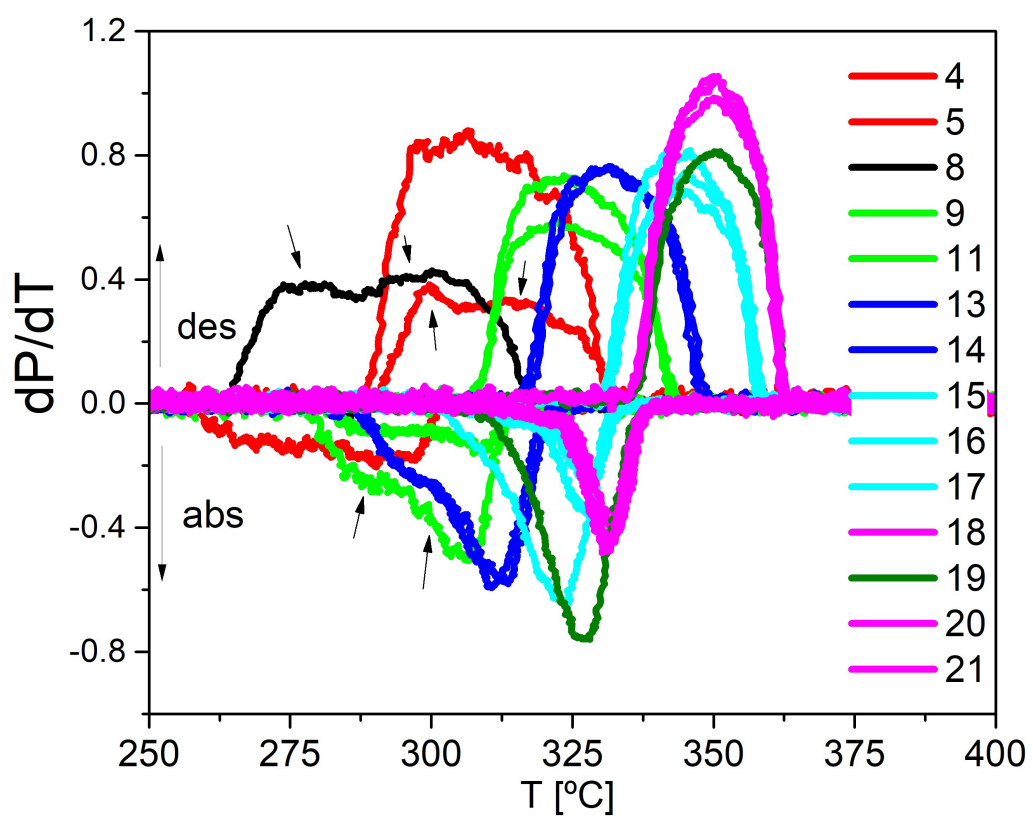

Figura 9.5: Se muestran las derivadas $\frac{d P}{d T}$ las curvas de cinéticas no isotérmicas correspondientes a distintos ciclos de absorción y desorción realizados sobre una muestra fabricada por la vía A. A ciertas presiones pueden distinguirse más de un proceso.

El parámetro $k$ representa el tiempo para alcanzar la mitad de la carga de hidrógeno. Para $n>1$, las curvas presentan un punto de inflexión, y se pueden asociar a procesos que involucran nucleación.

Mientras que con una única función de Hill se pudieron ajustar las etapas de las cinéticas de desorción relativamente bien, en el caso de las curvas cinéticas de absorción es requerida una función de dos componentes de Hill:

$$
\alpha(t)=A_{1} \cdot \frac{t_{1}^{n_{1}}}{k_{1}^{n}+t_{1}^{n}}+A_{2} \cdot \frac{t_{2}^{n}}{k_{2}^{n}+t_{2}^{n}}
$$

Para ilustrar esto, en las figuras 9.6 y $a$ y $b$ se muestran algunos de los ajustes realizados. A altas temperaturas una de las componentes deviene dominante como si un proceso principal ocurriera durante la reacción. A bajas temperaturas ambas componentes son comparables en importancia, asociados a la existencia de dos procesos igualmente relevantes. Los valores ajustados son mostrados en las tablas 9.1 y 9.2 (Las tablas fueron tomadas de las publicaciones $[95,96])$.

A presiones $~ 10 b a r$ (suficientemente por encima de la presión de equilibrio), la diferencia entre los parámetros cinéticos $k$ de cada componente depende de la temperatura, cambiando hasta en un orden de magnitud.

A pesar de que los polvos consisten en dispersiones con una distribución heterogénea de tamaños, las constantes cinéticas muestran un comportamiento bien definido con la temperatura en el caso de la ruta $a$ : uno de los parámetros característicos $k$ se mantiene constante en relación al parámetro de la otra componente que aumentaba monótonamente. Por otro lado, en todos los casos existe al menos una componente asociada a un proceso de nucleación y el comportamiento de nucleación es diferente para cada ruta. Mientras que a 

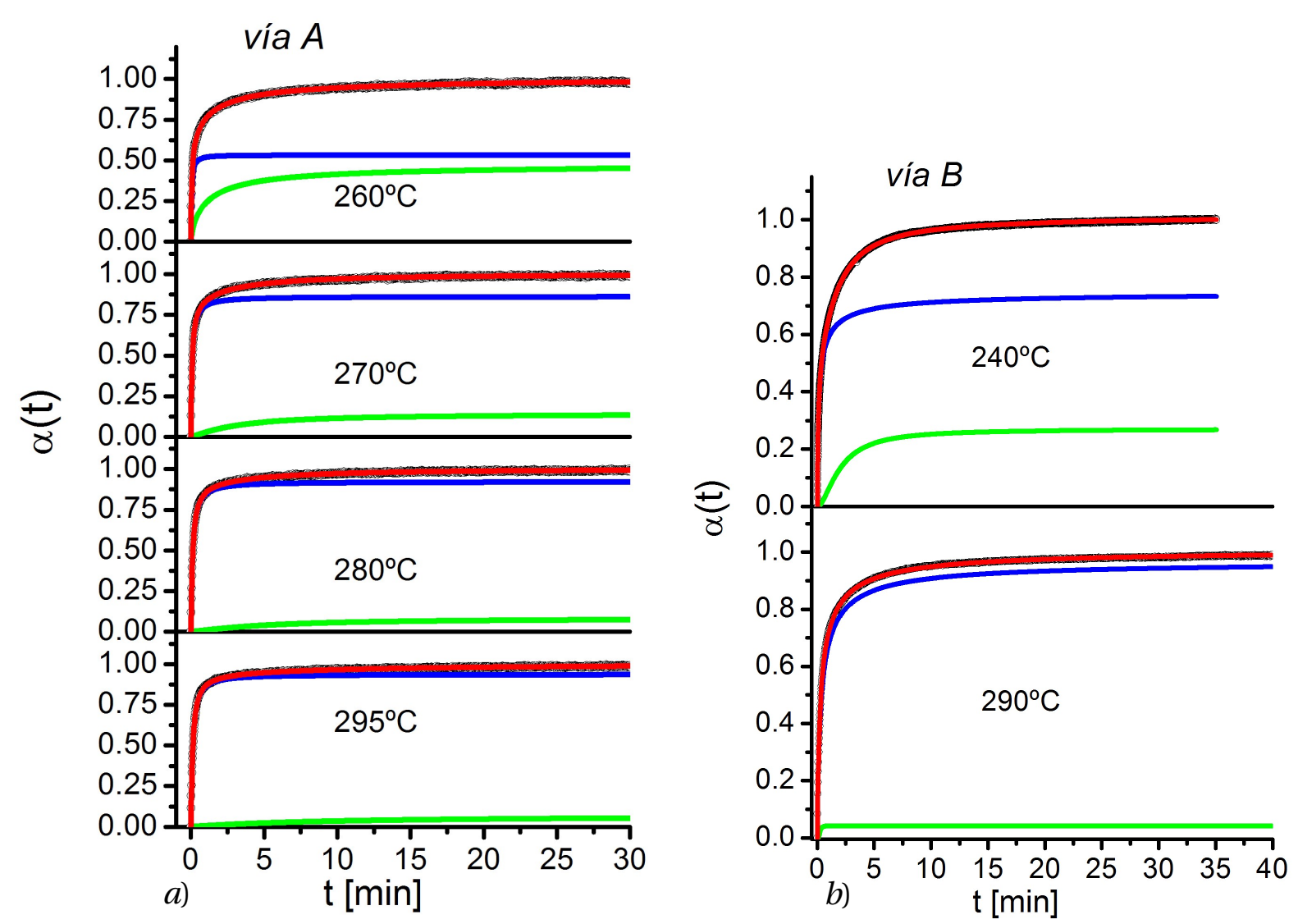

Figura 9.6: Se muestran ajustes de las curvas cinéticas de absorción a T constante, para muestras fabricadas por las las vías A $(a)$ y B $(b)$ ). Se requería el uso de una función compuesta de dos funciones de Hill para obtener ajustes satisfactorios.

altas temperaturas la componente de nucleación es la mayoritaria en las muestras fabricadas por la vía $A$, se asocia a la componente minoritaria en el caso de las muestras fabricadas por la vía $B$. 
Tabla 9.1: Parámetros cinéticos de ajuste (I). Función de Hill.

\begin{tabular}{|c|c|c|c|c|c|c|c|}
\hline \multicolumn{4}{|c|}{ vía $\mathrm{A}$} & \multicolumn{4}{|c|}{ vía B } \\
\hline$P[$ bar $] T[K]$ & $\tau[\mathrm{min}]$ & $n$ & asíntota & $P[$ bar $] T[K]$ & $\tau$ & $n$ & asíntota \\
\hline$P=9,5$ & $\tau_{1}: 0,054$ & $n_{1}: 1,25$ & $\chi_{1}: 0,5321$ & $P=10$ & $\tau_{1}: 1,32$ & $n_{1}: 0,682$ & $\chi_{1}: 0,26618$ \\
\hline$T=543$ & $\tau_{2}: 1,035$ & $n_{2}: 0,81$ & $\chi_{2}: 0,4667$ & $T=513$ & $\tau_{2}: 18,75$ & $n_{2}: 1,66$ & $\chi_{2}: 0,73105$ \\
\hline$P=9,5$ & $\tau_{1}: 0,09$ & $n_{1}: 1,08$ & $\chi 1: 0,8612$ & $P=9,5$ & $\tau_{1}: 0,353$ & $n_{1}: 0,799$ & $\chi_{1}: 0,04125$ \\
\hline$T=543$ & $\tau_{2}: 3,19$ & $n_{2}: 1,22$ & $\chi_{2}: 0,1382$ & $T=563$ & $\tau_{2}: 0,239$ & $n_{2}: 3,77$ & $\chi_{2}: 0,95732$ \\
\hline$P=9,5$ & $\tau_{1}: 0,109$ & $n_{1}: 1,32$ & $\chi 1: 0,9207$ & & & & \\
\hline$T=563$ & $\tau_{2}: 7,955$ & $n_{2}: 0,87$ & $\chi_{2}: 0,0785$ & & & & \\
\hline$P=10$ & $\tau_{1}: 0,130$ & $n_{1}: 1,19$ & $\chi 1: 0,9356$ & & & & \\
\hline$T=563$ & $\tau_{2}: 10,1$ & $n_{2}: 1,05$ & $\chi_{2}: 0,0641$ & & & & \\
\hline
\end{tabular}

Tabla 9.2: Parámetros cinéticos de ajuste (II). Función de Hill.

\begin{tabular}{llll|llll}
\hline \multicolumn{7}{c}{ Cinéticas Isotérmicas a 7 bar. Componentes de Hill } \\
\hline \multicolumn{7}{c|}{ vía A } & \multicolumn{5}{c}{ vía B } \\
\hline$P[$ bar $] T[K]$ & $\tau[\mathrm{min}]$ & $n$ & asíntota & $P[$ bar $] T[K]$ & $\tau$ & $n$ & asíntota \\
\hline$P=7,5$ & $\tau_{1}: 0,67$ & $n_{1}: 1,07$ & $\chi_{1}: 0,709$ & & & & \\
$T=513$ & $\tau_{2}: 6,1$ & $n_{2}: 1,69$ & $\chi_{2}: 0,290$ & & $\tau_{1}: 1,30$ & $n_{1}: 0,873$ & $\chi_{1}: 0,509$ \\
\hline$P=7,5$ & $\tau_{1}: 0,841$ & $n_{1}: 0,81$ & $\chi 1: 0,988$ & $P=7,5$ & & & \\
$T=533$ & $\tau_{2}: 20,0$ & $n_{2}: 0,8$ & $\chi_{2}: 0,012$ & $T=513$ & $\tau_{2}: 18,0$ & $n_{2}: 1,115$ & $\chi_{2}: 0,491$ \\
\hline$P=7,5$ & $\tau_{1}: 0,167$ & $n_{1}: 1,20$ & $\chi 1: 0,953$ & $P=7,5$ & $\tau_{1}: 2,04$ & $n_{1}: 0,88$ & $\chi_{1}: 0,674$ \\
$T=563$ & $\tau_{2}: 9,4$ & $n_{2}: 1,77$ & $\chi_{2}: 0,047$ & $T=563$ & $\tau_{2}: 0,37$ & $n_{2}: 1,13$ & $\chi_{2}: 0,326$ \\
\hline
\end{tabular}

\subsection{Cinéticas de absorción y desorción no isotérmica}

\section{Análisis cinético formal}

Se mostrarán en esta sección los resultados de haber aplicado el método isoconversional descrito en la sección 2.3. Se obtuvieron las energías de activación de acuerdo al método de Friedman (ecuación 2.13) y a partir de ello las funciones $y(\alpha)$ y $z(\alpha)$ (ecuaciones 2.8 y 2.9). Se desarrollará la aplicación del método isoconversional de manera completa para una serie de corridas de desorción DSC en $\mathrm{H}_{2}$ y se mostrarán los resultados más importantes para el resto.

\subsubsection{Análisis de las curvas calorimétricas en $\mathrm{H}_{2}$}

Vía A

El método se pudo aplicar a las curvas de desorción DSC de la primera serie realizada (tabla 4.1), correspondientes a las muestras fabricadas por vía A (MT42) y vía B (MT48). Para el 
resto de las corridas, correspondientes a otras muestras, sólo pudieron obtenerse las energías de activación de acuerdo al método de Kissinger $^{1}$ (ver Apéndice G).

En el caso de las desorciones que presentaron claramente dos picos (muestra MT42, figura

a)

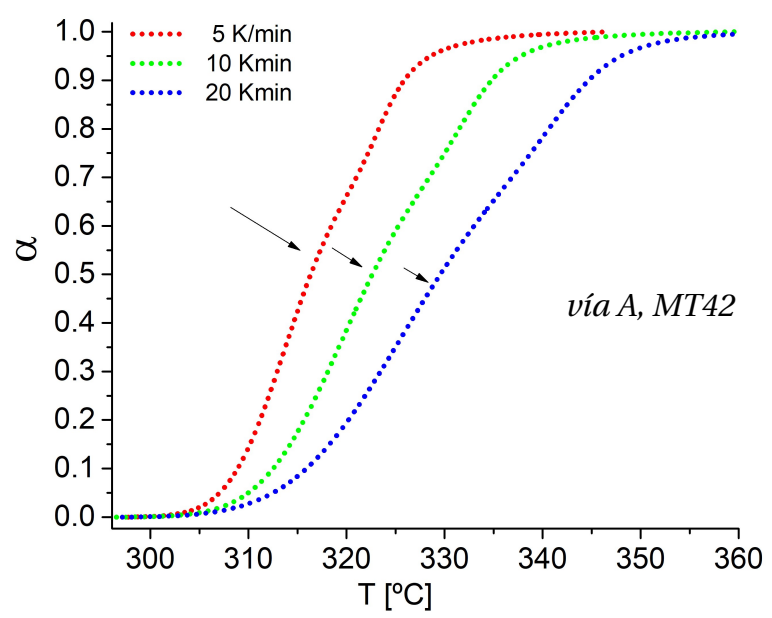

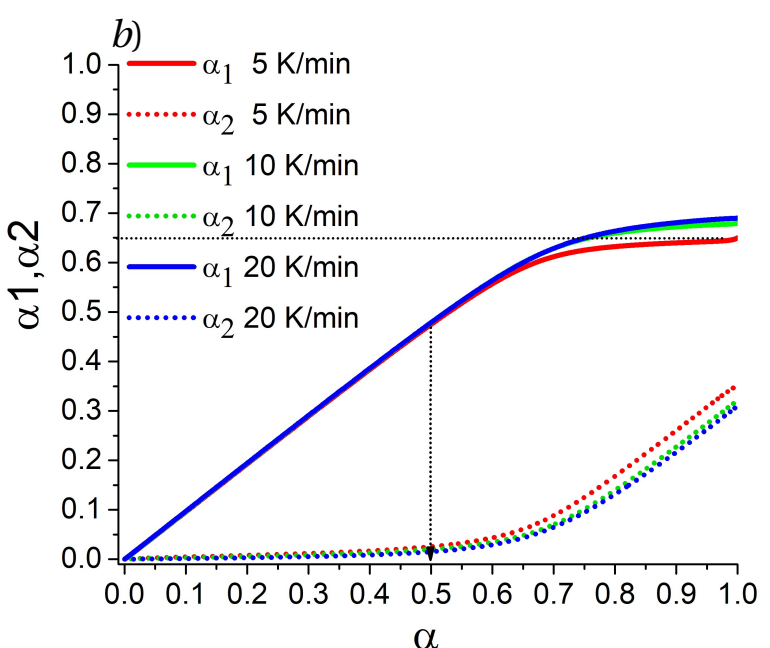

Figura 9.7: Fracciones de fase transformadas total $\alpha(T)$ (figura $a$ ), y respectivas componentes de ajuste (figura $b$ ). Corresponden a las curvas calorimétricas que presentaron dos picos bien definidos (figura 8.3a). Las componentes $\alpha_{1}$ y $\alpha_{2}$ obtenidas por integración de los ajustes se graficaron en función del grado de transformación total $\alpha$ y coinciden respectivamente para todas las corridas.
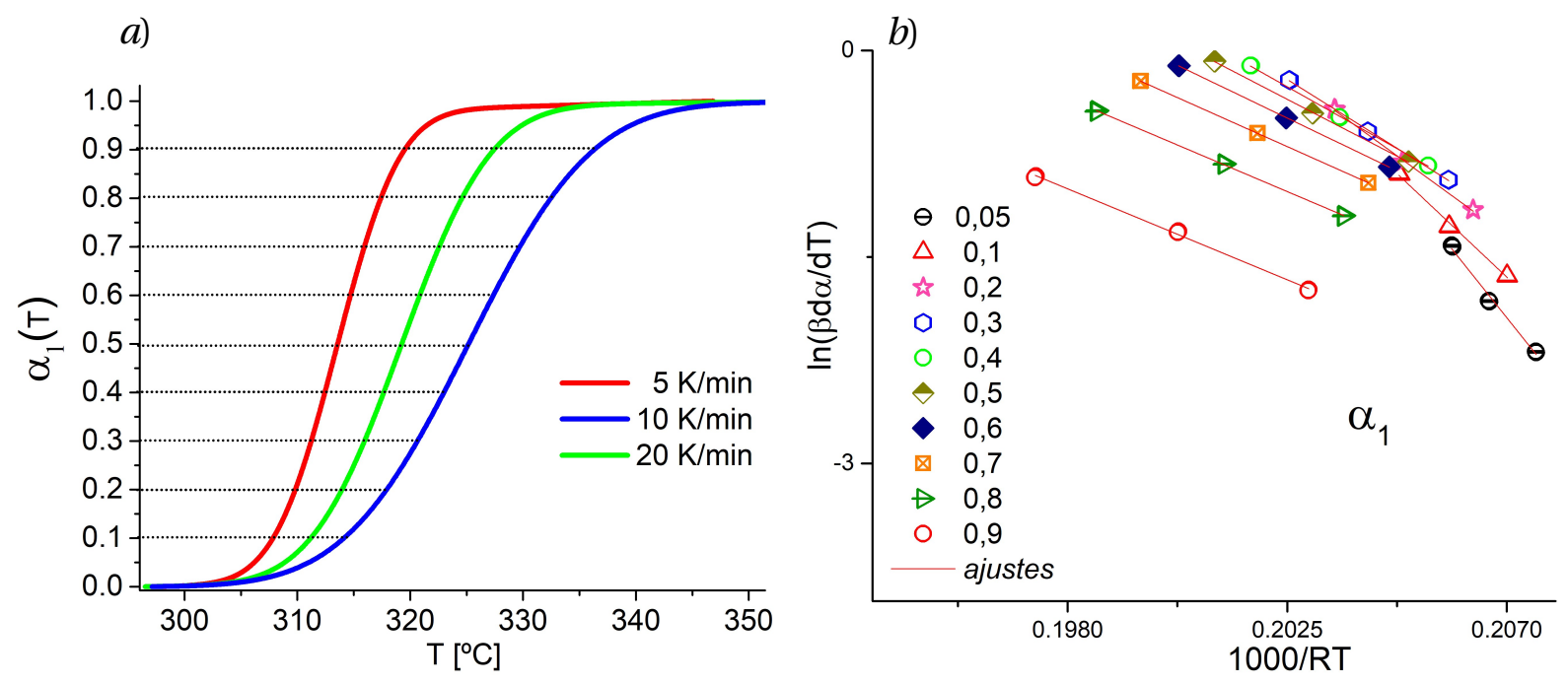

Figura 9.8: $a$ : Fracción de fase transformada asociada al primer proceso durante la desorción. $b$ : Gráficos isoconversionales y ajustes, para distintos grados de transformación $\alpha_{1}$ indicados en la figura. Componente 1 de las corridas de desorción de $H_{2}$, vía A.

8.3a), fue posible realizar un ajuste con dos componentes que representan los dos procesos

${ }^{1}$ Esto se debió a diferentes razones. En el caso de las absorciones por no estar completas las series a distintas
velocidades, por lo que se contaba solo con los picos de las curvas. En el caso de las muestras con grafito por
haberse realizado a diferentes presiones y por lo tanto cambia el prefactor asociado a la presión (ecuación 2.4). 
principales. Las funciones que ajustaban satisfactoriamente las curvas fueron funciones tipo Perason VII, lo que resulta razonable teniendo en cuenta las posibles asimetrías de las curvas $^{2}$. En la figura F.10 del Apéndice F se muestran los ajustes realizados. A partir de ello fue posible considerar las componentes $\alpha_{1}(t)$ y $\alpha_{2}(t)$ obtenidas de la integración de las componentes de ajuste $C_{1}$ y $C_{2}$. En la figura 9.7 se muestran las componentes obtenidas por integración. Se presentan normalizadas a 1 y a la vez normalizadas a la fracción que representaba cada una en la transformación total. Para esto se calculó el área total de la curva. En todas las corridas (diferente velocidad de calentamiento), la primera componente representaba alrededor de $\sim$ 0,63-0,65 de la transformación y la otra, naturalmente, $\sim 0,37$ 0,35 . Los procesos se superponen hacia el final del primer proceso, superando la mitad de la transformación global $(\alpha \sim 0,5)$.

Se aplicó el método isoconversional a cada componente $\alpha_{i}$. En la figura 9.8a se muestra la fracción de fase transformada durante el primer proceso, $\alpha_{1}(T)$. Para distintos valores de $\left(\alpha_{1}, \mathrm{~T}\right)$ se tiene una conjunto de puntos. De acuerdo a la ecuación 2.13, se obtienen puntos alineados asociados a las distintas velocidades de calentamiento ${ }^{3}$. Así los ajustes lineales fueron satisfactorios para la mayor parte del proceso ( $\alpha \epsilon[0,1-0,9])$ como se muestra en la figura 9.8b. Los puntos obtenidos para la velocidad de calentamiento más baja, $(1 \mathrm{~K} / \mathrm{min})$, se desviaban sistemáticamente del comportamiento lineal, algo que también ocurrió al aplicar el método de Kissinger, lo que indica diferentes regímenes dependientes de las velocidades de calentamiento.

A partir de esto se obtiene las energía de activación como pendiente de las rectas ajustadas. El mismo procedimiento se aplicó para la componente $\alpha_{2}$. Se muestran los valores obtenidos con los errores de ajuste en la figura 9.9. En la misma se puede apreciar claramente dos comportamientos distintos asociados a cada componente.

Se muestra también la energía $E$ global, calculada mediante el mismo método, sin hacer el ajuste de componentes. Claramente coincide con $E_{1}$ en la primera parte de la transformación y con $E_{2}$ hacia el final. Usando las energías respectivas de cada proceso se construyeron las funciones $y(\alpha)$ y $z(\alpha)$ (ecuaciones 2.8 y 2.9). Las mismas se muestran normalizadas (con nombres $\mathrm{f} y \mathrm{z}$ respectivamente) en la figura 9.10. Es notable la coincidencia de las funciones $y$ y $z$ para todas las velocidades de calentamiento ${ }^{4}$. Por otro lado las funciones $z(\alpha)$ alcanzan su máximo en el valor máximo en $~ 0,61$. Recurriendo al protocolo de Mălek (figura 2.2) se infiere que esto se aproxima al modelo de JMAK. En la figura 9.11 se muestra el ajuste realizado sobre las curvas aplicando el modelo de JMAK, resultando satisfactorio (ver tabla 9.3) y con un exponente $n \sim 3,1$ que se asocia a un proceso con una tasa de nucleación decreciente [115]. Las funciones $\mathrm{f}$ y $\mathrm{z}$ normalizadas correspondientes al segundo proceso se muestran en las figuras $9.12 a$ y $b$. En este caso se muestran separadamente para apreciarlas mejor.La funciones $f(\alpha)$ tienen su máximo en $\sim 0,5$, desplazados hacia la izquierda respecto de los máximos de las funciones $z(\alpha)$ (con una ligera diferenciación adicional de la $z(\alpha)$ a $20 \mathrm{~K} / \mathrm{min}$ ).

\footnotetext{
${ }^{2}$ Estas funciones tienen un comportamiento $\sim \frac{1}{t}$ lo que coincide con el comportamiento de las funciones de Hill, usados para ajustar las curvas de desorción.

${ }^{3}$ Ver figura F.13 del Apéndice.

${ }^{4}$ Un gráfico isoconversional en 3D permite apreciar simultáneamente la dependencia de E con el grado de transformación y la similitud o no de las funciones correspondientes a distintas velocidades (figuraF.11).
} 


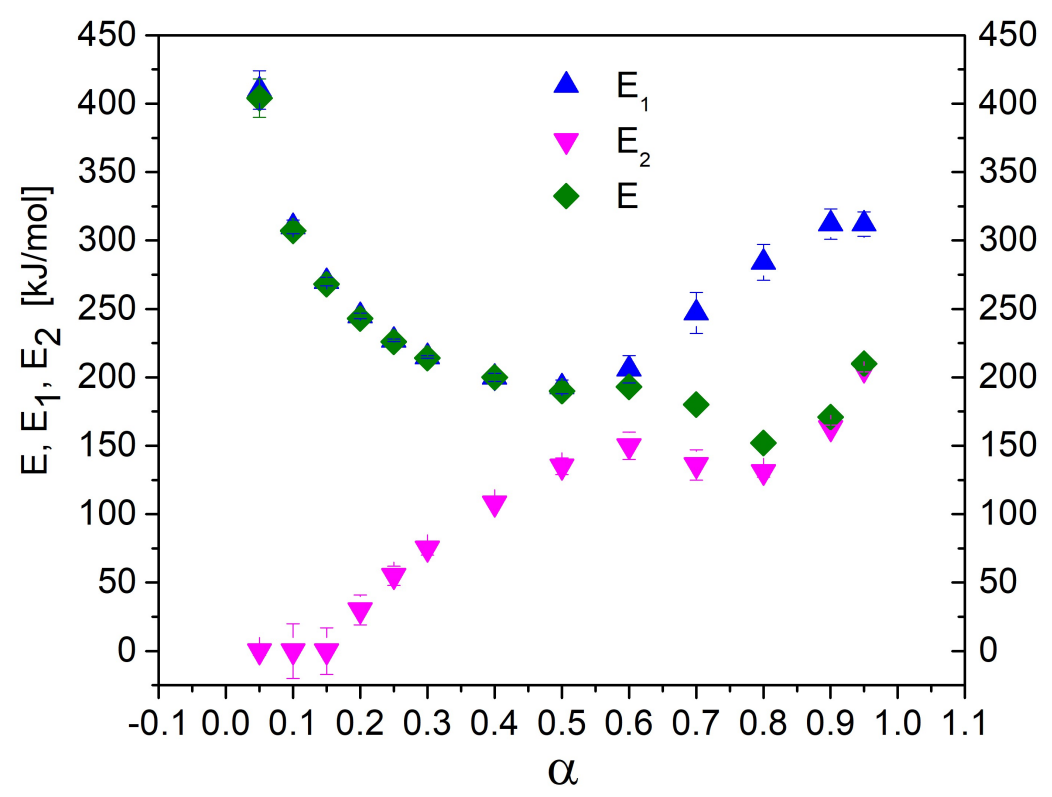

Figura 9.9: Energías de activación obtenidas mediante el método isconversional para las desorciones en $\mathrm{H}_{2}$, vía A. Las energías de cada proceso tienen una dependencia bien definida. En verde se muestra la energía calculada sin hacer el ajuste de componentes.

El máximo de las funciones $z(\alpha)$ se alcanzan para $\alpha \leqslant 0,54$ lo que indica que las curvas en este caso deben ajustarse con un modelo de Sěstak-Berggren (mostrado en la figura 9.12a).

En resumen, de esta sección se mostró la aplicabilidad del método isoconversional para los procesos complejos de deshidruración de los sistemas fabricados por la vía A en condiciones cercanas a las de equilibrio. De acuerdo a este método, la presencia de procesos diferenciados implica energías diferenciadas. ${ }^{5}$

${ }^{5}$ Es interesante mencionar que las funciones $\mathrm{f} \mathrm{y} \mathrm{z} \mathrm{construidas} \mathrm{utilizando} \mathrm{energía} \mathrm{E} \mathrm{global} \mathrm{condujo} \mathrm{a} \mathrm{funciones}$ que no satisfacían la hipótesis isocinética, lo que respalda la necesidad de considerar las componentes. 


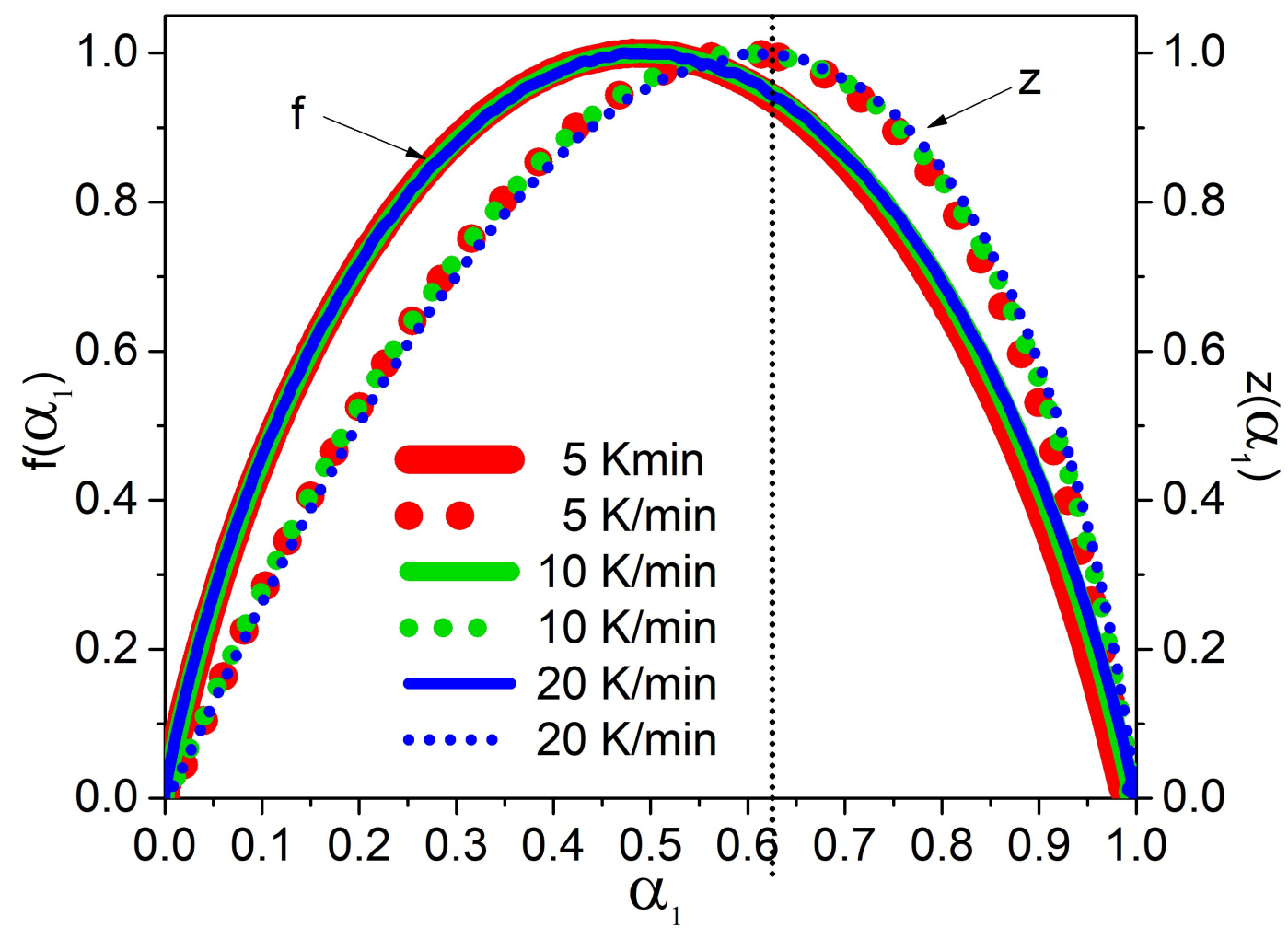

Figura 9.10: Se muestran las funciones $f(\alpha)$ y $z(\alpha)$ correspondientes a la componente 1 ajustada, asociada al primer proceso durante la desorción no isotérmica programada en $H_{2}$, (vía A). El $\alpha_{m}$ del máximo teórico de las funciones $z(\alpha)$ de acuerdo al modelo de JMAK está indicado en línea punteada $(0,632)$ y es muy próximo al valor experimental de los máximos de las funciones. 


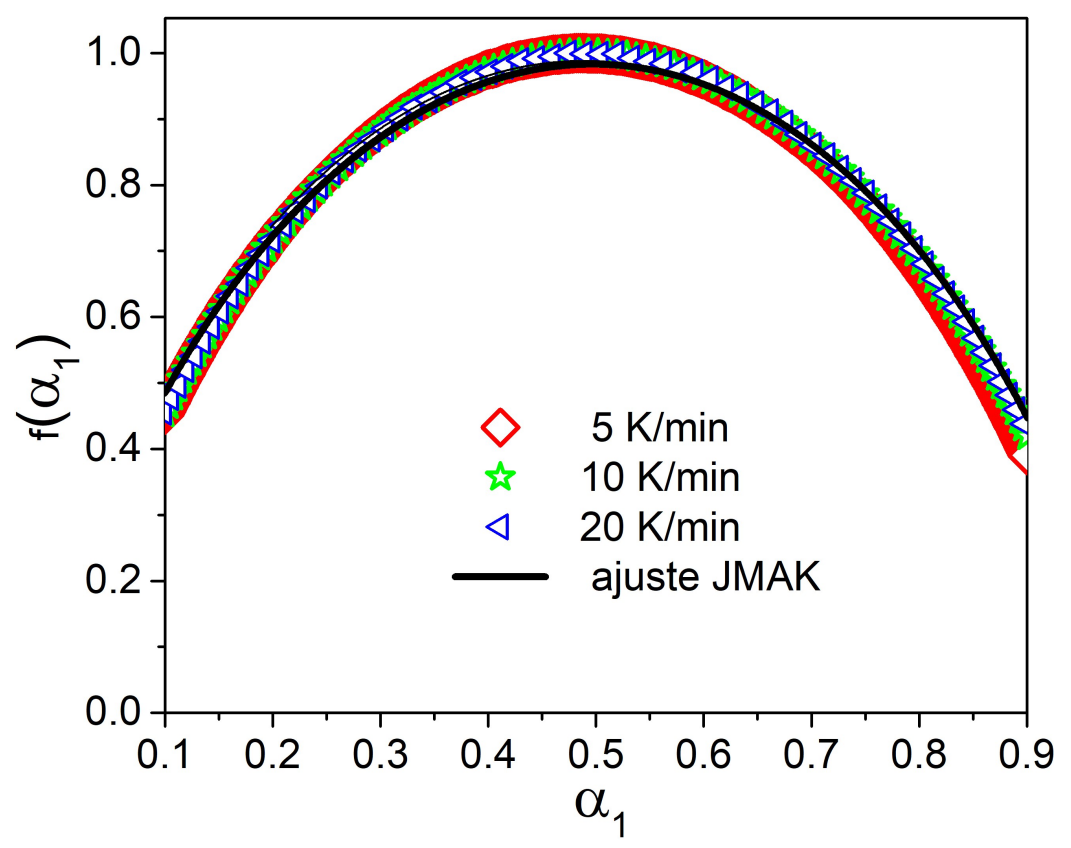

Figura 9.11: Se muestran las funciones $f(\alpha)$ normalizadas y el ajuste realizado utilizando la función de JMAK. 

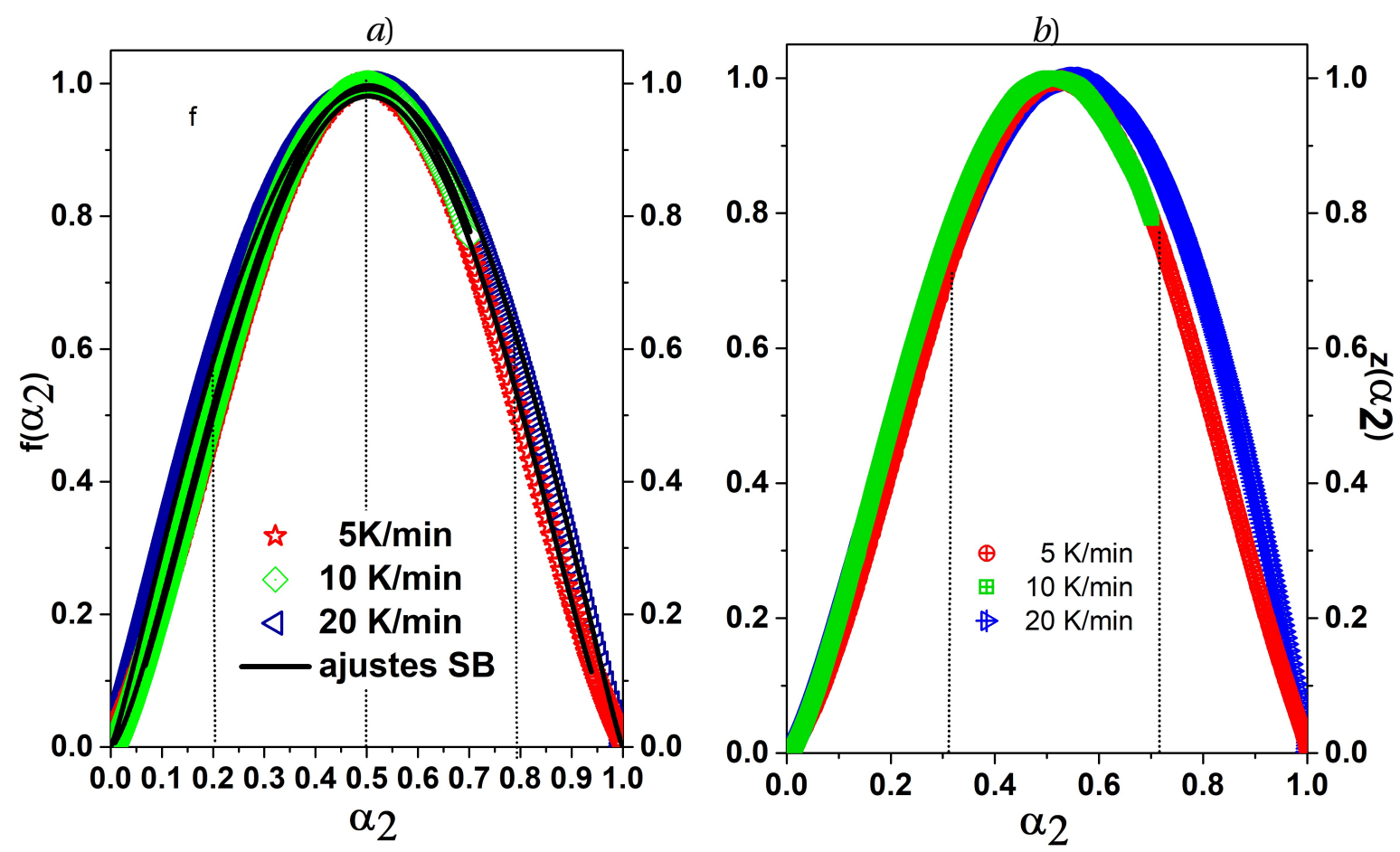

Figura 9.12: Se muestran las funciones $f(\alpha)(a)$ y $z(\alpha)(b)$ correspondientes a la componente 2 ajustada, asociada al segundo proceso durante la desorción no isotérmica programada en $H_{2}$, (vía A).

\section{Parámetro n de ajuste de la componente $f\left(\alpha_{1}\right)$}

\begin{tabular}{|c|c|c|}
\hline$C_{1}$ & & $\mathrm{n}$ \\
\hline \multirow{3}{*}{ JMAK } & $f_{5_{K / \min }}:$ & $3,05_{1}$ \\
\hline & $f_{10_{K / \min }}:$ & $3,17_{1}$ \\
\hline & $f_{20} 0_{K / \min }:$ & 3,1829 \\
\hline
\end{tabular}

Tabla 9.3: Se muestran valores representativos del ajuste de la componente 1 (MT42). Tomando distintas regiones para realizar el ajuste se obtenían valores ligeramente mayores a 3.

\section{Vía B}

Se mostrará aquí el resultado de haber aplicado el método isoconversional a las muestras fabricadas por la vía B. El análisis se mostrará conjuntamente para las muestras MT45 y MT48. Se usaron las respectivas curvas calorimétricas obtenidas en flujo de Ar y presión parcial de $\mathrm{H}_{2}$. A partir de las curvas respectivas $\alpha(T)$ (figura F.12) se obtuvieron gráficos isoconversionales o "Iso-plots", (figuras 9.13 y F.13b) y de las pendientes de los ajustes las energías de activación (figuras 9.14a y $b$ ). 


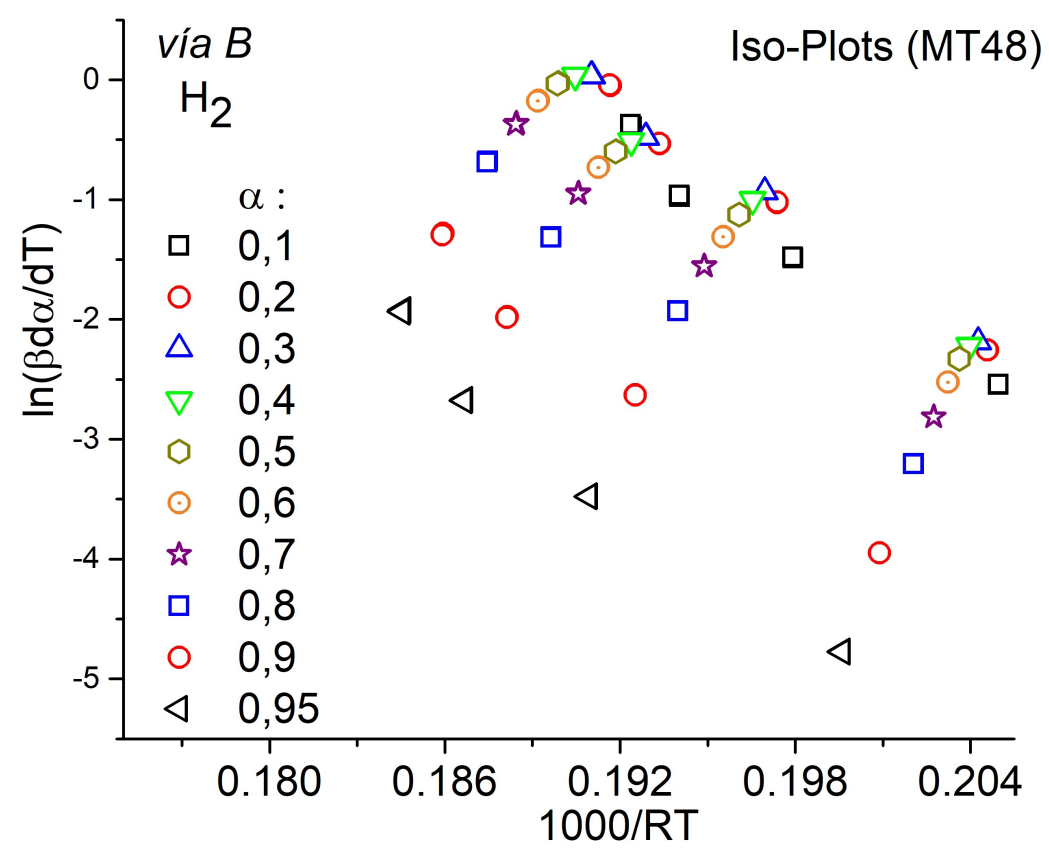

Figura 9.13: Puntos de del gráfico isoconversional para calcular la energía de activación de las desorciones en $\mathrm{H}_{2}$ de una muestra fabricada por la vía B.

En el caso de las muestras fabricadas por vía B, los Ios gráficos mostraron que en este caso no hay un régimen diferenciado de velocidades de calentamiento, como si se observó en el caso de la muestra fabricada por la vía A (los gráficos de Kissinger muestran lo mismo, ver figura s F.13 y G.2a).

El valor de la energía a lo largo de transformación es prácticamente constante en ambos casos. La energía obtenida para las cinéticas en $\mathrm{H}_{2}, \sim 160 \frac{\mathrm{kJ}}{\mathrm{mol}}$, resulta prácticamente el doble que el de las cinéticas en $\mathrm{Ar}, \sim 75 \frac{\mathrm{kJ}}{\mathrm{mol}}$. Esto se explica dada la interacción con el gas circundante (posible flujo de partículas ingresantes cerca de la presión de equilibrio).

De acuerdo a los observado en las curvas DSC en $\mathrm{H}_{2}$ y en Ar respectivamente para esta vía de fabricación, las funciones $f(\alpha)$ normalizada y $z(\alpha)$ correspondientes a las corridas en $\mathrm{H}_{2}$ (figuras $9.15 a$ y $b$ ) presentan una forma menos compleja para las las distintas velocidades de calentamiento, en contraposición a la estructura claramente compleja para las funciones obtenidas de las corridas en Ar (figura 9.16). Corresponde interpretar entonces la energía como una energía global asociada a los procesos superpuestos. La no superposición de la curvas impide aplicar el protocolo de Mălek, sin embargo los máximos de las funciones $z(\alpha)$ sugieren que puede utilizarse un ajuste de SB, como se muestran en la figura 9.15a. En el caso de las curvas obtenidas en Ar, la realización de ajustes requeriría mayor cuidado y una previa descomposición utilizando algún criterio adecuado debido al alto grado de superposición de las curvas (figura 9.16). 
a)

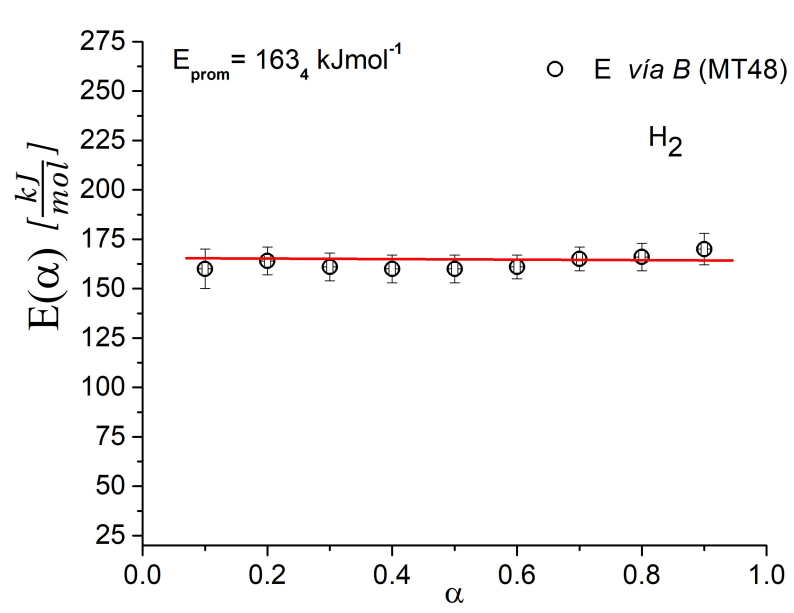

b)

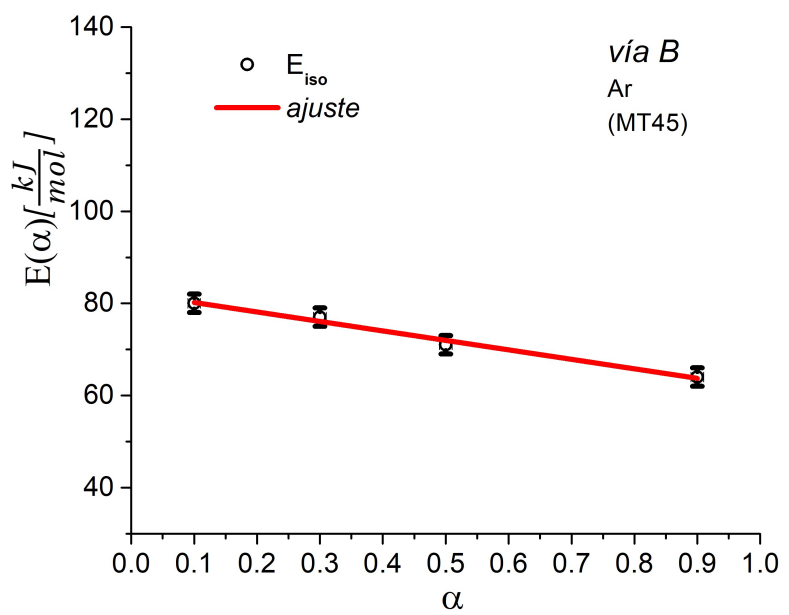

Figura 9.14: Energías de activación obtenidas mediante el método isoconversional para las desorciones en $\mathrm{H}_{2}$ y en flujo de Ar de muestras fabricadas por la vía B.
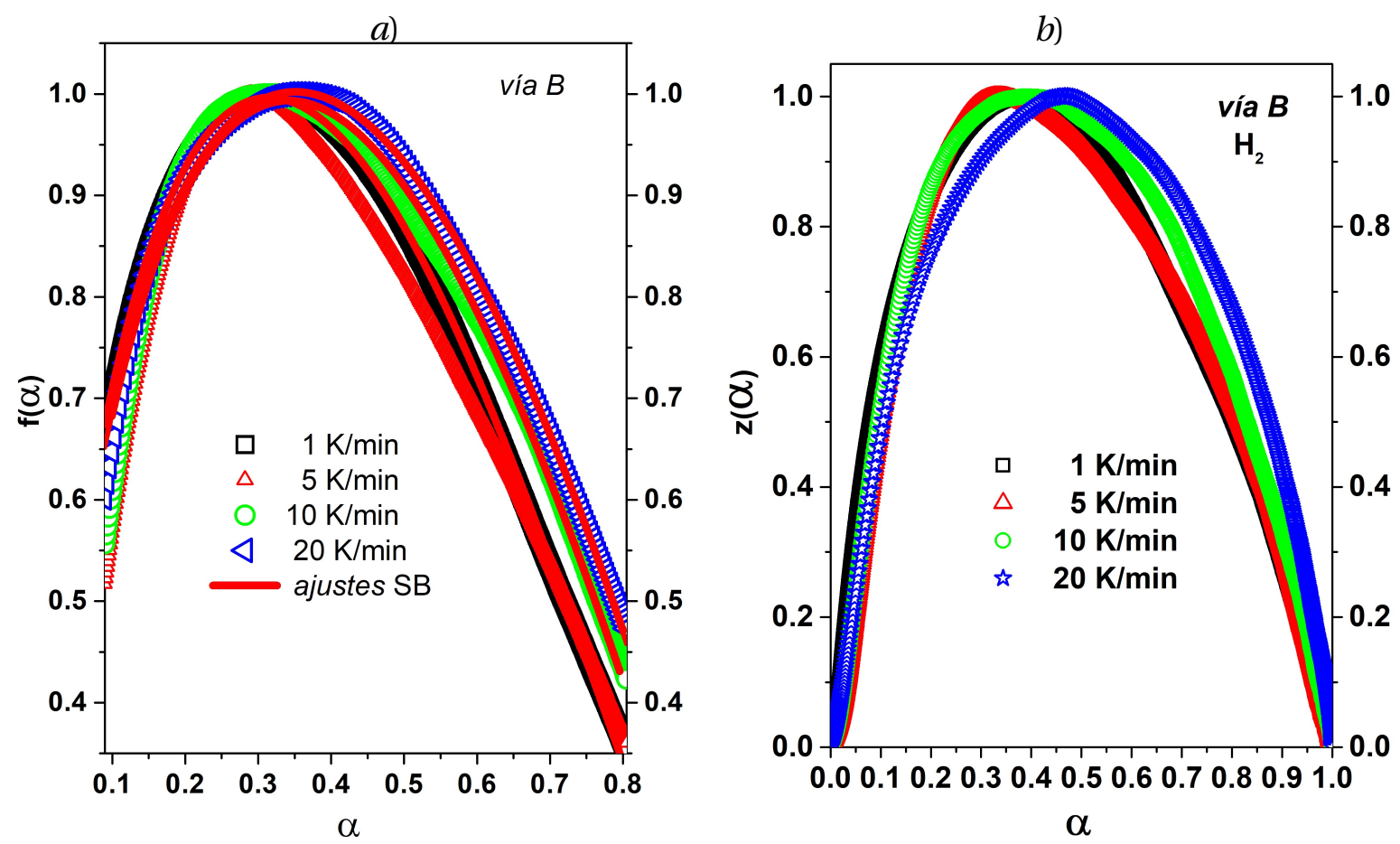

Figura 9.15: Se muestran las funciones $f(\alpha)$ normalizadas $(a)$ y $z(\alpha)(b)$ correspondientes a las desorciones no isotérmicas en $\mathrm{H}_{2}$ para la muestra MT48 fabricada por la vía B. Se muestran también los ajustes con el modelo $S B$ realizado sobre las funciones $\mathrm{f}(\alpha)$. 


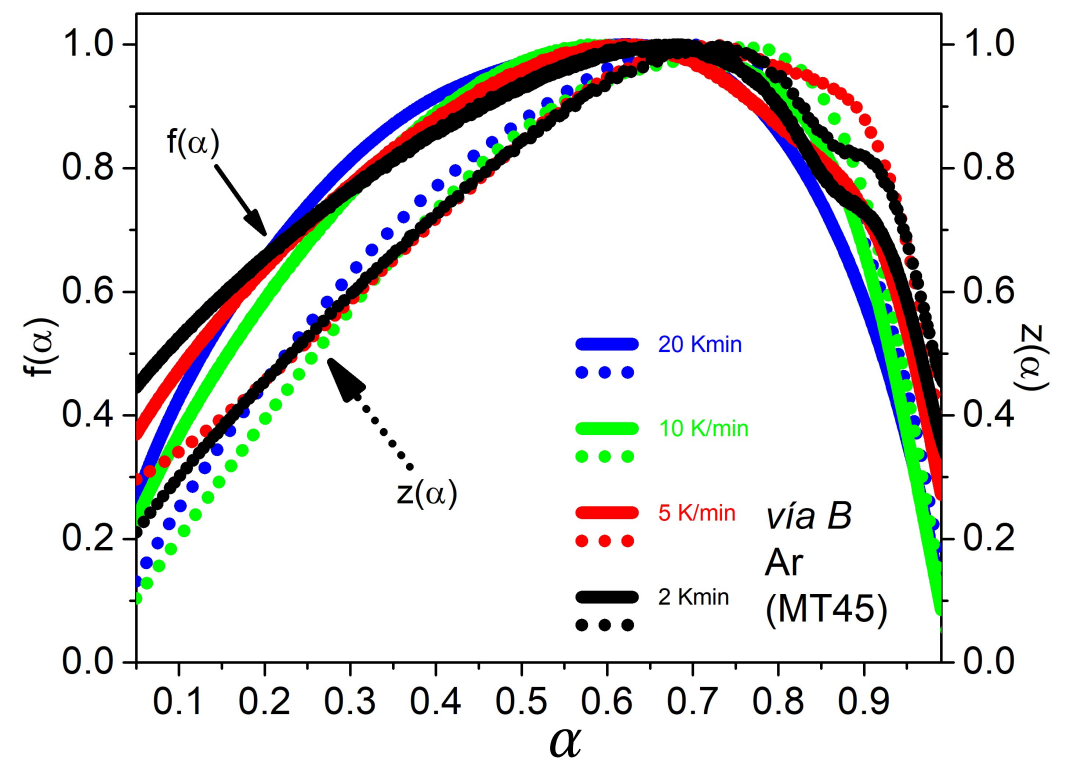

Figura 9.16: Se muestran las funciones $f(\alpha)$ normalizada junto con las funciones $z(\alpha)$ correspondientes a las desorciones DSC en Ar para la muestra MT45 fabricada por la vía B.

\section{Ciclado y absorciones}

Las curvas de desorción durante el ciclado en $H_{2}$ (2da y 3ra desorción) no responden estrictamente a un comportamiento térmicamente activado tipo Arrhenius, exceptuando el primer ciclo. En el caso de las absorciones, los dos procesos principales se superponen nuevamente, por lo que se requiere realizar una descomposición de las curvas para obtener separadamente las energías de activación correspondientes. Se muestra la energía global calculada en la figura 9.17a. A pesar de la dispersión por las diferencias en cada ciclo, se observa un comportamiento definido. La energía de activación obtenida para desorciones en Ar para una muestra previamente sometida a varios ciclos de carga y descarga de hidrógeno, se muestran en la figura 9.17b. Nuevamente los valores son menores que los de la energía de activación para desorciones en $\mathrm{H}_{2}$. 

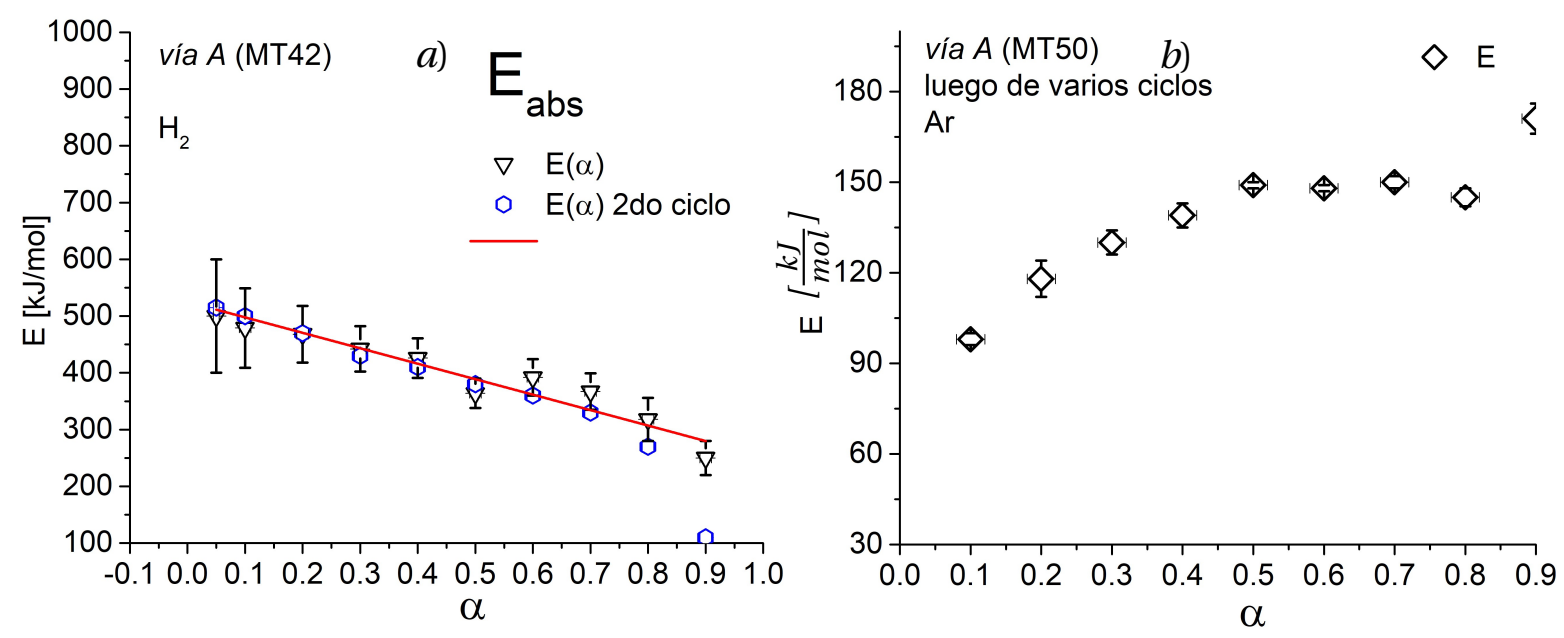

Figura 9.17: Energías de activación obtenidas mediante el método isoconversional para muestras fabricadas por la vía directa, A. a: Se muestran las energías calculadas para uno de los ciclos de absorción en $H_{2}$ y para la global E (el resto de los ciclos daban valores similares) correspondientes a la muestra MT42. $b$ : Se muestran la energía calculada para las desorciones en flujo de Ar de la muestra fabricada por vía A sometida previamente a varios ciclos de carga y descarga de hidrógeno (MT50T).

\subsubsection{Análisis de las curvas calorimétricas en $\mathrm{Ar}$}

\section{Vía G}

La muestras con grafito (20\% at. (muestra CMT14)) presentaron una energía de activación como la que se muestra en la figura 9.18. Las funciones $\mathrm{f} y \mathrm{z}$ mostradas en la figura 9.19 revelan que se superponen para grados avanzados de la transformación y se diferencian ligeramente hacia el comienzo de la misma, dependiendo la etapa de nucleación de la velocidad de calentamiento. Las funciones $z(\alpha)$ tienen su máximo cercano al esperado para un modelo tipo JMAK, particularmente para la corrida de mayor velocidad de calentamiento. 


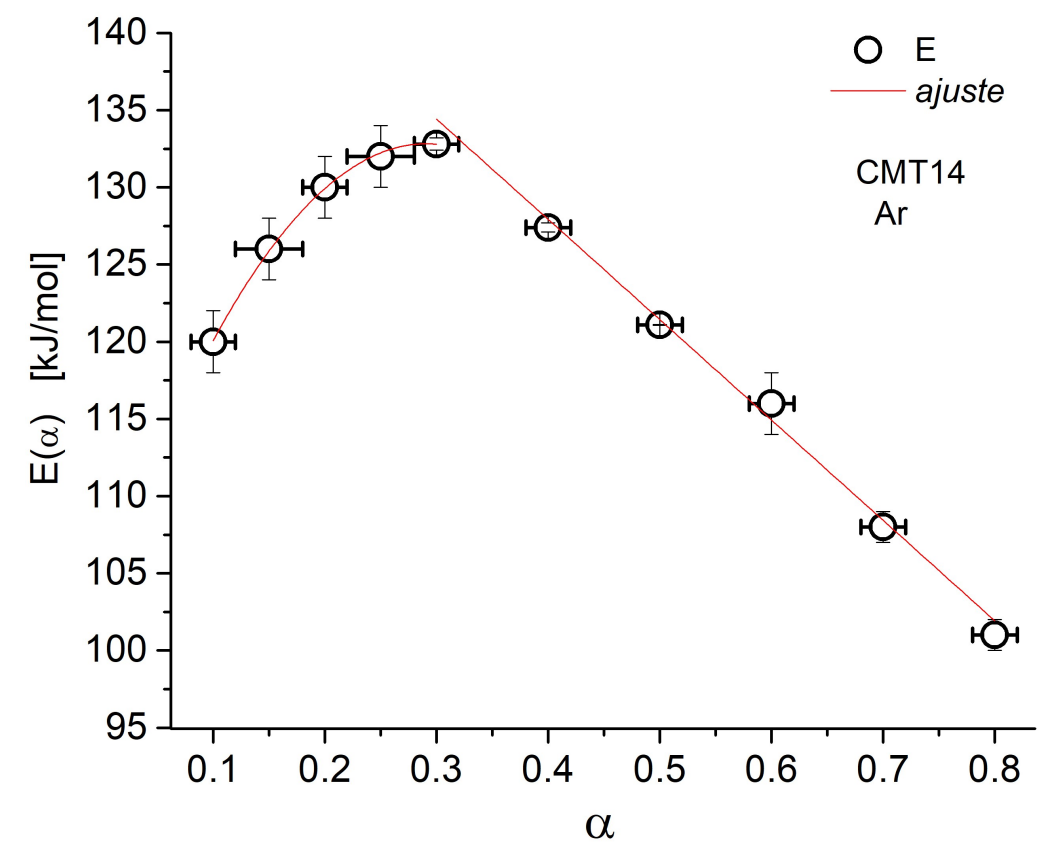

Figura 9.18: Energías de activación obtenidas mediante el método isoconversional para las desorciones de una muestra con grafito, $20 \%$ at. C, CMT14.

a)

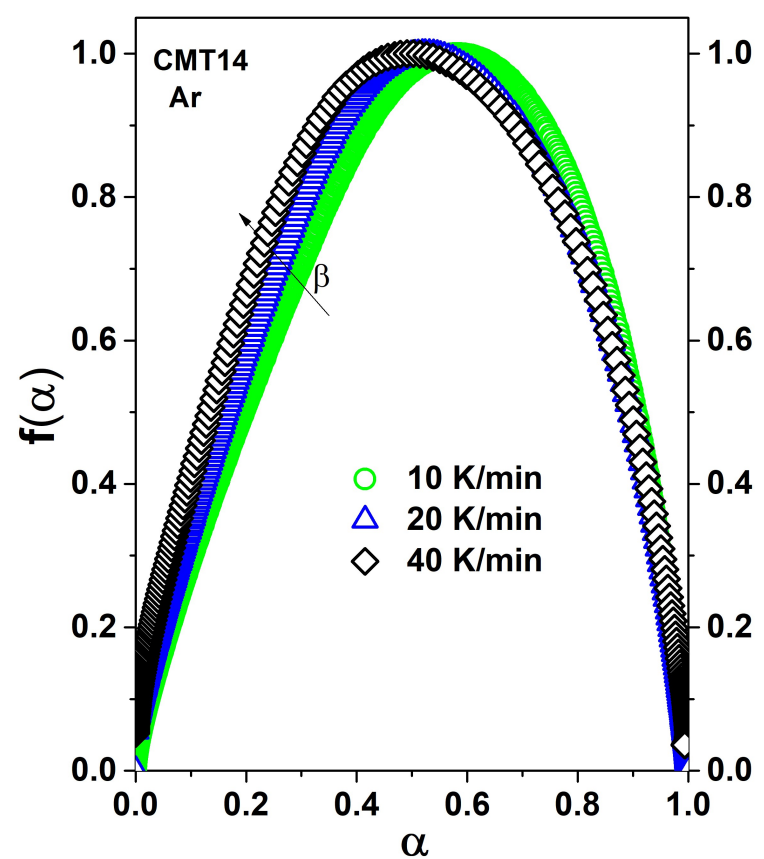

b)

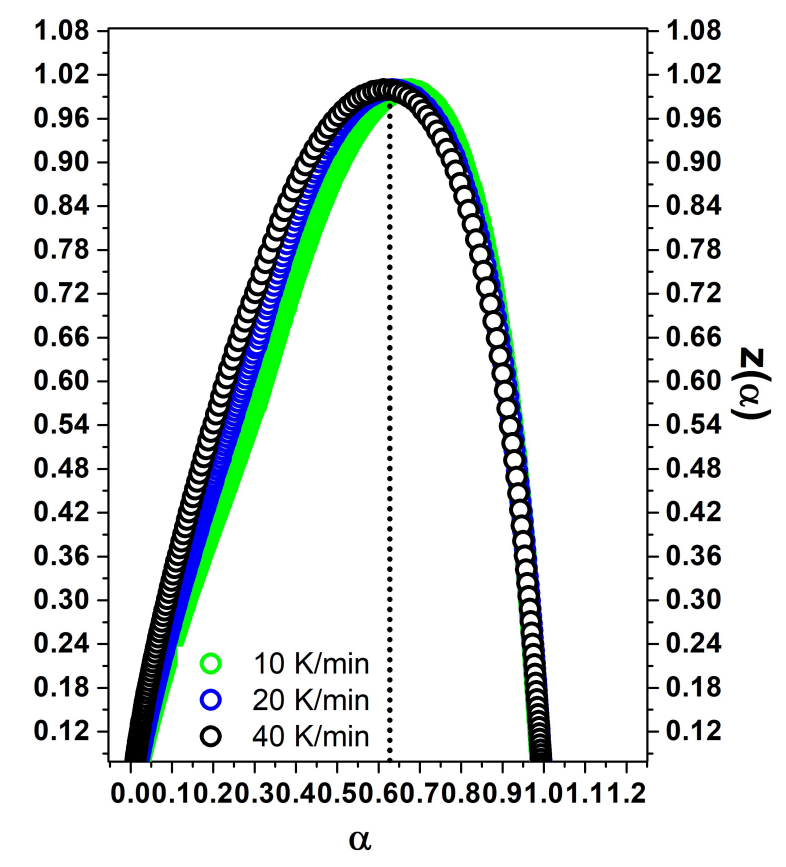

Figura 9.19: Se muestran las funciones $f(\alpha)(a)$ y $z(\alpha)(b)$ correspondientes a la componente 2 ajustada, asociada al segundo proceso durante la desorción no isotérmica programada en $H_{2}$, (vía A). 


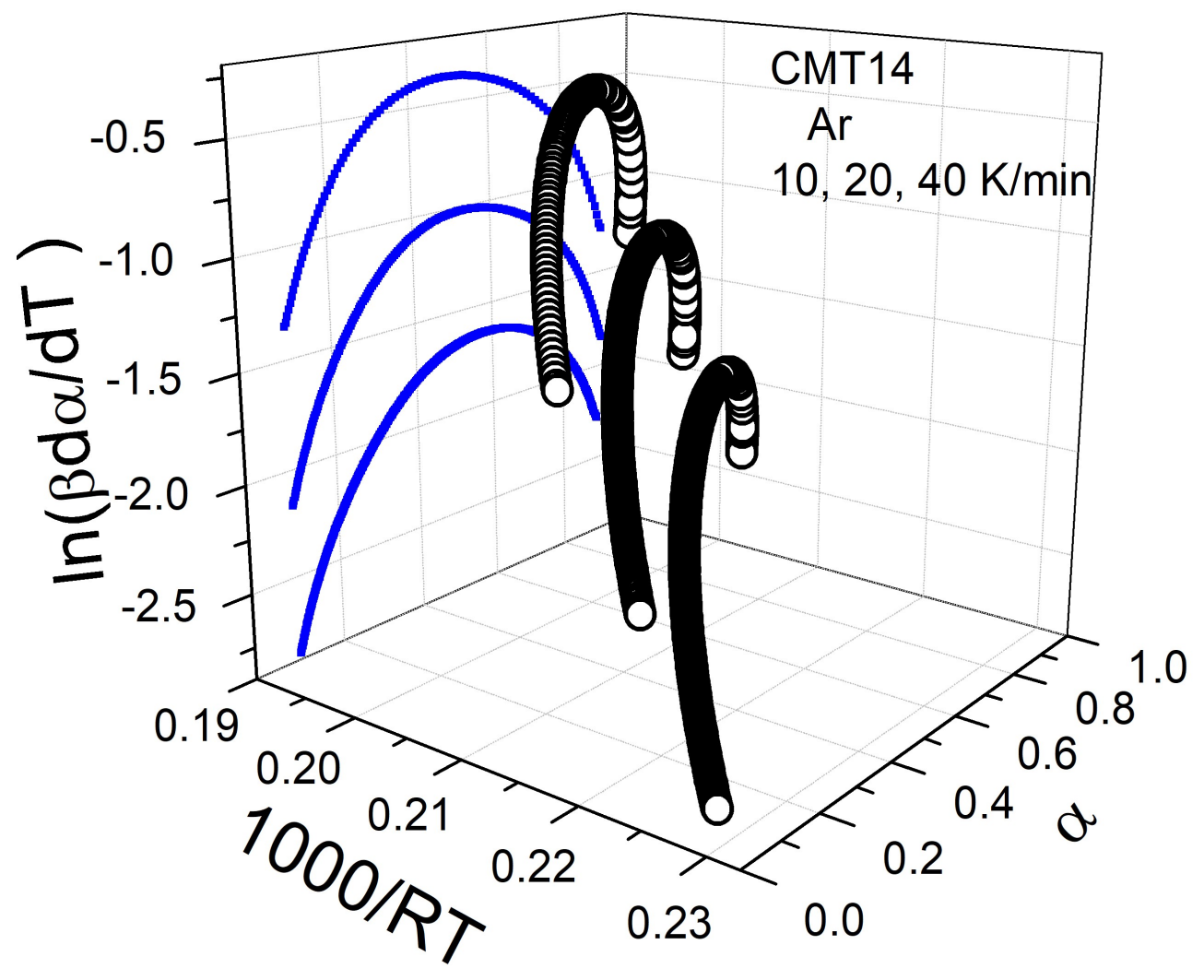

Figura 9.20: Se representa en un gráfico 3D, IsoPLot3D, las curvas que brindan la energía de activación. Simultánemente las proyecciones sobre el plano yz permiten comparar las funciones comportadas como $\sim \ln (f(\alpha))$. 


\section{Capítulo 10}

\section{Conclusiones}

\section{Sobre las cinéticas de formación}

Se lograron sistemas hidrurados como potenciales reservorios de hidrógeno con tiempos de formación 1-2 hs. La cinética de formación de hidruros en los sistemas $M g_{(1-x)} T i_{x}$ mejora notablemente al incrementar la cantidad de Ti. Esto es atribuido a las propiedades abrasivas del Ti.

Haciendo un balance entre la necesidad de una velocidad de formación lo más alta posible (menos horas de molienda) y una densidad gravimétrica aceptable, se puede establecer que las composiciones en el rango $x \in[0,2-0,3]$ presentan las mejores propiedades de formación sin pérdida apreciable de capacidad. En particular en el caso de la ruta $A$ de fabricación, la velocidad de formación del $\mathrm{MgH}_{2}$ no se incrementa notablemente para $x>0.4$.

Se caracterizaron las cinéticas de formación de composites hidrurados preparados por distintas vías, destacándose la posibilidad de lograr modelar su formación con un modelo predictivo simple que incluya la formación de las fases principales. Los ajustes de las curvas cinéticas de formación con el modelo de componentes tipo Gompertz concuerdan satisfactoriamente con la identificación de etapas diferenciadas de formación de las fases $\mathrm{MgH}_{2}$ y $\mathrm{TiH}_{2}$ en el caso de la vía $A$. Esto es consistente con la necesidad de ajustar con una única componente las curvas cinéticas en el caso de la vía $B$ en la que la fase $\mathrm{TiH}_{2}$ ya está formada en el inicio de la molienda. Resulta que los parámetro $k_{i}$ pueden ser interpretados como constantes que caracterizan empíricamente la formación de fases por molienda. Las mayores velocidades de reacción se corresponden con la vía $\mathrm{B}$ lo que destaca el rol catalítico del $\mathrm{TiH}_{2}$. Esta ruta constituye una buena posibilidad para la fabricación de un sistema basado en $\mathrm{Mg}$, con una fase catalítica estable $\mathrm{TiH}_{2}$ que permita la completa reacción $\mathrm{Mg} \Rightarrow \mathrm{Mg} \mathrm{H}$.

La molienda en atmósfera de deuterio a altas presiones produce dispersiones con características semejantes a las anteriores.

El agregado de hasta un $5 \%$ de grafito preserva la cinética de formación de hidruros mientras que porcentajes mayores producen un retardo en la formación del $\mathrm{Mg} \mathrm{H}_{2}$ sin alterar la del $\mathrm{TiH}_{2}$.

El método de fabricación utilizado produce dispersiones nanoestructuradas de gran refinamiento estructural y composicional, con gran superficie específica, bordes de grano y defectos en general, lo cual redunda en un mejoramiento de las cinéticas de hidruración/deshidruración. Teniendo en cuenta que se lograron materiales con tiempos de forma- 
ción rápida, a bajas presiones y con gran reproducibilidad, puede decirse que el método de molienda mecánica mediante molino vibratorio resulta comparativamente más eficiente y menos costoso para la formación del hidruro $\mathrm{MgH}_{2}$ [54].

\section{Sobre la termodinámica de los sistemas}

Las propiedades termodinámicas de las dispersiones nanoestructuradas obtenidas se asemejan a las halladas para sistemas nanocristalinos basados en $\mathrm{Mg}$, aventajando al $\mathrm{Mg} \mathrm{H}_{2}$ en bulk que requiere temperaturas de desorción mayores a $300^{\circ} \mathrm{C}$ a 1 bar.

Las distintas vías de fabricación producen sistemas con características termodinámicas similares que se preservan a lo largo de los ciclos de absorción y desorción de hidrógeno realizados. La muestra preparada con deuterio, por su parte, presentó diferencias en la temperatura de desorción luego de un cierto número de ciclos.

\section{Sobre las cinéticas de hidruración y tratamientos térmicos}

Estos sistemas pueden absorber hidrógeno desde temperaturas de $\sim 240{ }^{\circ} \mathrm{C}$ a 3 bar de presión. Las cinéticas de hidruración en el rango de temperaturas [250-300] ${ }^{\circ} \mathrm{C}$ y de presiones entre 5 y 10 bar permitían alcanzar más del $90 \%$ de la carga de hidrógeno en pocos minutos, siendo óptimo el valor de $\sim 10 \mathrm{bar}$.

En el caso de las desorciones, a partir de $250^{\circ} \mathrm{C}$ y presiones de 0,001 bar se podía lograr la descarga completa en pocos minutos. Las distintas vías de fabricación producen sistemas con características cinéticas que en general se preservaban a lo largo de los ciclos de absorción y desorción de hidrógeno realizados.

\section{Comparación de vías}

Se identificaron diferencias y semejanzas en las cinéticas de hidruración/deshidruración de muestras fabricadas por las distintas vías. Particularmente las vía A y B producen dispersiones finas estequiométricamente iguales y con granulometría semejante pero con cinética distinta. Esto indica una gran sensibilidad, de las propiedades cinéticas, a las características nanoestructurales (acoples de interfase $\mathrm{Mg} / \mathrm{Mg} \mathrm{H}_{2} / \mathrm{Ti} \mathrm{H}_{2}$, bordes de grano y otros defectos). Las cinéticas de sistemas equivalentes, hidrurado y deuterado respectivamente, no revelaron diferencias durante los ciclos de absorción/desorción de hidrógeno realizados a temperatura constante. Las cinéticas de las muestras fabricadas con grafito dependían del porcentaje atómico de grafito incorporado en la molienda. El agregado de hasta un $10 \%$ at. mostró preservar la velocidad de descarga de hidrógeno, mientras que se puede incorporar hasta un $20 \%$ at. sin alterar la velocidad de carga. No obstante la cinética se ve afectada debido a una modificación de la superficie de interacción por recubrimiento de las partículas con grafito. Esto modifica los mecanismos de absorción. Mientras que en la bibliografía se ha observado que en general las propiedades de sistemas con grafito se pierden rápidamente en los primeros ciclos, se ha encontrado que durante varios ciclos las dispersiones preservan su 
capacidad y velocidad de absorción/desorción de hidrógeno.

\section{Sobre el análisis}

En general, se observó la existencia de regímenes cinéticos simples o complejos de acuerdo a la magnitud de la fuerza impulsora. La complejidad de tales regímenes en las cinéticas isotérmicas, pudo caracterizarse mediante los exponentes de Avrami. Estos se comportan de manera diferente para muestras fabricadas por distintas vías. En el caso de la vía B el grado de superposición de los procesos es notable, contrariamente al caso de las cinéticas de la vía A. En particular la primera etapa de desorción a bajas temperaturas para las muestras fabricadas por la vía $\mathrm{B}$, mostraron estar notablemente más limitadas por procesos de nucleación que la vía A.

La modelización de las cinéticas isotérmicas de absorción mediante dos componentes principales de Hill resulta satisfactoria. Esto responde al régimen complejo de procesos existentes identificado para cada vía y dependiente del grado de avance de la transformación. Los experimentos de cinéticas en etapas revelaron que pueden controlarse los regímenes de los procesos manteniendo o restaurando la fuerza impulsora.

En cuanto a las cinéticas no isotérmicas, tanto realizadas en el Sievert como los barridos, calorimétricos aportaron de manera complementaria evidencia clara y valiosa, principalmente sobre la heterogeneidad de la cinética de las muestras fabricadas por las vías A y B, es decir se halló evidencia experimental de la existencia de múltiples procesos, dependientes de la vía de fabricación. Más aún, la posibilidad de distinguir los procesos en las curvas (diferente grado de superposición) es sensible tanto a las vías de fabricación como a las condiciones del experimento, particularmente a la presión parcial de $H_{2}$ y eventualmente al envejecimiento de la muestra.

Se encontró que el agregado de diferentes cantidades de grafito puede modificar el régimen de procesos logrando curvas aparentemente simples si se agrega $20 \%$ at. C (aunque probablemente con menos cantidad se pueda lograr esto). Se mostró que las muestras que presentaron regímenes bien diferenciados (vías A y D), preservan esta estructura compleja a lo largo de varios ciclos.

El método isoconversional aplicado resultó adecuado para obtener energías de activación comportadas de acuerdo al grado de superposición de los procesos. Las energías así obtenidas también manifiestan eventualmente la existencia de regímenes dependientes de la velocidad de calentamiento. Las energías de activación para procesos sin presión parcial de $\mathrm{H}_{2}$ resultaron más bajas. En el caso de las muestra fabricadas por vía directa (A), la descomposición de las curvas en componentes permitió un análisis satisfactorio de los procesos observados asociados a los diferentes picos de las corridas de desorción calorimétrica. Se mostró que el comienzo de la transformación está regido por un proceso de nucleación y crecimiento de acuerdo a un modelo de JMAK, con un exponente $>3$ que indica una tasa de nucleación decreciente. El segundo proceso debe ajustarse con un modelo SB. En las muestras fabricadas por vía B estos procesos se superponen reflejándose en una energía de activación global constante a lo largo de la transformación. En el caso de las muestras con grafito, en el inicio de la reacción los procesos involucrados se ven afectados ligeramente por el régimen de velocidades de calentamiento. Las funciones deben ser ajustadas con un modelo de SB si bien 
guardan cierta semejanza con un modelo de nucleación y crecimiento tipo JMAK.

\section{Comentarios finales}

A modo de conclusión final, se destaca la identificación y ajuste satisfactorio de los procesos de sorción de la fase $\mathrm{MgH}_{2}$ mediante una modelo de JMAK resulta trascendente desde el punto de vista básico, pero también desde el punto de vista aplicado dado que es uno de los sistemas más prometedores como reservorio de hidrógeno. La aplicación del método de análisis utilizado es novedosa para este tipo de sistemas y mostró ser satisfactoria. La fabricación e investigación de dispersiones mediante distintas vías ofreció también información valiosa para profundizar en los mecanismos de sorción involucrados en este tipo de sistemas a través de un mayor análisis de la microestructura y bordes de grano. Se destaca también la posibilidad de sintonizar diferentes regímenes de desorción incorporando grafito sin modificar sustancialmente la velocidad de la transformación. Esto ofrece una perspectiva interesante para el desarrollo de reservorios híbridos que utilizan C. 


\section{Apéndice A}

\section{MODELOS CINÉTICOS}

\section{A.0.1. Modelos cinéticos}

\begin{tabular}{|c|c|c|c|}
\hline Modelos & Símbolo & $f(\alpha)$ & $g(\alpha)=k t$ \\
\hline Johnson-Mehl-Avrami-Kolmogorov & JMAK(n) & $n(1-\alpha)\left[-\ln (1-\alpha)^{1-\frac{1}{n}}\right.$ & \\
\hline reacción 2D & $\mathrm{R} 2$ & $(1-\alpha)^{\frac{1}{2}}$ & \\
\hline reacción 3D & R3 & $(1-\alpha)^{\frac{1}{3}}$ & \\
\hline difusión 2D & D2 & $\frac{1}{[-\ln (1-\alpha)]}$ & \\
\hline Jander & D3 & & \\
\hline & MA2 & & {$\left[-\ln (1-\alpha)^{\frac{1}{2}}\right.$} \\
\hline & CV3 & & $1-[1-\alpha]^{\frac{1}{3}}$ \\
\hline & CV2 & & $1-[1-\alpha]^{\frac{1}{2}}$ \\
\hline Ginstling-Brounshtein & CVD3:D4 & $\frac{3}{2}\left[(1-\alpha)^{-\frac{1}{3}}-1\right]$ & $1-\left[\frac{2 \alpha}{3}\right][1-\alpha]^{\frac{2}{3}}$ \\
\hline & SCI & & $\alpha$ \\
\hline \multicolumn{4}{|l|}{ Modelos empíricos } \\
\hline Sěstak-Berggren & $S(m, n, p)$ & $\alpha^{m}(1-\alpha)^{n}\left[-\ln (1-\alpha)^{p}\right]$ & \\
\hline Reacción de orden $n$ & $R O(n)$ & $(1-\alpha)^{n}$ & \\
\hline
\end{tabular}

Tabla A.1: Se presentan en la tabla una lista de los modelos más utilizados en el análisis de las cinéticas.

\section{A.0.2. Modelos de Sěstak-Berggren y de Hill}

Derivando la función de Hill

$$
\alpha(t)=\frac{t^{n}}{k^{n}+t^{n}}
$$

se verifica que es solución de la ecuación

$$
\frac{d \alpha}{d t}=\alpha^{p} \cdot(1-\alpha)^{q}
$$

siempre que $p$ y $q$ cumplan $p+q=2$, resultando $p=\frac{n-1}{n}$ y $q=\frac{n+1}{n}$. Si bien tiene la forma aparente de la función de $S(m, n)$, la condición entre $p$ y $q$ hace que sea muy diferente. La condición implica una correlación directa entre las potencias que ponderan la influencia 
de las fases transformada $\alpha$ y sin transformar $1-\alpha$ en la reacción. Mientras que el modelo $S(m, n)$ no tiene una solución analítica para la función $g(\alpha)$, la integral de la ecuación A.2 usando la condición para los exponentes tiene solución analítica:

$$
\int_{o}^{\alpha} \frac{d \alpha^{\prime}}{\alpha^{\prime p}\left(1-\alpha^{\prime}\right)^{2-p}}=-\frac{\alpha^{1-p} \cdot(\alpha)^{p-1}}{p-1}
$$

la función de Hill tiene asociada entonces una función $z(\alpha)=-f(\alpha) \cdot g(\alpha)=f(\alpha) \alpha^{1-p} \cdot(\alpha)^{p-1} \frac{1}{p-1}$

La función de Hill puede ser derivada de un modelo logístico. Asumiendo que la tasa instantánea relativa de crecimiento

$$
r(t) d t=\frac{d \alpha}{\alpha(t)}
$$

depende de la fase sin transformar y decrece en el tiempo, se propone la forma

$$
r(t)=\frac{n}{t^{s}}(1-\alpha(t))
$$

considerando el caso particular $\mathrm{s}=1$

$$
\frac{n}{t} d t=\frac{d \alpha}{\alpha(1-\alpha)}
$$

separando variables e integrando la ecuación , se obtiene como solución la función de Hill A.1

\section{A.0.3. Modelo de Kolmogorov-Johonson-Mehl-Avrami y sus alcances}

M. Avrami [144] describe en forma general las cinéticas de cambio de fase. Como se adelantó, los trabajos publicados por Avrami, Johonson, Kolmogorov y Mehl, han constituido un punto de partida vastamente utilizado en los análisis cinéticos que se encuentran en la literatura. He aquí una breve síntesis del desarrollo del enfoque más general de su teoría de transformación de fase de un sistema a partir de los conceptos de nucleación, granulación y crecimiento $^{1}$. Esta generalidad permitirá vislumbrar la persistencia del uso de la teoría y sus extensiones. Se trata de una descripción que considera la necesaria aparición de núcleos de la nueva fase por encima de un tamaño crítico, distribuidos de cierta forma, y el subsiguiente crecimiento de tales núcleos que devienen en granos de la nueva fase. El análisis y desarrollo que hace originalmente Avrami toma en cuenta el aspecto probabilístico de la distribución de pequeños núcleos y el tipo de ley de crecimiento de tales núcleos (considera tres casos). A partir de ello logra obtener la representación analítica de lo que llama 'phase change formula, $V=V\left(t, T_{0}, r\right)$, para dar el grado de avance de la reacción en términos de la fracción de volumen de fase transformada, como función del tiempo $t$, la historia térmica y la posición en el sistema. También da una expresión para la densidad de granos, es decir el número de centros de grano por unidad de volumen, como función de $t, T_{0}$, y la posición, $N=N\left(t, T_{0}, r\right)$. Las fórmulas se desarrollan considerando la' densidad de granos' usando el concepto de 'volumen extendido', y luego teniendo en cuenta el impingement entre los vo-

\footnotetext{
${ }^{1}$ Ya en ese entonces, muchos investigadores habían advertido la necesaria existencia de una pre-fase heterogénea formada por pequeños clusters de nueva fase inmersos en la vieja fase, antes de alcanzarse la temperatura de transición de fase para que la misma pueda iniciarse.
} 
lúmenes extendidos. Justamente el trabajo se focaliza en demostrar que el análisis de las cinéticas de transformación de fase en términos de la existencia de nucleación, granulación y crecimiento es mucho más sencillo si se hace a través de las cantidades extendidas, es decir, fracción de volumen extendido, densidad de granos extendida y densidad de microestructura extendida $^{2}$. Esto es así porque es más sencillo obtener las fórmulas para tales cantidades extendidas, luego sólo hay que expresar las cantidades reales en términos de las extendidas y todo es función de la ley de crecimiento de los volúmenes de grano de la nueva fase. Cabe mencionar que las consideraciones de Avrami son también aplicables al caso general en que existan heterogeneidad de impurezas que catalizan la reacción proveyendo superficies activadoras de adsorción que pueden ser centros ávidos de nucleación ${ }^{3}$.

Las expresiones respectivas para $V=V\left(t, T_{0}, r\right)$ y $N=N\left(t, T_{0}, r\right)$ en términos de la distribución de tamaño de volúmenes granulares son:

$$
\begin{aligned}
& V=\int v F(v) d v \\
& N=\int F(v) d v
\end{aligned}
$$

En el caso de que los granos no presenten isotropía respecto de alguna dirección, debe agregarse la dependencia espacial $\eta$ expresada a través de $N=N\left(\eta, t, T_{0}, r\right)$ y $F=F\left(\eta, v, t, T_{0}, r\right)$. Todo el análisis de Avrami sigue siendo válido aún en estas circunstancias.

El volumen extendido sería el volumen total que suman todos lo granos existentes a cierto tiempo de reacción sin tener en cuenta la interpenetración o 'impingement' entre los volúmenes de los granos reales. Se requiere una correspondiente 'distribución extendida' de volúmenes para expresar las cantidades extendidas:

$$
\begin{gathered}
\widetilde{V}=\int_{0}^{\infty} \tilde{v} F(\tilde{v}) d \tilde{v} \\
\widetilde{N}=\int_{v_{c}}^{\infty} F(\tilde{v}) d \tilde{v}
\end{gathered}
$$

Luego, a partir del conocimiento de $\tilde{N}$ y la ley de crecimiento de los granos individuales, pueden ser calculados $V, N$ y $F$ y por tanto queda determinada la cinética de los agregados granulares.

Lo que hace Avrami es reescribir la ecuación A.6 usando una redefinición útil y estadísticamente más adecuada de la densidad para la distribución de puntos. Esto es, tomando distribuciones promedio para la densidad de puntos. Teniendo en cuenta el número $N_{\vec{R}}$ de centros contenidos en el volumen $\Omega_{\vec{R}}$ en torno a $\vec{R}$, se tiene el promedio $N(\vec{R})=\frac{N_{\vec{R}}}{\Omega_{\vec{R}}}$, que sería

\footnotetext{
${ }^{2}$ Denotada por $F(v) d v$ es la densidad de frecuencia de volumen, o distribución de volúmenes, es decir el número de centros de grano, o núcleos por unidad de volumen en el rango v, v+dv.

${ }^{3}$ Así como los clusters de la pre-fase, estas impurezas o defectos, en general sitios ávidos para la formación de núcleos, pueden estar desde el principio de la reacción, por lo que aquí aparece la dependencia con la 'prehistoria' del sistema, pueden ser introducidos físicamente o ser formados químicamente durante la reacción, y por tanto dependen de la 'historia' de la reacción.
} 
la densidad de puntos en torno a $\vec{R}$. El volumen $\Omega_{\vec{Q}}$ debe ser subdividido en celdas $\Delta w{ }^{4}$ Luego, la densidad de volumen extendido en torno a un punto $\vec{R}$, A.6, se convierte en una densidad de volumen extendido promedio dado por

$$
\tilde{V}(t, \vec{R})=\int \tilde{N}\left(t^{\prime}, \vec{Q}\right) d \Omega_{\vec{Q}}
$$

Siendo $t^{\prime}$ el tiempo retardado asociado al tiempo $t-t^{\prime}$ requerido para que un grano en $\vec{Q}$ crezca hasta $\vec{R}$ a una velocidad $\vec{G}$, que es función de la temperatura. En la presencia de anisotropía debería integrarse $\tilde{N}$ también en las distintas direcciones.

La ecuación A.8 es bien general y puede aplicarse a varios casos de distribuciones de centros de grano(núcleos), ya sea isotrópicamente distribuidos, aleatoriamente distribuidos sobre superficies foráneas, aleatoriamente distribuidos sobre bordes de grano de la vieja fase (grain boundary nucleation). Luego Avrami relaciona para distintos casos la densidad de volumen extendido $\tilde{V}$ y y la ley de crecimiento de grano $\tilde{v}\left(t, t^{\prime}\right)$ que da la evolución en el tiempo del crecimiento del volumen de grano. Por ejemplo para el caso en que la densidad de núcleos es uniforme $\left(\frac{d N}{d r}=0\right)$ la expresión correspondiente es

$$
\tilde{V}(t, \vec{R})=\int_{0}^{t} \tilde{v}\left(t, t^{\prime}\right) \frac{\partial \tilde{N}}{\partial t^{\prime}} d t^{\prime}
$$

Primero considera tres casos con distinto tipo de crecimiento dimensional de grano, por lo que aparece un prefactor para $\tilde{N}$ para considerar solo la fracción efectiva de núcleos que crecen según el tipo de crecimiento. Tal prefactor está asociado al volumen $\tilde{v}\left(t, t^{\prime}\right)$ en cada uno de los casos. Es en función de esta 'ley de crecimiento' en términos de la cual quedan expresadas las cantidades de interés, en particular, la fracción de volumen trasformado $V(t, \vec{R})$. Avrami demuestra por distintas vías que, asumiendo que la interacción entre los granos que se tocan es solo de contacto, sin involucrar otros mecanismos, y asumiendo también una distribución inicial, -y por tanto posterior- localmente aleatoria de los núcleos. la relación entre el volumen real V y el extendido $\tilde{V}$ está dado por ${ }^{5}$

$$
V(t, \vec{R})=1-\exp ^{-\tilde{V}(t, \vec{R})}
$$

y mediante la ecuación A.9 se obtiene:

$$
\begin{gathered}
V(t, \vec{R})=1-\exp ^{-\int_{0}^{t} \tilde{v}\left(t, t^{\prime}\right) \frac{\partial \tilde{N}}{\partial t^{\prime}} d t^{\prime}} \\
v\left(t, t^{\prime}\right)=\int_{t^{\prime}}^{t} \frac{\partial \tilde{v}\left(t, t^{\prime}\right)}{\partial t} \exp ^{-\tilde{V}(t)} d t
\end{gathered}
$$

\footnotetext{
${ }^{4}$ Consultar el trabajo original para comprender detalladamente el rango conceptual en el que deben tomarse estos volúmenes involucrados.

${ }^{5}$ Una demostración que desarrolla a partir de esta distribución aleatoria localmente es tomando la distribución de Bernoulli. Considerando la probabilidad para que en un elemento de volumen $w$ en torno a $\vec{r}$ no haya núcleos de grano y tomando el límite infinitesimal del volumen, aparece el factor exponencial.Luego la probabilidad de que un volumen en torno a $\vec{R}$ no se haya trasformado es justamente $1-V$, y resulta de un producto de probabilidades de volúmenes infinitesimales no transformados que siguen una ley exponencial derivada de la distribución de Bernoulli.
} 
Así, el grado de avance de la reacción en términos de la fracción de volumen transformado deviene en una expresión sencilla en términos de la tasa de nucleación $\frac{\partial \tilde{N}}{\partial t^{\prime}}$ y la ley de crecimiento $\tilde{v}\left(t, t^{\prime}\right)$.

Bajo las siguientes suposiciones:

- Nucleación aleatoria y homogénea sobre toda la fase no transformada

- Crecimiento isotrópico de los núcleos-grano a una velocidad invariante frente a la extensión de la transformación.

cambiando de notación $V \rightarrow \alpha$ resulta:

$$
\alpha(t, T)=1-e^{-K(T) t^{n}}
$$

esperando $n=4$ en el caso de crecimiento tridimensional, aunque en la práctica se obtienen valores no enteros. La constante K está asociada a la ley de crecimiento de los granos y depende de la temperatura. Es en general ampliamente considerado que sigue una ley tipo Arrehenius $K(T)=A \cdot e^{-\frac{E_{a}}{k_{B} T}}$, donde el factor pre-exponencial se ha intentado asociar sin argumentos sólidos a la frecuencia de intentos para que tenga lugar la reacción que requiere de una energía $E_{a}$. El factor exponencial tiene como origen la distribución de Maxwell que da la fracción de moléculas con energía cinética mayor a $E_{a}$.

Tomando la ecuación A.13 se obtiene la clásica expresión para realizar un 'Avrami plot' graficando $\ln (-\ln (1-f))$ vs $t$. Según la ecuación A.13

$$
\ln [-\ln (1-\alpha)]=n \cdot \ln (t)+\ln (K)
$$




\section{Apéndice B}

\section{CINÉTICAS DE FORMACIÓN}
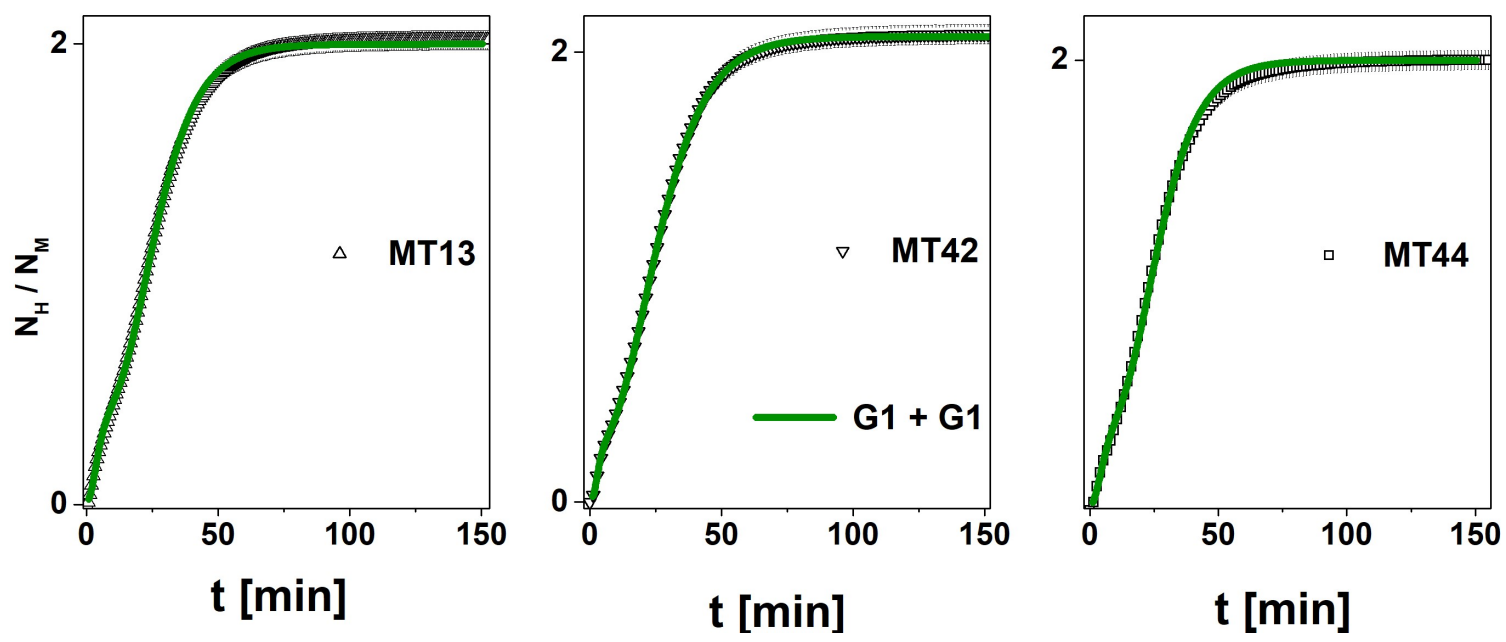

Figura B.1: Ajustes (en verde) con dos componentes de Gompertz de curvas cinéticas de formación (en negro) para muestras homólogas-Vía A
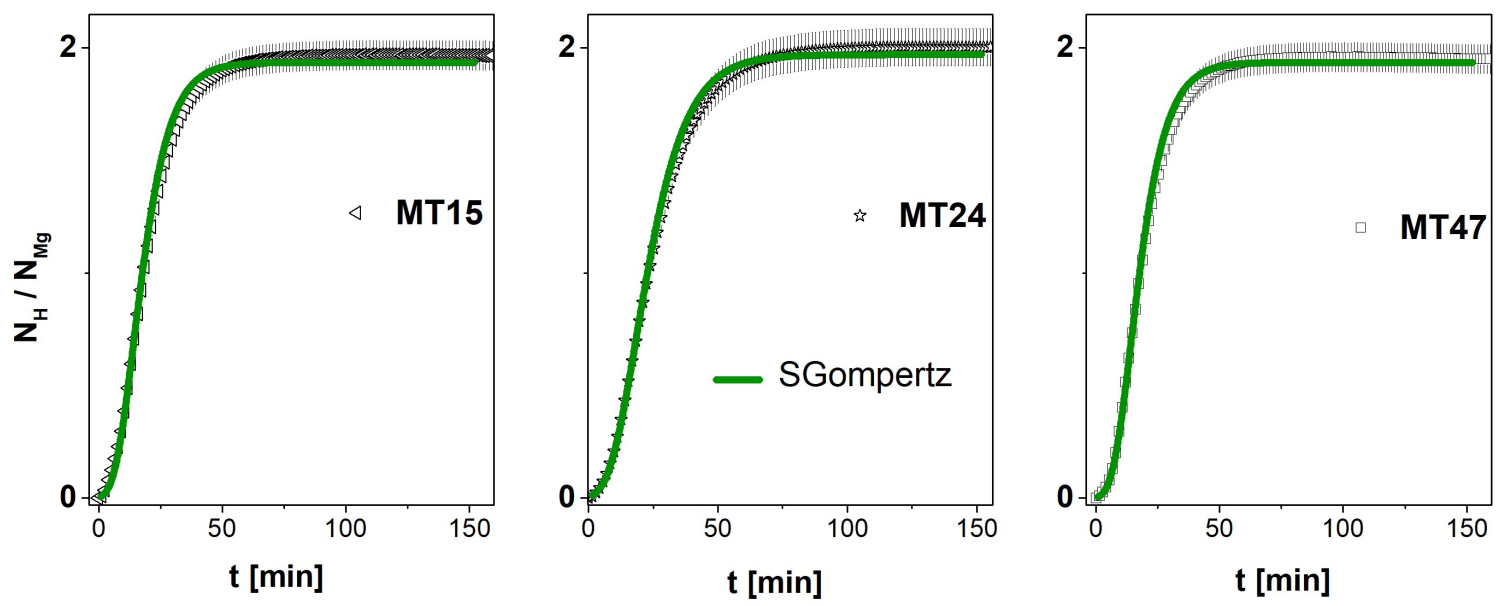

Figura B.2: Ajustes (en verde) con dos componentes de Gompertz de cinéticas de formación (en negro) para muestras homólogas-Vía B 


\begin{tabular}{|c|c|c|c|c|}
\hline \multicolumn{5}{|c|}{ Parámetros ajustados para muestras homólogas } \\
\hline & \multicolumn{2}{|c|}{ ruta $\mathrm{A}$} & \multirow{4}{*}{ MT38 } & ruta $B$ \\
\hline \multirow[t]{3}{*}{ MT13 } & $a_{1}: 1,6$ & $a_{2}: 0,4$ & & $a: 1,949(1)$ \\
\hline & $k_{1}: 0,0933(2)$ & $k_{2}: 0,426(1)$ & & $k: 0,1292(1)$ \\
\hline & $\tau_{1}: 23,58(2)$ & $\tau_{2}: 4,63(2)$ & & $\tau: 14,33(1)$ \\
\hline \multirow[t]{3}{*}{ MT42 } & $a_{1}: 1,6$ & $a_{2}: 2-a_{1}$ & MT24 & $a: 1,971(1)$ \\
\hline & $k_{1}: 0,0932(4)$ & $k_{2}: 0,425(2)$ & & $k: 0,1017(2)$ \\
\hline & $\tau_{1}: 24,13(3)$ & $\tau_{2}: 3,756(9)$ & & $\tau: 18,05(3)$ \\
\hline \multirow[t]{6}{*}{ MT44 } & $a_{1}: 1,6$ & $a_{2}: 2-a_{1}$ & MT47 & $a: 1,937(1)$ \\
\hline & $k_{1}: 0,0938(2)$ & $k_{2}: 0,327(1)$ & & $k: 0,1291(1)$ \\
\hline & $\tau_{1}: 23,13(2)$ & $\tau_{2}: 3,902(2)$ & & $\tau: 14,33(1)$ \\
\hline & & & MT15 & $a: 1,937(2)$ \\
\hline & & & & $k: 0,1256(3)$ \\
\hline & & & & $\tau: 14,32(2)$ \\
\hline
\end{tabular}

Tabla B.1: Se presentan en esta tabla los parámetros ajustados de la(s) componente(s) de Gompertz para dos series de cinéticas (vías A y B).

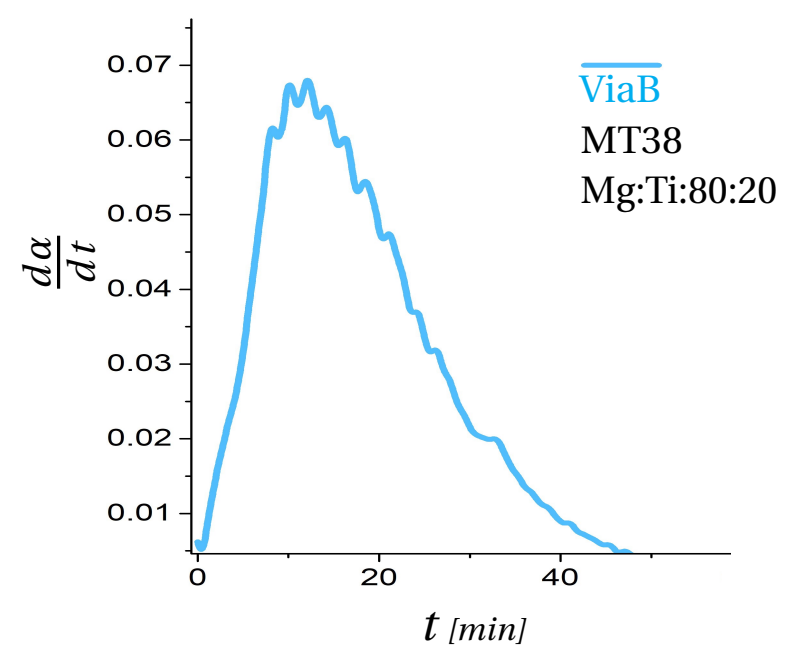

a)

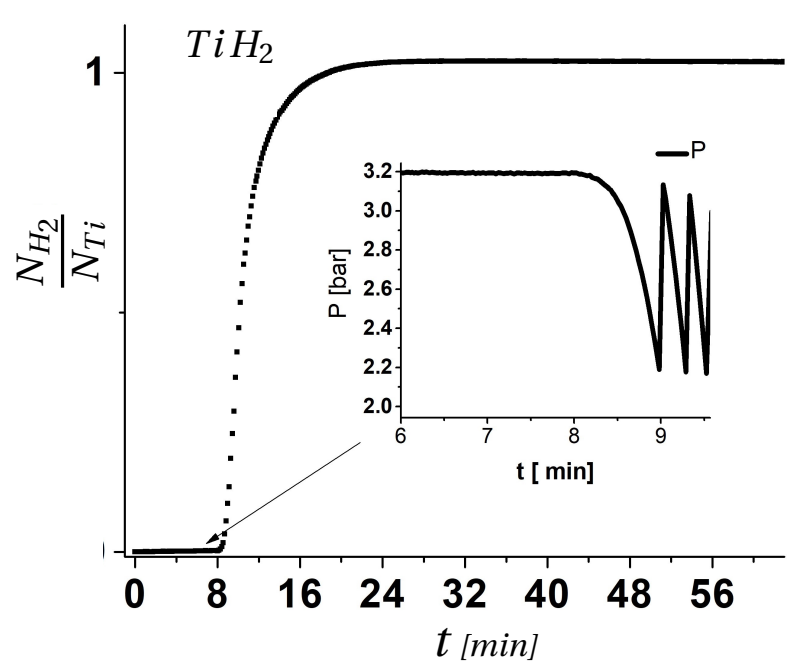

b)

Figura B.3: $a$ : Derivada de una curva cinética de formción correspondiente a una muestra fabricada mediante la vía B, de composición Mg:Ti:80:20. b: Formación de $\mathrm{TiH}_{2}$ mediante molienda mecánica. Luego de un breve períódo (pocos minutos) de iniciada la molienda, la formación de la fase $\delta-\mathrm{TiH}_{2}$ es muy rápida. 


\section{Apéndice C}

\section{DIFRACCIÓN}

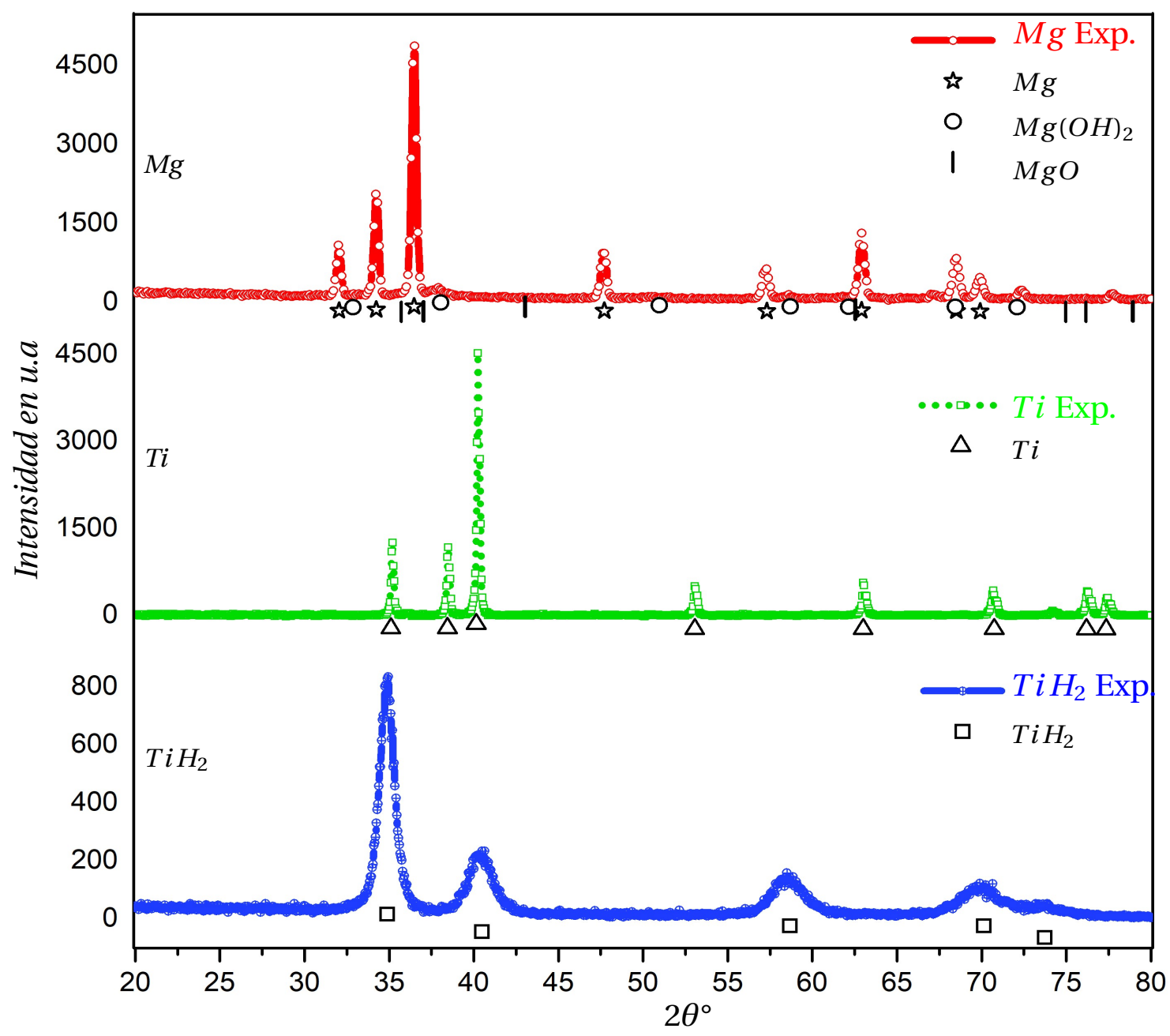

Figura C.1: Patrones de difracción de rayos X correspondinetes al Mg, el Ti y el $\mathrm{Ti} \mathrm{H}_{2}$ usados para las moliendas. Se utilizó radiación $\mathrm{Cu} K_{\alpha} \lambda_{1}=1,54056 \AA$. Claramente el $T i H_{2}$ presenta picos más anchos asociados a una reducción del tamaño de grano durante la molienda mecánica. 


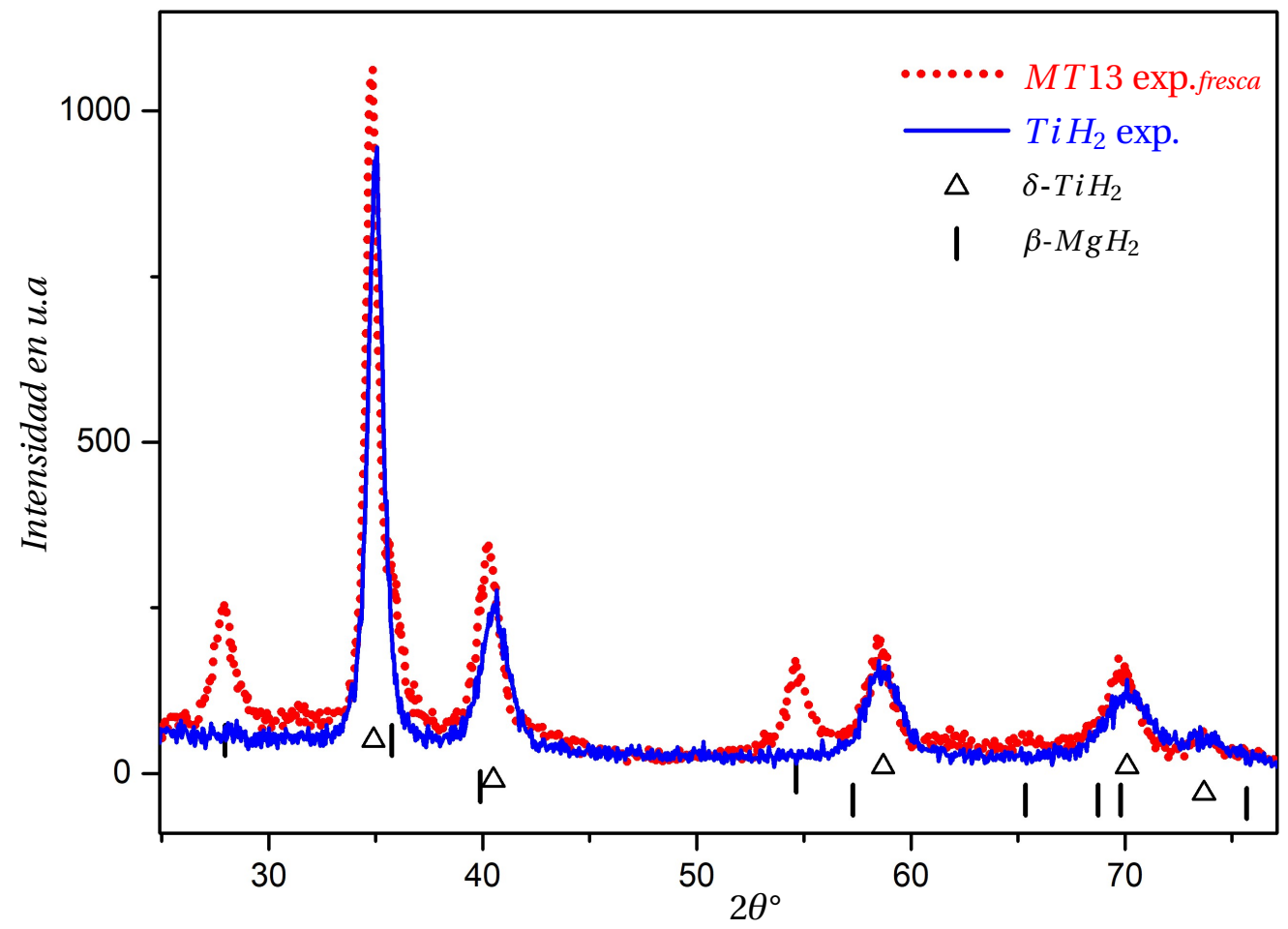

Figura C.2: Patrones de difracción correspondientes a una muestra fresca preparada por la vía A y a $\mathrm{TiH}_{2}$ preparado por molienda. Se puede ver claramente que la anchura de los picos de la fase $\delta$ - $T i H_{2}$ es la misma tanto cuando se prepara sola como cuando se forma en los it composites MgTi hidrurados.

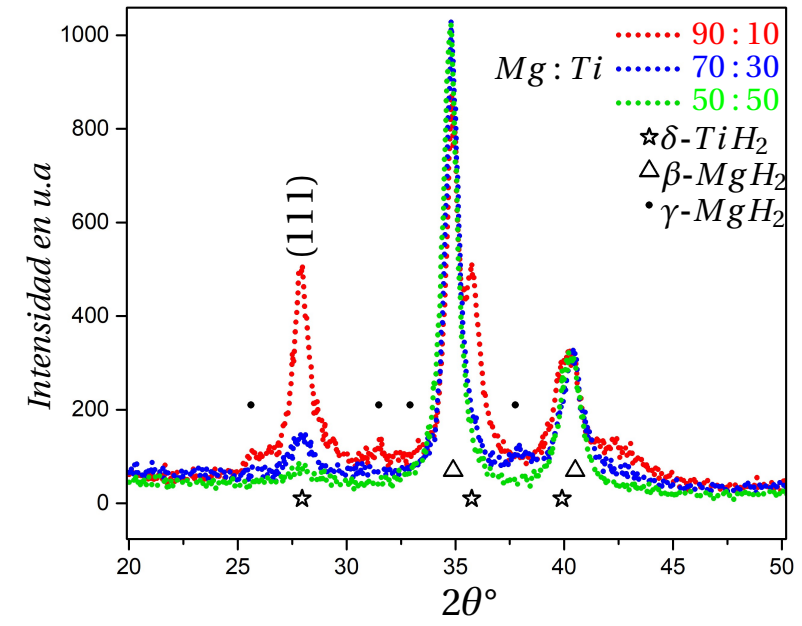

a)

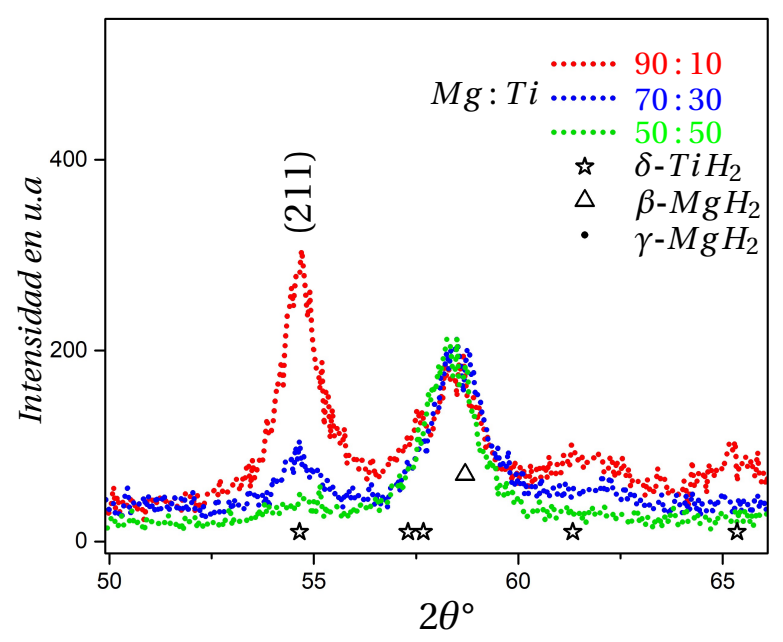

b)

Figura C.3: Se comparan patrones de difracción de rayos $\mathrm{X}$ para sistemas $M g-T i$ frescos preparados por la vía A, con distinto porcentaje atómico de Ti. Se muestran amplificadas las regiones de bajo ángulo $(a)$ y alto ángulo (b) a fin de resaltar el adelgazamiento de los picos (111) y (222) a medida que se incrementa la proporción de Ti. 


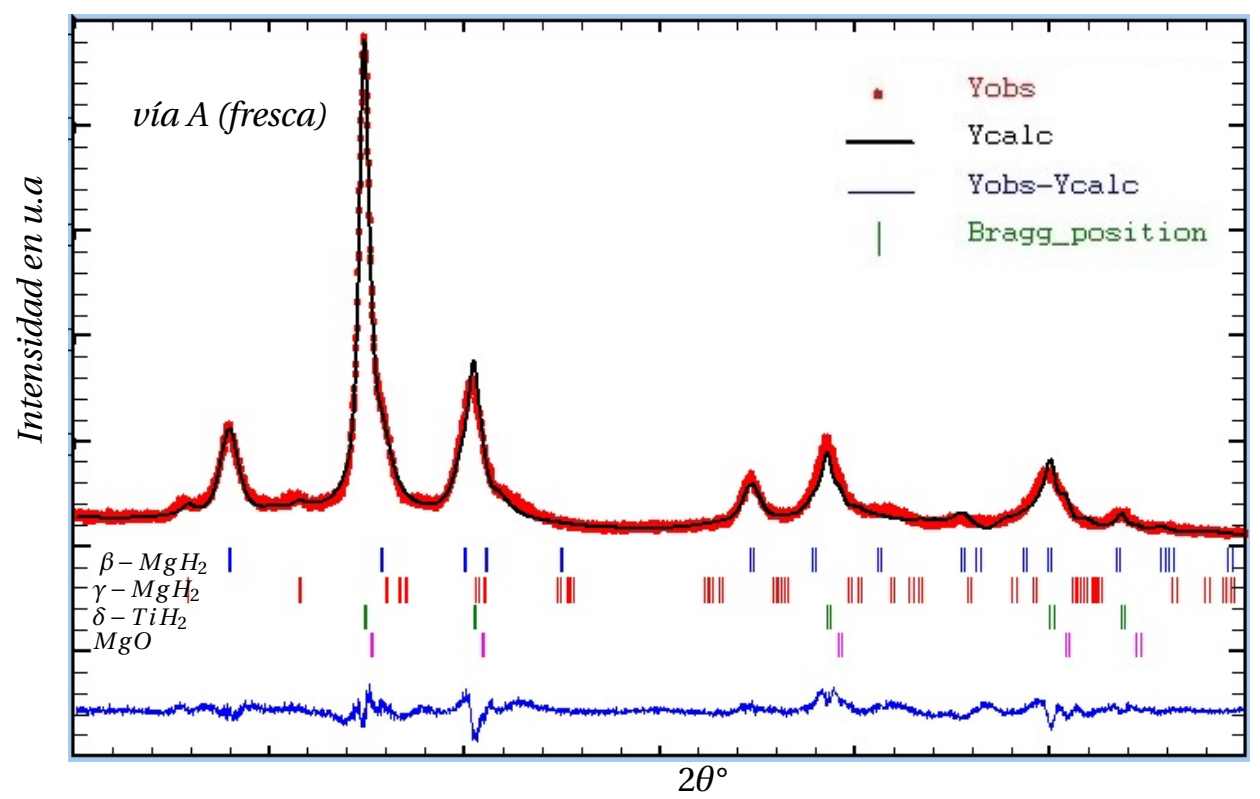

Figura C.4: Patrón de difracción y Refinamiento Rietveld de una muestra fresca fabricada por las vía A (MT13).

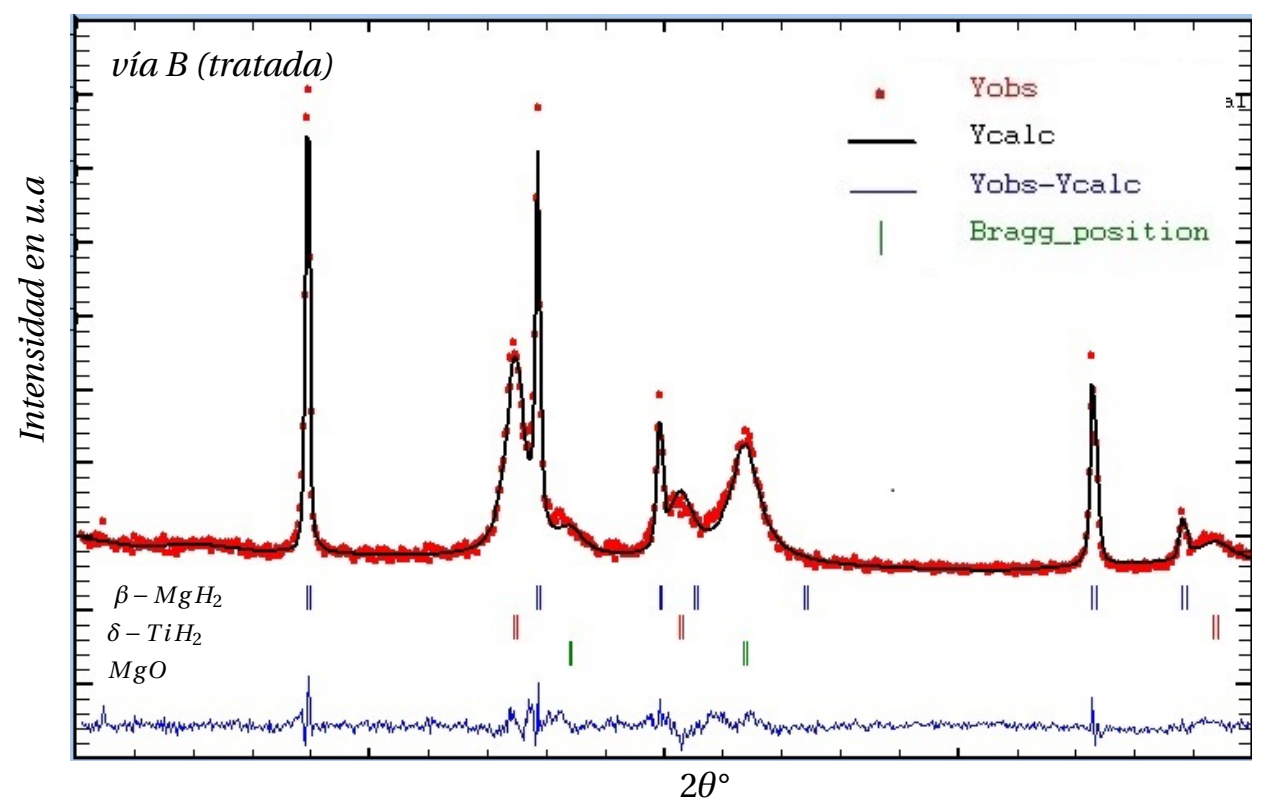

Figura C.5: Patrón de difracción y Refinamiento Rietveld de una muestra tratada fabricada por las vía B (MT24). 


\section{Apéndice D}

\section{MICROSCOPÍA}

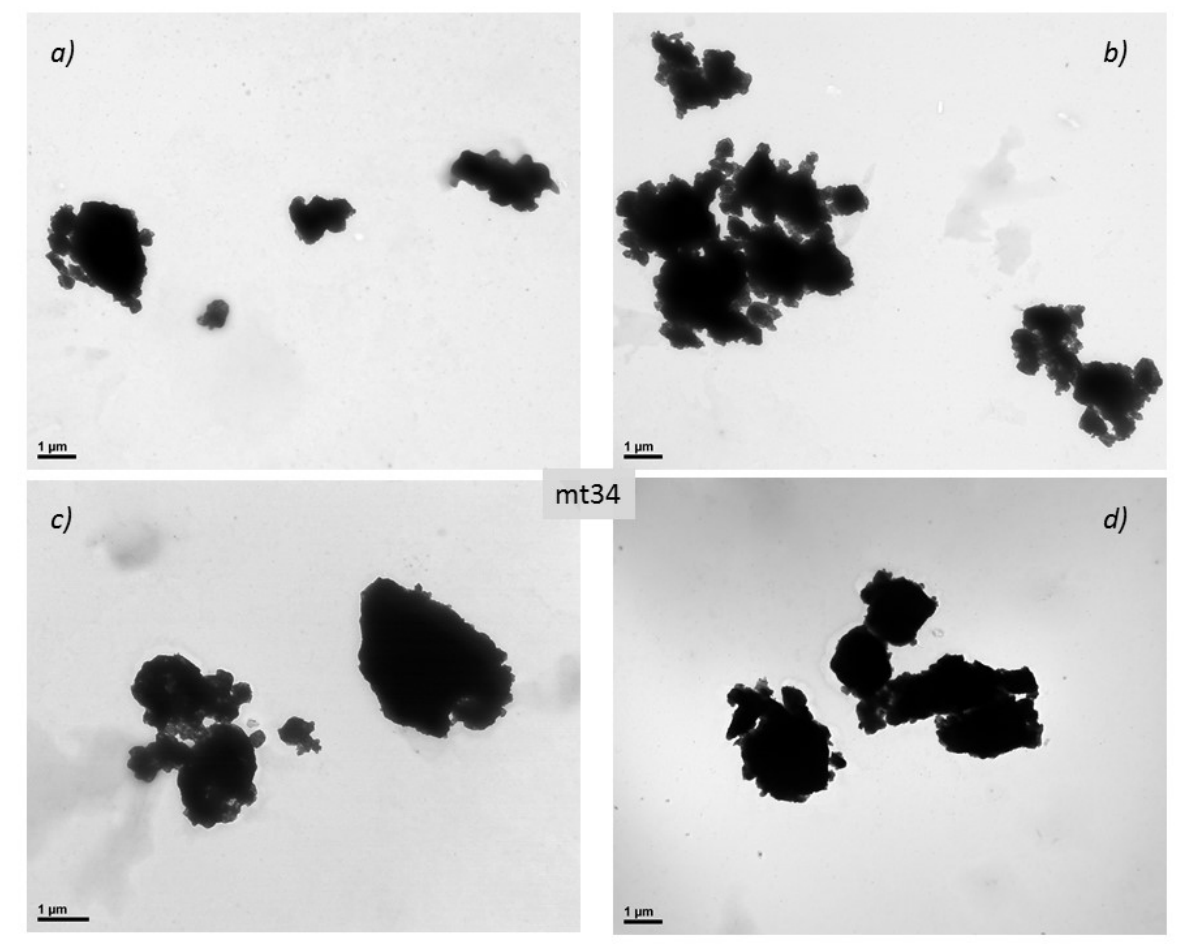

Figura D.1: Serie de imágenes TEM (FCV) mostrando tamaños y morfología de los conglomerados de una muestra fresca. Las imágenes de la muestra tratada térmicamente se muestran en el figura5.10. 


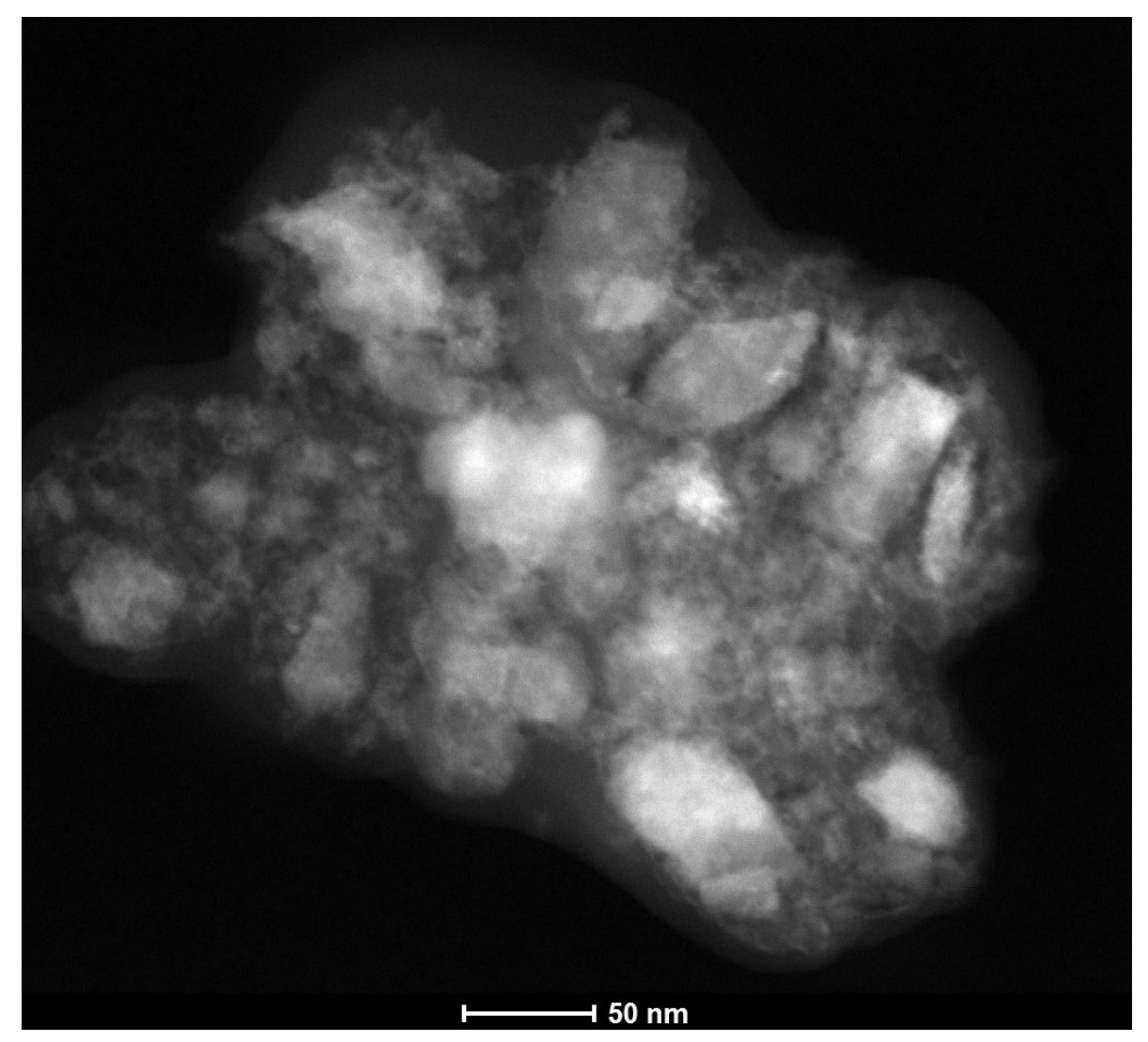

Figura D.2: Imágen de campo oscuro de una muestra con grafito. Las regiones claras corresponden a las regiones identificadas con la fase $\mathrm{TiH}_{2}$. 

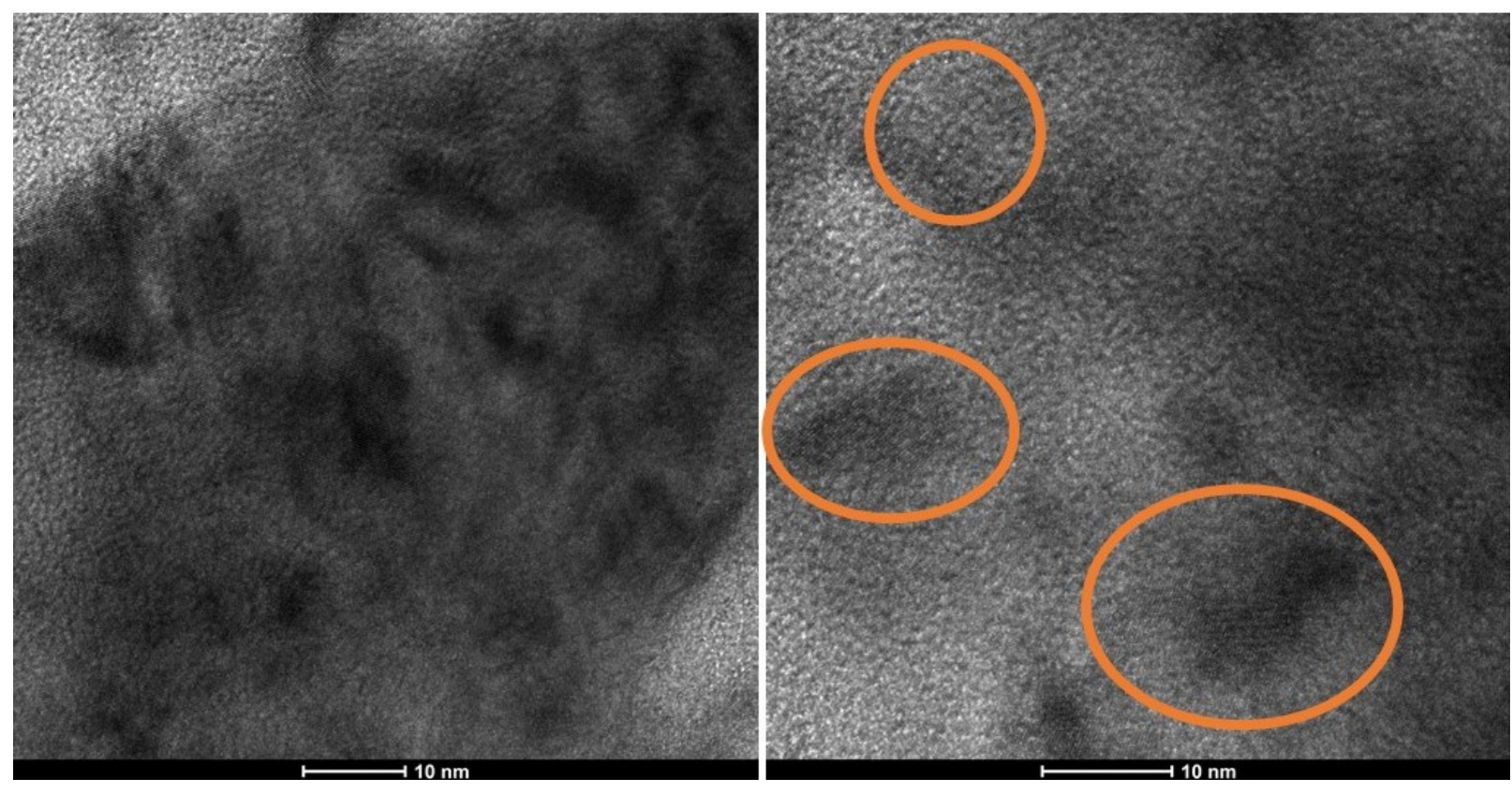

Figura D.3: Imágen de alta resolucion HR para una muestra con grafito (20\% at.) indicando las regiones donde se apreciaban mejor los planos cristalinos.
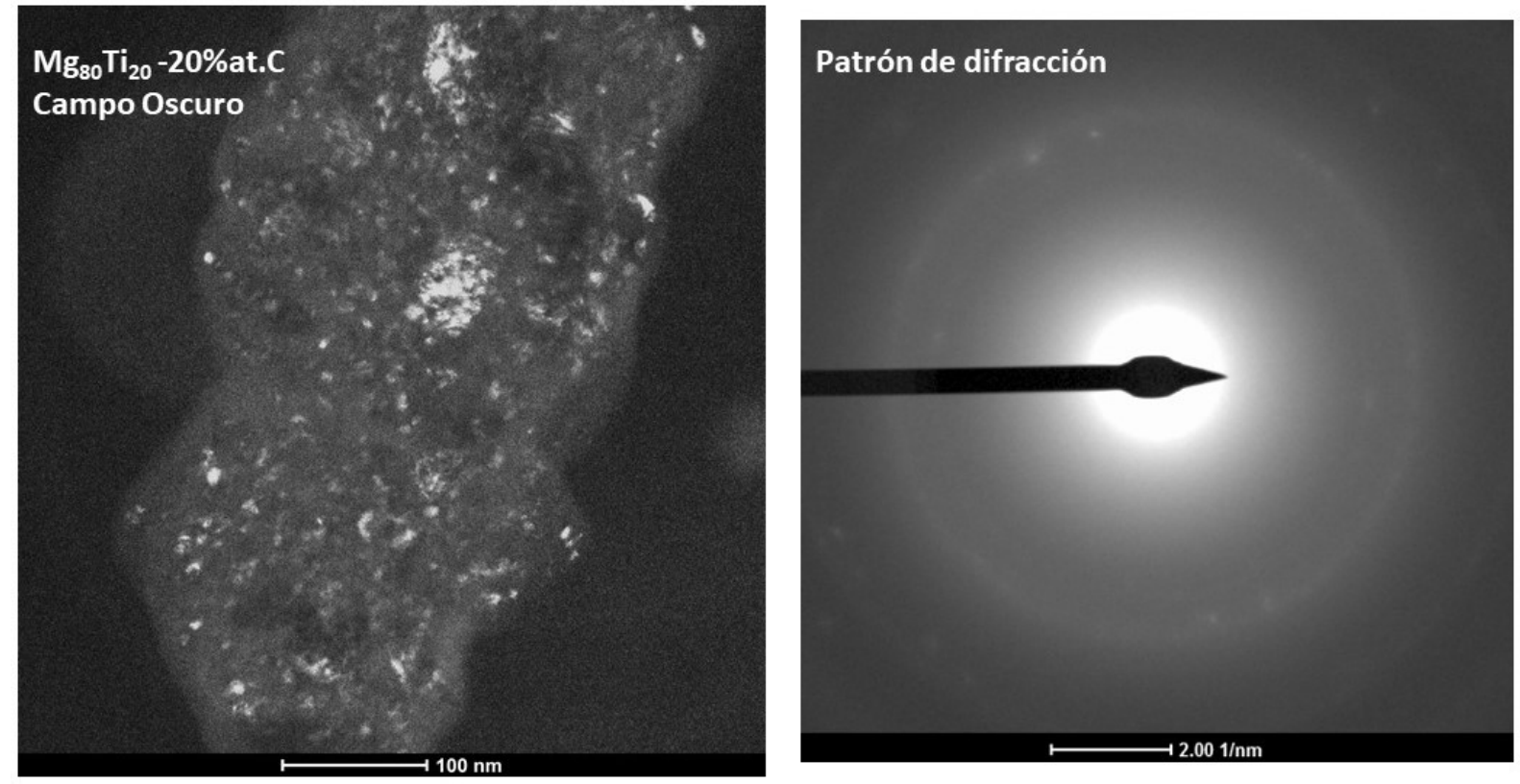

Figura D.4: Imágen de campo oscuro y patrón de difracción para una muestra con grafito, correpondiente a la partícula de la figura 5.18 . 


\section{Apéndice E}

\section{CINÉTICAS DE ABSORCIÓN/DESORCIÓN}

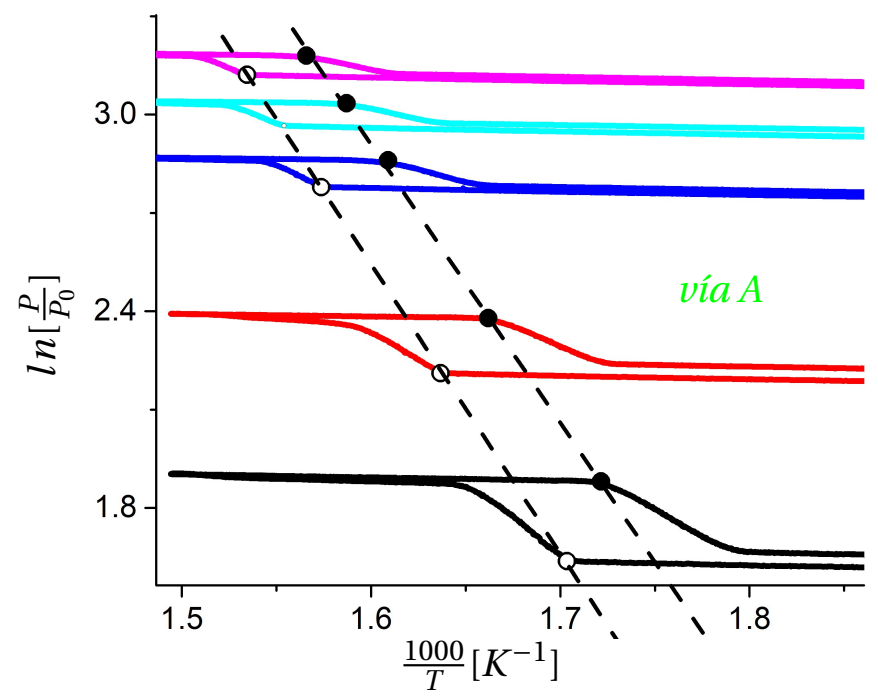

Figura E.1: Se muestran las curvas de tratamientos térmicos en coordenadas transformadas (coordenadas de Van't Hoff) a fin de apreciar la linealidad de los puntos de comienzo de las desorciones y absorciones.

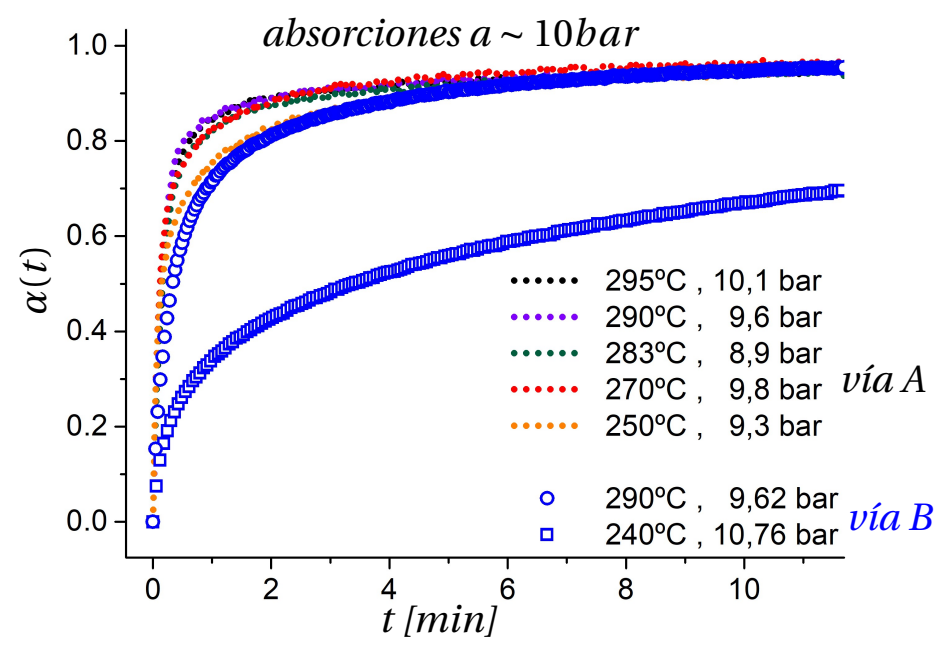

Figura E.2: Comparación de cinéticas de absorción de las muestras MT13(vía A) y MT24(vía B). Se realizaron a una presión de $\sim 10$ bar y a distintas temperaturas. La muestra MT24 presenta comparativamente una notable ralentización de su cinética al disminuir la temperatura. 


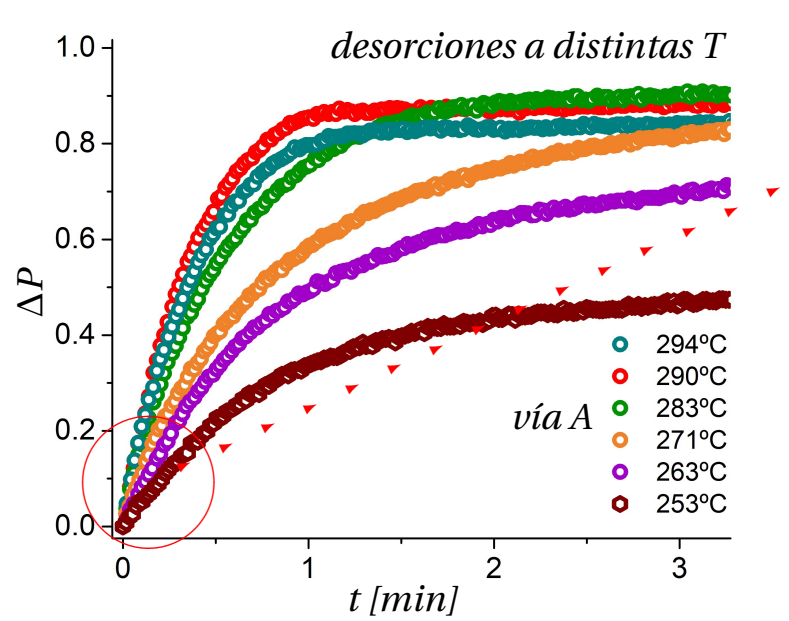

a)

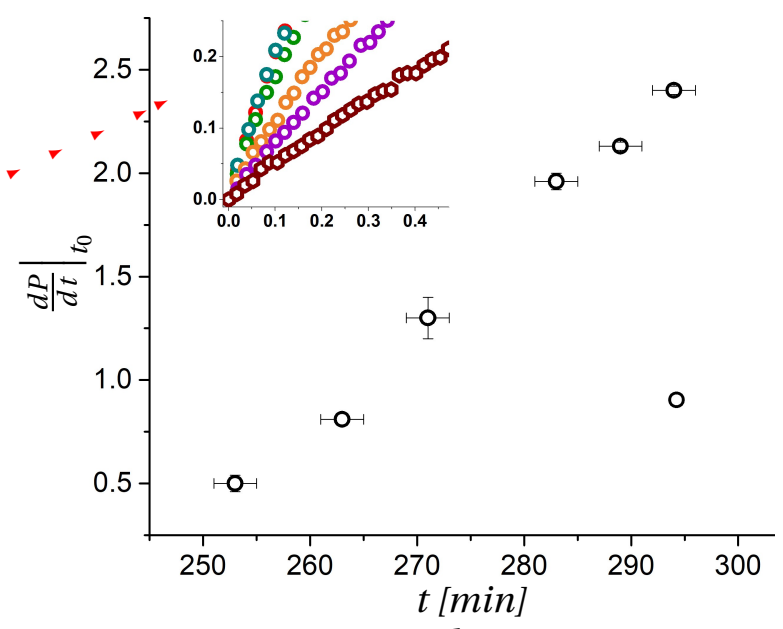

b)

Figura E.3: $a$ ):Se comparan curvas cinéticas de desorción para distintas temperaturas (primeros ciclos de desorción de la muestra MT13 (vía A).b): Para los primeros ciclos, dada la repetitividad, es posible obtener en forma aproximada las rectas tangentes al inicio de las curvas. Se grafican las pendientes (velocidades) iniciales de las cinéticas de la figura $a$ ) en función de la temperatura.

\section{Calibración del Volumen del equipo volumétrico}

Se pretende determinar el volumen de todo o parte del equipo a partir de un volumen calibrado (conocido) $V_{c}$. En la situación inicial se encuentra el volumen conocido $V_{c}$ lleno de $H_{2}$ u otro gas a una presión alta $P_{1}$ y el resto del volumen (V) en vacío o con una presión residual $P_{0}$. Al abrir la llave que los comunica se igualarán las presiones a una presión final $P_{2}$ que, por conservación del número total de moles, satisface:

$$
P_{1} V_{c}+P_{0} V=P_{2}\left(V_{c}+V\right)
$$

de modo que puede determinarse el volumen desconocido $V$ :

$$
V=\frac{V_{c}\left(P_{1}-P_{2}\right)}{\left(P_{2}-P_{0}\right)}
$$

En la práctica se hacen varias determinaciones secuenciales de $P_{1}$ y $P_{2}$, que se ajustan bien con una recta ya que:

$$
P_{1}=\left(1+V / V_{c}\right) P_{2}-\left(V / V_{c}\right) P_{0}=m P_{2}-b
$$

Del ajuste no sólo puede determinarse el volumen, a partir de la pendiente:

$$
V / V_{c}=m-1
$$

sino también la presión $P_{0}$ que, en general, se conoce con poca precisión:

$$
P_{0}=b /(m-1)
$$


En las medidas realizadas $P_{0}$ resulta del orden de 0,22 bar y $V=\sim 17,26 \mathrm{~cm} 3$.

\section{Dependencia con la temperatura: volumen efectivo.}

En los experimentos, el reactor se calienta a una temperatura T, estando el resto del sistema a temperatura ambiente $T_{a}$ con una zona de transición entre ambos. De manera sencilla se puede suponer que habrá un cierto volumen $V_{r}$ a la temperatura T y el resto $V_{s}=V-V_{r}$ a $T_{a}$, así como el volumen calibrado $V_{c}$, que está siempre a $T_{a}$. En ese caso la ecuación E deberá modificarse para tener en cuenta las distintas temperaturas:

$$
P 1 V c / T_{a}+P_{0} V_{s} / T_{a}+P_{0} V_{r} / T=P_{2}\left(V_{c} / T_{a}+V_{s} / T_{a}+V_{r} / T\right)
$$

y entonces

$$
\left(P_{1}-P_{2}\right) V_{c}=\left(P_{2}-P_{0}\right)\left(V_{s}+V_{r} T_{a} / T\right)=\left(P_{2}-P_{0}\right) . V_{e f}(T)
$$

donde definimos un volumen efectivo

$$
V_{e f}(T)=\left(V_{s}+V_{r} T_{a} / T\right)
$$

que es el valor que surgirá de los ajustes de $P_{1}$ vs. $P_{2}$ ya que:

$$
P 1=\left(1+V_{e f} / V_{c}\right) P_{2}-\left(V_{e f} / V_{c}\right) P_{0}=m P_{2}-b
$$

Se midió el volumen efectivo (que es el volumen mencionado en el apartado anterior) para varias temperaturas entre $24^{\circ} \mathrm{C}$ y $400^{\circ} \mathrm{C}$. Los valores muestran un decrecimiento con $\mathrm{T}$ a partir del cual, ajustando la expresión E.4 pueden determinarse los valores de $V_{r}$ y $V_{s}$. ( $\left.V_{s}=13,886 \mathrm{~cm} 3 ; V_{r}=3,485 \mathrm{~cm}^{3}\right)$. Notemos que el volumen total resultante $V=V_{s}+V_{r}$ está en buen acuerdo con el medido previamente. Todo ocurre como si el volumen del reactor (volumen efectivo a esa temperatura) fuera bastante menor que el delimitado por la válvula de cierre, lo cual es esperable. 


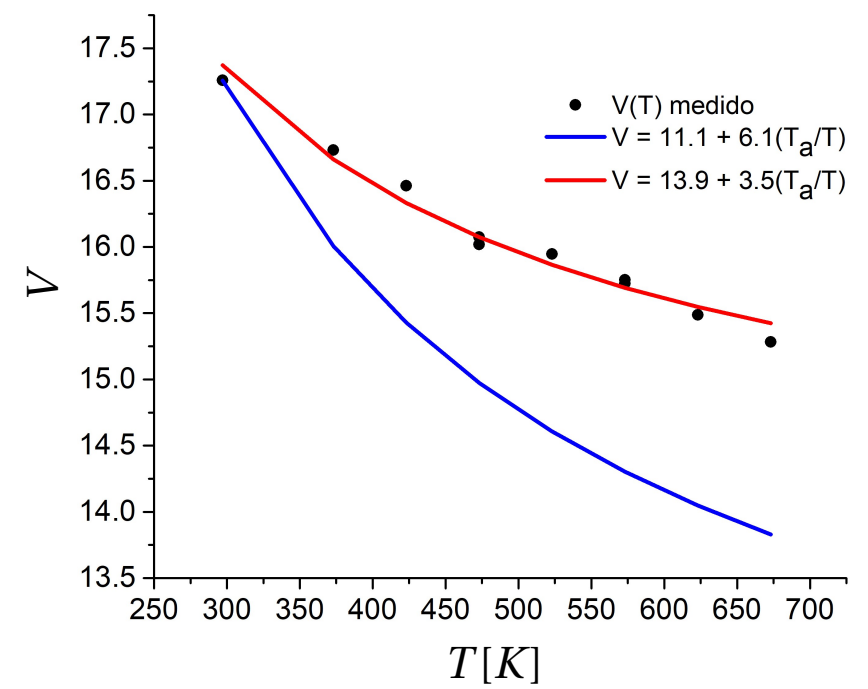

Figura E.4: Volumen efectivo medido en función de la temperatura. Se muestran los puntos experimentales y el ajuste.
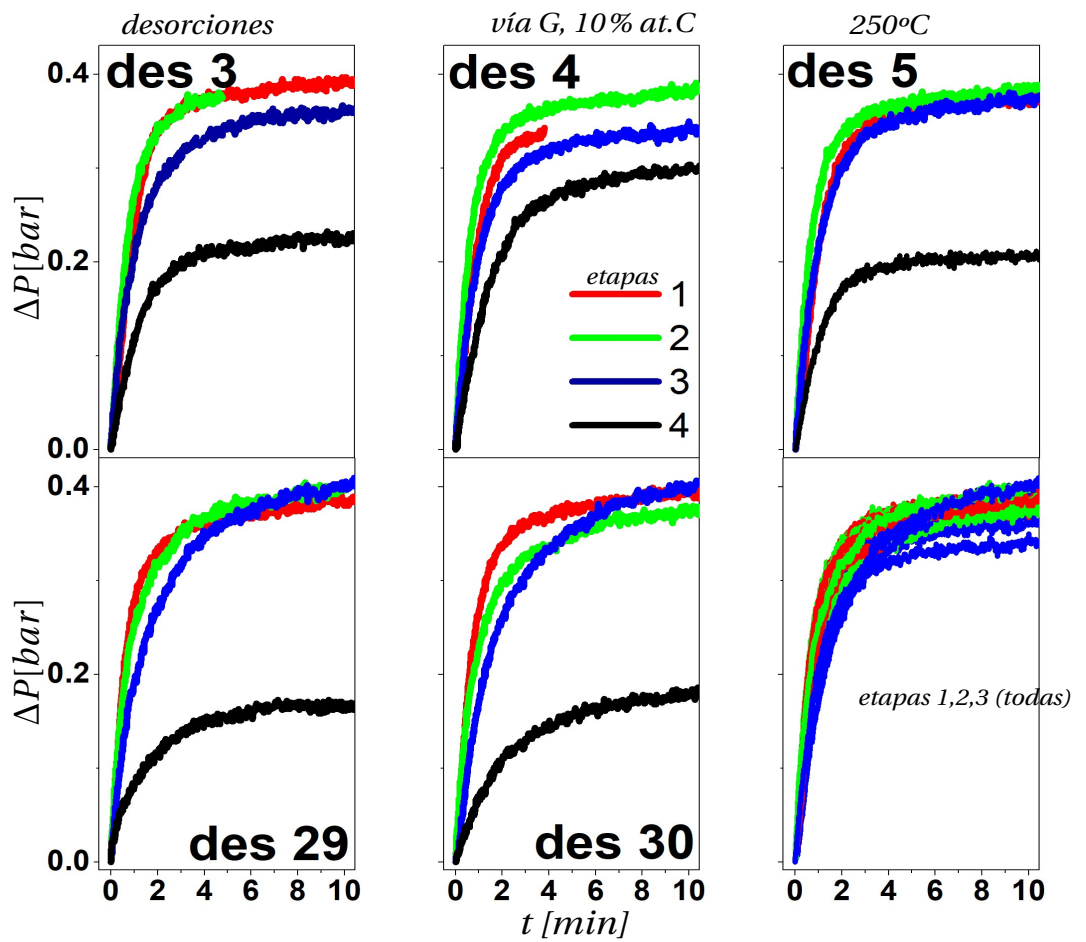

Figura E.5: Desorciones en etapas, vía G (10\% at. C). Comparación de varios ciclos de desorciones en etapas (ciclos 3,4,5,29 y30) de una muestra fabricada con $10 \%$ de grafito (CMT08). En cada gráfico se muestran las 4 etapas requeridas para la descarga completa. En el último(abajo, derecha) se comparan todas juntas las 3 primeras etapas de todos los ciclos correspondientes a las figuras anteriores. 
a)

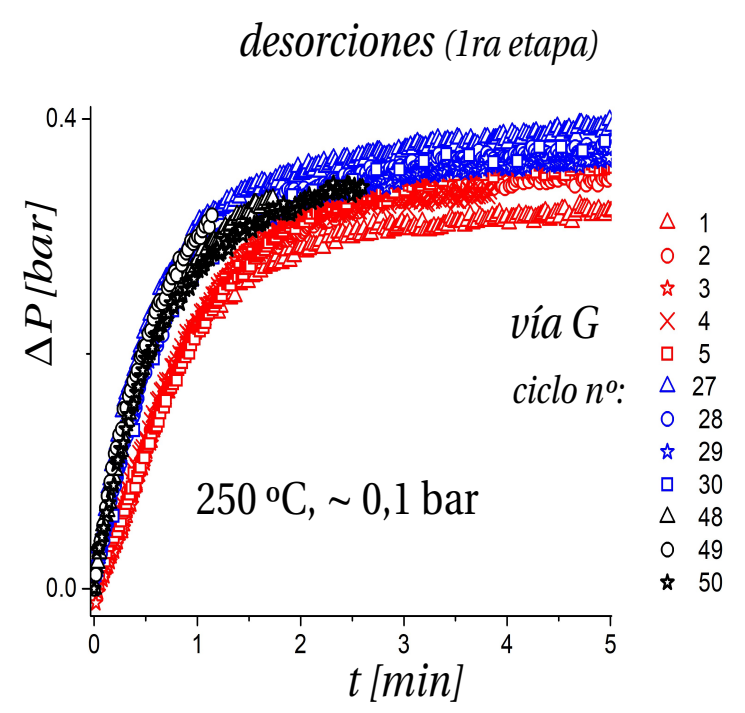

b)

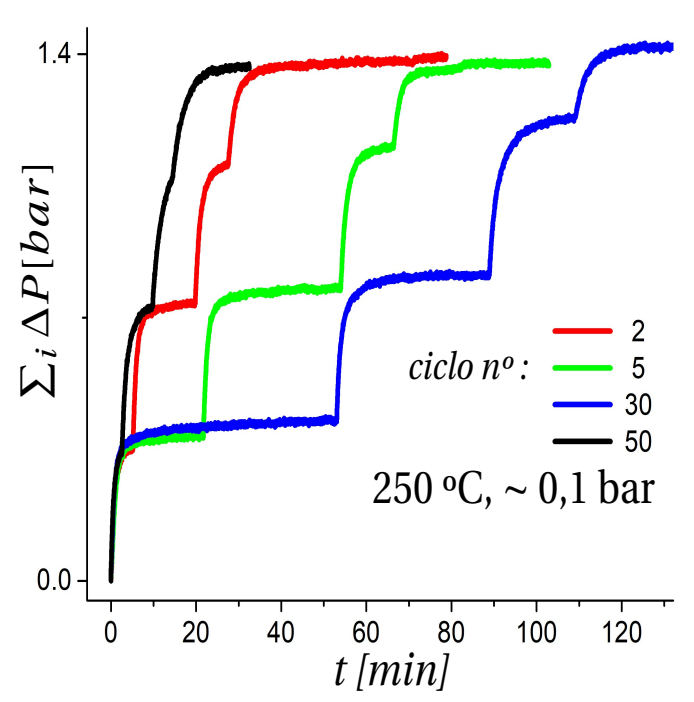

Figura E.6: a): Comparación de la cinética de la primera etapa de desorción de distintos ciclos. Las desorciones corresponden a la muestra CMT08 (10\% at.C). b) Comparación de las cinéticas de desorción completas entre los primeros y los últimos ciclos. La cinética se conserva. 


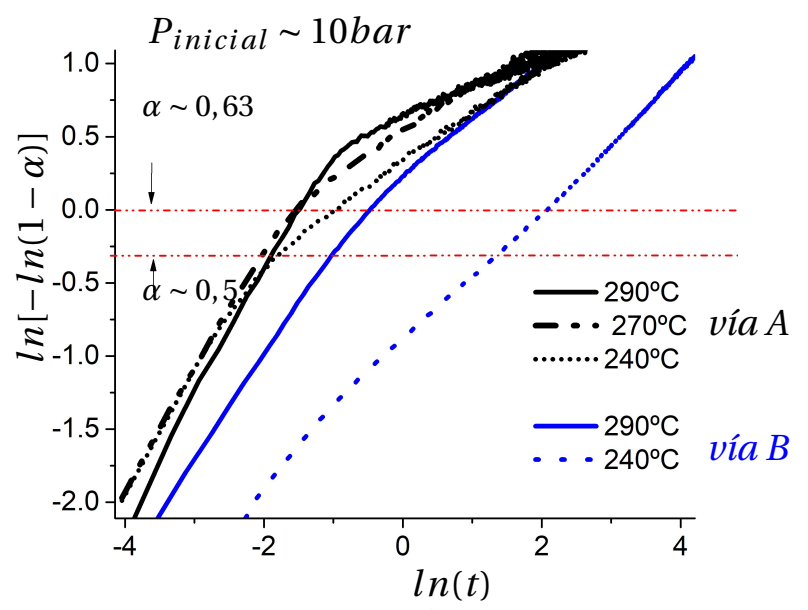

a)

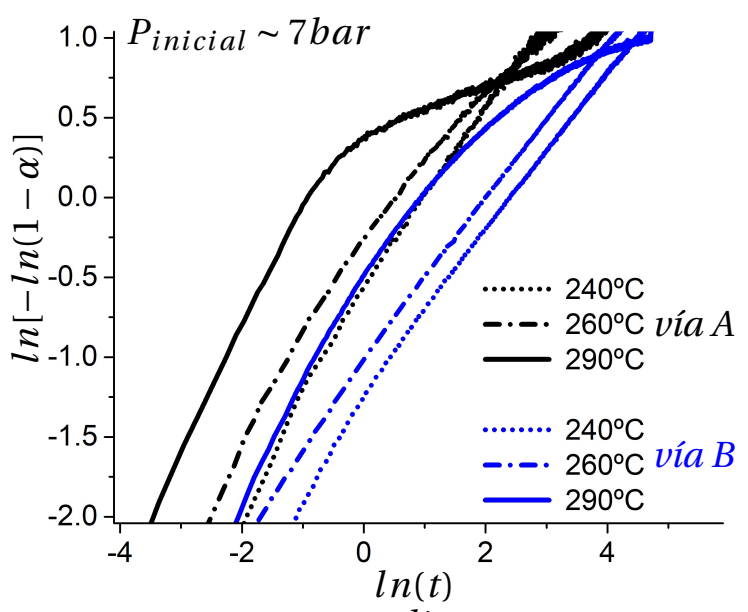

b)

Figura E.7: Se comparan los gráficos de Avrami para absorciones de las muestras MT13 (vía A) y MT24 (vía B). Se graficaron en las regiones de $\alpha \in[0,15 ; 0,95]$ constuyéndose a partir de la curvas cinéticas de la figura E.2. En el caso de la vía A, a mayores presiones iniciales $\left(P_{i} \sim 10 \mathrm{bar}\right)$ se distinguen mejor diferentes regímenes. En el caso de la vía $\mathrm{B}$, el cambio de un régimen simple (línea recta) a régimenes complejos es evidente al reducir la fuerza impulsora $\frac{\Delta P}{T}$. No obstante, en este caso los gráficos de Avrami muestran una transición más suave.

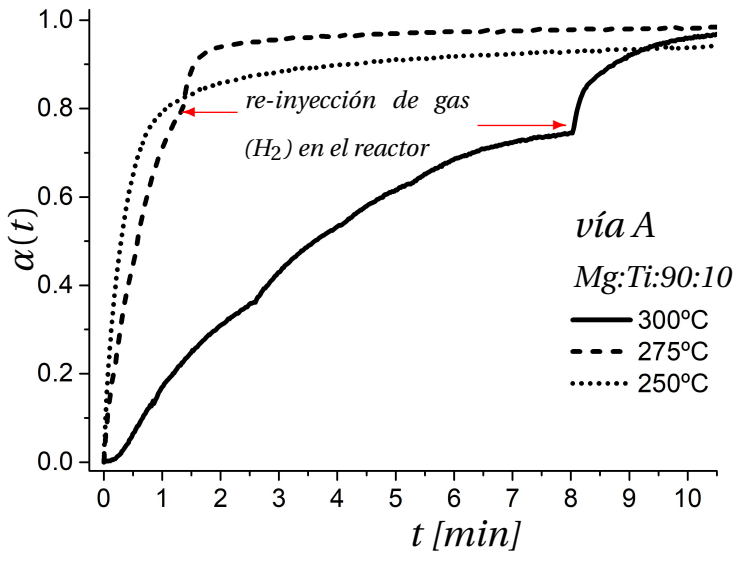

a)

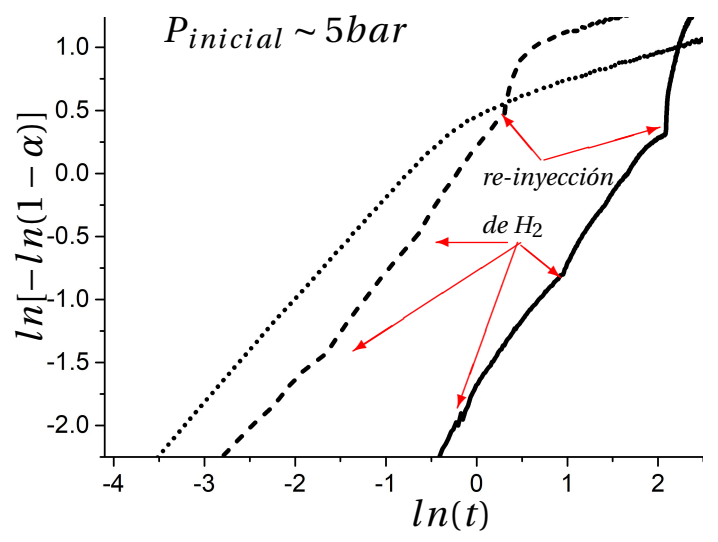

b)

Figura E.8: $a$ ): Cinéticas de absorción iniciadas a $\sim 5$ bar y a distintas temperaturas realizadas sobre una muestra de composición Mg:Ti:90:10 fabricada por vía A (MT39, tabla 3.1). Las cinéticas a $\mathrm{T}=275^{\circ} \mathrm{C}$ y $\mathrm{T}=300^{\circ} \mathrm{C}$ se realizaron en etapas, es decir reinyectando rápidamente gas $\mathrm{H}_{2}$ a medida que se ralentizaba la transformación. La cinética a $\mathrm{T}=275^{\circ} \mathrm{C}$ se realizó en etapas de 4,$52 ; 4,61 ; 5$ y 5,9 bar. La cinética a T=300 ${ }^{\circ} \mathrm{C}$ se realizó en etapas de 5,$5 ; 5,1 ; 4,9$; 5,1 y 7,4 bar. $b$ ): Se comparan los gráficos de Avrami de la figura $a$ ). Se indican los puntos correspondientes a la re-inyección de gas en el reactor para recuperar la velocidad de la hidruración (aumento de fuerza impulsora $\Delta P$ ).En el caso de $\mathrm{T}=300^{\circ} \mathrm{C}$, el gráfico de Avrami premite identificar los puntos de reinyección de gas que no son evidentes en la curva cinética. Las absoricones por etapas evidencian que los mecanismos involucrados, asociados a la pendiente $\mathrm{n}\left((\alpha)\right.$ se conservan mientras se mantenga la fuerza impulsora $\frac{\Delta P}{T}$. 

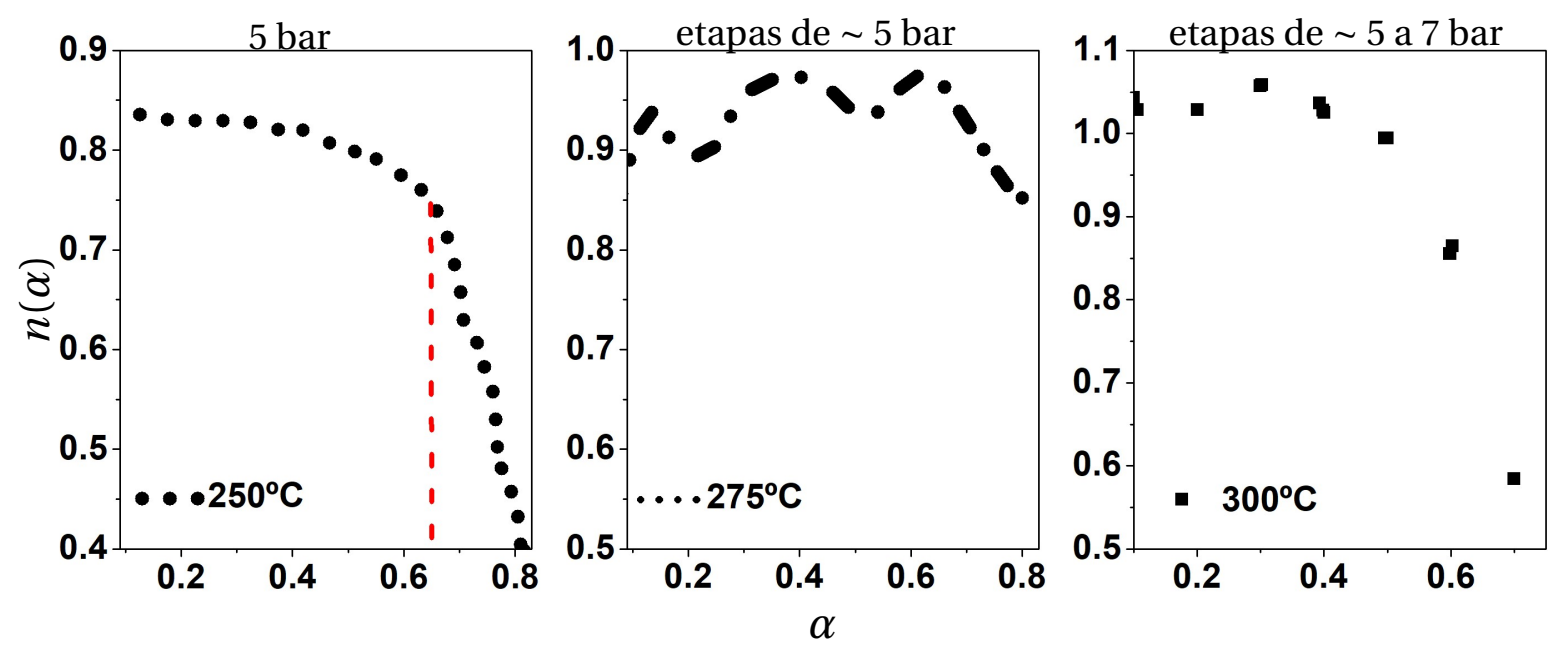

Figura E.9: Exponentes de Avrami calculados para curvas de absorción a 5 bar $\left(250^{\circ} \mathrm{C}\right)$ y en etapas entre 4 a 7 bar $\left(275^{\circ} \mathrm{C}\right.$ y $\left.300^{\circ} \mathrm{C}\right)$, Vía A, composición 90:10 (MT39).
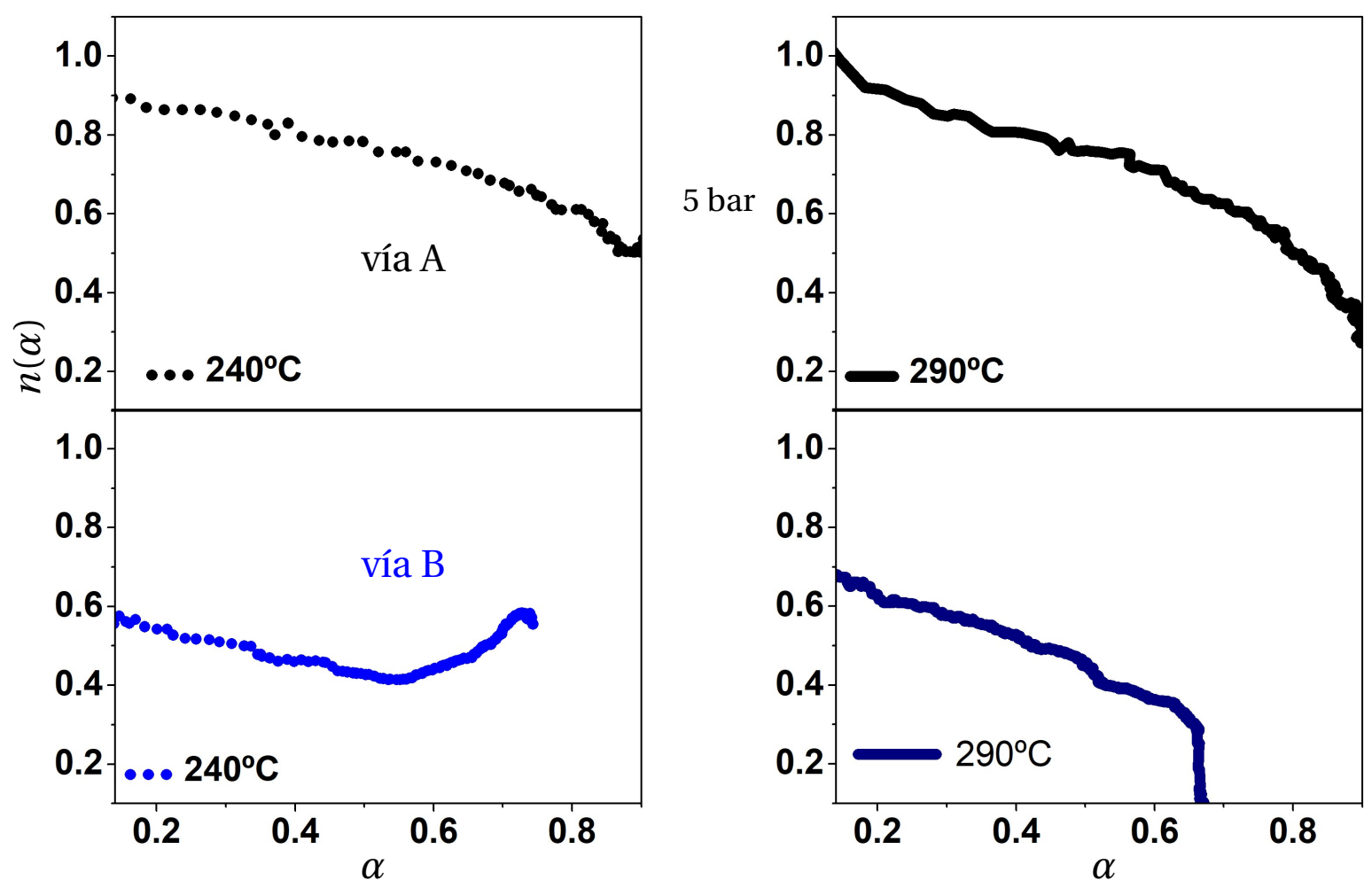

Figura E.10: Exponentes de Avrami calculados para curvas de absorción a 5 bar, Vías A (MT13) y B (MT24). El cambio abrupto en la curva a $290^{\circ} \mathrm{C}$ de la vía B corresponde la finalización de la cinética. En este caso no se re-inyectó gas para restaurar la fuerza impulsora. 


\section{Apéndice F}

\section{CALORIMETRÍA}

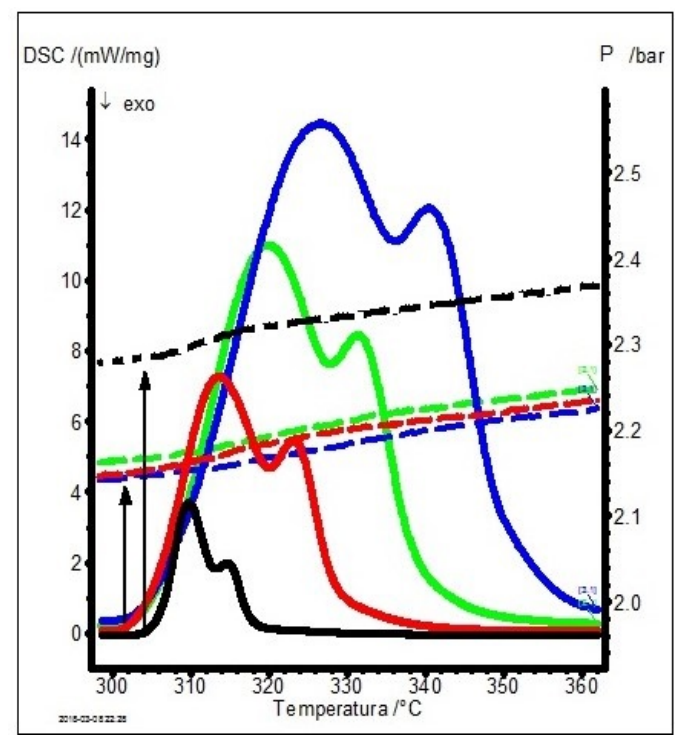

a)

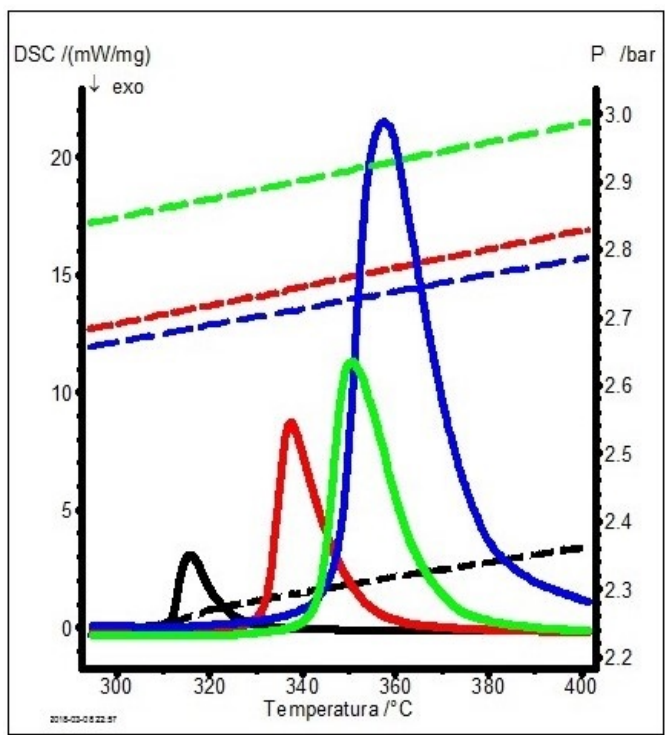

b)

Figura F.1: Se presentan simultáneamente las curvas de desorción DSC (trazo contínuo) y la presión medida durante cada corrida (trazo discontínuo). Se indican con el mismo color las medidas para cada velocidad de calentamiento. a): Muestra MT42. La corrida de $1 \mathrm{~K} / \mathrm{min}$ se aparta ligeramente del comportamiento general debido a una diferencia en la presión inicial de la misma manera, en $b$ las desorciones están corridas en T dada la diferencia en las presiones. 


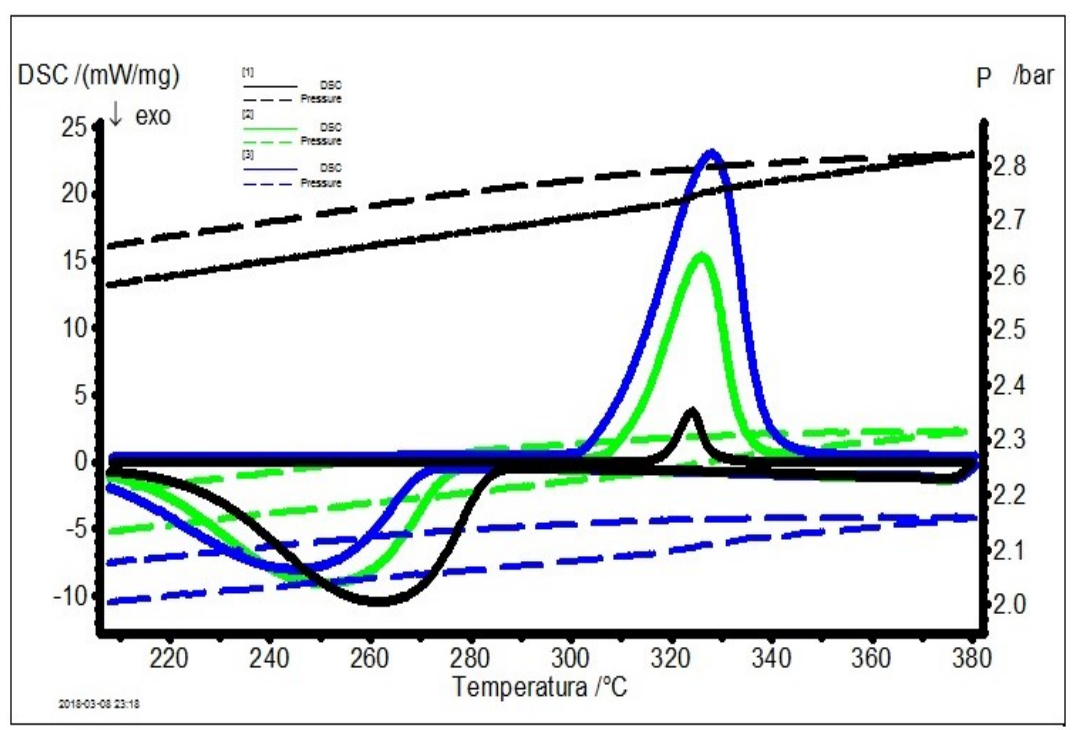

Figura F.2: Corridas de desorción/absorción DSC en $\mathrm{H}_{2}$, muestra CMT13. Se presentan simultáneamente las curvas de desorción DSC (trazo contínuo) y la presión medida durante cada corrida (trazo discontínuo). Se indican con el mismo color las medidas para cada velocidad de calentamiento.

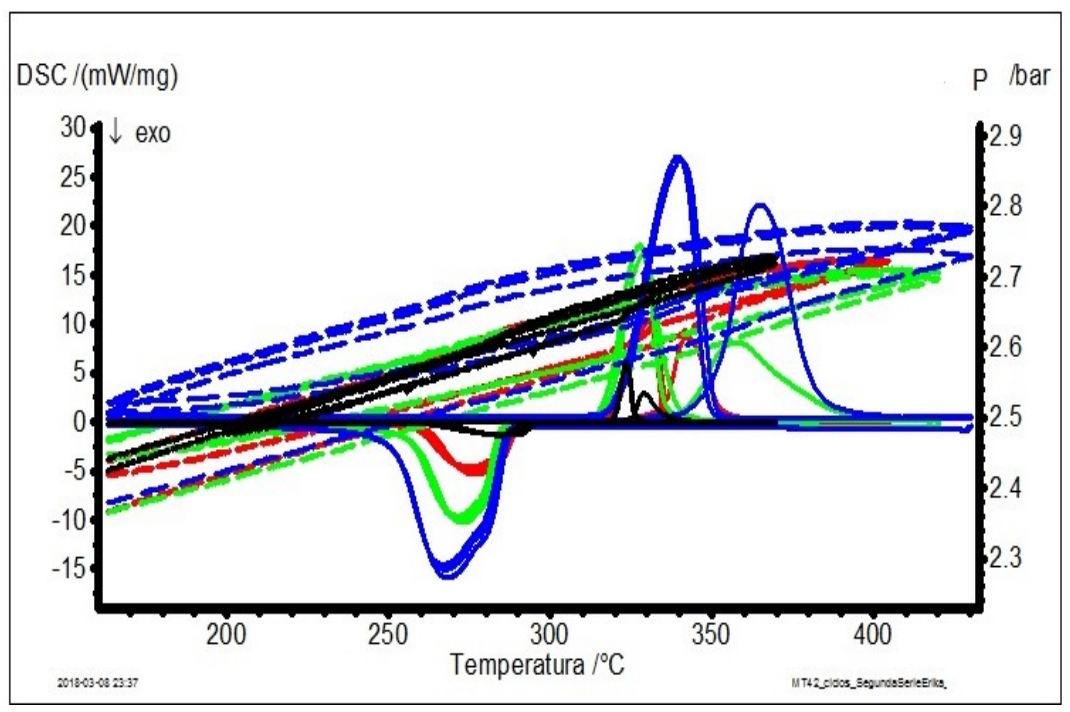

Figura F.3: Señal DSC (trazo contínuo) y P(T) (trazo discontínuo) durante los ciclos de desorción/absorción DSC en $\mathrm{H}_{2}$, muestra MT42. Segunda serie de medidas. 


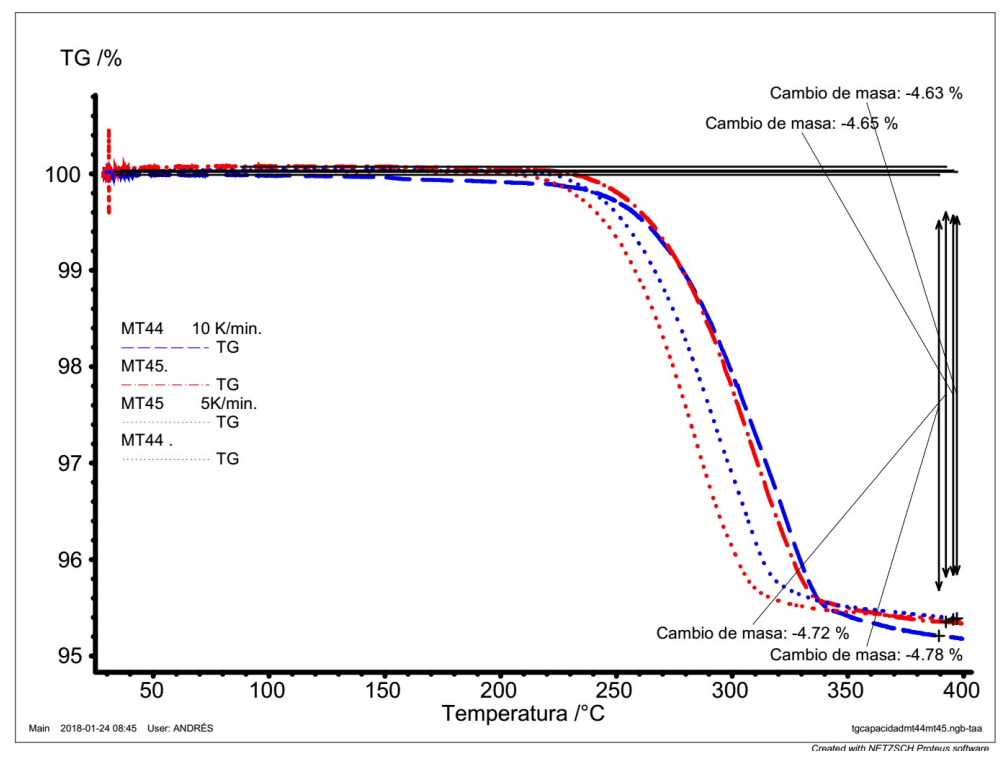

Figura F.4: Medidas TG realizadas para las muestras fabricadas por las vías A ( MT44) y B (MT45). Se indican algunas de las estimaciones de la pérdida de peso de la muestra debido a al desorción de hidrógeno.

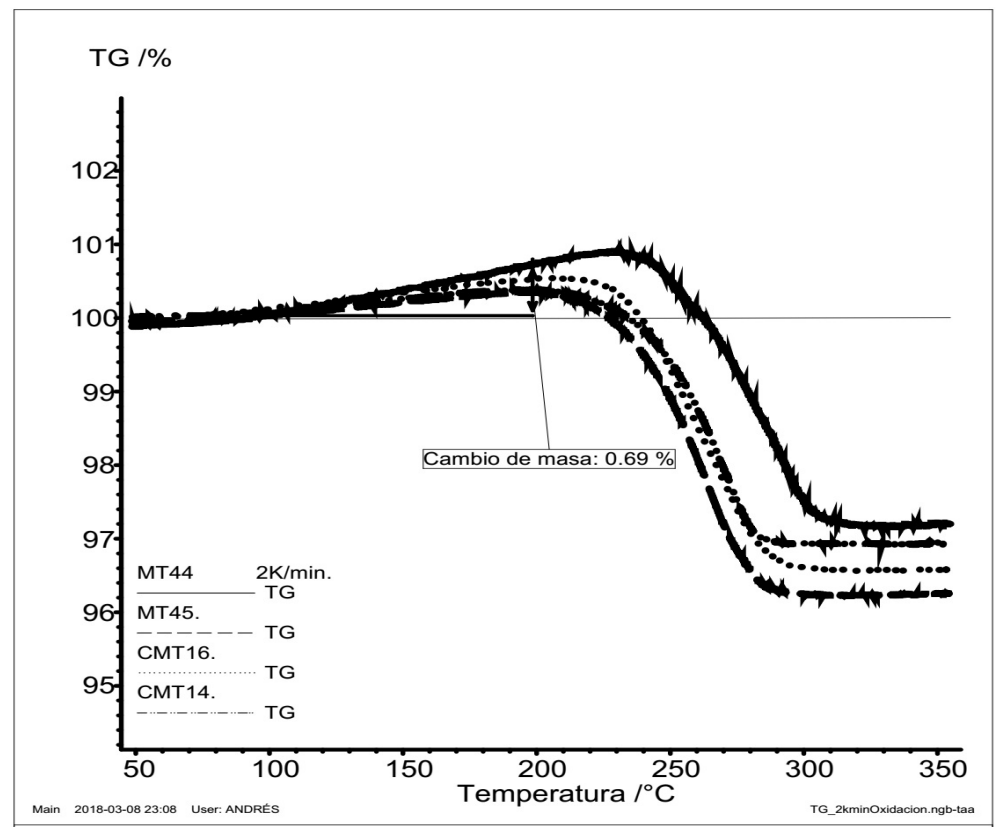

Figura F.5: Medidas TG a $2 \mathrm{~K} / \mathrm{min}$ para muestras fabricadas por disitntas vías. La probable oxidación provoca un aumento de masa antes de la desorción de hidrógeno, disminuyendo la capacidad de la muestra. 


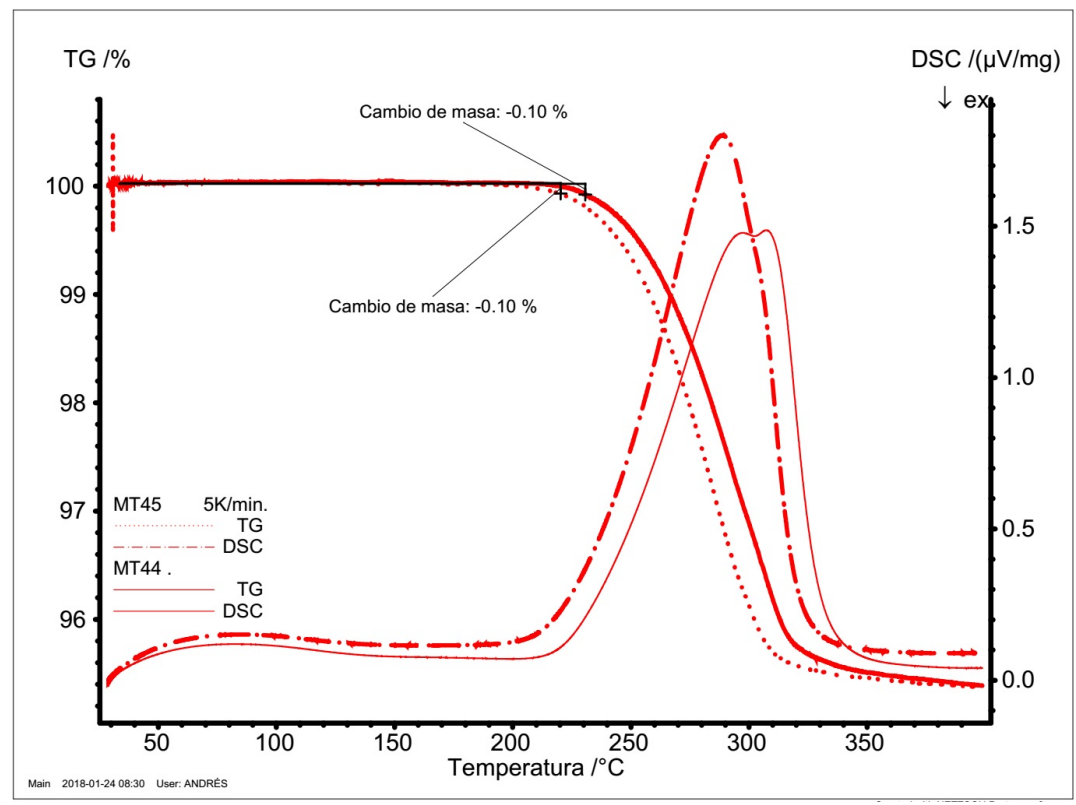

Figura F.6: Medidas combinadas TG-DSC realizadas para las muestras fabricadas por las vías A ( MT44) y B (MT45) a una velocidad de $5 \mathrm{~K} / \mathrm{min}$.

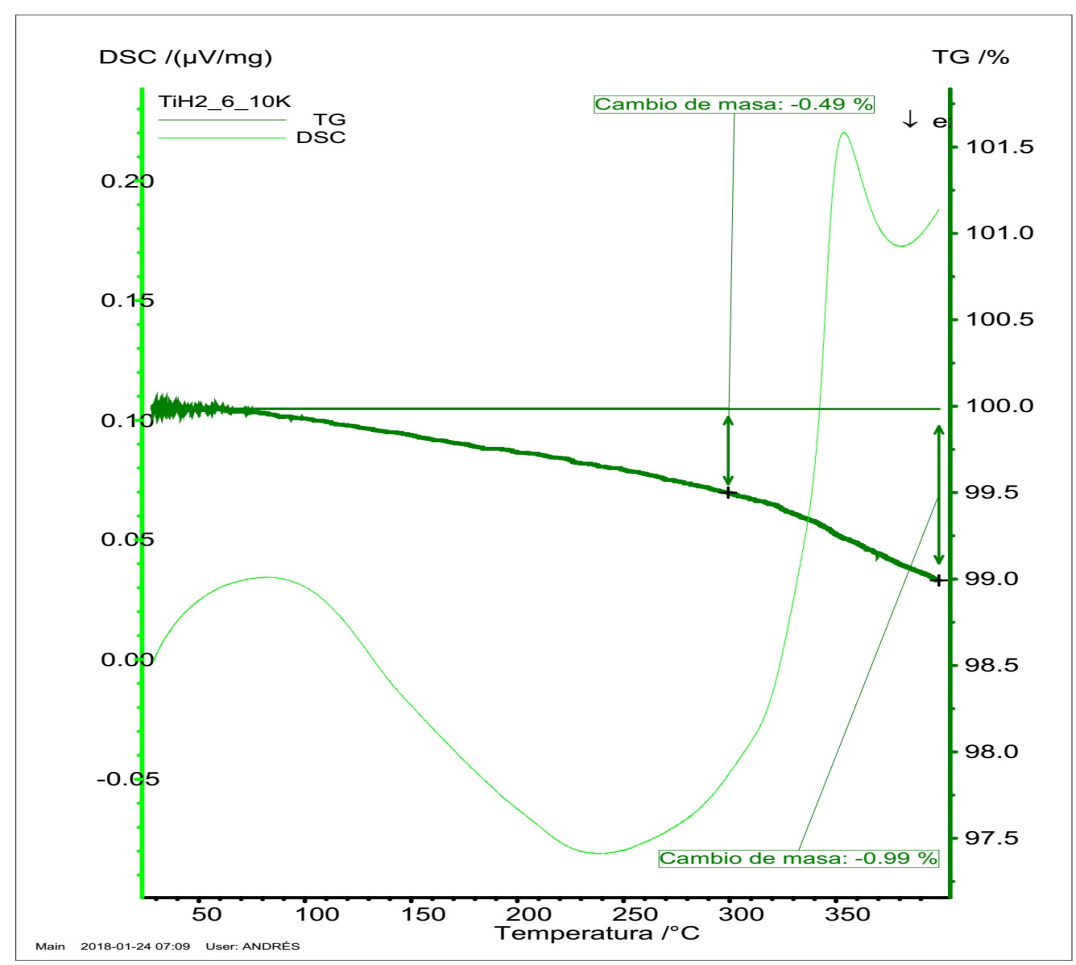

Figura F.7: Medida TG-DSC a $10 \mathrm{~K} / \mathrm{min}$ realizada con una muestra de $\mathrm{TiH}_{2}$ fabricada en nuestro laboratorio. 


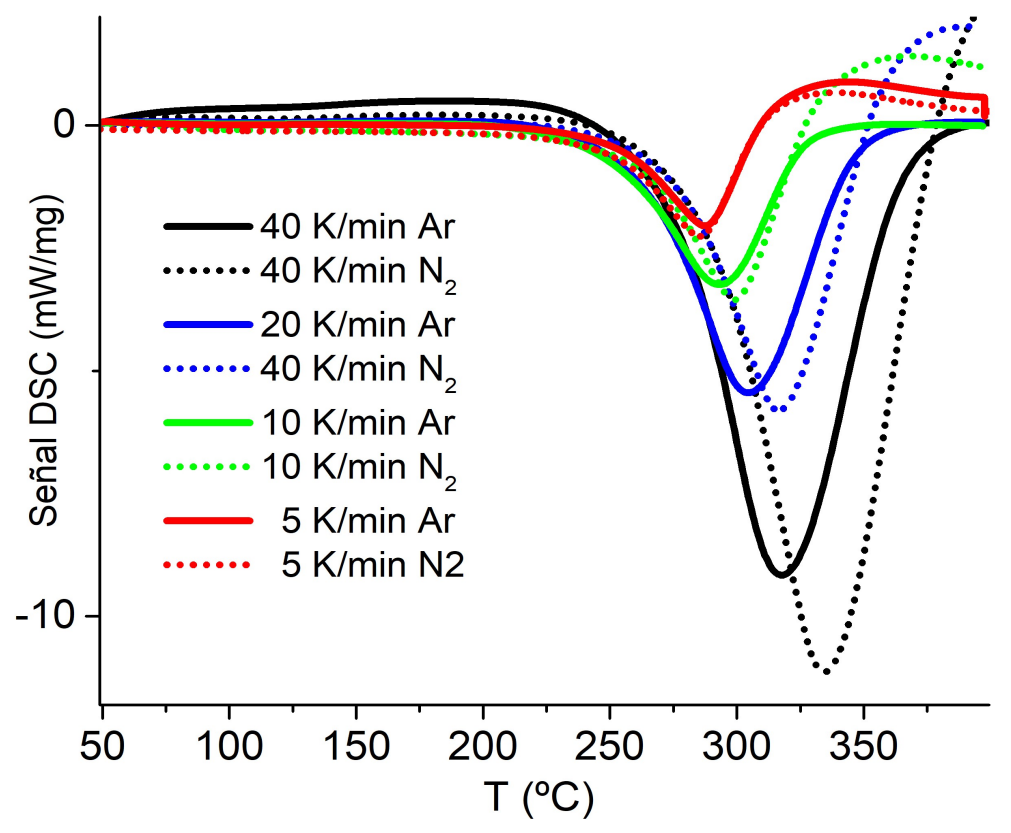

Figura F.8: Se comparan en la figura las corridas DSC realizadas en flujo de $\operatorname{Ar}$ o $\mathrm{N}_{2}$ a distintas velocidades (IFLP). Se realizaron con especímenes de la misma muestra con grafito, $20 \%$ at. Se observa ligera diferencia en la dependencia de las posiciones de los picos según el flujo utilizado (Ar o $N_{2}$ ). 


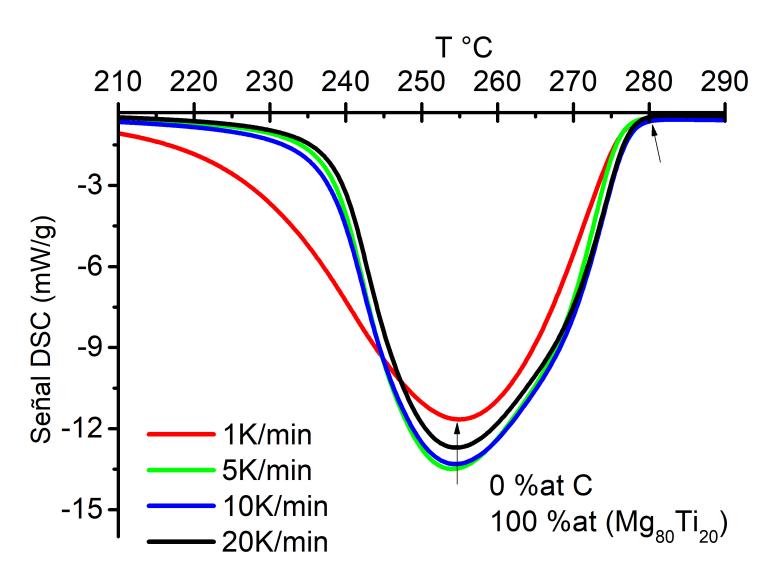

a)

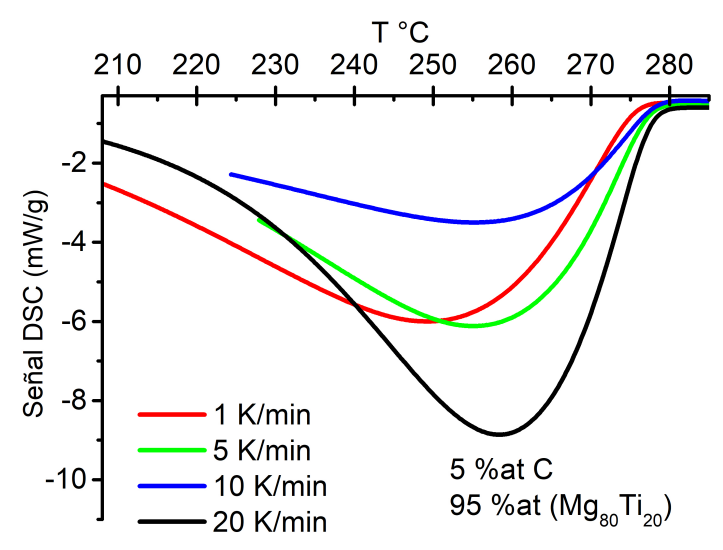

c)

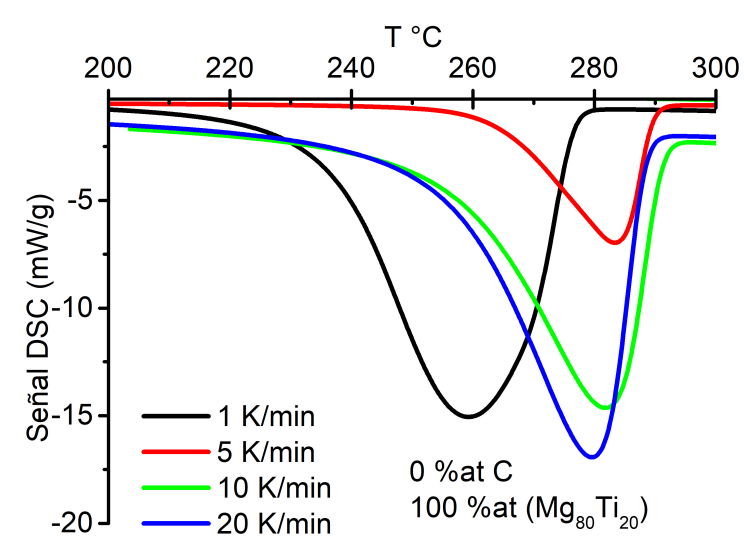

b)

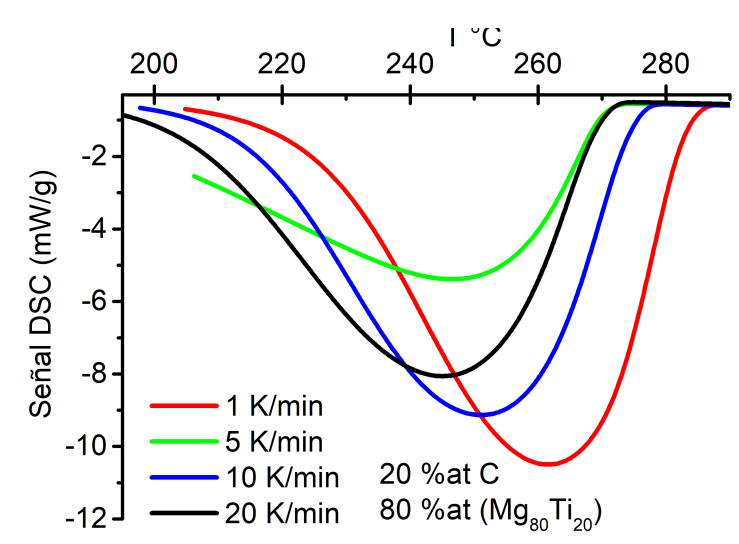

d)

Figura F.9: Las figuras muestran absorciones de hidrógeno durante el enfriamiento espontáneo posterior a las desorciones calorimétricas de la serie I, figura 8.3. Se indican las velocidades de calentamiento correspondientes a las desorciones previas. 

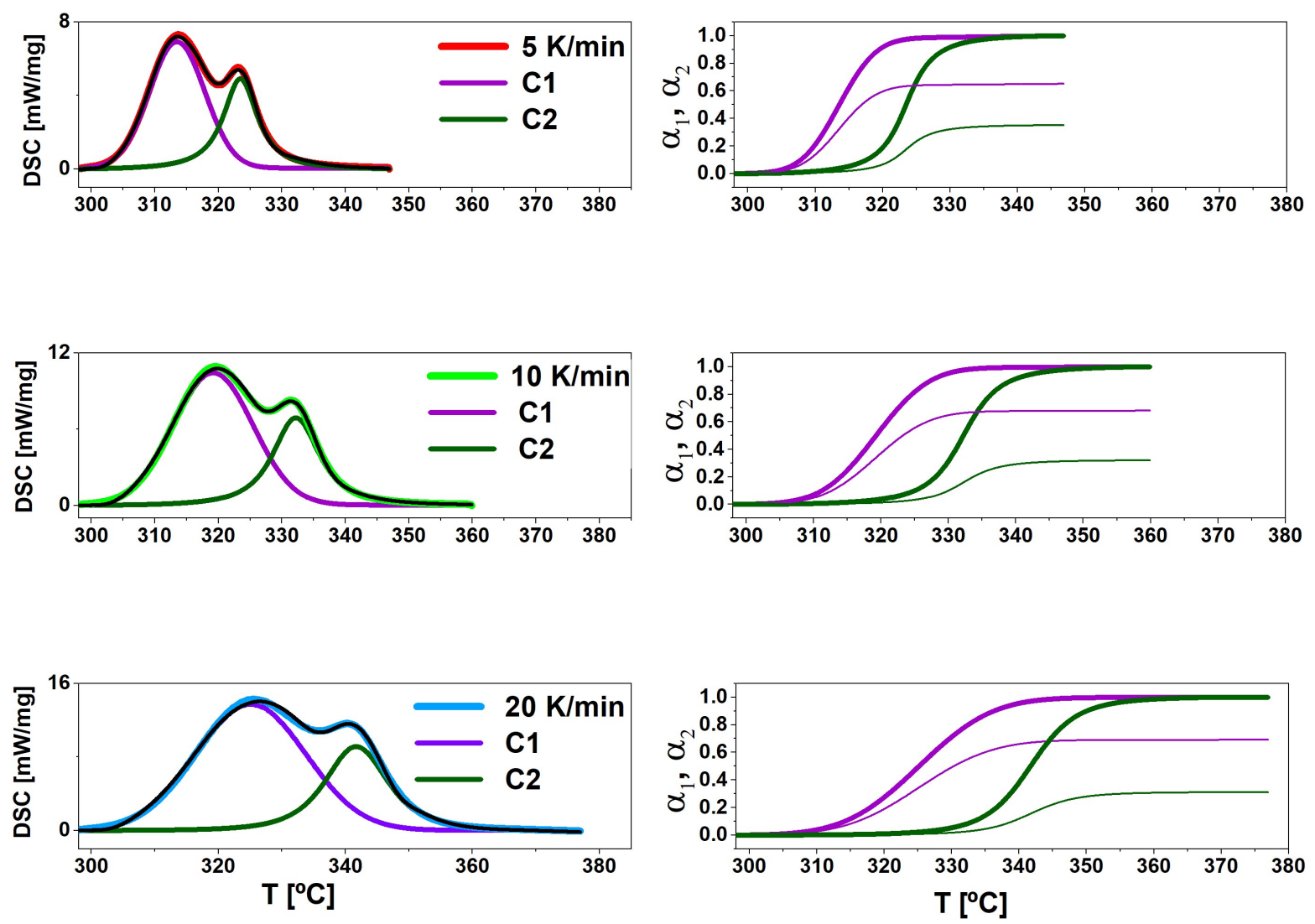

Figura F.10: A la izquierda se muestran las curvas experimentales y los ajustes de las desorciones DSC en $H_{2}$, correspondientes a las corridas de la muestra MT42, vía A. La función de Pearson ajustaba satisfactoriamente la curvas con doble pico. La suma de componentes de ajuste C1 y C2 (curva negra) se superpone con las curvas experimentales (líneas de color). A la derecha se muestran las componentes $\alpha_{1}$ y $\alpha_{2}$ asociadas a los dos proceso distintos. Se muestran normalizadas a 1 y también normalizadas a la fracción correspondiente del proceso total según se pudo estimar mediante la proporción de áreas de cada componente. 


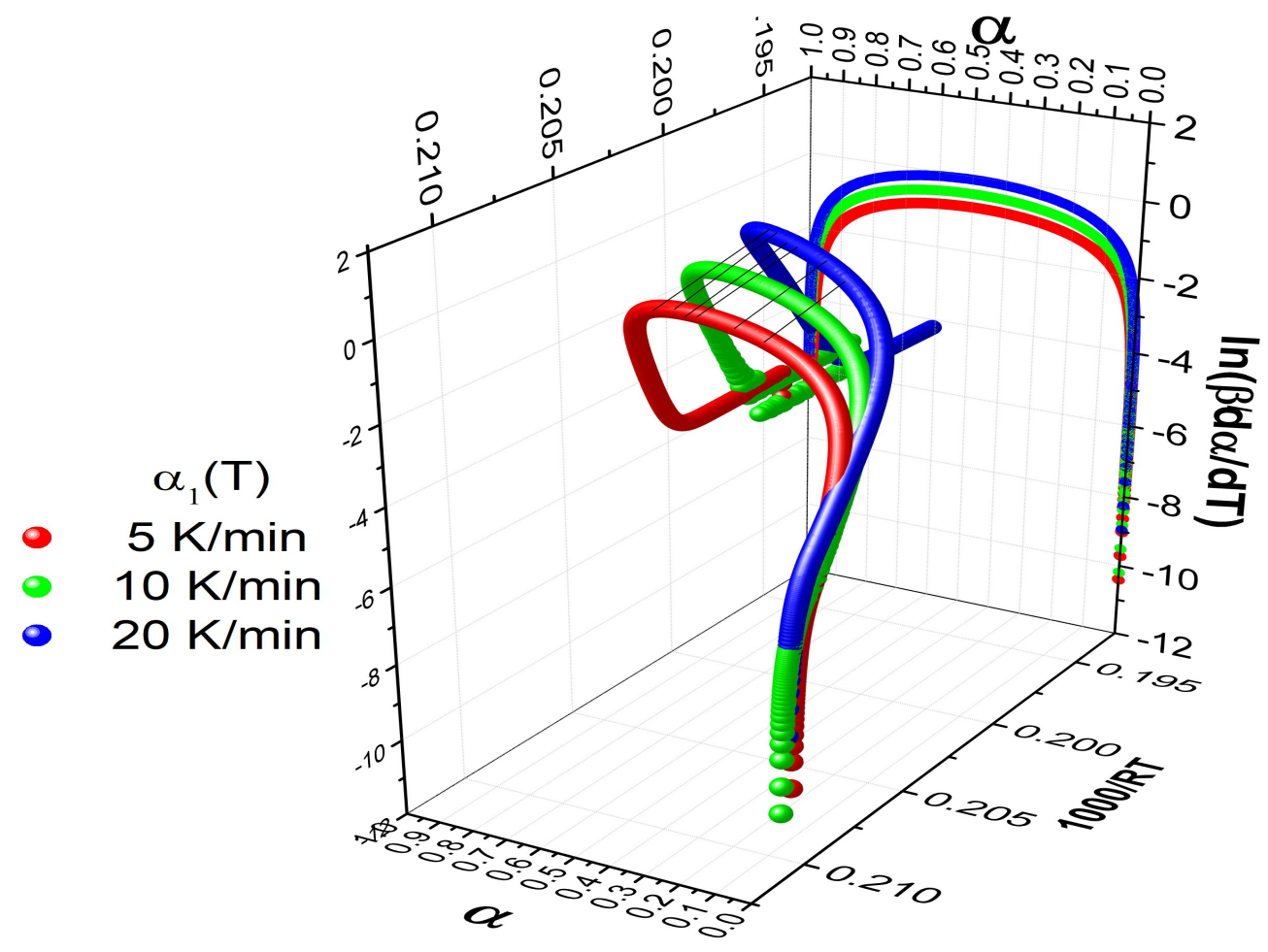

Figura F.11: Mediante un IsoPlot en 3D para la componente $\mathrm{C} 1$ ajustada con el modelo de JMAK, MT42, vía A, se puede apreciar la clara dependencia de le energía en función de $\alpha$ (pendientes de las rectas que unen las curvas). También es útil para ver simultáneamente la similutud de las funciones proyectadas en el plano yz, que corresponden a funciones comportadas como $\sim \ln (y(\alpha)$ ). Deben exluirse las colas de las curvas en los extremos de la transformación, dada la indetermnación en la fracción de fase transformada y de la temperatura respectiva necesarias para obtener las pendientes de las rectas que unene las curvas. 


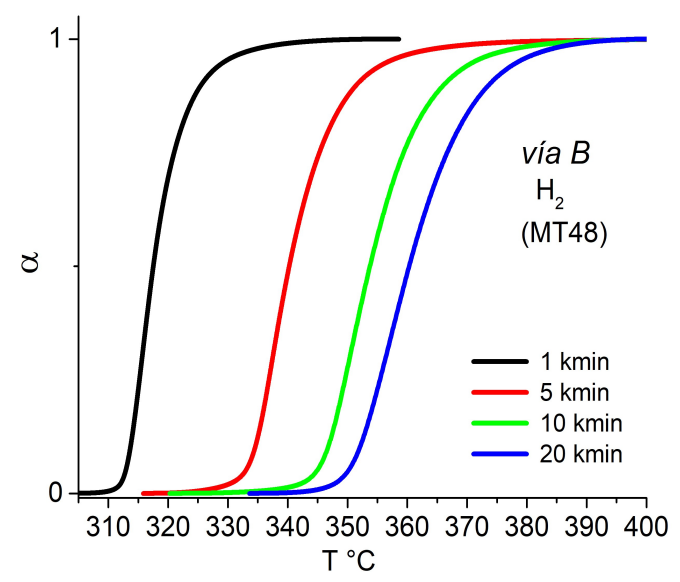

a)

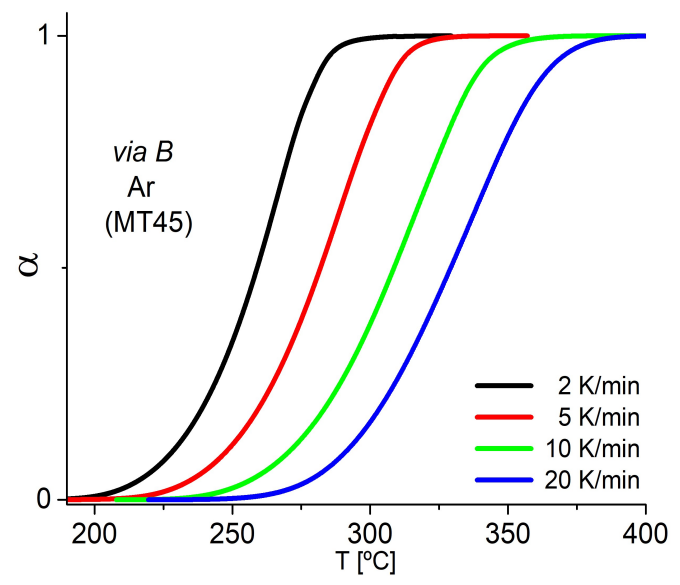

b)

Figura F.12: Fracciones de fase transformadas en función de T, obtenidas de las corridas DSC en $\mathrm{Ar}$ e $\mathrm{H}_{2}$. Muestras MT45 y MT48 respectivamente.

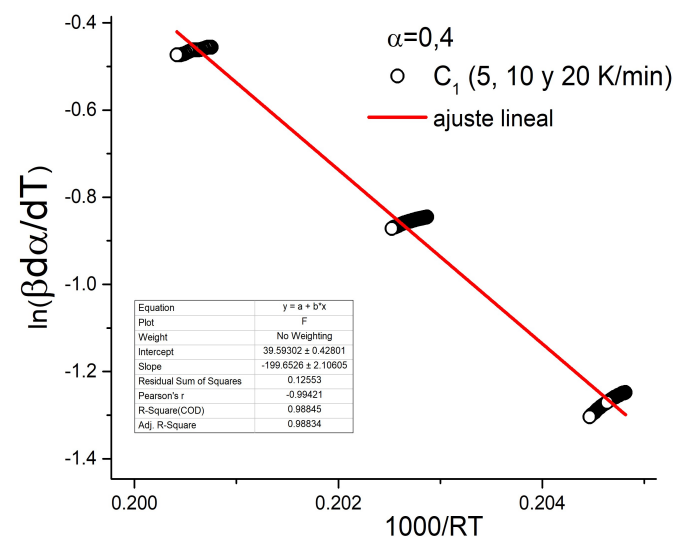

a)

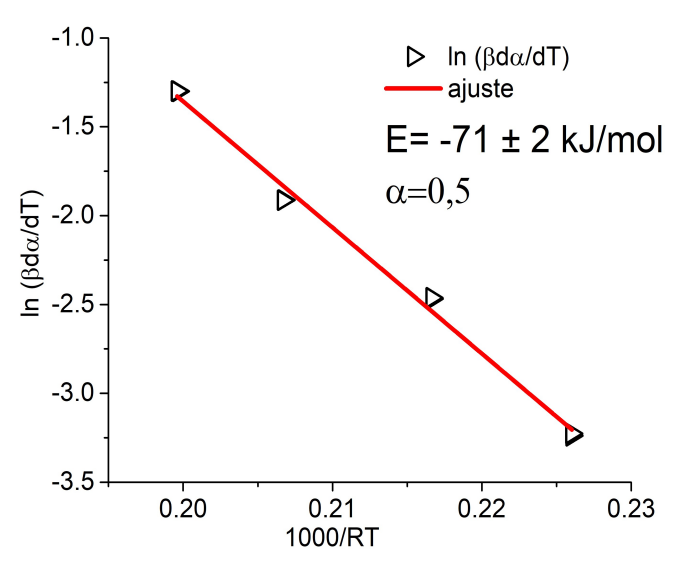

b)

Figura F.13: $a$ : Se ilustra la continuidad de las pendientes al variar el grado de transformación, algo que también se puede apreciar con los gráficos 3D o IsoPlots. $b$ : Se muestra ilustrativamente el ajuste para $\alpha=0,5$ correspondiente a las corridas en Ar sobre la muestra MT45. Los puntos asociados a todas las velocidades de calentamiento presentaban este comportanmiento lineal para la mayor parte de la transformación. 


\section{Apéndice G}

\section{ENERGÍAS DE ACTIVACIÓN}

\section{G.1. Método de Kissinger}

Derivando las ecuaciones 2.5 y 2.6, para obtener la temperatura $\mathrm{T}_{m}$ del máximo de la curva DSC, se tiene:

$$
\frac{E}{R T_{m}^{2}}=\frac{A}{\beta} \times \exp ^{-\frac{E}{R T_{m}}}
$$

a partir de esto, aplicando el logaritmo:

$$
\ln \left(\frac{\beta}{T_{m}^{2}}\right)=\frac{-E}{R T_{m}}+\text { cte. }
$$

siendo $\beta$ la velocidad constante de calentamiento $\frac{d T}{d t}$ del experimento. Entonces a partir de la ecuación G.1, graficando $\ln \left(\frac{\beta}{T_{m}^{2}}\right)$ Vs. $\frac{1}{R T_{m}}$ para diferentes valores de $\beta$, podemos construir el denominado gráfico de Kissinger para obtener las energías de activación como las pendientes de las rectas ajustadas. 


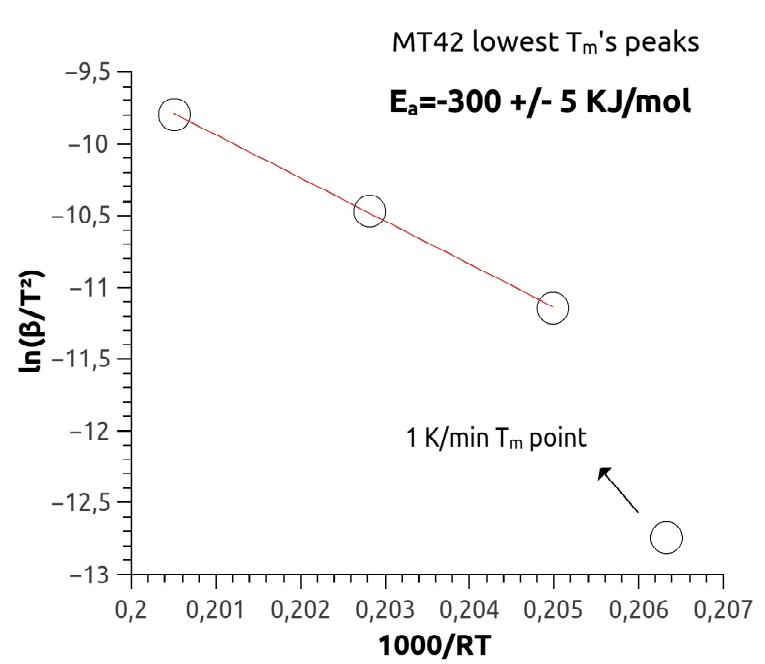

(a) K-Plot for the MT42 sample

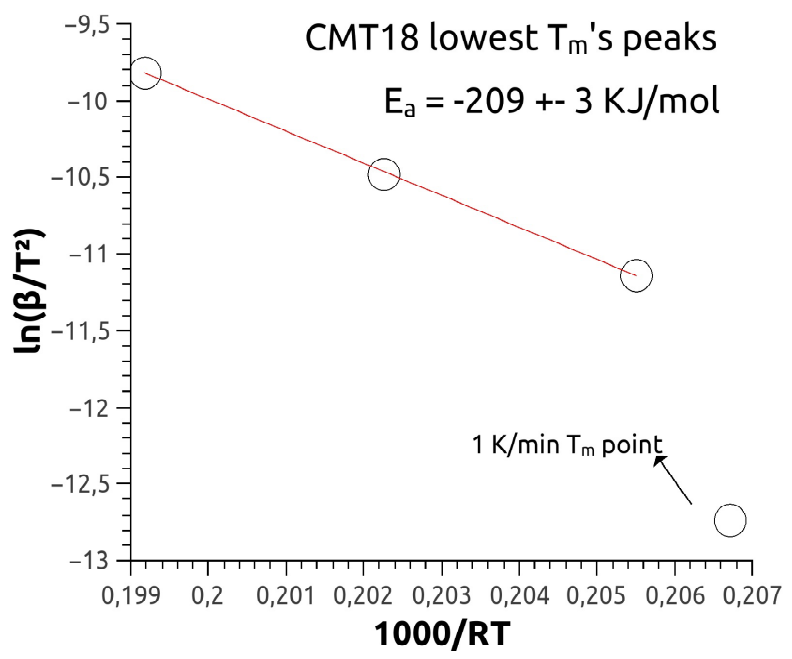

(c) K-Plot for the CMT18 sample.

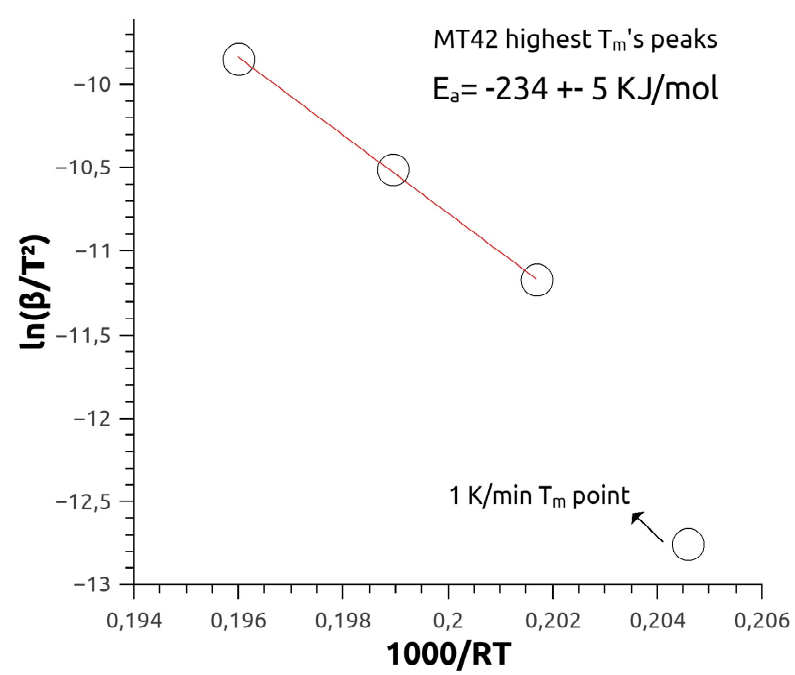

(b) K-Plot for the MT42 sample.

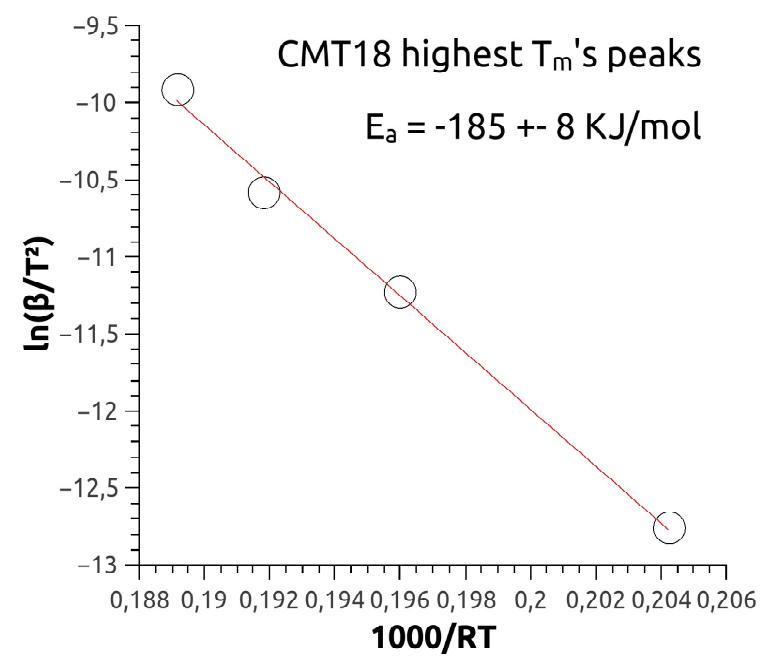

(d) K-Plot for the CMT18 sample

Figura G.1: Gráficos de Kissinger calculados a partir de los picos de las curvas DSC de la primera serie de desorciones calorimétricas realizadas en $\mathrm{H}_{2}$. Vías A y G ( $5 \%$ at. de grafito) 


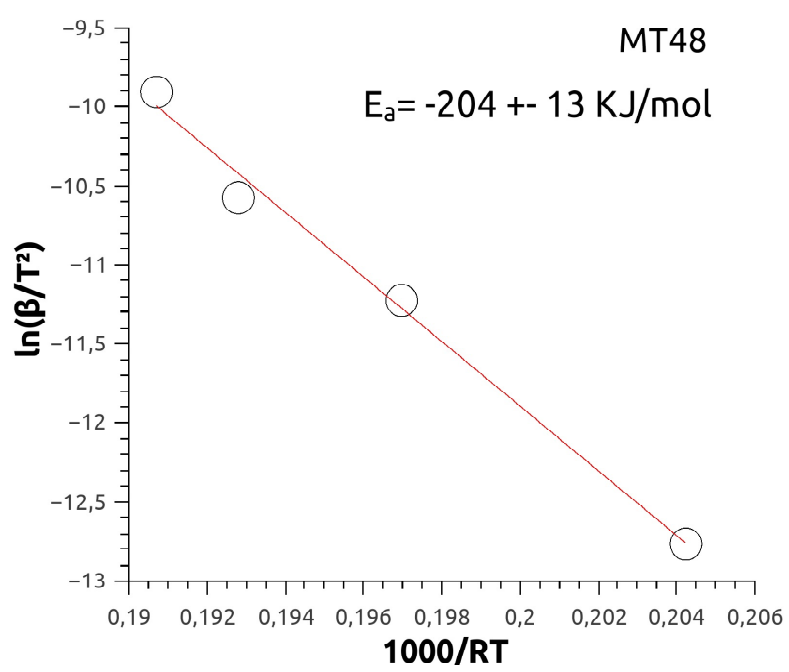

(a) K-Plot for the MT48 sample

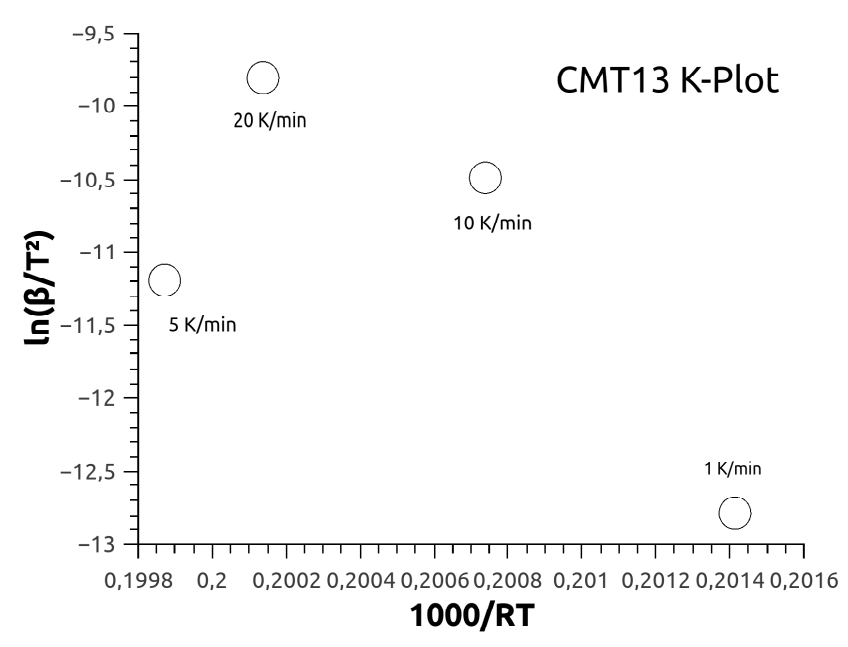

(b) K-Plot for the CMT13 sample.

Figura G.2: Gráficos de Kissinger calculados a partir de los picos de las curvas DSC de la primera serie de desorciones calorimétricas realizadas en $\mathrm{H}_{2}$. Vías By G (20\% at. de grafito).

\begin{tabular}{|c|c|c|c|c|c|c|}
\hline \multirow{2}{*}{ Velocidades } & \multicolumn{2}{|c|}{$M g_{80} T_{20}$} & $M i_{80}\left(T i H_{2}\right)_{20}$ & \multicolumn{2}{c|}{$\begin{array}{c}M g_{80} T i_{20}-C \\
5 \% \mathrm{C} C\end{array}$} & $\begin{array}{c}M g_{80} T i_{20}-C \\
20 \% \text { at C }\end{array}$ \\
\hline & Pico $T_{<}$ & Pico $T_{>}$ & picos simple & Pico $T_{<}$ & Pico $T_{>}$ & picos simple \\
\hline $1 \mathrm{~K} / \mathrm{min}$ & $309.8^{\circ} \mathrm{C}$ & $314.7^{\circ} \mathrm{C}$ & $315.8^{\circ} \mathrm{C}$ & $308.7^{\circ} \mathrm{C}$ & $315.8^{\circ} \mathrm{C}$ & $324^{\circ} \mathrm{C}$ \\
\hline $5 \mathrm{~K} / \mathrm{min}$ & $313.6^{\circ} \mathrm{C}$ & $323.2^{\circ} \mathrm{C}$ & $337.5^{\circ} \mathrm{C}$ & $312.1^{\circ} \mathrm{C}$ & $340.6^{\circ} \mathrm{C}$ & $328.6^{\circ} \mathrm{C}^{1} \mathrm{cal}^{\circ}$ \\
\hline $10 \mathrm{~K} / \mathrm{min}$ & $319.9^{\circ} \mathrm{C}$ & $331.4^{\circ} \mathrm{C}$ & $350.7^{\circ} \mathrm{C}$ & $321.5^{\circ} \mathrm{C}$ & $353.9^{\circ} \mathrm{C}$ & $326^{\circ} \mathrm{C}$ \\
\hline $20 \mathrm{~K} / \mathrm{min}$ & $326.7^{\circ} \mathrm{C}$ & $340.5^{\circ} \mathrm{C}$ & $357.5^{\circ} \mathrm{C}$ & $330.7^{\circ} \mathrm{C}$ & $362.7^{\circ} \mathrm{C}$ & $327.8^{\circ} \mathrm{C}$ \\
\hline Kissinger $\rightarrow$ & $E_{a}=-300 \mathrm{KJ} / \mathrm{mol}$ & $E_{a}=-234 \mathrm{KJ} / \mathrm{mol}$ & $E_{a}=-204 \mathrm{KJ} / \mathrm{mol}$ & $E_{a}=-209 \mathrm{KJ} / \mathrm{mol}$ & $E_{a}=-185 \mathrm{KJ} / \mathrm{mol}$ & $E_{a}=-$ \\
\hline
\end{tabular}

Tabla G.1: Temperatura de picos de desorción DSC y energías de activación obtenidas mediante el método de Kissinger. Corresponden a las curvas DSC en hidrógeno. Primera serie de medidas. Notar la similitud entre los valores de temperatura $T_{m}$ del primer pico de desorción para las muestras que presentaban dos picos. Adicionalmente, las energías de activación correspondientes decrecen notablemente, no así para las asociadas a los picos de temperatura más altos.

\begin{tabular}{|c|c|c|c|c|}
\hline $\begin{array}{c}\text { Velocidades } \\
\text { previas DSC }\end{array}$ & $M g_{80} \mathrm{Ti}_{20}$ & $M g_{80}\left(\mathrm{TiH}_{2}\right)_{20}$ & $\begin{array}{c}M g_{80} \mathrm{Ti}_{20}-\mathrm{C} \\
5 \text { at\% C }\end{array}$ & $\begin{array}{c}M g_{80} \mathrm{Ti}_{20}-\mathrm{C} \\
20 \text { at\% } \mathrm{C}\end{array}$ \\
\hline $1 \mathrm{~K} / \mathrm{min}$ & 254.9 & $259.3^{\circ} \mathrm{C}$ & $249.2^{\circ} \mathrm{C}$ & $261.6^{\circ} \mathrm{C}$ \\
\hline $5 \mathrm{~K} / \mathrm{min}$ & 254.1 & $283.3^{\circ} \mathrm{C}$ & $255.2^{\circ} \mathrm{C}$ & $264.9^{\circ} \mathrm{C}$ \\
\hline $10 \mathrm{~K} / \mathrm{min}$ & 254.4 & $281.8^{\circ} \mathrm{C}$ & $255.3^{\circ} \mathrm{C}$ & $251.1^{\circ} \mathrm{C}$ \\
\hline $20 \mathrm{~K} / \mathrm{min}$ & $254.5^{\circ} \mathrm{C}$ & $279.5^{\circ} \mathrm{C}$ & $258.3^{\circ} \mathrm{C}$ & $244.9^{\circ} \mathrm{C}$ \\
\hline
\end{tabular}

Tabla G.2: Valores de temperatura de los picos DSC correspondientes a las absorciones calorimétricas en $H_{2}$ correspondientes a la primera serie. 


\section{Bibliografía}

[1] Ibrahim Dincer y Canan Acar. "Review and evaluation of hydrogen production methods for better sustainability”. En: International journal of hydrogen energy 40.34 (2015), págs. 11094-11111.

[2] Peter Palensky y Dietmar Dietrich. "Demand side management: Demand response, intelligent energy systems, and smart loads". En: IEEE transactions on industrial informatics 7.3 (2011), págs. 381-388.

[3] Matthew P Johnson y col. "Energy peak shaving with local storage”. En: Sustainable Computing: Informatics and Systems 1.3 (2011), págs. 177-188.

[4] Alexandre Oudalov, Rachid Cherkaoui y Antoine Beguin. "Sizing and optimal operation of battery energy storage system for peak shaving application”. En: Power Tech, 2007 IEEE Lausanne. IEEE. 2007, págs. 621-625.

[5] Kein Huat Chua, Yun Seng Lim y Stella Morris. "Energy storage system for peak shaving”. En: International Journal of Energy Sector Management 10.1 (2016), págs. 3-18.

[6] Gregorio Marbán y Teresa Valdés-Solís. “Towards the hydrogen economy?” En: International Journal of Hydrogen Energy 32.12 (2007), págs. 1625-1637.

[7] Louis Schlapbach y Andreas Züttel. "Hydrogen-storage materials for mobile applications”. En: Nature 414.6861 (2001), págs. 353-358.

[8] Andreas Züttel. "Materials for hydrogen storage”. En: Materials Today 6.9 (2003). ., págs. 24 -33. ISSN: 1369-7021. DOI: http : / / dx . doi . org/10 . 1016 / S1369 7021 (03) 00922 - 2. URL: http : / / www . sciencedirect . com/science/article / pii/S1369702103009222.

[9] Ibrahim Dincer y Marc A Rosen. Exergy: energy, environment and sustainable development. Newnes, 2012.

[10] Henrik Lund. "Renewable energy strategies for sustainable development". En:Energy 32.6 (2007), págs. 912-919.

[11] David L. Trimm y Z. Ilsen Önsan. “ONBOARD FUEL CONVERSION FOR HYDROGENFUEL-CELL-DRIVEN VEHICLES”. En: Catalysis Reviews 43.1-2 (2001), págs. 31-84. DOI: 10 . 1081/CR-100104386. eprint: http : / / dx . doi . org/10 . 1081/CR - 100104386. URL: http://dx.doi .org/10.1081/CR-100104386. 
[12] D.K. Ross. "Hydrogen storage: The major technological barrier to the development of hydrogen fuel cell cars". En: Vacuum 80.10 (2006). The World Energy Crisis: Some Vacuum-based Solutions, págs. 1084 -1089. ISSN: 0042-207X. DOI: http://doi .org/ 10 . 1016 / j . vacuum . 2006 . 03 .030. URL: http : / / www . sciencedirect . com / science/article/pii/S0042207X06001485.

[13] P Paul Vermeulen. "Hydrogen storage in Mg-Ti thin film alloys: an in situ characterization study”. Tesis doct. Technische Universiteit Eindhoven, 2009.

[14] Debabrata Das y T.Nejat Veziroğlu. "Hydrogen production by biological processes: a survey of literature". En: International Journal of Hydrogen Energy 26.1 (2001). ., págs. 13 -28. ISSN: 0360-3199. DOI: http : / / dx . doi . org / 10 . 1016 / S0360 3199 (00) 00058 - 6. URL: http: / / www . sciencedirect . com/science/article/ $\mathrm{pii} / \mathrm{S} 0360319900000586$.

[15] Godfrey Boyle. “Renewable energy, power for a sustainable future. 2004”. En: UK: Oxford University Press, The Open University ().

[16] Fundamentals of Renewable Energy Processes . Elsevier, 2009. DOI: 10.1016/b978-012-374639-9 .x0001-2. URL: https ://doi .org/10 .1016\%2Fb978-0-12-3746399. $\times 0001-2$.

[17] Michael Grätzel. "Photoelectrochemical cells”. En: Nature 414.6861 (2001), págs. 338-344.

[18] Jossé Ignacio Linares Hurtado y Beatriz Yolanda Moratilla Soria. El hidrógeno y la energía. Asociación Nacional de Ingenieros del ICAI, 2007.

[19] RS Irani. "Hydrogen storage: high-pressure gas containment”. En: MRS bulletin 27.9 (2002), págs. 680-682.

[20] María Esther Guervós Sánchez. "Principales técnicas de almacenamiento de hidrógeno". En: Marzo del (2003).

[21] A. A. Nayeb-Hashemi y J. B. Clark. “The Co-Mg (Cobalt-Magnesium) system”. En: Bulletin of Alloy Phase Diagrams 8.4 (1987), págs. 352-355. ISSN: 0197-0216. DOI: 10 . 1007/BF02869272. URL: http://dx.doi.org/10.1007/BF02869272.

[22] Maximilian Fichtner. "Preface to the viewpoint set: Nanoscale materials for hydrogen storage”. En: Scripta Materialia 56.10 (2007). Viewpoint set no. 42 "Nanoscale materials for hydrogen storage”, págs. 801 -802. ISSN: 1359-6462. DOI: http: / / dx . doi .org/ 10.1016/j . scriptamat . 2007 .01 .030. URL: http: //www . sciencedirect.com/ science/article/pii/S1359646207000863.

[23] Gavin Walker. Solid-state hydrogen storage: materials and chemistry. Elsevier, 2008.

[24] Marine Ponthieu. “Nouveaux materiaux riches en Mg pour le stockage d'hydrogene: composes Mg6Pd1-xMTx (MT= Ni, Ag, Cu) massifs et nanoconfines et nanocomposites MgH2-TiH2”. Tesis doct. .: Paris Est, 2013.

[25] A Züttel y col. "Hydrogen sorption by carbon nanotubes and other carbon nanostructures”. En: Journal of Alloys and Compounds 330 (2002), págs. 676-682.

[26] AC Dillon y col. "Carbon nanotube materials for hydrogen storage”. En: Conference proceedings on US DOE hydrogen program review. 2000. 
[27] Nina V Krainyukova y Evgeniy N Zubarev. "Carbon honeycomb high capacity storage for gaseous and liquid species”. En: Physical review letters 116.5 (2016), pág. 055501.

[28] RC Jr Bowman y col. Hydrogen in Intermetallic Compounds Ii: Surface and Dynamic Properties, Applications. 1. ${ }^{\mathrm{a}}$ ed. Vol. 67. Springer Science \& Business Media, 2006.

[29] E. Hahne y J. Kallweit. “Thermal conductivity of metal hydride materials for storage of hydrogen: Experimental investigation”. En: International Journal of Hydrogen Energy 23.2 (1998). ., págs. 107 -114. ISSN: 0360-3199. DOI: http: //dx .doi .org/10 .1016/ S0360 - 3199 (97 ) 00020 - 7. URL: http : / / www . sciencedirect . com / science / article/pii/S0360319997000207.

[30] Jinsong Zhang y col. "A review of heat transfer issues in hydrogen storage technologies". En: Journal of Heat Transfer 127.12 (2005), págs. 1391-1399.

[31] M Dornheim y col. "Hydrogen storage in magnesium-based hydrides and hydride composites”. En: Scripta Materialia 56.10 (2007), págs. 841-846.

[32] Elena David. “An overview of advanced materials for hydrogen storage”. En: Journal of materials processing technology 162 (2005), págs. 169-177.

[33] Abdul M Seayad y David M Antonelli. "Recent Advances in Hydrogen Storage in MetalContaining Inorganic Nanostructures and Related Materials”. En: Advanced Materials 16.9-10 (2004), págs. 765-777.

[34] J Huot, M-L Tremblay y R Schulz. "Synthesis of nanocrystalline hydrogen storage materials”. En: Journal of Alloys and Compounds 356.. (2003), págs. 603-607.

[35] US DOE. “Targets for onboard hydrogen storage systems for light-duty vehicles”. En: US Department of Energy, Office of Energy Efficiency and Renewable Energy and The FreedomCAR and Fuel Partnership .. (2009), pág. .

[36] Bogdan Baranowski y col. Carbon nanomaterials in clean energy hydrogen systems. Springer Science \& Business Media, 2008.

[37] Corina M. Chanquía y col. "Highly active La0.4Sr0.6Co0.8Fe0.2O3- nanocatalyst for oxygen reduction in intermediate temperature-solid oxide fuel cells". En: Journal of Power Sources 270 (2014), págs. 457 -467.

[38] A Zaluska, L Zaluski y JO Ström-Olsen. "Sodium alanates for reversible hydrogen storage”. En: Journal of Alloys and Compounds 298.1 (2000), págs. 125-134.

[39] Billur Sakintuna, Farida Lamari-Darkrim y Michael Hirscher. "Metal hydride materials for solid hydrogen storage: A review”. En: International Journal of Hydrogen Energy 32.9 (2007). ., págs. 1121 -1140. ISSN: 0360-3199. DOI: http://dx . doi .org/10 . 1016/ j . ijhydene . 2006 . 11 .022. URL: http : / / www . sciencedirect . com/science / article/pii/S0360319906005866.

[40] James A Ritter y col. Reversible hydrogen storage materials. US Patent 8,153,554. 2012.

[41] Maximilian Fichtner. "Properties of nanoscale metal hydrides". En: Nanotechnology 20.20 (2009), pág. 204009.

[42] Borislav Bogdanović y Gary Sandrock. "Catalyzed complex metal hydrides". En: MRS bulletin 27.9 (2002), págs. 712-716. 
[43] R Griessen y col. "Yttrium and lanthanum hydride films with switchable optical properties”. En: Journal of Alloys and Compounds 253 (1997), págs. 44-50.

[44] Vincent Bérubé y col. "Size effects on the hydrogen storage properties of nanostructured metal hydrides: a review”. En: International Journal of Energy Research 31.6-7 (2007), págs. 637-663.

[45] M Terzieva y col. "Hydriding and dehydriding characteristics of mixtures with a high magnesium content obtained by sintering and mechanical alloying”. En: International journal of hydrogen energy 20.1 (1995), págs. 53-58.

[46] M Bououdina y col. "Effect of nickel alloying by using ball milling on the hydrogen absorption properties of TiFe". En: International journal of hydrogen energy 24.9 (1999), págs. 885-890.

[47] A_C Dillon y col. "Storage of hydrogen in single-walled carbon nanotubes". En: 386.6623 (1997), pág. 377.

[48] C Liu y col. "Hydrogen storage in single-walled carbon nanotubes at room temperature”. En: Science 286.5442 (1999), págs. 1127-1129.

[49] Svetlana Yu Zaginaichenko y col. Carbon Nanomaterials in Clean Energy Hydrogen Systems-II. Springer, 2011.

[50] Yahui Sun y col. "Tailoring magnesium based materials for hydrogen storage through synthesis: current state of the art”. En: Energy Storage Materials (2017).

[51] RA Varin, T Czujko y Z Wronski. "Particle size, grain size and $\gamma$-MgH2 effects on the desorption properties of nanocrystalline commercial magnesium hydride processed by controlled mechanical milling”. En: Nanotechnology 17.15 (2006), pág. 3856.

[52] Rudy WP Wagemans y col. "Hydrogen storage in magnesium clusters: quantum chemical study”. En: Journal of the American Chemical Society 127.47 (2005), págs. 16675-16680.

[53] K-F Aguey-Zinsou y col. "Using MgO to improve the (de) hydriding properties of magnesium”. En: Materials Research Bulletin 41.6 (2006), págs. 1118-1126.

[54] KB Gerasimov y col. “"Hysteresis” in interaction of nanocrystalline magnesium with hydrogen”. En: international journal of hydrogen energy34.4 (2009), págs. 1916-1921.

[55] Bogdan Bogdanov y col. "Nanostructured materials. Selected Synthesis Methods". En: ().

[56] Philippe Knauth y Joop Schoonman. Nanostructured materials: Selected synthesis methods, properties and applications. Vol. 8. Springer Science \& Business Media, 2006.

[57] SX Tao y col. "First-principles predictions of potential hydrogen storage materials: Nanosized Ti (core)/Mg (shell) hydrides”. En: Physical Review B 83.19 (2011), pág. 195403.

[58] Challapalli Suryanarayana. "Mechanical alloying and milling”. En: Progress in materials science 46.1-2 (2001), págs. 1-184.

[59] C. Koch. "Materials Synthesis By Mechanical Alloying”. En: Annual Review of Materials Research 19.1 (1989), págs. 121-143. DOI: 10.1146/annurev .matsci .19.1.121. URL: https://doi.org/10.1146\%2Fannurev.matsci.19.1.121. 
[60] CC Koch. "Synthesis of nanostructured materials by mechanical milling: problems and opportunities”. En: Nanostructured Materials 9.1-8 (1997), págs. 13-22.

[61] H-J Fecht. "Nanostructure formation by mechanical attrition". En: Nanostructured Materials 6.1-4 (1995), págs. 33-42.

[62] IP Jain, Chhagan Lal y Ankur Jain. "Hydrogen storage in Mg: a most promising material”. En: International Journal of Hydrogen Energy 35.10 (2010), págs. 5133-5144.

[63] P Selvam y col. "Magnesium and magnesium alloy hydrides". En: International Journal of Hydrogen Energy 11.3 (1986), págs. 169-192.

[64] A Reiser, B Bogdanović y K Schlichte. “The application of Mg-based metal-hydrides as heat energy storage systems”. En: International Journal of Hydrogen Energy 25.5 (2000), págs. 425-430.

[65] DM Borsa y col. "Structural, optical, and electrical properties of Mg y Ti 1- y H x thin films”. En: Physical review B 75.20 (2007), pág. 205408.

[66] Tatsuo Noritake y col. "Charge density analysis of magnesium hydride”. En: $R \& D$ Rev. Toyota CRDL 38.2 (2003), pág. 15.

[67] O. Friedrichs y col. "Chemical and microstructural study of the oxygen passivation behaviour of nanocrystalline Mg and MgH2". En: Applied Surface Science 252.6 (2006), págs. 2334 -2345. ISSN: 0169-4332. DOI: http: / / dx .doi .org/10.1016/ j .apsusc . 2005 .04 .018. URL: http : / /www . sciencedirect.com/science/article/pii/ S0169433205006549.

[68] F Leardini y col. "Reaction pathways for hydrogen desorption from magnesium hydride/hydroxide composites: bulk and interface effects”. En: Physical Chemistry Chemical Physics 12.3 (2010), págs. 572-577.

[69] Maximilian Fichtner. Preface to the viewpoint set: Nanoscale materials for hydrogen storage. 2007.

[70] Nobuko Hanada, Takayuki Ichikawa e Hironobu Fujii. "Catalytic effect of nanoparticle $3 \mathrm{~d}$-transition metals on hydrogen storage properties in magnesium hydride $\mathrm{MgH} 2$ prepared by mechanical milling”. En: The Journal of Physical Chemistry B 109.15 (2005), págs. 7188-7194.

[71] Philip CH Mitchell y col. "Hydrogen spillover on carbon-supported metal catalysts studied by inelastic neutron scattering. Surface vibrational states and hydrogen riding modes". En: The Journal of Physical Chemistry B 107.28 (2003), págs. 6838-6845.

[72] Nobuko Hanada, Takayuki Ichikawa e Hironobu Fujii. "Catalytic effect of nanoparticle 3d-transition metals on hydrogen storage properties in magnesium hydride $\mathrm{MgH} 2$ prepared by mechanical milling”. En: The Journal of Physical Chemistry B 109.15 (2005), págs. 7188-7194.

[73] G Liang y col. "Hydrogen desorption kinetics of a mechanically milled MgH 2+ 5at. \% V nanocomposite”. En: Journal of Alloys and Compounds 305.1 (2000), págs. 239-245.

[74] JF Pelletier y col. "Hydrogen desorption mechanism in MgH 2- Nb nanocomposites". En: Physical review B 63.5 (2001), pág. 052103. 
[75] J Huot y col. "Structure of nanocomposite metal hydrides". En: Journal of alloys and compounds 330 (2002), págs. 727-731.

[76] J Huot y col. "Investigation of dehydrogenation mechanism of MgH 2-Nb nanocomposites”. En: Journal of Alloys and Compounds 348.1 (2003), págs. 319-324.

[77] G Liang y col. "Catalytic effect of transition metals on hydrogen sorption in nanocrystalline ball milled MgH 2-Tm ( Tm= Ti, V, Mn, Fe and Ni) systems". En: Journal of Alloys and Compounds 292.1 (1999), págs. 247-252.

[78] Jean Charbonnier y col. "Hydrogenation of transition element additives (Ti, V) during ball milling of magnesium hydride”. En: Journal of Alloys and Compounds 383.1 (2004), págs. 205-208.

[79] H Gijs Schimmel y col. "Hydrogen cycling of niobium and vanadium catalyzed nanostructured magnesium”. En: Journal of the American Chemical Society 127.41 (2005), págs. 14348-14354.

[80] G Liang y col. "Hydrogen storage properties of the mechanically milled MgH 2-V nanocomposite”. En: Journal of Alloys and Compounds 291.1 (1999), págs. 295-299.

[81] Patricia De Rango y col. "Nanostructured magnesium hydride for pilot tank development”. En: Journal of Alloys and Compounds 446 (2007), págs. 52-57.

[82] Jean Charbonnier y col. "Structural analysis of activated Mg (Nb) H 2". En: Journal of alloys and compounds 404 (2005), págs. 541-544.

[83] U Kaess y col. "Hydrogen and deuterium diffusion in titanium dihydrides/dideuterides". En: Journal of alloys and compounds 259.1-2 (1997), págs. 74-82.

[84] G Liang y R Schulz. "Synthesis of Mg-Ti alloy by mechanical alloying”. En: Journal of materials science 38.6 (2003), págs. 1179-1184.

[85] A Baldi y col. "Nanoscale composition modulations in Mg y Ti 1- y H x thin film alloys for hydrogen storage”. En: international journal of hydrogen energy 34.3 (2009), págs. 1450-1457.

[86] G Liang y R Schulz. "Synthesis of Mg-Ti alloy by mechanical alloying”. En: Journal of materials science 38.6 (2003), págs. 1179-1184.

[87] Fusheng Sun y FH Sam Froes. "Synthesis and characterization of mechanical-alloyed Ti-xMg alloys”. En: Journal of alloys and compounds 340.1 (2002), págs. 220-225.

[88] Kohta Asano, Hirotoshi Enoki y Etsuo Akiba. "Synthesis of HCP, FCC and BCC structure alloys in the Mg-Ti binary system by means of ball milling”. En: Journal of Alloys and Compounds 480.2 (2009), págs. 558-563.

[89] Anca Anastasopol y col. "Reduced enthalpy of metal hydride formation for Mg-Ti nanocomposites produced by spark discharge generation”. En: Journal of the American Chemical Society 135.21 (2013), págs. 7891-7900.

[90] Kondo-François Aguey-Zinsou y José-Ramón Ares-Fernández. "Hydrogen in magnesium: new perspectives toward functional stores”. En: Energy \& Environmental Science 3.5 (2010), págs. 526-543. 
[91] V Iosub y col. "Direct synthesis of Mg (AlH 4) 2 and CaAlH 5 crystalline compounds by ball milling and their potential as hydrogen storage materials". En: international journal of hydrogen energy 34.2 (2009), págs. 906-912.

[92] WP Kalisvaart y col. "Hydrogen storage in binary and ternary Mg-based alloys: a comprehensive experimental study”. En: International Journal of Hydrogen Energy 35.5 (2010), págs. 2091-2103.

[93] Robin Gremaud y col. "Hydrogenography: An Optical Combinatorial Method To Find New Light-Weight Hydrogen-Storage Materials”. En: Advanced Materials 19.19 (2007), págs. 2813-2817.

[94] R Gremaud y col. "An optical method to determine the thermodynamics of hydrogen absorption and desorption in metals". En: Applied Physics Letters 91.23 (2007), pág. 231916.

[95] A Biasetti, M Meyer y L Mendoza Zélis. "Formation kinetics and microstructure of Mg-Ti hydrides made by reactive ball milling”. En: International Journal of Hydrogen Energy 39.16 (2014), págs. 8767 -8771. ISSN: 0360-3199. DOI: http: / /dx . doi .org/ 10.1016/ j . ijhydene. 2013 . 12 .034. URL: http : / / www . sciencedirect . com / science/article/pii/S0360319913029674.

[96] A Biasetti, M Meyer y L Mendoza Zélis. "Hydriding kinetics of Mg TiH 2 fine dispersions obtained by mechanosynthesis”. En: Powder Technology 307 (2017), págs. 145-152.

[97] En: ().

[98] S Isobe y col. "Catalytic effect of 3d transition metals on hydrogen storage properties in mechanically milled graphite”. En: Journal of Physics and Chemistry of Solids 65.2 (2004), págs. 535-539.

[99] Georgios K Dimitrakakis, Emmanuel Tylianakis y George E Froudakis. "Pillared graphene: a new 3-D network nanostructure for enhanced hydrogen storage". En: Nano letters 8.10 (2008), págs. 3166-3170.

[100] Alan Chambers y col. "Hydrogen storage in graphite nanofibers". En: The Journal of Physical Chemistry B 102.22 (1998), págs. 4253-4256.

[101] CZ Wu y col. "Effect of carbon/noncarbon addition on hydrogen storage behaviors of magnesium hydride”. En: Journal of Alloys and Compounds 414.1-2 (2006), págs. 259-264.

[102] V Fuster y col. "Characterization of graphite catalytic effect in reactively ball-milled MgH2-C and Mg-C composites”. En: international journal of hydrogen energy 36.15 (2011), págs. 9051-9061.

[103] HW Kroto y col. “This Week’s Citation Classic®”. En: Nature 318 (1985), págs. 162-3.

[104] Albin Chaise y col. "Enhancement of hydrogen sorption in magnesium hydride using expanded natural graphite”. En: International Journal of Hydrogen Energy 34.20 (2009), págs. 8589-8596.

[105] IL Shabalin, SG Keens y col. "Hydrogen materials science and chemistry of carbon nanomaterials. The use of neutron scattering techniques for investigation of hydrogen storage systems". En: Proceedings of the 11th International Conference (ICHMS'2009). AHEU, Kyiv. 2009, págs. 44-45. 
[106] M Seifi, DK Ross y A Giannasi. "Raman characterisation of single-walled carbon nanotubes produced by the catalytic pyrolysis of methane". En: Carbon 45.9 (2007), págs. 1871-1879.

[107] Daniel J Bull y col. "Pressure-dependent deuterium reaction pathways in the Li-N-D system”. En: Physical Chemistry Chemical Physics 12.9 (2010), págs. 2089-2097.

[108] PA Georgiev y col. "The rotational and translational dynamics of molecular hydrogen physisorbed in activated carbon: a direct probe of microporosity and hydrogen storage performance”. En: Carbon 44.13 (2006), págs. 2724-2738.

[109] Norbert Gérard y Shuichiro Ono. "Hydride formation and decomposition kinetics". En: Hydrogen in Intermetallic Compunds II. Springer, 1992, págs. 165-195.

[110] Melvin Avrami. "Kinetics of phase change. I General theory". En: The Journal of Chemical Physics 7.12 (1939), págs. 1103-1112.

[111] Melvin Avrami. "Kinetics of phase change. II Transformation-time relations for random distribution of nuclei”. En: The Journal of Chemical Physics 8.2 (1940), págs. 212-224.

[112] Melvin Avrami. "Granulation, phase change, and microstructure kinetics of phase change. III”. En: The Journal of chemical physics 9.2 (1941), págs. 177-184.

[113] NA Kolmogorov. "The statistics of crystal growth in metals". En: Isvestiia Academii Nauk SSSR-Seriia Matematicheskaia 1 (1937), págs. 333-359.

[114] William A Johnson. "Reaction kinetics in process of nucleation and growth". En: Transaction of AIME 135 (1939), págs. 416-458.

[115] Jiří Málek. “The applicability of Johnson-Mehl-Avrami model in the thermal analysis of the crystallization kinetics of glasses”. En: Thermochimica Acta 267 (1995), págs. 61-73.

[116] Jiří Málek. "The applicability of Johnson-Mehl-Avrami model in the thermal analysis of the crystallization kinetics of glasses". En: Thermochimica Acta 267.. (1995), págs. 61-73. DOI: 10 . 1016/0040-6031 (95) 02466 - 2. URL: https : / / doi . org/10 . $1016 \% 2 \mathrm{~F} 0040-6031 \% 2895 \% 2902466-2$.

[117] B. J. Kooi. "Extension of the Johnson-Mehl-Avrami-Kolmogorov theory incorporating anisotropic growth studied by Monte Carlo simulations”. En: Phys. Rev. B 73 (5 2006), pág. 054103. DOI: 10 .1103/PhysRevB .73.054103. URL: https : / / ink . aps .org/ doi/10.1103/PhysRevB.73.054103.

[118] Mario Castro y col. "Model for crystallization kinetics: Deviations from KolmogorovJohnson-Mehl-Avrami kinetics”. En: Applied physics letters 75.15 (1999), págs. 2205-2207.

[119] Erik Woldt. "The relationship between isothermal and non-isothermal description of Johnson-Mehl-Avrami-Kolmogorov kinetics”. En: Journal of Physics and Chemistry of Solids 53.4 (1992), págs. 521-527.

[120] C. E. Rodríguez Torres y col. "Study of the kinetics of the recrystallization of coldrolled low-carbon steel”. En: Metallurgical and Materials Transactions A 33.1 (2002), págs. 25-31. DOI: 10.1007/s11661-002-0003-y. URL: https ://doi .org/10.1007\% 2Fs11661-002-0003-y. 
[121] F. Baitalow, H.-G. Schmidt y G. Wolf. "Formal kinetic analysis of processes in the solid state”. En: Thermochimica Acta 337.1-2 (1999). ., págs. 111 -120. ISSN: 00406031. DOI: https : / / doi . org/10 . 1016/S0040 - 6031 (99) 00242 - 7. URL: http : //www.sciencedirect.com/science/article/pii/S0040603199002427.

[122] B. J. Kooi. "Monte Carlo simulations of phase transformations caused by nucleation and subsequent anisotropic growth: Extension of the Johnson-Mehl-AvramiKolmogorov theory”. En: Phys. Rev. B 70 (22 2004), pág. 224108. DoI: 10 . 1103 / PhysRevB . 70 . 224108. URL: https : / / link . aps . org/doi / 10 . 1103/PhysRevB 70.224108.

[123] Eloi Pineda y Daniel Crespo. "Microstructure development in Kolmogorov, JohnsonMehl, and Avrami nucleation and growth kinetics”. En: Phys. Rev. B 60 (5 1999), págs. 3104-3112. DOI: 10 . 1103 / PhysRevB . 60 . 3104. URL: https : / / link . aps . org/doi/10.1103/PhysRevB.60.3104.

[124] Nikolay V Alekseechkin. "Extension of the Kolmogorov-Johnson-Mehl-Avrami theory to growth laws of diffusion type”. En: Journal of Non-Crystalline Solids 357.16 (2011), págs. 3159-3167.

[125] M Fanfoni y M Tomellini. "The johnson-mehl-avrami-kohnogorov model: a brief review”. En: Il Nuovo Cimento D 20.7 (1998), págs. 1171-1182.

[126] Jaroslav Šesták y Gunnar Berggren. "Study of the kinetics of the mechanism of solidstate reactions at increasing temperatures". En: Thermochimica Acta 3.1 (1971), págs. 1-12. DOI: 10 . 1016/0040-6031 (71)85051-7. URL: https : //doi .org/10 . 1016\%2F0040$6031 \% 2871 \% 2985051-7$.

[127] Gustavo A Lozano y col. “Transport phenomena versus intrinsic kinetics: Hydrogen sorption limiting sub-process in metal hydride beds”. En: International Journal of Hydrogen Energy 39.33 (2014), págs. 18952-18957.

[128] J.F. Fernández y C.R. Sánchez. "Rate determining step in the absorption and desorption of hydrogen by magnesium". En: Journal of Alloys and Compounds 340.1-2 (2002). ., págs. 189 -198. ISSN: 0925-8388. DOI: https : //doi .org/10.1016/S09258388 (02) 00120 - 2. URL: http : / / www . sciencedirect . com/science/article/ pii/S0925838802001202.

[129] T Reti. "On the physical and mathematical interpretation of the isokinetic hypothesis". En: Journal de Physique IV (Proceedings). Vol. 120. EDP sciences. 2004, págs. 85-91.

[130] JD Hancock y JH Sharp. "Method of comparing solid-state kinetic data and its application to the decomposition of kaolinite, brucite, and BaCO3”. En: Journal of the American Ceramic Society 55.2 (1972), págs. 74-77.

[131] Yuepeng Pang y Qian Li. "A review on kinetic models and corresponding analysis methods for hydrogen storage materials". En: International Journal of Hydrogen Energy 41.40 (2016), págs. 18072-18087. DOI: 10 . 1016/ j . i jhydene . 2016 . 08 . 018. URL: https://doi.org/10.1016\%2Fj.ijhydene.2016.08.018. 
[132] Moshe H. Mintz y J. Bloch. "Evaluation of the kinetics and mechanisms of hybriding reactions". En: Progress in Solid State Chemistry 16.3 (1985), págs. 163-194. DOI: 10 . 1016/0079-6786 (85) 90004-4. URL: https : / / doi . org/10 . 1016\%2F0079-6786\% $2885 \% 2990004-4$.

[133] Peter Šimon. “Isoconversional methods”. En: Journal of Thermal Analysis and Calorimetry 76.1 (2004), pág. 123.

[134] Jiří Málek. “The kinetic analysis of non-isothermal data”. En: Thermochimica Acta 200... (1992). .., págs. 257 -269. ISSN: 0040-6031. DOI: http: //dx . doi .org/10 . 1016/0040$6031(92) 85118-\mathrm{F}$.

[135] “The kinetic analysis of non-isothermal data”. En: Thermochimica Acta 200 (1992), págs. 257 -269. ISSN: 0040-6031. DOI: http : / / dx . doi . org / 10 . 1016 / 0040 6031 (92) 85118 -F. URL: http : / / www . sciencedirect . com/science/article / pii/004060319285118F.

[136] L Mendoza-Zélis, M Meyer y L Baum. "Complex quaternary hydrides Mg 2 (Fe, Co) H y for hydrogen storage”. En: international journal of hydrogen energy 36.1 (2011), págs. 600-605.

[137] Robin Gremaud y col. "Hydrogenography: An Optical Combinatorial Method To Find New Light-Weight Hydrogen-Storage Materials”. En: Advanced Materials 19.19 (2007), págs. 2813-2817.

[138] R Gremaud y col. "An optical method to determine the thermodynamics of hydrogen absorption and desorption in metals”. En: Applied Physics Letters 91.23 (2007), pág. 231916.

[139] R Checchetto, G Trettel y A Miotello. "Sievert-type apparatus for the study of hydrogen storage in solids”. En: Measurement Science and Technology 15.1 (2004), pág. 127. URL: http://stacks.iop.org/0957-0233/15/i=1/a=017.

[140] Anthony J. Lachawiec, Thomas R. DiRaimondo y Ralph T. Yang. “A robust volumetric apparatus and method for measuring high pressure hydrogen storage properties of nanostructured materials”. En: Review of Scientific Instruments 79.6 (2008), pág. 063906. DOI: 10.1063/1.2937820. URL: https://doi .org/10.1063\%2F1. 2937820.

[141] M. Meyer y L. Mendoza-Zélis. "Hydrogen sorption properties of mechanically alloyed Mg1-2xFexTix powder mixtures”. En: Journal of Alloys and Compounds 611.. (2014). ,, págs. 11 -18. ISSN: 0925-8388. DOI: http : //dx . doi .org/10 .1016/j . jallcom . 2014 . 05 . 105. URL: http: //wWw . sciencedirect.com/science/article/pii/ S0925838814011918.

[142] M Ponthieu y col. "Synthesis by reactive ball milling and cycling properties of MgH2TiH2 nanocomposites: kinetics and isotopic effects”. En: international journal of hydrogen energy 39.18 (2014), págs. 9918-9923.

[143] Sylvain Goutelle y col. "The Hill equation: a review of its capabilities in pharmacological modelling”. En: Fundamental \& clinical pharmacology 22.6 (2008), págs. 633-648. 
[144] Melvin Avrami. "Granulation, Phase Change, and Microstructure Kinetics of Phase Change. III”. En: The Journal of Chemical Physics 9.2 (1941), págs. 177-184. DOI: 10 . 1063/1 . 1750872. eprint: http: //dx . doi .org/10 . 1063/1 . 1750872. URL: http: //dx.doi.org/10.1063/1.1750872. 